\title{
Crisis Management
}

Beyond the HumanitarianDevelopment Nexus Edited by Atsushi Hanatani,
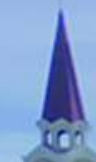
and

(i) 1013

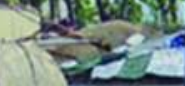

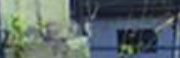
it. 2. 4.5

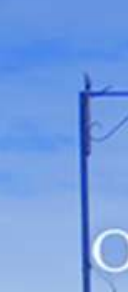
Oscar A. Gómez, and Chigumi Kawaguchi

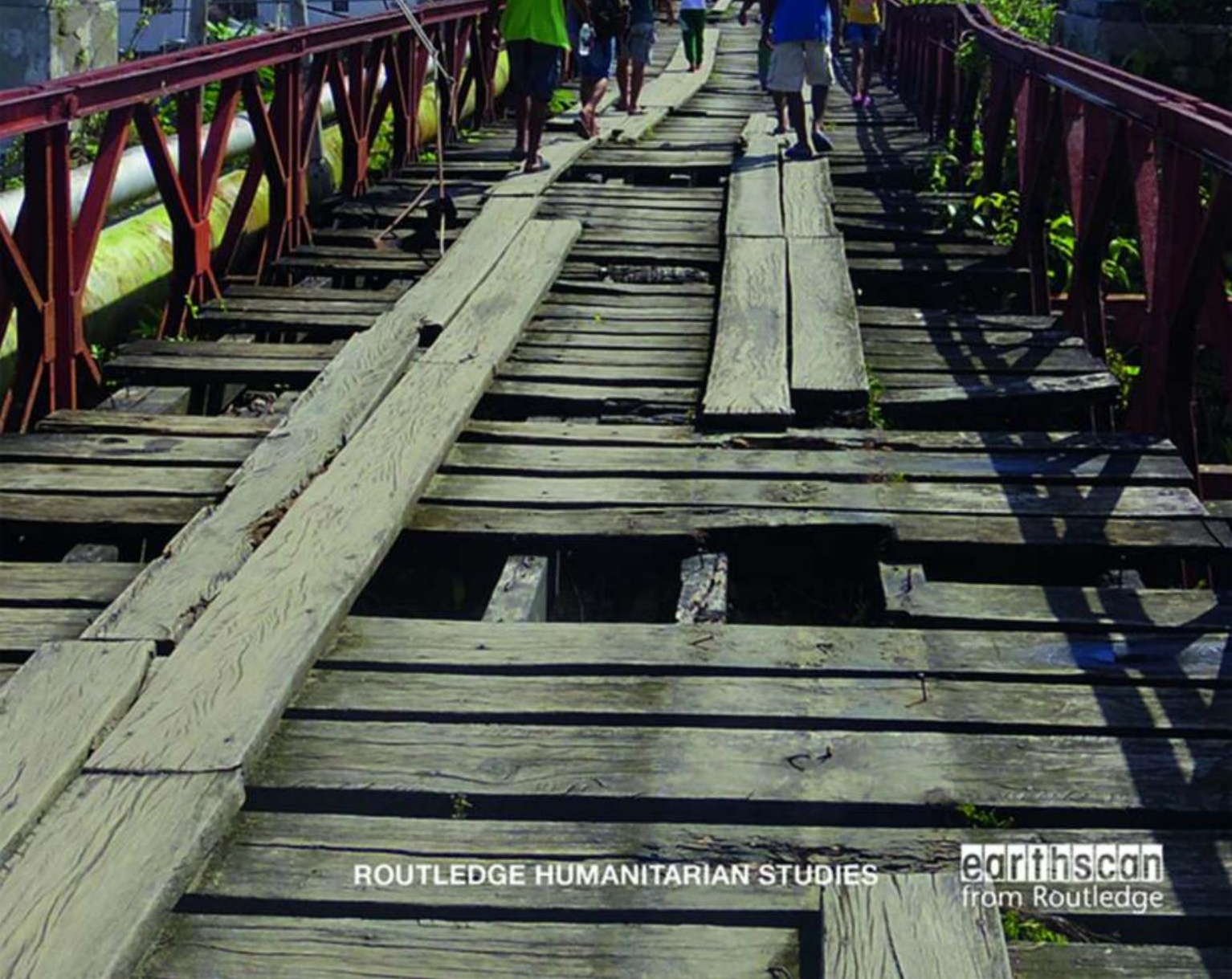


'The continuum in Rwanda after the genocide and in Indonesia after the Tsunami were typical of the unstructured processes which accompany the transition from humanitarian relief to development. The extent to which local ownership of governments and civil society is prepared and empowered to take charge following man-made or natural disasters is a major determinant of the length and sustainability of recovery. In the absence of standard patterns and processes, we are left with sets of principles and values, which are ultimately much more valuable as a guide to action. This book does well to distinguish the very different circumstances of recovery, both from natural disasters and from conflict.'

- Stephen Browne, former UN Humanitarian and Development Coordinator

'The aid world is split into development and humanitarian assistance. This book tackles the long-standing question of how different aid instruments can best be combined to meet human needs defying categorization. It provides a rich series of case studies, as well as a unique Japanese perspective on the continuum of aid.' - Julia Steets, Director of the Global Public Policy Institute (GPPi)

'This is an ambitious and honest effort to address and deconstruct the on-going dilemma of responding to one crisis after the other in increasingly complex environments. This collection of articles demonstrates the non-linear nature of recovery and reconstruction. It is recommended reading for practitioners and scholars.'

\section{- Margareta Wahlstrom, President of Swedish Red Cross and former Special Representative of the UN Secretary General for Disaster Risk Reduction}

'An important contribution to current global conversations around crisis prevention and sustaining peace. Through detailed case studies from some of the most difficult conflict and disasters of the past 30 years, this book brings new analysis to the dilemmas around linking emergency response and long-term development that have eluded the aid sector for decades.'

- Christina Bennett, Humanitarian Policy Group, Overseas Development Institute, UK 


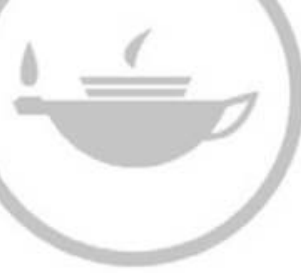

Taylor \& Francis Taylor \& Francis Group

http://taylorandfrancis.com 


\section{Crisis Management Beyond the Humanitarian- Development Nexus}

In addressing humanitarian crises, the international community has long understood the need to extend beyond providing immediate relief, and to engage with long-term recovery activities and the prevention of similar crises in the future. However, this continuum from short-term relief to rehabilitation and development has often proved difficult to achieve. This book aims to shed light on the continuum of humanitarian crisis management, particularly from the viewpoint of major bilateral donors and agencies. Focusing on cases of armed conflicts and disasters, the authors describe the evolution of approaches and lessons learnt in practice when moving from emergency relief to recovery and prevention of future crises.

Drawing on an extensive research project conducted by the Japan International Cooperation Agency Research Institute, this book compares how a range of international organizations, bilateral cooperation agencies, NGOs, and research institutes have approached the continuum in international humanitarian crisis management. The book draws on six humanitarian crises case studies, each resulting from armed conflict or natural disasters: Timor-Leste, South Sudan, the Syrian crisis, Hurricane Mitch in Honduras, the Indian Ocean earthquake and tsunami in Indonesia and Typhoon Yolanda. The book concludes by proposing a common conceptual framework designed to appeal to different stakeholders involved in crisis management.

Following on from the World Humanitarian Summit, where a new way of working on the humanitarian-development nexus was highlighted as one of five major priority trends, this book is a timely contribution to the debate which should interest researchers of humanitarian studies, conflict and peace studies, and disaster risk-management.

Atsushi Hanatani is Senior Advisor and former Senior Director of the Office for Peacebuilding and Reconstruction at the Japan International Cooperation Agency.

Oscar A. Gómez is Research Fellow at the Japan International Cooperation Agency Research Institute.

Chigumi Kawaguchi is Research Fellow at the Japan International Cooperation Agency Research Institute. 


\section{Routledge Humanitarian Studies Series}

Series editors: Alex de Waal and Dorothea Hilhorst

Editorial Board: Mihir Bhatt, Dennis Dijkzeul, Wendy Fenton, Kirsten fohnson, Julia Streets, Peter Walker

The Routledge Humanitarian Studies series in collaboration with the International Humanitarian Studies Association (IHSA) takes a comprehensive approach to the growing field of expertise that is humanitarian studies. This field is concerned with humanitarian crises caused by natural disaster, conflict or political instability and deals with the study of how humanitarian crises evolve, how they affect people and their institutions and societies, and the responses they trigger.

We invite book proposals that address, among other topics, questions of aid delivery, institutional aspects of service provision, the dynamics of rebel wars, state-building after war, the international architecture of peacekeeping, the ways in which ordinary people continue to make a living throughout crises, and the effect of crises on gender relations.

This interdisciplinary series draws on and is relevant to a range of disciplines, including development studies, international relations, international law, anthropology, peace and conflict studies, public health and migration studies.

\section{Disaster Management in Australia}

Government coordination in a time of crisis

George Carayannopoulos

\section{Production of Disaster and Recovery in Post-Earthquake Haiti}

Disaster industrial complex

Juliana Svistova and Loretta Pyles

\section{International Humanitarian NGOs and State Relations}

Principles, politics, and identity

Andrew F. Cunningham

\section{Grisis Management Beyond the Humanitarian-Development Nexus Edited by Atsushi Hanatani, Oscar A. Gómez and Chigumi Kawaguchi}

For more information about this series, please visit: https://www.routledge.com 


\section{Grisis Management Beyond the Humanitarian- Development Nexus}

Edited by Atsushi Hanatani,

Oscar A. Gómez and

Chigumi Kawaguchi 
First published 2018

by Routledge

2 Park Square, Milton Park, Abingdon, Oxon OX14 4RN

and by Routledge

711 Third Avenue, New York, NY 10017

Routledge is an imprint of the Taylor \& Francis Group, an informa business

(C) 2018 selection and editorial matter, Atsushi Hanatani, Oscar A.

Gómez and Chigumi Kawaguchi; individual chapters, the contributors

The right of Atsushi Hanatani, Oscar A. Gómez and Chigumi

Kawaguchi to be identified as the authors of the editorial material, and of the authors for their individual chapters, has been asserted in accordance with sections 77 and 78 of the Copyright, Designs and Patents Act 1988.

All rights reserved. No part of this book may be reprinted or reproduced or utilized in any form or by any electronic, mechanical, or other means, now known or hereafter invented, including photocopying and recording, or in any information storage or retrieval system, without permission in writing from the publishers.

Trademark notice: Product or corporate names may be trademarks or registered trademarks, and are used only for identification and explanation without intent to infringe.

British Library Cataloguing-in-Publication Data

A catalogue record for this book is available from the British Library

Library of Congress Cataloging-in-Publication Data

A catalog record for this book has been requested

ISBN: 978-1-138-54343-0 (hbk

ISBN: 978-1-351-00682-8 (ebk)

Typeset in Baskerville

by codeMantra 


\section{Contents}

List of figures and tables $i x$

List of contributors $\quad x i$

Foreword xiv

Preface xoi

Acknowledgements xviii

Abbreviations $x x$

\section{PART I}

Background and foundation 1

1 Introduction: addressing the humanitariandevelopment nexus since the Cold War

YUKIE OSA AND ATSUSHI HANATANI

2 A theory for the continuum: multiple approaches to humanitarian crises management

OSCAR A. GÓMEZ AND CHIGUMI KAWAGUCHI

\section{PART II}

Humanitarian crisis management in armed conflicts

3 The continuum in the management of armed conflict: an overview

TOSHIYA HOSHINO AND GHIGUMI KAWAGUGHI

4 Should the 'continuum' for peacebuilding focus on development or conflict prevention? The case of Timor-Leste 


\section{viii Contents}

5 Comparative analysis of donor approaches to the continuum under a fragile peace: the case of South Sudan

6 The Syrian Givil War: politicization of the crisis and challenges and dilemmas for humanitarian response

\section{PART III}

Humanitarian crisis management of disasters

7 The continuum in the management of disasters: an overview

HIROSHI HIGASHIURA AND OSCAR A. GÓMEZ

8 Prevention through the continuum of crisis management: the case of Honduras after Hurricane Mitch

OSGAR A. GÓMEZ

9 How can recovery be linked with long-term development? The case of Indonesia MIKIO ISHIWATARI

10 Typhoon Yolanda in the Philippines: qualitative analysis of institutional and political factors influencing the continuum

\section{GONGLUSION}

11 The continuum beyond the humanitarian-development nexus

ATSUSHi HANATANi, OSGAR A. GÓMEZ

AND GHIGUMI KAWAGUCHI 


\section{Figures and tables}

\section{Figures}

1.1 Distribution of international humanitarian assistance and top seven governmental and EU institutional donors, 2016 11

2.1 Timing and intensity of the three tracks for livelihoods recovery 23

$\begin{array}{ll}2.2 & \text { Linear model } \\ 2.3 & 29\end{array}$

2.3 Multilayered activities model $\quad 29$

2.4 Multilayered activities model applied to a protracted crisis 31

3.1 Overlapping intervention models between peace and conflict 40

3.2 The core business of multi-dimensional United Nations peacekeeping operations $\quad 42$

4.1 ODA disbursements to Timor-Leste 53

4.2 ODA sectoral disbursements by donor $\quad 57$

5.1 Bilateral ODA by sector for South Sudan, 2013-2014 average $\quad 78$

5.2 Total assistance to Sudan (2001-2011) and South Sudan (2011-2014) by DAC countries and EU institutions across $\begin{array}{lr}\text { phases of transitions } & 90\end{array}$

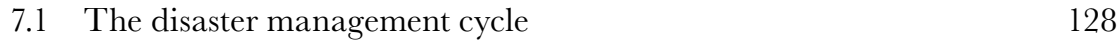

8.1 Timeline of policy events relevant to the disaster management 142

8.2 Bilateral aid to Honduras, 1997-2011 144

$\begin{array}{lll}\text { 8.3 Commitments to the reconstruction process } & 147\end{array}$

9.1 Trends and key indicators in Aceh and Yogyokarta 165

10.1 Total cumulative amount of ODA (2005-2014): comparison
between 'all sectors' and 'humanitarian aid'

\section{Tables}

2.1 Summary of general approaches to the continuum 25

6.1 Number of Syrian refugees in neighboring countries 106

6.2 Number of beneficiaries by cross-border operations of the UN
and its partners, July 2014 to February 2017

6.3 UK DFID funding inside Syria by organizations, 2011-2014 111 
$\mathrm{x} \quad$ List of figures and tables

6.4 US humanitarian assistance inside Syria, FY 2013-2016 112

9.1 Evolving recovery mechanisms in Indonesia 178

9.2 Good practices of linking recovery and long-term development $\quad 180$

$\begin{array}{lll}10.1 & \text { Chronology of events following Typhoon Yolanda } & 188\end{array}$

11.1 Analysis of disasters and armed conflict case studies 216

11.2 Factors affecting success of the continuum 220 


\section{Contributors}

Oscar A. Gómez is Research Fellow at the Japan International Cooperation Agency Research Institute. He holds a Ph.D. on Environmental Studies from Tohoku University. His main interest is global governance and the theorypractice of human security, with special emphasis on the environment, migration, disasters, and international cooperation. He was part of a panel discussion at the UN on human security operationalization in 2013, and co-authored background papers for 2014 and 2016 Human Development Reports. He has worked as a consultant for several UN agencies in Latin America. Alongside this book, he is editing another volume on human security norms in the ASEAN+3, and preparing new research on emerging powers and non-Western humanitarianism.

Atsushi Hanatani is Senior Advisor and former Senior Director at the Office for Peacebuilding and Reconstruction at the Japan International Cooperation Agency in Tokyo. He has a Ph.D. in International Development from Nagoya University. His research interests include common pool resources management, peacebuilding studies and African development. He is a regular member of the International Network on Conflict and Fragility (INCAF), DAC, and has participated as Panelist/Moderator/Presenter in international fora such as Solutions Alliance (SA) Roundtable, International Dialogue on Migration (IDM) organized by IOM and the Forum on Refugee and Migration Policy organized by the International Institute of International Affairs, Chatham House.

Hiroshi Higashiura is Professor at the Japanese Red Cross Academy. His fields of research are Red Cross history, disaster management, international humanitarian law, international disaster laws \& regulations, global health, and disaster nursing. He started his 37-year Red Cross career in 1970 at the Japanese Red Cross Society. Since then, he has worked at the International Federation of Red Cross and Red Crescent Societies as a preparedness officer (1976-1981) and as head of the Asia \& Pacific Department (1997-2002). He joined the Japanese Red Cross Academy as a professor in 2007.

Tomoaki Honda is Research Fellow at the Canon Institute for Global Studies. He has a Ph.D. in Media and Governance from Keio University. His fields 
of research are public policy studies (Japan), international peace cooperation, peacebuilding, and non-traditional security studies. His main research interest is Japan's peacebuilding policy and ways of using Japan Self Defense Forces for peace operations. His recent works focused on Japan's changing Peace Keeping Operations policy under the present Cabinet.

Toshiya Hoshino is Guest Professor, former Dean of Osaka School of International Public Policy and former Vice President for Global Engagement at Osaka University. He received his Ph.D. in International Public Policy from Osaka University. He was a previous Minister-Counselor the Permanent Mission of Japan to the United Nations, Senior Research Fellow at the Japan Institute of International Affairs, Guest Scholar at Columbia University, Visiting Fellow at Princeton University; and Special Assistant, the Embassy of Japan in the United States. He is a specialist in international politics and security studies, United Nations system studies, UN peace and security (conflict prevention, peacemaking, peacekeeping, and peacebuilding), human security and humanitarian issues, security in the Asia-Pacific region as well as Japan's foreign and defense policies.

Mikio Ishiwatari is Senior Advisor in Disaster Management and Water Resources Management at Japan International Cooperation Agency and Visiting Professor, Graduate School of Frontier Sciences, The University of Tokyo. He received his Ph.D. in International Studies from the University of Tokyo. His fields of research are international studies as well as development assistance in disaster risk reduction and reconstruction. His previous positions include Senior DRM (Disaster Risk Management) Specialist and Senior Water Specialist at the World Bank; various positions related to DRM at the Ministry of Land Infrastructure, Transport and Tourism, Japan; and Urban Development Specialist at the Asian Development Bank.

Yasuhito Jibiki is Assistant Professor at the International Research Institute of Disaster Science (IRIDeS), Tohoku University. He received his Ph.D. in Interdisciplinary Informatics (major in International Relations) from the University of Tokyo. Before his posting at IRIDeS, he served as Project Assistant Professor of the Center for Integrated Disaster Information Research, the University of Tokyo (2010-2013). His current research focuses on disaster risk reduction in the international settings; examining efforts by sovereign states in adopting international norms into their local contexts and developing their own original standardization systems and frameworks.

Chigumi Kawaguchi is Research Fellow at the Japan International Cooperation Agency Research Institute (JICA-RI). She received her Ph.D. in International Public Policy from Osaka University. Her fields of research are comparative politics, security studies, international organization studies, international peace cooperation, peacebuilding, and conflict prevention. Before joining JICA-RI, she worked as a researcher in the International Peace Cooperation Division in the Ministry of Foreign Affairs, and the International 
Peace Cooperation Office in the Cabinet Office of Japan, and in the Graduate School of Security Studies at the National Defense Academy. She is currently working on a new research project in JICA-RI on gender-based violence in conflict-affected areas.

Yuichi Ono is Professor at the International Research Institute of Disaster Science (IRIDeS), Tohoku University, Assistant Director of IRIDeS, Chair of the Multi-Hazard Program of the Association of Pacific Rim Universities, and Director of the Global Centre for Disaster Statistics (a joint program with UNDP). He has a Ph.D. in Geography from Kent State University. His fields of research are international policy on disaster risk reduction, early warning systems and wind-related disasters. He previously held positions at the World Meteorological Organization, the United Nations International Strategy for Disaster Reduction, and the United Nations Economic and Social Commission for Asia and Pacific (ESCAP in Bangkok).

Yukie Osa is Professor at the Graduate School of Social Design Studies, Rikkyo University, and represents the Association for Aid and Relief, Japan (AAR). She received her Ph.D. in Human Security Studies from the University of Tokyo. Her fields of research are human security studies, international humanitarian law, transitional justice, and genocide studies. As head of emergency assistance operations, she was involved in AAR programs in Cambodia, the Former-Yugoslavia, Mozambique, Kosovo, Chechnya, Afghanistan, and other countries. As a member of the International Campaign to Ban Landmines (ICBL), she led the Japanese Mine Ban Campaign during and after the Ottawa Process. She was also a member of the Advisory Group for the United Nations Central Emergency Response Fund (UNCERF).

Yukako Sakabe Tanaka is Assistant Professor of the School of International Politics, Economics and Communication, Aoyama Gakuin University. She received her Ph.D. in Political Science from Waseda University. Her research focuses on the political economy of institutions, the causes of conflict, conflict resolution, democratization, state-building, and international cooperation, especially related to weak states. She previously worked at the Faculty of Political Science and Economics, Waseda University, the Embassy of Japan in Timor-Leste, the International Peace Cooperation Office in the Cabinet Office of Japan, and the UN Assistance Mission to Afghanistan. Her most recent paper discusses why democratization and state-building cause political violence in new democracies.

Ryoji Tateyama is Emeritus Professor of the National Defense Academy and a Visiting Fellow of the Institute of Energy Economics, Japan. He specializes in contemporary politic and international relations in the Middle East. He had previously worked for the United Nations Relief and Works Agency for Palestine Refugees in the Near East (UNWRA) and the Japanese Institute of Middle Eastern Economies. 


\section{Foreword}

Despite important gains against poverty around the world, many people are still affected by humanitarian crises. The lives and dignity of people are threatened by conflicts, natural disasters, extremism, hunger, worsening refugee situations, and infectious diseases, among others. In addressing such humanitarian crises, efforts by the global community are not limited to offers of short-term relief but also include support for long-term recovery and development activities, as well as the establishment of foundations for the prevention of similar crises in the future. Consequently, it is imperative to catalyze collective action effectively in order to achieve the best possible outcomes in these areas. This need for collective action was articulated at the outset of the present humanitarian system by the UN General Assembly in Resolution 46/182 of 1991 as a 'continuum from relief to rehabilitation and development.' Since the inception of the Japan International Cooperation Agency's (JICA's) operational strategy of providing integrated and 'seamless' assistance in 2008, JICA has dealt with several challenges from actual emergencies and in their aftermaths. The integration of the different phases of inter-linked activities - from humanitarian relief to long-term development with prevention - as a single crisis management process requires the improvement of our assistance system.

Japan's approach in international cooperation has been consciously geared towards helping partner countries become self-reliant states and working with them on an equal footing. In pursuing our philosophy of international cooperation, and aspiring to the creation of a free, peaceful and prosperous world for everyone, JICA continues to find and provide tailored and context-specific assistance for places in crisis. Hence, it is crucial to study the needs of recipient countries and design development cooperation effectively in partnership with them.

This volume is a tangible proof of our commitment to the UN 2030 Agenda for Sustainable Development that states that 'no one will be left behind,' and to the outcomes of the World Humanitarian Summit 2016 in Istanbul. At JICA, we explore the challenges faced by bilateral cooperation agencies in doing more than just providing relief after humanitarian crises to be more effective in dealing with them. In this regard, as this book clearly shows, the understanding of the non-linear transition across all phases within the crisis response process continuum should be recognized among both humanitarian and development agencies. 
In order to develop assistance strategies that will leave no one behind, international and local partners need to consider the great challenge of advancing all types of prevention activities, and the central role that local actors can play in addressing crises. The wide-ranging reviews and perspectives on the practices of crisis management offered in this book will help readers develop an understanding of the current situation and its associated obstacles, as well as ideas on how we should change the system to realize the continuum.

Shinichi Kitaoka

President

Japan International Cooperation Agency 


\section{Preface}

In 2015, the Japan International Cooperation Agency Research Institute (JICA-RI) initiated a three-year project, the 'Comparative Study of Humanitarian Crisis Management from the Perspective of Bilateral Cooperation Agencies.' The aims of the project were developing a better understanding and drawing attention to the difficulty of linking humanitarian and development actions. Originally, the project sought to evaluate human security in practice in Japanese ODA through the lens of JICA's 'Seamless Assistance' approach. However, this was transformed into a more inclusive review and evaluation of various approaches and tools across a variety of crises in different parts of the world.

This eleven-chapter volume is composed of contributions from established practitioners and academics in the field of human security and humanitarian crisis management. In order to see this history of crisis management in detail, the research is comprised not only of reviews of policies and consultation with the headquarters of major organizations, but also includes selected case studies that present humanitarian crisis management experiences over the last two decades. These case studies were chosen on the basis of their scale and impact on affected communities, the range of actors in crisis areas, geographical diversity, and the new challenges they brought to humanitarian crisis management. The book validates and assesses the continuum of humanitarian crisis management for both natural disasters and conflict-affected areas.

This book is organized into three key sections. Part I provides the background and analytical framework of the book. Chapter 1 presents the evolutionary process that led to the rise of international humanitarianism, important trends and reforms initiated in the international community as well as the theoretical and practical gaps that have emerged over the years. Chapter 2 delivers the analytical frameworks in response to the issues and challenges identified in Chapter 1. The authors propose a multi-layered activity model to understand the continuum and describe its strengths and weaknesses.

Parts II and III present two clusters of case studies to validate the continuum in humanitarian crisis management. Part II locates the development of peacebuilding as an approach to the continuum in the management of the aftermath of armed conflicts. Chapter 3 sets the tone for this section by introducing previous international efforts and practices in providing support for post-conflict countries 
transitions from conflict to peace and by examining the continuum in managing post-conflict states. Case studies of armed conflict such as those in Timor-Leste (Chapter 4), South Sudan (Chapter 5), and the Syrian crisis (Chapter 6) offer narratives on achieving post-conflict peacebuilding and sustainable peace. The case of Timor-Leste introduces a magnified view of a prolonged struggle for peace and the menaces brought about by the relapse into conflict. Despite the successful attainment of independence the case study from South Sudan considers reasons for the continuous relapse into conflict and the consequent long humanitarian crisis despite the tremendous amount of assistance from the international community in building a new state. The conflict in Syria illustrates the need for early implementation of a continuum approach and how the polarization of aid hinders this attempt.

Part III concentrates on the continuum as observed in disaster management. Chapter 7 explores its evolution in the disaster-risk reduction community based on humanitarian and developmental perspectives, and provides the background on which the subsequent case studies are developed. This section is substantiated by case studies of Hurricane Mitch in Honduras (Chapter 8), the Indian Ocean earthquake and tsunami in Indonesia (Chapter 9) and Typhoon Yolanda in the Philippines (Chapter 10). Representing the Latin American region through the case of Honduras after Hurricane Mitch (1998), this volume is able to present a disaster scenario over a protracted period and consider the challenges of engendering prevention against future disasters. The 2004 India Ocean tsunami in Indonesia is one of the large-scale disasters that paved the way for the emergence of the current disaster risk reduction mantra of 'build back better'. Lastly, Typhoon Yolanda, which devastated the central Philippines in 2013, was assessed as a model for the present continuum realization and challenges.

The Conclusion (Chapter 11) integrates all the ideas presented in this book. The editors summarize the key findings from the case studies, provide a synthesis of the factors identified in the two streams of crises, and discuss the implications for further improvement of international crisis management.

The book deviates from the typical compilation of international cooperation and aid case studies. Instead, it attempts to validate a theoretical model of humanitarian crisis management by examining the continuum through diverse case studies of crises. The editors and authors anticipate contributing to the scarce yet vital literature on the humanitarian-development nexus from the perspective of bilateral cooperation agencies. 


\section{Acknowledgements}

This publication owes a great deal of appreciation to a number of colleagues. First of all, the editors would like to extend their deepest gratitude to former and current directors of the Japan International Cooperation Agency Research Institute (JICA-RI) Hiroshi Kato, Ichiro Tambo, Naohiro Kitano and Nobuko Kayashima, who supported us all along the process of the project conception, proposition and execution. We also want to thank Dr. Julia Steets, director of the Global Public Policy Institute in Berlin, who was kind enough to discuss with us our research proposal, and later reviewed the research framework and case studies, providing precious feedback. She also made a public presentation, together with other authors of the book in Tokyo in December 2016, which was of great help as we prepared to wrap-up the research.

The chapter authors would like to express their sincerest thanks to the various individuals and institutions that supported their research and writing. In each of the countries covered by the research, including Timor-Leste, South Sudan, Jordan and Turkey, Honduras, the Philippines, Indonesia as well as the donor countries, authors benefitted from the generosity of local and international actors, who shared much about their work. Due to the nature of the research, we decided to keep all interviewees anonymous so we do not include personal acknowledgments here. To all of you that contributed to this work, please receive our sincere gratitude and appreciation, as well as apologies for any inaccuracies.

Several parts of the research have been presented at different academic venues, where feedback from the audience helped reconsidering some of our arguments and refining our conclusions. The general framework was presented at the International Association of Humanitarian Studies conference in Addis Ababa, Ethiopia, in March 2016. A first version of the general framework and some messages for the World Humanitarian Summit were distributed at the venue in Istanbul in May 2016. We would like to express our appreciation to Joe Leitmann from the World Bank, who took the time to read the draft of the messages and provide comments. The South Sudan case study was presented at the Academic Council on the United Nations System Conference in New York, the United States, in June 2016, the Japan Association for United Nations Studies in Osaka, Japan, in July 2017 and the Japan International Politics Association in Kobe, Japan, in October 2017. Professors Des Gasper and Dorothea Hilhorst of the 
International Institute of Social Studies (ISS), Erasmus University Rotterdam, were kind enough to organize a meeting at ISS in November 2016, where, together with Professor Thanh-Dam Truong, post-doctoral and doctoral students offered many comments and took part in a lively discussion. Findings of the three conflict case studies were presented at the International Studies Association (ISA) in Baltimore, the United States, in February 2017 and the Academic Council on the United Nations System Conference in Seoul, Korea, in June 2017. In the same year in May, findings in relation to disasters were presented in a side event of the Global Platform for Disaster Risk Reduction held in Cancun, Mexico; our co-hosts of the International Recovery Platform did a great job setting the scene and gathering a distinguished group of panelists. The editors appreciate all meaningful feedback from moderators and participants in all these venues.

All surveys were supported by local offices of JICA, which helped arranging meetings and many logistical details. Without their support, this research would not have been possible. The Departments of Global Environment, Infrastructure and Peacebuilding, Planning, as well as each regional department and the Secretariat of Japan Disaster Relief Team, were of great support throughout the research. We are also very much grateful to Ako Muto, head of the Peace and Development team for her continuous support. We would also like to extend our gratitude to the management, editorial and logistics team at JICA-RI comprising of Yasuhiko Sato, the fast and efficient staff of JICA's library, research officer Ayako Kono and research assistants Yuko Tobinai, Lisette Robles, Masashi Kawai and Hiromu Miyashita. Their tremendous support at different moments throughout the three years of the project is greatly appreciated. To all of them we are highly indebted.

Finally, we close by stating that the views and interpretations expressed in this volume are those of the authors and do not necessarily represent those of the organizations or the persons mentioned above. 


\section{Abbreviations}

\begin{tabular}{|c|c|}
\hline AusAID & Australian AID \\
\hline $\mathrm{BBB}$ & build back better \\
\hline BNPB & National Disaster Management Agency (Indonesia) \\
\hline BRR & $\begin{array}{l}\text { Rehabilitation and Reconstruction Agency of Aceh-Nias } \\
\text { (Indonesia) }\end{array}$ \\
\hline CD & community-driven \\
\hline CEPREDENAG & Central American Coordination Center for Natural \\
\hline CFW & $\begin{array}{l}\text { Disaster Prevention } \\
\text { cash-for-work }\end{array}$ \\
\hline COPECO & Permanent Commission for Contingencies (Honduras) \\
\hline CPA & Comprehensive Peace Agreement \\
\hline GRRP & $\begin{array}{l}\text { Yolanda Comprehensive Rehabilitation and Reconstruction } \\
\text { Plan (Philippines) }\end{array}$ \\
\hline DARTs & Disaster Assistance Response Teams (United States) \\
\hline DFAT & Department of Foreign Affairs and Trade (Australia) \\
\hline DFID & United Kingdom Department for International Development \\
\hline DRM & disaster risk management \\
\hline DRR & disaster risk reduction \\
\hline $\mathrm{EG}$ & European Commission \\
\hline $\mathrm{ECHO}$ & $\begin{array}{l}\text { European Civil Protection and Humanitarian Aid } \\
\text { Operations }\end{array}$ \\
\hline EGLAG & $\begin{array}{l}\text { Economic Commission for Latin America and the } \\
\text { Caribbean }\end{array}$ \\
\hline $\mathrm{EU}$ & European Union \\
\hline EWS & early warning system \\
\hline GDP & gross domestic product \\
\hline GFDRR & Global Facility for Disaster Reduction and Recovery \\
\hline GoS & Government of Sudan \\
\hline GoSS & Government of South Sudan \\
\hline HIPG & heavily indebted poor countries \\
\hline IASC & Inter-Agency Standing Committee \\
\hline ICRG & International Committee of the Red Cross \\
\hline
\end{tabular}




\begin{tabular}{|c|c|}
\hline IDF & Indonesian Multi-Donor Fund Facility for Disaster Recovery \\
\hline & internany aisplaced person \\
\hline IFI & international financial institutions \\
\hline IFRG & $\begin{array}{l}\text { International Federation of the Red Cross and Red Crescent } \\
\text { Societies }\end{array}$ \\
\hline IMF & International Monetary Fund \\
\hline INGAF & International Network on Conflict and Fragility \\
\hline IOT & Indian Ocean tsunami (2004) \\
\hline IRCG & International Red Cross/Red Crescent Conference \\
\hline ISIL & The Islamic State in Iraq and Levant \\
\hline JAM & Joint Assessment Mission \\
\hline JICA & Japan International Cooperation Agency \\
\hline JRF & Java Reconstruction Fund \\
\hline LRRD & Linking Relief, Rehabilitation and Development \\
\hline MDF & Multi Donor Fund for Aceh and Nias \\
\hline MDGs & Millennium Development Goals \\
\hline MOFA & Ministry of Foreign Affairs (Japan) \\
\hline MSF & Médecins Sans Frontières (Doctors without Borders) \\
\hline $\mathrm{NGO}$ & non-governmental organization \\
\hline OCHA & UN Office for the Coordination of Humanitarian Affairs \\
\hline ODA & Official Development Assistance \\
\hline OECD & Organisation for Economic Co-operation and Development \\
\hline OLS & Operation Lifeline Sudan \\
\hline OPARR & Office of Presidential Assistant for Rehabilitation and Recovery \\
\hline PDNA & post-disaster needs assessment \\
\hline PMRTN & Master Plan for National Reconstruction and Transformation \\
\hline PRSP & Poverty Reduction Strategy Paper \\
\hline RAY & Reconstruction Assistance in Yolanda: Build Back Better \\
\hline SARG & The Syrian Arab Red Crescent \\
\hline SDGs & Sustainable Development Goals \\
\hline SHARP & The Syria Humanitarian Assistance Response Plan \\
\hline SPLM/A & Sundanese People's Liberation Movement/Army \\
\hline SRTF & The Syria Recovery Trust Fund \\
\hline STAR & Sudan Transitional Assistance for Rehabilitation \\
\hline TEG & Tsunami Evaluation Coalition \\
\hline $\mathrm{UN}$ & United Nations \\
\hline UNDP & United Nations Development Programme \\
\hline UNHGR & United Nations High Commissioner for Refugees \\
\hline USAID & United States Agency for International Development \\
\hline WGA & whole-of-government approach \\
\hline WHS & World Humanitarian Summit \\
\hline
\end{tabular}




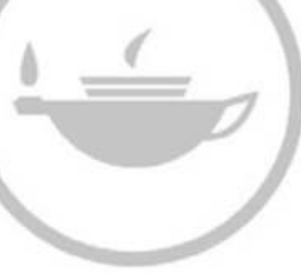

Taylor \& Francis Taylor \& Francis Group

http://taylorandfrancis.com 
Part I

Background and

foundation 


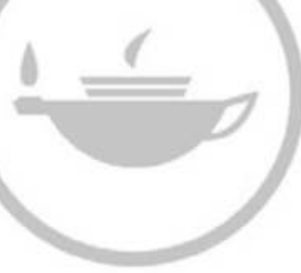

Taylor \& Francis Taylor \& Francis Group

http://taylorandfrancis.com 


\section{Introduction}

\section{Addressing the humanitarian-development nexus since the Cold War}

Yukie Osa and Atsushi Hanatani

\section{The era of unprecedented humanitarian crises}

In recent years, finding ways to deal with humanitarian crises has become one of the most compelling issues for the international community. Humanitarian crises encompass large-scale disruptions to people's sense of a 'normal' life, all too often affecting their survival, livelihood and dignity. The scale of human suffering nowadays has grown since World War II. More than 164.2 million people around the world need humanitarian assistance for survival (Development Initiatives 2017). At the end of 2015, 65.3 million people, or one in every 113 persons, had been displaced from their homes due to conflict or persecution (Edwards 2016), while an estimated 377 million people were affected by natural disasters in 2016 alone (Development Initiatives 2017, 19). Fears of famine once again plague the Horn of Africa and Yemen, while the rapid spread of infectious diseases continues to highlight our interconnected vulnerabilities.

Whenever such serious threats attract global attention, it is widely anticipated that donors, aid organizations, and non-governmental organizations (NGOs) will provide solidarity and active engagement. In principle, state actors from the affected countries are in charge of addressing disaster situations. However, when crises overwhelm their capacity to implement solutions because of the scale and complexity of the threats, or when governments themselves become the primary source of danger, support from external actors for the population at risk becomes necessary. This support has grown steadily - from about US\$800 million in 1989 to some US $\$ 4.4$ billion in 1999, reaching US\$27.3 billion in 2016 (Weiss 2013; Development Initiatives 2017). The budget allocated for humanitarian funds is normally around $10 \%$ of the total Official Development Assistance (ODA) budget in most of the major donor countries. However, this grew to $18.8 \%$ in 2016, generating discussions among the international community over what might be expected from this increase.

The practice of collective engagement from the international community in addressing humanitarian crises commenced only after the end of the Cold War. In the aftermath of World War II, the international community's work on peace and security was based on the sovereign state system, which became the basis for the establishment of the United Nations (UN) and prevention of new 
global confrontations. During the Cold War period, the reconstruction of wartorn countries and long-term development of newly independent countries were the main agendas of donors, while humanitarian action was largely left to nongovernmental institutions, such as the International Federation of the Red Cross and Red Crescent Movement and NGOs (Crisp 2007). It was only after the end of the Cold War that collective humanitarian support by the international community became fully functional through the UN. This was symbolically marked by the United Nations Security Council Resolution 688 of April 5, 1991, which provided the justification for an international response to the refugee crisis in northern Iraq in the aftermath of the first Gulf War (Hammerstad 2014, 180).

Successive crises in ensuing years made it clear that no single entity could fully serve the needs of an entire affected community in the crisis management process (Friis and Jarmyr 2008), resulting in the increased involvement of multiple actors in such endeavors. What started as a non-governmental undertaking has now become a concerted effort among inter-governmental organizations, sovereign states, the UN system, regional organizations, militaries and the private sector. In this way, the generation of broad concern and goodwill is a great achievement when compared with the preceding period of hot and less hot wars. Nonetheless, despite good intentions, the diversity in priorities and mandates of all the actors presently involved in the response to emergencies, as well as the ever-changing needs on the ground, make crisis management a very difficult task. Hence, when faced with present-day humanitarian challenges, more comprehensive and better managed humanitarian activities are urgently required.

\section{Improving crisis management: coordination and the humanitarian-development nexus}

Over the past 20 years, the international community has invested heavily in the intellectual and organizational development of the humanitarian crisis management concept and system. Two major areas requiring attention from the very beginning were (1) humanitarian coordination and (2) the humanitariandevelopment nexus. The coordination and nexus strategies in responding to the intricacies of several crisis contexts - together with the engagement of a great variety of actors with different visions - make humanitarian crisis management particularly challenging.

Of these two areas, coordination took precedence in the process of institutionalizing humanitarian action in the UN. The landmark General Assembly Resolution 46/182 in 1991 became a kind of new 'Magna Carta' in providing a basic framework for the international humanitarian system (Oshima 2004). The resolution established new arrangements for humanitarian coordination in the UN system (OCHA 2012) and strengthened the position of the UN Disaster Relief Coordinator by raising it to the level of Under Secretary General and renaming it the Emergency Relief Coordinator. The resolution also gave way to the creation of the Department of Humanitarian Affairs, which later became the UN Office for the Coordination of Humanitarian Affairs (OCHA) in 1998. 
Further reforms led to the creation of the Humanitarian Reform Agenda in 2005, by which the Cluster System for the coordination of humanitarian action was introduced to enhance predictability, accountability and partnership among multiple actors, particularly UN agencies. This was followed by the introduction of the transformative agenda in 2011, which stressed leadership, accountability and improved coordination.

Despite all this progress on coordination reforms, the issue of the humanitariandevelopment nexus has remained on the margins. During the 1990s, a major debate on improving the humanitarian crisis management revolved around the question of a disconnect between humanitarian assistance and development cooperation. It attempted to link the different forms of assistance to the changing nature of crises and needs, particularly in relation to protracted internal conflicts. Discussions stemmed from the recognition that there were certain gaps between humanitarian and development assistance in terms of (1) funding (temporal period of engagement and types of activities eligible for funding); (2) institutions (philosophy, mandates, strategies, approaches); and (3) partnerships and coordination (between different actors and between capitals and field offices within the same organizations). While it was more or less clear that the provision of life-saving assistance implies relief and that going back to non-crisis normality constitutes development, whatever lies in the middle (including prevention and preparedness) is less well understood.

The first-generation concept of a 'relief to development continuum' model was based on the idea of a linear or chronological transition from short-term relief by humanitarian actors to long-term development by traditional donors. It sought to bridge funding gaps that may arise between these two phases and actors. This was later replaced by the 'contiguum' model, where different phases and elements of assistance are thought to exist concurrently, with emphasis on shared responsibility between humanitarian and development actors rather than a temporal transition between them. ${ }^{1}$ While continuum and contiguum vary in emphasis, they both highlight three aspects of linking: (1) applying development principles early on in emergency settings to ensure the ground for development is prepared, (2) ensuring a smooth transition as well as continuity and coordination between interventions, and (3) using development cooperation to support prevention and disaster risk reduction (Steets 2011).

Several other approaches have been developed to analyze and address the nexus based on those two concepts, many of which are still used today. Some of these approaches include the long standing Linking Relief, Rehabilitation and Development (LRRD), which was originally proposed by the European Union (EU) in 1996; the Development(al) Relief approach, which was suggested by the United States (US) in the early 1990s together with other related concepts such as Relief to Development and Transition; the United Nations Development Programme (UNDP)-led Early Recovery, which is a part of the Humanitarian Cluster System; and the Gap approach spearheaded by the Office of the United Nations High Commissioner for Refugees (UNHCR) and the World Bank in 1999, that originated from the Brooking Process (Crisp 2007; Suhrke 
and Ofstad 2005). There is also the Seamless Assistance emerging from the Japan International Cooperation Agency (JICA)'s strategy, and the Resilience Approach which appeared in several bilateral donor's papers such as EU institutions, United States Agency for International Development (USAID), the United Kingdom Department for International Development (DFID) and various UN agencies during the past ten years. These will all be discussed in more detail in the next chapter. It is fair to say, however, that the use of these approaches still remains within the confines of the respective donors or organizations who invented them.

\section{Bridging the nexus and remaining issues}

Responding to the rise of these debates, donor policies on humanitarian development and security have also undergone major changes. Donors have created new funding instruments and offices or have devised bureaucratic procedures to fill the gap between humanitarian and development assistance and improve their ability to deal with 'transitional' activities. Among these are ECHO's Global Plans, the EC's Humanitarian Plus funding, the UK's Global Conflict Prevention Pool (GCCP), and the World Bank's Post-Conflict Unit and Post-Conflict Fund. Such trust funds are usually operationalized and managed by UN agencies and the World Bank. Donors have applied these instruments to enable appropriate financing to countries in prolonged periods of crisis and those suffering from major natural disasters.

In the 2011 World Development Report, the World Bank selected the theme 'Conflict, Security and Development' to address the cyclical nature of violence and emphasize that the repeated spiral model of institutional transformation and confidence are pathways to break the vicious cycle of conflict and violence (World Bank 2011). In the same year, OECD countries, together with international organizations and financial institutions, agreed to support conflictaffected and fragile countries through the 'New Deal for Engagement in Fragile Countries' (New Deal) at the 4th High Level Forum on Aid Effectiveness in Busan, Korea. One of the principles of donor engagement in fragile contexts is 'trust', predicated on the commitment to risk-sharing between fragile countries and donors to ensure continued engagement even in times of transition (OECD 2011). The New Deal is upheld as a guiding principle for OECD donors' engagement in fragile contexts through the fora of dialogue among donors (INCAF: International Network on Conflict and Fragility), and between donors and countries in fragile situations (International Dialogue on Peacebuilding and Statebuilding).

In regard to humanitarian actors, 17 donor governments - along with the European Commission, OECD, International Red Cross and Red Crescent Movement, NGOs, and academics - gathered and formulated the 'Principles and Good Practice of Humanitarian Donorship' (Good Humanitarian Donorship 2003). The 23 identified principles and good practices provided both a framework for guiding official humanitarian aid and a mechanism for encouraging greater donor 
accountability, support for the transition to development, and the prevention of future crises. ${ }^{2}$ Another effort that deserves mention is the Sphere Project, which has tried to develop standards for action that NGOs can use to increase their professionalism after the chaotic response to the Rwandan genocide in 1994. Yet, all of these innovations remain as work in progress and, as the former UN SecretaryGeneral Ban Ki-moon said in his remarks after five years in office, 'we will not create a safer and more secure world without building a more global, accountable and robust humanitarian system' (United Nations Secretary-General 2012).

Some evaluation studies on the relationship between humanitarian and development aid suggest that there is still a long way to go in achieving a better system for humanitarian crisis management (Macrae and Harmer 2004; Steets 2011). It is argued that the international community for humanitarian action is still a rather messy assemblage of actors and activities lacking a leader (ALNAP 2015, 18). Despite various coordination and cooperation frameworks, the entire process of humanitarian action remains unmanaged. Another criticism is the unremitting lack of evidence-based studies on this topic. Much of the available literature consists of secondary desk reviews. While much has been written from a humanitarian perspective, there are insufficient studies written from a development perspective (Hinds 2015). Moreover, as the authors of this book suggest, there is even disagreement on what the problem is behind the continuum of humanitarian crisis management - not just among development practitioners but also from communities working specifically on disasters, peacebuilding and other types of crises.

\section{The 2016 World Humanitarian Summit}

Amid this context, the World Humanitarian Summit (WHS) was held on May 24-25, 2016, in Istanbul with the thematic goals of (1) re-inspiring and reinvigorating commitment to humanity and the universality of humanitarian principles, (2) initiating a set of concrete actions and commitments aimed at enabling countries and communities to better prepare for and respond to crises, and becoming resilient to shocks, and (3) sharing of best practices that can help save lives around the world, putting affected people at the center of humanitarian action, and alleviating suffering. The UN Secretary-General Ban Ki-moon expected the WHS to be

an opportunity for 'we the peoples' - Heads of State and Government, representatives of affected communities, national and international aid organizations, global opinion leaders, private sector leaders and others - to agree that we can and must do better to end conflict, alleviate suffering and reduce risk and vulnerability.

(United Nations General Assembly 2016, 3)

In the global consultation leading up to the Summit, a synthesis report entitled 'Restoring Humanity: Global Voices Calling for Action' was discussed in Geneva in October 2015. This preceded the Secretary-General's Report, 'One Humanity: 
Shared Responsibility' in February 2016. The UN Secretary-General's report advanced five core responsibilities, namely:

1 global leadership to prevent and end conflict;

2 uphold the norms that safeguard humanity;

3 leave no one behind;

4 change people's lives - from delivering aid to ending need; and

5 invest in humanity.

From all these responsibilities, points 4 and 5 specifically addressed the problems of the humanitarian-development nexus and the inherent challenges of coordinated and strategic crisis management.

Under the fourth responsibility, the report includes some ambitious recommendations for the transcendence of the humanitarian and development divide to deliver collective outcomes, a division that, as the report stresses, makes no sense for the affected populations. The report suggests that 'we must commit to work according to comparative advantage, under one leadership, and to move beyond the comfort of traditional silos, mandates and institutional boundaries to operate with a greater diversity of partners and in support of local and national actors' (United Nations General Assembly 2016, para. 177). One of the recommendations called upon donors to move beyond humanitarian-development divisions that foster fragmentation in aid towards an approach that allows strategic outcomes to be achieved in a predictable and sustainable manner (ibid., para. 157).

The fifth responsibility, focused on addressing financial concerns, yielded the most considerable achievement during this Summit - the development of a Grand Bargain for effective funding and expenditure methods. The Grand Bargain proposal covers ten goals with a total of 51 commitments, including a strong emphasis on supporting and including locals and the joint and efficient, long-term commitment beyond humanitarian actors. This proposal articulates the need to work together efficiently, transparently and harmoniously, not only with humanitarian and development workers but with new and existing partners, including the private sector, individuals and non-traditional sources of funding (IASC 2017). Bridging the gap between the humanitarian and development divide is therefore an important aspect and comprises one of the ten work streams through which the Grand Bargain is being implemented. However, progress has so far remained unclear (Horvath, Ruppert and Steets 2017).

The WHS generated more than 3,000 commitments to action and launched more than a dozen new partnerships and initiatives to turn the 'Agenda for Humanity' into a meaningful change for the world's most vulnerable people. In particular, the Grand Bargain and the agreement on collective outcomes across the UN system potentially mean a new era for humanitarian assistance which works more closely with development, climate change, disaster-risk reduction, peacebuilding and other communities of practice. Furthermore, in the WHS summary report (United Nations General Assembly 2016), the Secretary-General noted that a new and coherent approach is required in addressing root causes, 
increasing political diplomacy for prevention and conflict resolution, and bringing humanitarian, development and peacebuilding efforts together. Although a reform of the humanitarian system has not been realized as some expected, the overall effects of the Summit should not be underestimated.

As with Resolution 46/182, the basic assumption of the Summit was that more coordinated and cooperative actions among related actors would lead to a solution to the problem. However, it remains to be seen if such an actor-based approach will result in a system that is greater than the sum of its parts or will end up obscuring each actor's responsibilities. The WHS is just a single step towards effective humanitarian crisis management, and continued efforts to fully implement the commitments are required.

\section{About this book: the continuum of humanitarian crisis management}

From all these reforms and debates, a number of fundamental questions can be raised: To what extent have these new ideas and institutions resulted in better management of humanitarian crises? What factors or conditions promote or hinder cooperative actions among actors? And does the difference between crises and contexts matter in realizing coordinated actions among different actors, and if so, in what ways? There are therefore good reasons to assess the level of achievement to date and to identify what remains to be done based on concrete case studies of humanitarian crisis management. Critical perspectives can be shared by different actors based around these questions.

As the road towards the WHS indicates, the relationship between humanitarianism and development is at the center of the need for reform in crisis management. Hilhorst (2016) stressed this difficulty of distinguishing between crisis and normality: conflict and disasters are visible breakpoints in the social order, creating a considerable degree of chaos and disruption but are also marked by processes of continuity and re-ordering. Humanitarian aid appears clearly in the realm of crisis, but a new set of practices should be interpreted as an appreciation of aid that builds people's capacities to manage their own lives. This has also been emphasized by the present UN Secretary-General Antonio Guterres, who pointed out the need 'to build and sustain peace across the continuum, from prevention, conflict resolution and peacekeeping to peacebuilding and long-term development' (United Nations Secretary-General 2017; emphasis added). The underlying reason is that the critical phase of emergencies is only the tip of the iceberg of a much more complex phenomenon requiring comprehensive, longterm strategies for a wider range of actors to reach sustainable solutions or, as another previous head of UNHCR Sadako Ogata succinctly described, the recognition that 'there are no humanitarian solutions to humanitarian problems' (Tan 2005).

Shedding light on this predicament is the main purpose of this book. It is the result of a three-year research project funded by Japan International Cooperation Agency Research Institute since January 2015 entitled 'Comparative Study 
of Humanitarian Crisis Management from the Perspective of Bilateral Cooperation Agencies.' Reflecting on the history of practice and research on the problem of linking humanitarian and development action, several features of the research design deserve mention.

First, the driving concepts of the research were the continuum - the task of providing more than relief by connecting the phases of response, recovery and prevention - and crisis management, which is defined as the overall process of aiming to realize such a continuum. In Chapter 2, Gómez and Kawaguchi explore this 'humanitarian-development' framework in detail, looking at the continuum both in terms of actors and phases, and the degree to which the established humanitarian mandates constrained their effective performance. Crisis management is used as a proxy of the humanitarian-development nexus wording for two reasons: first, since the gray zone between them is what is under question, it is necessary to have a neutral framing that avoids the traps of sectionalism underlying a monolithic conception of humanitarian action and development; besides, such framing also recognizes the wider spectrum of actors involved in doing more than providing relief, as described above.

Moreover, the 'humanitarian-development' framing starts by approaching the problem of the continuum from the point of view of the international supply side; however, whether this is the best way to approach humanitarian crisis management has to be questioned. From the recipient side, the difference between humanitarian and development actors makes little sense, as local actors and contexts are critical for success throughout all phases of relief, recovery and prevention (OCHA and DARA 2014). Framed within this context, the authors approached the discussion based on the phases of the crisis and their continuum, focusing on people's needs while evaluating how two or more epistemic communities can work together to address changing needs after an emergency.

Second, this book has taken a special interest in the approaches of major bilateral donors (i.e., the US, the UK, Japan and the European Union, as a quasi-bilateral actor). There are concerns regarding the 'bilateralization' (Macrae and Harmer 2004) of humanitarian action due to the large proportion of humanitarian funding provided by governments (see Figure 1.1). Despite concerns over the categorical diminution of aid independence and neutrality, there is a scarcity of research on how these actors actually contribute to realizing the continuum of crisis management.

As early as the mid-1990s, there have been several approaches and tools (such as in-kind, technical and financial assistance) to address the problem of realizing the continuum. For example, the Bureau for Humanitarian Response (now Democracy, Conflict and Humanitarian Assistance, DCHA) was created by the United States Agency for International Development (USAID) in 1992 (Olson 2005). ECHO was created in 1992 and, in the same year, the United Kingdom Overseas Development Administration (now the Department for International Development, DFID) modified its structure to cover relief assistance. In April 1992, the International Emergency Relief Division was created by the Ministry of Foreign Affairs of Japan to manage disaster-related emergency assistance. By separating management of humanitarian issues from the rest of ODA, the need 


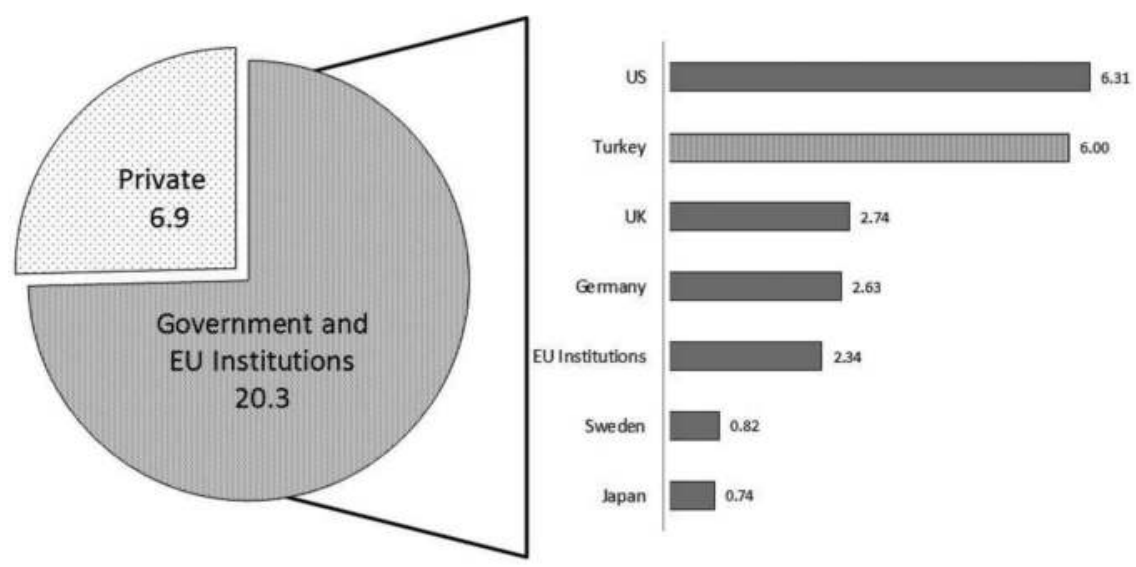

Figure 1.1 Distribution of international humanitarian assistance and top seven governmental and EU institutional donors, 2016 (US\$ billions).

Note: EU institutions are included separately for comparison. Turkey is shaded differently because the humanitarian assistance it voluntarily reports to the DAC is largely composed of hosting Syrian refugees in Turkey.

Source: authors, based on Development Initiatives (2017).

for improving humanitarian-development nexus increased, with donor agencies playing the key role in realizing it.

Subsequent efforts by different governments to realize the continuum of humanitarian crisis management deserve objective review and evaluation. In addition to these government agencies, contributions from bilateral donors appear as windows of opportunity to resolve sectionalism through their long-term programming and diplomatic significance. Bilateral donors/agencies, especially embassies and development agencies, are expected to have a longer presence in crisis-affected areas, allowing them to develop a more holistic perspective of the problem. In sum, the deep examination of policies and past experiences of the bilateral donors and agencies offers a meaningful opportunity to improve humanitarian crisis management.

In order to see this history of crisis management in detail, the research for this volume was not only limited to reviews of policies and consultations with the headquarters of major organizations. It also comprises a series of case studies that present humanitarian crisis management experiences over the last two decades. The book validates and assesses the continuum of humanitarian crisis management across selected case studies in the streams of both natural disasters and conflict-affected areas. Each of the two types of crises is preceded by an introduction that highlights specific ways that practitioners and scholars have approached the problem of the continuum from their own experiences and with different tools (Chapters 3 and 7). Similar actors appear in both types of crises, although their paths and strategies are meaningfully different. Understanding the differences of the continuum in both types of crisis scenarios is also one of this project's goals. 
Case studies were selected on the basis of their globally significant impacts, the balance in the presence of actors in crisis areas, geographical diversity, and the new challenges they brought to humanitarian crisis management. The disasters that were induced by armed conflict such as Timor-Leste (Chapter 4), South Sudan (Chapter 5), and the Syrian crisis (Chapter 6) provide accounts of achieving post-conflict peacebuilding and sustaining peace. The case of Timor-Leste introduces a magnified view of a prolonged struggle for peace and the periodic or subsequent menaces brought about by the relapse into conflict. Despite the earlier attainment of peace, the case of South Sudan explores the recurring relapse into conflict and the long humanitarian crisis. The conflict in Syria illustrates the early need for development and promotion of the continuum.

On the other hand, the section on humanitarian crisis management in disaster contexts is substantiated by case studies of Hurricane Mitch in Honduras (Chapter 8), the Indian Ocean earthquake and tsunami in Indonesia (Chapter 9), and Typhoon Yolanda in the Philippines (Chapter 10). Looking at Honduras after Hurricane Mitch (1998) presents a long-term disaster scenario representing the Latin American region through which the challenge of engendering prevention after a catastrophe is protracted. The 2004 India Ocean tsunami in Indonesia was also a globally significant large-scale disaster, paving the way to the emergence of the current disaster risk reduction mantra of 'build back better.' Lastly, Typhoon Yolanda, which devastated central Philippines in 2013, is assessed as a model for the present continuum realization and a consideration of the challenges in undertaking this word.

The team has conducted interviews with international organizations, bilateral cooperation agencies, NGOs, government officials and research institutes at the headquarters and field levels in 13 countries. In May 2016, the research team produced some messages for the WHS that were distributed to introduce this research project to relevant stakeholders and field practitioners.

This book aims to find ways forward in humanitarian crisis management from an academic perspective, while retaining an awareness of the existing history of efforts. Despite all of the attention on the nexus problem, there are few publications dedicated to understanding the continuum and the evolution of approaches. The IFRG made some early efforts through the works of Hagman, Beer and Röda Korset (1984), Hagman (1988) and McAllister (1993), as well as Anderson and Woodrow (1989). Afterward, there are multiple works of gray literature, consultant reports, policy papers, and some journal articles; however, there is scarcely any academic monographs dedicated to this theme - perhaps with the exception of Macrae's (2001) book on political emergencies. This dearth of publications on the humanitarian-development nexus is attributed to the excessive attention given to coordination - the other major issue in the emergence of the humanitarian sector in global governance, as described above (Smillie 1998). Another possible explanation is that consolidating humanitarian affairs as a separate operational branch has until now been the main priority. In any case, the nexus has unfortunately not been followed by the development of a dedicated academic research community.

In addition to the WHS, there has been a series of major events in 2015 and 2016 such as the adoption of the Sustainable Development Goals, the Paris 
Declaration on Climate Change, a review of the peacekeeping and peacebuilding architecture, and the Sendai Framework for Action in Disaster Risk Reduction, among others. These events have reinforced the need for crosscutting coherence between different approaches to the global governance of humanitarian crises. This book is intended to provide the basis for such coherence, moving beyond the humanitarian-development nexus by conceiving of a humanitarian crisis management that is better informed by the past and more relevant to present challenges.

\section{Notes}

1 More recently, linking humanitarian and, development aid to political and security objectives is attracting international attention, especially in conflict and fragile environments (Hinds 2015).

2 There are currently 42 members of the Good Humanitarian Donorship group. See: https://www.ghdinitiative.org/ghd/gns/about-us/about-ghd.html.

\section{References}

ALNAP. 2015. The State of the Humanitarian System 2015 Edition. London: ALNAP/ODI.

Anderson, Mary B, and Peter J. Woodrow. 1989. Rising from the Ashes: Development Strategies in Times of Disaster. Boulder, CO: Westview Press.

Crisp, Jeff. 2007. Humanitarian Action and Coordination. In The Oxford Handbook on the United Nations, edited by Thomas G. Weiss and Sam Daws, 479-495. New York: Oxford University Press.

Development Initiatives. 2017. Global Humanitarian Assistance Report 2017. Bristol: Development Initiatives.

Edwards, Adrian. 2016. UNHCR The UN Refugee Agency: Global Forced Displacement Hits Record High. UNHCR. www.unhcr.org/news/latest/2016/6/5763b65a4/ global-forced-displacement-hits-record-high.html.

Friis, Karsten and Pia Jarmyr (eds.). 2008. Comprehensive Approach: Challenges and Opportunities in Complex Crisis Management. Oslo: NUPI.

Good Humanitarian Donorship. 2003. GHD Principles \& Good Practice. www.ghdinitiative. $\mathrm{org} / \mathrm{ghd} / \mathrm{gns} /$ principles-good-practice-of-ghd/principles-good-practice-ghd.html.

Hagman, Gunnar. 1988. From Disaster Relief to Development. Geneva: Henry Dunant Institute.

Hagman, Gunnar, Henrik Beer, and Svenska Röda Korset. 1984. Prevention Better than Cure: Report on Human and Environmental Disasters in the Third World (3rd ed.). Stockholm: Swedish Red Cross.

Hammerstad, Anne. 2014. The Rise \& Decline of a Global Security Actor: UNHCR, Refugee Protection, \& Security. Oxford: Oxford University Press.

Hilhorst, Dorothea. 2016. Aid-Society Relations in Humanitarian Crises and Recovery. Inaugural lecture presented on September 22, 2016, in acceptance of the chair of Humanitarian Aid and Reconstruction, Institute of Social Studies, Eramus University, Rotterdam.

Hinds, Róisín. 2015. GSDRC Helpdesk Research Report 1185: Relationship Between Humanitarian and Development Aid. Birmingham: GSDRC, University of Birmingham.

Horvath, Andras Derzsi, Lotte Ruppert, and Julia Steets. 2017. Independent Grand Bargain Report. Berlin: GPPi.

IASC. 2017. Grand Bargain (Hosted by the IASG). Inter-Agency Standing Committee. https://interagencystandingcommittee.org/grand-bargain-hosted-iasc. 
Macrae, Joanna. 2001. Aiding Recovery? The Crisis of Aid in Chronic Political Emergencies. London: Zed Books.

Macrae, Joanna, and Adele Harmer. 2004. Good Humanitarian Donorship and the European Union: Issues and Options. Background Paper Prepared for an Informal Meeting of the Humanitarian Aid Committee, Dublin, March 25-26. www.odi.org/sites/odi.org.uk/ files/odi-assets/publications-opinion-files/442.pdf.

McAllister, Ian. 1993. Sustaining Relief with Development: Strategic Issues for the Red Cross and Red Crescent. Dordrecht: Martinus Nijhoff.

OCHA. 2012. General Assembly Resolution 46/182. OCAH on Message. www.unocha. org/sites/unocha/files/dms/Documents/120402_OOM-46182_eng.pdf.

OCHA and DARA. 2014. Saving Lives Today and Tomorrow: Managing the Risks of Humanitarian Crises. OCHA Policies and Studies Series. New York: OCHA.

OECD. 2011. International Engagement in Fragile States: Can't We do Better? Conflict and Fragility. Paris: OECD Publishing.

Olson, Richard Stuart. 2005. The Office of U.S. Foreign Disaster Assistance (OFDA) of the United States Agency for International Development (USAID): A Critical Functure Analysis, 1964-2003. http://pdf.usaid.gov/pdf_docs/Pnadc353.pdf.

Oshima, Kenzo. 2004. The Responsibility to Protect and Humanitarian Engagement. In The Humanitarian Decade: Challenges for Humanitarian Assistance in the Last Decade and into the Future, edited by Office for the Coordination of Humanitarian Affairs (OCHA), 3-5. New York: United Nations.

Smillie, Ian. 1998. Relief and Development: The Struggle for Synergy. Occasional Paper 33. Providence, RI: Thomas J. Watson Jr. Institute for International Studies, Brown University.

Steets, Julia. 2011. Donor Strategies for Addressing the Transition Gap and Linking Humanitarian and Development Assistance: A Contribution to the International Debate. Berlin: GPPi.

Suhrke, Astri, and Arve Ofstad. 2005. Filling 'the Gap': Lessons Well Learnt by the Multilateral Aid Agencies. CMI Working Paper. Bergen, Norway.

Tan, Vivian. 2005. Ogata Calls for Stronger Political will to Solve Refugee Crises. UNHCR. www.unhcr.org/news/latest/2005/5/4297406a2/ogata-calls-stronger-political-solverefugee-crises.html.

United Nations General Assembly. 2016. One Humanity: Shared Responsibility: Report of the Secretary-General for the World Humanitarian Summit. United Nations General Assembly, Seventieth Session, Doc. A/70/709, February 2.

United Nations Secretary-General. 2012. Secretary-General's Remarks to the General Assembly on his Five-Year Action Agenda: 'The Future We Want.' January 25. www. un.org/sg/en/content/sg/statement/2012-01-25/secretary-generals-remarks-generalassembly-his-five-year-action.

- 2017. Remarks to the Security Council Open Debate on 'Maintenance of International Peace and Security: Conflict Prevention and Sustaining Peace.' January 10. www.un.org/sg/en/content/sg/speeches/2017-01-10/secretary-generals-remarksmaintenance-international-peace-and.

Weiss, Thomas G. 2013. Humanitarian Business 29. Boston, MA: Polity Press.

World Bank. 2011. World Development Report 2011: Conflict, Security, and Development. Washington, DC: World Bank. 


\title{
2 A theory for the continuum Multiple approaches to humanitarian crises management
}

\author{
Oscar A. Gómez and Chigumi Kawaguchi
}

\section{Introduction}

The notion that 'relief alone is not enough' is common to all actors involved in the management of humanitarian crises. This notion was officially framed at the United Nations (UN) in 1991 as a 'continuum from relief to rehabilitation and development,' and up until today, this remains a challenging task in the agenda of international assistance organizations, as we saw in Chapter 1. Support by the international community to the full picture of humanitarian crisis management is not merely a token of altruism, but close to a duty. In fact, absence or failure to offer adequate protection and assistance in the face of crisis is heavily criticized, motivating a great deal of soul-searching, usually followed by renewed compromises for doing better. That has been the case after famines in the Horn of Africa in the 1980s, sadly repeated in 2011, the mass atrocities in Rwanda and Kosovo, a devastating tsunami in the Indian Ocean in 2004, to name but a few events behind the prominence of humanitarian crises on the international agenda.

Recent reviews on the topic show that there is no conceptual clarity or agreement on what realizing the continuum actually means (Steets 2011; Otto 2013) and despite much talk, it generally include negative reports about progress in practice. However, the continuum is important not only because of the possible gains in efficiency, but also because aid that fails to recognize the dynamics of a crisis can harm already embattled populations. For instance, free provision of goods and services can destroy the jobs of local actors who provide those things during normal times. Unmanaged recovery may also interfere with the plans for building back better, making societies less resilient. Besides, giving priority to the continuum opens opportunities to include crisis prevention and preparedness in established development activities. Recognizing and acting within the continuum throughout humanitarian crisis management is thus a human security challenge that deserves more attention (see Kaldor, Martin and Selchow 2007; Gómez 2014; Kamidohzono, Gómez and Mine 2016; Tanaka 2015).

Given this lack of conceptual clarity, we put forward in this chapter a theoretical model for studying the continuum of humanitarian crisis management. The model is based on the main approaches devised after the Cold War by multilateral and bilateral actors, and a critical approach to their consistency/coherence 
with the original problem at hand. Moreover, we suggest that one of the reasons why shared understanding on the continuum has not been possible is due to the paucity of efforts to clarify its meaning in a way that leads to an understanding compatible with both humanitarian crises in general and crisis-specific settings. Therefore, the model we suggest is also conceived in conversation with other epistemic communities working on peacebuilding and disaster risk reduction, which are reviewed in depth in the introductions to the corresponding case studies. These allow us to suggest an analytical framework good enough to orient case studies, which we could later report through the research findings.

Before moving on, a couple of clarifications are however necessary. First, it should be clear that by sticking to the original framing of the problem as the continuum, we are not favoring any single approach or specific policy. We use the word 'continuum' as a neutral, analytical concept to describe the problem of 'doing more than relief' and allow comparisons across different policies and approaches. In the 1990s, the word 'continuum' was put forward as an approach to the problem, but one that emphasized a linear sequence of phases and actors, and was strongly criticized for its inaccuracy (DHA 1995). This explains its early disappearance from some organizations' parlance, such as the UN Development Programme (UNDP) (Smillie 1998, xxviii) and the European Civil Protection and Humanitarian Aid Operations (ECHO). This criticism still can be heard (Macrae 2001), especially when new approaches are presented; yet no alternative to describe the problem has been agreed. Other candidates have important limitations: the term 'contiguum' has received little attention outside its European proponents, and it is not properly a word; the concept of a 'gap' is too generic, and is historically too close to the work of the UN High Commissioner for Refugees (UNHCR) (Crisp 2001). While the 'humanitarian-development nexus' is an appealing name, it conceals what may be in fact part of the problem - for those affected by crisis, the difference between humanitarian and developmental aid makes no sense (OCHA and DARA 2014). Mindful of these criticisms and ready to reflect them through our analysis, the concept of the continuum still seems an attractive option to frame our discussion of the problem.

Second, in this paper, realizing the continuum is presented as the heart of crisis management, by which we understand the comprehensive effort of the international community to deal with humanitarian emergencies. This understanding is not central to the scholarship on crisis management (Boin, McConnell and Hart 2008), but through the process leading up to the World Humanitarian Summit in 2016, it has been put forth as an umbrella concept that tries to align in the field certain mandates that sometimes work in silos at the international level: humanitarian relief, peacebuilding, disaster risk reduction, development and climate change. ${ }^{1}$ Therefore, management implies attention to the different phases of a crisis, and thus our research is not limited to relief only. Multiple phases and actors reflect the dynamic change of needs throughout a crisis and its aftermath, requiring both short-term and long-term commitments to achieve the final goal of securing humans. Thus, 'management' is preferred over mere assistance and 
aid because the term reflects the changing nature of the global commitment, suggesting there is some sort of system covering all phases of crisis, as well as the multiplicity of actors involved.

Lastly, while conceptual in spirit, the present research is also the result of a series of 50 semi-structured interviews made with different stakeholders involved in crisis management. Two rounds of face-to-face interviews were held in February and May-June 2015 at headquarters in Tokyo, Brussels, Geneva, London, New York, and Washington DC., together with complementary videoconferences, consultations, and interviews. Interviewees included the employees of bilateral agencies, international organizations, non-governmental organizations (NGOs), and academics and practitioners who work in single mandate or multi-mandate organizations. All have experience in the approaches covered by the research. In addition, insights gained from several events held during the 2015 World Conference on Disaster Risk Reduction, as well as the 2016 World Humanitarian Summit and its preparatory activities, provided important inputs to the research.

In the next section, we start by distilling the basic elements that require consideration when theorizing on the continuum as it was originally introduced in the 1991 UN resolution. After that, we review the most relevant, direct approaches to define and realize the continuum by both bilateral and multilateral actors. From these experiences, we proceed to sketch a model that could be used to study the continuum empirically. The last section sums up the discussion, offering a synthesis of the model of the continuum and its limits.

\section{A framework for comparison}

The UN Resolution 46/182 presented the ideal of the continuum as an essential goal and tool for the emerging humanitarian system in general. This resolution was not the first time such a vision had been put forward (see Kent 1983; McAllister 1993; Barnett 2011) but because it is a widely recognized landmark in global humanitarian affairs, it offers an appropriate starting point for our work. The resolution gave impetus to the emergence and consolidation of humanitarian affairs through the UN system, as well as among donors, who created specific divisions to deal with humanitarian affairs in the following years, as described in Chapter 1.

The resolution is, nonetheless, ambiguous in its description of the continuum: in some sections it is presented as a matter of phases, and in others as a matter of actors. In terms of phases, the resolution emphasizes the importance of prevention and preparedness, explaining that 'economic growth and sustainable development are essential' for this purpose. Then, once a crisis occurs, the continuum implies 'a smooth transition from relief to rehabilitation and development' (United Nations General Assembly 1991). In other sections, it also refers to 'reconstruction' and 'recovery,' evidence of the multiplicity of similar concepts resulting from a lack of general agreement on an established definition. Regarding actors, the resolution distinguishes between development assistance organizations 
and 'those responsible for emergency and recovery', who are merely expected to collaborate. The resolution also warns against contributions to humanitarian assistance affecting existing contributions to international cooperation efforts for development.

This ambiguity between phases and actors regarding the crux of the continuum offers an appealing frame to compare existing approaches. While the two components overlap, and both are necessary in practice, they represent different perspectives on what the problem is. Realizing the continuum in terms of phases suggests the problem is devising the strategy for undertaking in a timely manner the different types of necessary post-crisis activities. On the other hand, describing the problem in terms of actors implies that coordination is the main hurdle preventing or promoting the realization of the continuum. If we take strategy to be the major concern, covering needs is more important than who actually does the job. Contrastingly, coordination assumes that actors and their mandates are fixed, so success is mainly a matter of joint efforts. Comparing the weight given to either phases or actors in approaches to the continuum during the last quarter century will help elucidate the commonalities and discrepancies between these approaches.

Finally, there is an additional factor that deserves special mention: funding. How money flows during the management of a crisis greatly influences the kinds of problems that are relevant in realizing the continuum. Does it help to develop strategies that connect phases? Or does it help to coordinate actors? Or both? Or neither? For instance, the resolution established contingency funding dedicated exclusively to emergencies, so it hindered from the very beginning the process of transforming relief money into recovery money. Observe how Steets (2011), in her analysis of the continuum/contiguum, argues for distinguishing the disconnect between humanitarian and development assistance and the funding gap, as two issues deserving separate treatment. While we consider the two to be close enough to make overall suggestions, we take her point and include funding as an additional parameter for comparison.

\section{General approaches to the continuum: multilateral and bilateral experiences}

Following the 1991 UN resolution and focusing on bilateral actors, there are at least four major efforts to directly address the problem of the continuum, namely: Linking Relief, Rehabilitation and Development (LRRD), 'Relief to Development' or 'Developmental relief,' the Seamless Approach, and Resilience. Besides, there are two major multilateral efforts that deserve mention because they keep receiving attention in practice: the gap approach and early recovery through the humanitarian cluster coordination. That said, it should be noted that many other organizations during the nineties and afterwards developed their own tools to address the continuum through their own expertise. Smillie (1998) presents UNHCR's Quick Impact Projects (QIPs) as an example of how the organization stretches its mandate to do development-like activities. In its transformation 
from a development agency to a humanitarian or hybrid one, the World Food Program (WFP) also created tools for transition, such as Protracted Relief and Recovery Operations (Shaw 2011), through which the change from relief to service delivery and autonomy is supported. The United Nations Children's Fund (UNICEF) also has a double humanitarian-development mandate although, by 1998, Macrae and Bradbury (1998) suggest the agency only reluctantly became involved in crisis; yet, nowadays UNICEF leads the education cluster, which has been evaluated as functioning very well (Steets et al. 2010). The UN Development Programme (UNDP) was set for a slow start, creating in 1995 an Emergency Response Division, which became the Bureau for Crisis Prevention and Recovery (BCPR), seeking to become the 'UN Coordinator for Recovery' (Mark Malloch Brown, quoted by Suhrke and Ofstad 2005, 9), a bureau that was dissolved in 2014 (Call and Collin 2015, 11); the Food and Agriculture Organization (FAO), the International Labour Organization (ILO) and the International Organization for Migration (IOM) have also activities tailored to recovery and transition.

In this section, we introduce each of them before analyzing their commonalities and differences in relation to the elements identified in the previous section. It is worth noting that other organizations developed their own approaches for their internal work, as Higashiura and Gómez describe about the Red Cross Movement in Chapter 7 of this volume, and as has also been reported on UNICEF (Macrae and Bradbury 1998) and the WFP (Shaw 2011). Still, we focused on those efforts that tried to reach consensus beyond the original organization involved.

\section{LRRD by the European Union}

Among 'bilateral' approaches, EU's Linking Relief, Rehabilitation and Development (LRRD) (EC 1996) is perhaps the longest standing example of an approach to the continuum. LRRD was originally the EU's proposal to realize the continuum, although a footnote suggests that this should be replaced by 'the contiguum' to reflect how operations are simultaneous in the field. There have been two EC communications devoted to it $(1996,2001)$ and it was later part of the European Consensus on Humanitarian Aid (EC 2007); LRRD is usually associated with ECHO, although ideally it was to involve also the Directorate-General for International Cooperation and Development (DEVCO) for development, ${ }^{2}$ and even the European External Action Service (EEAS, previously RELEX) in charge of common foreign and security policy.

The LRRD approach focuses on pointing out the main issues that are problematic in the gray zone between relief and development. These include:

- $\quad$ strategic planning policy comprising political, developmental, social and technical aspects,

- coordination both between donors and internal to the EU;

- timing for smooth handover and articulation between different aid approaches;

- faster decision-making procedures; 
- $\quad$ selection of adequate implementing partners, which includes a wide range of actors, such as NGOs (60\%), UN agencies (20\%), and the Red Cross (15\%); and

- $\quad$ ability to mobilize resources - but not necessarily new mechanisms.

Besides, the communications recognize the existence of other issues beyond the reach of the LRRD approach that affect what can actually be achieved, such as the approval from the recipient country and the trade-off between speed and flexibility and quality control.

While these issues apply in general to the continuum, the LRRD has a clear focus on coordinating EU's aid internally. However, a 2014 review (ADE and Humanitarian Futures Programme 2014, 90) suggests that this has been largely unsuccessful, particularly because 'humanitarian aid strives to remain independent, while development aid seeks to align with recipient governments.' Also problematic is the perception that, in the end, LRRD has been mainly about how to handover ECHO projects to other instruments of the European Union, which is a non-starter. At the implementation level, there have been efforts of enhanced collaboration beyond handovers and exit strategies, such as the Joint Humanitarian-Development Framework (JHDF) methodology; yet, overall, Morazan et al. $(2012,21)$ observe that 'what has been missing ... is the political will to understand and support these complex dynamics of crisis resolution and LRRD in a meaningful manner.'

\section{Relief to Development by the United States}

United States Agency for International Development (USAID) is other organization that has put emphasis on the continuum even before 1991. The Office of US Foreign Disaster Assistance (OFDA) was created in 1964 as part of USAID in charge of initial relief, which in the seventies and eighties was broadened to disaster assistance, implying prevention/preparedness as well as recovery and rehabilitation (Olson 2005). This overstretch of functions was not welcomed by all in OFDA and it is still a source of conflict over mission boundaries. The uneasiness also reflects a general disinterest of development with disasters and a difficult relationship between USAID and OFDA, which, similar to the EU, has been the focus of the agency action on the continuum. Besides, it should be borne in mind that other branches of the federal government also have a direct role in responses to humanitarian crises, like the Departments of State and Defense, while some other offices may jump in depending on the needs on the ground, complicating coordination.

Yoshikawa $(2013,11)$ affirms that the 'US government has no strategy or lead office with a mandate or dedicated resources for managing transitions from relief to development,' but instead several bureaus in different departments play roles. This has resulted, as Koddenbrock and Büttner (2009, 130) suggest, in a less focused debate, where several concepts exist: development-relief, relief to development, or relief, transition, and development. These examples tend to be crisis-specific, such as 
the Office for Transition Initiatives (OTI) created in 1994 to work mainly in conflicts (Mendelson-Forman 2014, 40), or USAID long standing work on food security, which has been central to USAID approaches to the continuum. ${ }^{3}$ In this sense, a report related to the President Clinton Greater Horn of Africa Initiative created in 1994 to improve food security and prevent conflict, deserves especial mention. The report (Inter-Agency Team on Rapid Transitions from Relief to Development 1996) puts forward some principles and operating guidelines for the realization of the continuum, summarized in four basic points:

1 local responsibility for the transition;

2 international responsibility to assure positive impact through strategic coordination;

3 relief programs reinforcing development; and

4 development designed for prevention or mitigation.

Then, the report provides a meticulous analysis of USAID constraints to put these in practice, dealing with the corporate culture, legislation and regulations, financial and human resources, program planning and policies and procedures.

\section{The Gap Approach}

An early example of trying to bridge the division between humanitarian UN agencies and International Financial Institutions (IFIs) was the Brookings Process spearheaded by UNHCR and the World Bank in 1999 (Crisp 2001). The Bank had created in 1997 its own Post-Conflict Unit and UNHCR was looking for other partners while trying to provide permanent solutions to displacement. Two gaps were the focus of the attention: institutional arrangements and funding systems. As a solution, the UNHCR and the World Bank proposed 'not another coordinating mechanism, nor a global trust fund. It is an action- and field-oriented coalition formed on a voluntary basis and aimed at ensuring a more predictable coherent, flexible and timely response of the key players in a given post-conflict situation' (UNHCR 1999, cited by Crisp 2001). While this initiative has survived with other names, the Brooking Process barely got off the ground (Suhrke and Ofstad 2005). Suhrke and Ofstad suggest that behind this was resistance by donors to developing a regime demanding more funds and a new bureaucratic layer, preferring instead control over the money and more coordination.

\section{Seamless assistance by Japan}

After leaving UNHCR, Sadako Ogata became the president of the Japan International Cooperation Agency (JICA), where she continued supporting initiatives exploring the gap agenda (Kamidohzono, Gómez and Mine 2016). During her long tenure, a seamless assistance 'that spans everything from prevention of conflict and natural disasters to emergency aid following a conflict or disaster, assistance for prompt recovery, and mid- to long-term development assistance' 
became one of the organizations' main strategies until 2017. Pressure to attend emergencies has resulted in multiple tools and organization changes, such as a fast track system for technical cooperation and more deployment of staff to local offices. Seamless assistance has been especially important in the area of natural hazards, involving concerns about (1) timeliness, (2) sectors, (3) levels of national governance and other actors involved, and (4) how to combine structural and non-structural measures for mitigation and adaptation (JICA 2015). JICA is, nonetheless, only in charge of implementation of ODA, and only of bilateral, development flows, while the Ministry of Foreign Affairs (MOFA) manages the core of Japan's humanitarian assistance. Therefore, JICA's seamless assistance is only about JICA's assistance itself, in contrast to EU's LRRD and resilience approaches addressing the differences between humanitarian, development and foreign affairs institutions. ${ }^{4}$ From MOFA's side, the first humanitarian policy was drafted in 2011. It includes smooth transition ${ }^{5}$ as a policy of response in reference to the different phases of crisis management, although somehow limited to refugee crises. The policy endorses the Good Humanitarian Donorship principles, but it presents nothing more than linear thinking about the continuum without further detail (MOFA 2011). ${ }^{6}$

\section{Early recovery through the Humanitarian Cluster System}

Early recovery was one of eleven clusters through which humanitarian organizations are coordinated nowadays. Initially, early recovery was about generating 'self-sustaining, nationally owned, and resilient processes for post-crisis recovery. Early Recovery encompasses governance, livelihoods, shelter, environment and social dimensions, including the reintegration of displaced populations' (IASC 2006, 1). The initial model comprises two major phases being linked by early recovery activities. Early Recovery is also described as a multidimensional process, guided by development principles in a humanitarian setting, in which the national ownership and leadership is vital. In practice, the Early Recovery cluster has been seen as one of the less effective (Taylor et al. 2012), overlapping with cluster coordination because it covers sectors for which other clusters already exist. Steets et al. (2010) show how the cluster helped closing gaps left by other clusters, for instance street cleaning in Haiti, but such a catch-all approach was not sustainable, generating doubts about what early recovery actually is (Bailey et al. 2009) and whether having a cluster was not actually part of the problem (Steets et al. 2010, 122). In 2012, it was decided that this cluster would be established only exceptionally, 'where early recovery areas are not covered by existing clusters or alternative mechanisms' (IASC 2012).

The 2015 revision of the reference module for cluster coordination at country level (IASC 2015) further reflects the evolution of the system in relation to the continuum. First, it opens with a new section on clusters and government-led sectors, through which it is suggested that adequate and not constrained government capacity may conduce to no activation of clusters, but work through national sectors. The continuum is thus ideally subordinated to the local process. Second, 


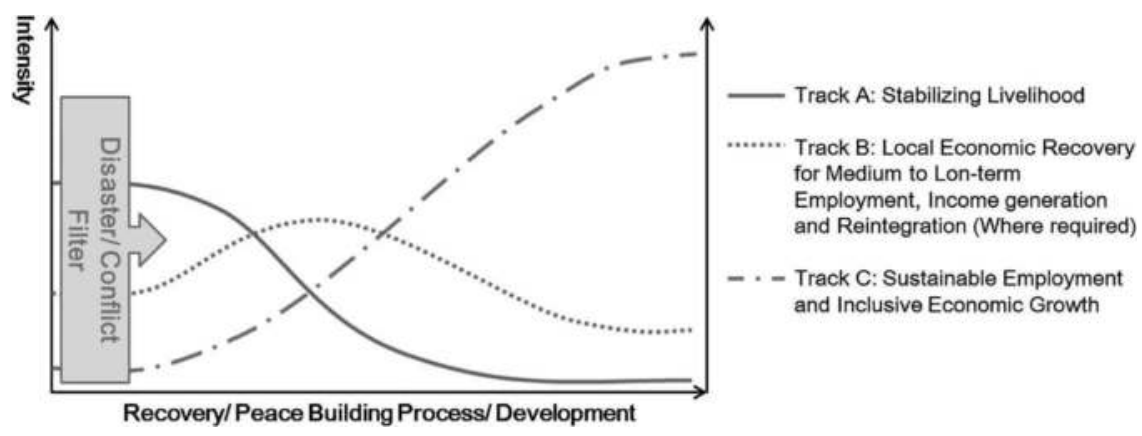

Figure 2.1 Timing and intensity of the three tracks for livelihoods recovery. Source: UNDP (2013, 9).

two phases of the crises are recognized: emergency and recovery; where the latter during which de-activation or transition of the clusters 'to national emergency or recovery and development coordination structures' takes place. Clusters are due to transition or de-activate, even merge, at their own pace, modifying their activities to support local capacity and preparedness. In principle, this appears as a handover of the operation (i.e., a linear transition) - although in practice several of the same agencies and organizations with flexible mandates will continue as development partners. So, for instance, the BCPR created tools for livelihoods and economic recovery, with a model more sophisticated than the original one of the Inter-Agency Standing Committee (IASC), identifying different interacting levels through which recovery takes place (UNDP 2013; see Figure 2.1).

\section{Resilience}

In 2011 a famine struck once again the Horn of Africa, triggering attention to what a comprehensive approach to crisis management implied. This resulted in the emergence of resilience, a concept equally embraced, at least in paper, by USAID (2012), DFID (2011) and the EU institutions (EC 2012, 2013, 2015). The definition is mostly common, referring to 'the ability of people, households, communities, countries, and systems to mitigate, adapt to and recover from shocks and stresses in a manner that reduces chronic vulnerability and facilitates inclusive growth' (USAID 2012). There is less emphasis on crisis phases and more on forging a shared vision for all actors that need to be involved to do their share. While the appeal is general, all the organizations highlight their internal problems coordinating humanitarian and development branches. Issues are similar to those from decades ago in relation to programming, common analysis, coordination and better financing mechanisms, with the important addition of learning and innovation.

Resilience is still regarded an experimental approach. UK's DFID has made efforts to embed the approach in all country programs, starting from a 
Multi-hazard Disaster Risk Assessment, and from there on influencing the programming. It has also made available multi-year resources for implementing partners to develop their own capabilities as well as tools for better understanding of resilience impact of interventions. The large number of works on resilience published by the Overseas Development Institute, an influential London based think tank, suggests commitment, although the OECD (2014) points out that the implementation is weak. The EU appears to be a step ahead pushing implementing partners to operationalize (ECHO 2014) and gathering a wide range of relevant experiences in order to inform forthcoming practice (EC 2015). USAID tried joint planning cells in order to help humanitarian and development areas work together in the Horn of Africa and the Sahel, but the experiment did not spread. While there is agreement at the senior, headquarters level, implementation is not clear - it was mentioned that some local offices may not even know about the concept.

\section{Comparative analysis of general approaches to the continuum}

In this section, we look across the approaches described above, using the strategycoordination-funding framework in relation with phases and actors to organize the presentation. The aim is to highlight commonalities and divergences, as well as emerging trends that could be useful when proposing a model that links crisis-specific views of the continuum challenge. Particularly interesting here is the emphasis on coordination, which tends to concentrate attention on problems internal to each donor, or among a couple of agencies. We present a summary of the main characteristics in Table 2.1, which includes a row summarizing the main issues highlighted by each of the approaches.

\section{Phases and strategy}

The first row in Table 2.1 gathers the phases included in each of the approaches reviewed. The phase in these approaches reflects how intervener transfer phases in their strategy. Relief and development are common on four of the six approaches, but in between these two, different terms such as rehabilitation, emergency, prevention, prompt recovery, are included in two of the six approaches. While the term rehabilitation is used, its meaning is not well-understood (Rebelle 1999, 36; Steets 2011), and instead recovery has become a more standard word for this phase. UNDP's early recovery policy (UNDP 2008) stresses that early recovery is not a stage in the continuum, though the seamless approach and others present it as such (Steets 2011).

Perhaps the most interesting feature is the way Resilience places less emphasis on distinguishing phases. Definitions of resilience do include an overall idea of different activities, for instance when the terms 'mitigate, and adapt to and recover' appear in the USAID case. However, the essence of the approach is defined by the efforts taken to avoid the identification of phases. A key message, 
Table 2.1 Summary of general approaches to the continuum

\begin{tabular}{|c|c|c|c|c|c|c|}
\hline Approaches & $L R R D$ & Relief to development & The gap & Seamless & Early recovery & Resilience \\
\hline Phases & $\begin{array}{l}\text { Relief } \\
\text { Rehabilitation } \\
\text { Development }\end{array}$ & $\begin{array}{l}\text { Relief } \\
\text { Development }\end{array}$ & $\begin{array}{l}\text { (No special } \\
\text { emphasis) }\end{array}$ & $\begin{array}{l}\text { Prevention } \\
\text { Emergency } \\
\text { Prompt recovery } \\
\text { Development }\end{array}$ & $\begin{array}{l}\text { Emergency } \\
\text { Recovery } \\
\text { Development }\end{array}$ & (No special emphasis) \\
\hline Major Issues & $\begin{array}{l}\text { Strategic planning } \\
\text { Coordination } \\
\text { Timing } \\
\text { Implementing } \\
\text { partners } \\
\text { Resource } \\
\text { mobilization }\end{array}$ & $\begin{array}{l}\text { Local responsibility } \\
\text { International } \\
\text { strategic } \\
\text { coordination } \\
\text { Relief reinforcing } \\
\text { development } \\
\text { Development for } \\
\text { prevention or } \\
\text { mitigation }\end{array}$ & $\begin{array}{l}\text { Institutional } \\
\text { arrangements } \\
\text { Funding systems }\end{array}$ & $\begin{array}{l}\text { Timeliness } \\
\text { Multi-sector } \\
\text { Multi-level of local } \\
\text { governance } \\
\text { Combine structural } \\
\text { and non-structural } \\
\text { measures for } \\
\text { mitigation and } \\
\text { adaptation }\end{array}$ & $\begin{array}{l}\text { Augment ongoing } \\
\text { emergency } \\
\text { assistance } \\
\text { Support spontaneous } \\
\text { recovery activities } \\
\text { Prepare for longer } \\
\text { term recovery }\end{array}$ & $\begin{array}{l}\text { Focus on the most } \\
\text { vulnerable } \\
\text { Shared objectives } \\
\text { System wide } \\
\text { approaches } \\
\text { Pre-emption- } \\
\text { early action } \\
\text { Governance }\end{array}$ \\
\hline $\begin{array}{l}\text { Actors involved } \\
\text { in practice }\end{array}$ & ECHO-DEVCO & $\begin{array}{l}\text { USAID \& US } \\
\text { agencies }\end{array}$ & $\begin{array}{l}\text { UNHCR and The } \\
\text { World Bank }\end{array}$ & JICA & $\begin{array}{l}\text { Cluster system, UN } \\
\text { actors }\end{array}$ & $\begin{array}{l}\text { EGHO-DEVCO } \\
\text { Partners } \\
\text { DFID-UK Partners } \\
\text { USAID }\end{array}$ \\
\hline
\end{tabular}

Source: authors. 
which originates on the LRRD and is reaffirmed in the proposition of Resilience, is that all activities occur in parallel. A commitment to resilience pursues contiguous participation during the entire crisis. Moreover, it is worth observing that prevention is not conceived as a phase in these propositions, but rather as a major issue to be internalized in humanitarian and developmental action. To be clear: there is no lack of support for preparedness and prevention, but this is not conceived as a phase in the process. Other specific issues, such as timing and implementing partners, are also ambiguous about the essence of the problem of the continuum. So, as far as it can be seen from the viewpoint of phases, it is difficult to distinguish whether activities or actors with fixed mandates are emphasized.

\section{Actors and coordination}

Seen from the viewpoint of their origin, general approaches tend not to go beyond the organizations that propose them. LRRD is mostly about connecting ECHO with DEVCO, whereas Developmental Relief and the Seamless Approach focus on connecting projects and programs internal to the country and their organizations - across US agencies, including USAID/OFDA, and inside Japan. They reflect a trend among donors to adopt the so-called whole-of-government approach (WGA); ideally developing cross-governmental structures for decision making, planning, coordination and funding under a single strategy, and encouraging some donors to 'integrate humanitarian and development responses and bridge aid, security and peacebuilding' (Bennett 2015, 14). While the proposition of the WGA is, in principle, motivated by the efficiency and effectiveness of humanitarian crisis management, accountability and value for money also play an important role (ibid., 11) — which explains the observations about funding presented below.

The Resilience approach, as presented by the EU, and by other bilateral agencies and NGOs, has tried to go beyond donor-centric action, and the EU compendium of activities showcases progress (EC 2015). Large initiatives that are still ongoing have been tested on the Horn of Africa and the Sahel. Yet, tools presented as joint planning cells (USAID), Joint Humanitarian-Development Framework (JHDF) methodologies (ECHO-DEVCO), ${ }^{7}$ and Multi-Hazard Disaster Risk Assessments (DFID), suggest internal practices are the main engine for action.

Underlying the Resilience approach's lack of emphasis on phases is the push for deeper and more meaningful coordination. This concern for coordination is common to most of the approaches, and is highlighted in the extent to which the terms 'humanitarian' and 'development' refer not to phases but to actors. Now, and twenty years ago, making different kinds of organizations sit down and work together is difficult. In the case of the USA, the fact that the Secretary of State oversees refugee situations, the Department of Defense also plays a distinct role and commands an independent budget, and that twenty other government offices are also involved in assistance, makes coordination even more complex (Koddenbrock and Büttner 2009). Resilience aims partly to offer a common framework for all these actors. 
Issues included in Table 2.1, and the tools described above, are efforts to get everyone on the same page, at least in terms of understanding each crisis. Difficulties ensuing from different planning and funding cycles are the target of these tools, but ulterior problems are also pointed out. For instance, as noted above, humanitarian independence and development partnership with the government tend to conflict. The evaluation suggests that the issue of getting humanitarian and development actors to talk has all along been challenging. The call for political will, shared objectives, and governance embraced through Resilience is a consequence of this background.

It is also worth noting that the Seamless assistance is an outlier in this sense, in as much as its focus on coordination is mainly on different levels of local actors, rather than on the donor or international level. This does not mean that other approaches have no consideration for these actors. They explicitly put more vulnerable people in the center and recognize local responsibility. Nonetheless, it is not clear in an overall sense to what extent the other approaches include affected populations, not to mention conferring on them the actual ownership of cooperation activities.

\section{Funding}

Funding is scarcely mentioned by the bilateral approaches listed, mainly because these address internal arrangements, but for multilateral approaches is fundamental. It also follows that these approaches are not necessarily supported by new resources, but instead focus on improving the use of existing funds, which explains the difference between bilateral and multilateral. The case of the EU institutions is also a little different since they deal with several pots of money, which are intended for different purposes. This situation is common to the Japanese system, where the Ministry of Foreign Affairs controls humanitarian funding, while JICA uses mainly development funds. The dedicated report on LRRD and EU financing instruments by Morazan et al. (2012), discusses in detail the pros and cons of considering the need for new, transition-oriented pots of money, versus adding flexibility to existing instruments favoring the latter. However, in the case of Japan, the Seamless Assistance does not address the division of funds in any way.

It is worth observing that Early Recovery is one of the clusters receiving less support from donors, which is one of the reasons its emphasis has been transformed into crosscutting support for other clusters. This certainly has to do with the lack of understanding about what early recovery means, and also with the fact that in recovery situation different actors come into play, especially IFIs, who may see no need in channeling resources through the cluster system (OCHA, UNDP and DOCO 2015, 37). IFIs promote and administer their own donor pooled funds (Fengler, Ihsan and Kaiser 2008), and these are different from those the OCHA uses for resource allocations during emergencies that on principle are limited to funding life-saving activities and humanitarian needs. Nevertheless, such funds only represent a very small portion of all the resources $(4.4 \%$ of the total humanitarian response in 2014; Development Initiatives 2014). 


\section{Conceptualizing the continuum}

From the presentation of efforts on the continuum following the 1991 UN resolution, two major components on its conceptualizations can be distinguished. First, a model through which the challenge of realizing the goal of the continuum is rationalized and, second, a list of issues which needs to be addressed in order to succeed in this goal. In the following two sub-sections, we advance a synthesis of the examples reviewed so far.

\section{A model for convergence in humanitarian crisis management}

The most basic depiction of the continuum between the approaches reviewed is as a linear movement between phases and/or between actors. Therefore, a general model should at least address these two issues: the issue of linearity, and the issue of giving prominence to phases or actors. These two issues are closely interlinked, so we need to discuss them in tandem.

As we mentioned in the introduction, linearity was a major reason of disagreement on the use of the continuum as an approach. The linear understanding originates from presentations such as 'from relief to development,' for which there is total correlation between phases and traditional actors. Linearity takes usually the shape of a handover between aid providers and between funds. The presumption is that humanitarian and development are well-defined, static identities of actors. However, it should be noted that this may apply, and only to a limited extent, to those actors with strict mandates such as OCHA, UNDP, UNHCR, OFDA, or ECHO, but it seems to be less important for the rest of the actors, particularly for most of the NGO implementers, for bilateral assistance in general (Yoshikawa 2013) and, perhaps more importantly, for local actors (OCHA and DARA 2014).

Including a phase or a gray zone in the middle of relief and development disrupts the correlation between phases and actors, but the idea of linearity is not necessarily changed. The gray zone in the middle has received multiple names: rehabilitation, early recovery, reconstruction, with early recovery becoming a standard term for the Cluster System, and recovery a standard for natural disasters. The gray zone implies that for crisis management the traditional division of actors is not enough, requiring:

1 some expansion of their work;

2 joint work between them; and/or

3 the help of new actors.

A continuum model based on actors would promote (2) in the form of coordination, while a model based on phases would encourage the innovation and transformation of organizations implied by (1) and (3). Given the challenging nature of crisis management, we suggest that changing mandates and mindsets must remain an option, and so is the emphasis on phases over actors. 
There is another compelling reason to favor phases: the centrality of local actors in pursuing the continuum. By downplaying phases, the actor coordination-oriented understanding of the continuum accommodates external actors, particularly those with established humanitarian and development mandates. However, this is at the cost of overlooking those actors without such constraints, beginning with local government, which ideally should lead all the phases, and not merely be treated as one actor among many. In other words, an actor-based conceptualization of the continuum tends to become an international coordination guide, rather than a demand-driven crisis management model. The fact that phases also play a crucial role conveying the idea of progress is not a minor point. The idea of progress is the basic motivation of affected populations, local authorities, and even aid providers.

Adopting phases at the heart of the model does not mean linearity (see Figure 2.2). The point about contiguity and joint work highlighted through coordination models is still valid and needs to be internalized. Indeed, it could be said that the importance and the challenge of continuum conceptualizations is to ensure that a framework based on phases does not interfere with the multiple, non-linear processes that are ongoing in the affected areas. As we suggest in Figure 2.3, the different phases should be presented as layers that overlap for long periods, although they present different intensities as the crisis progresses. Note that this multilayered activity model combines sequencing and layering in so far as changes within the dominant phase follow one after the other, but still for extended periods of time activities belonging to different phases overlap on the ground, addressing diverse, quickly changing needs as the crisis evolves.

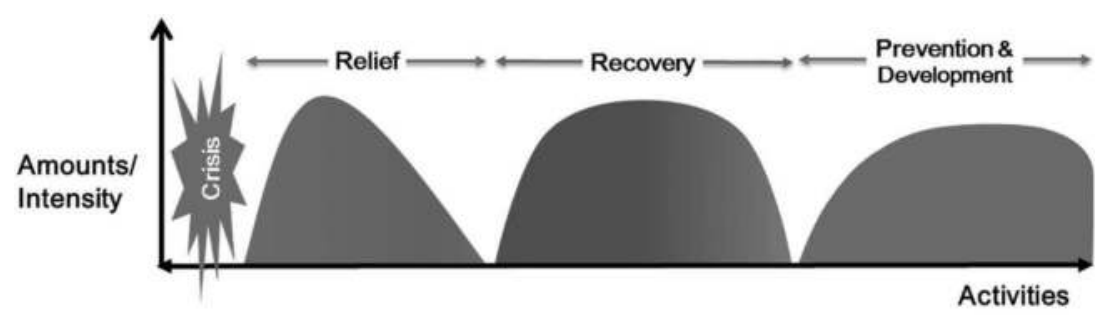

Figure 2.2 Linear model.

Source: authors.

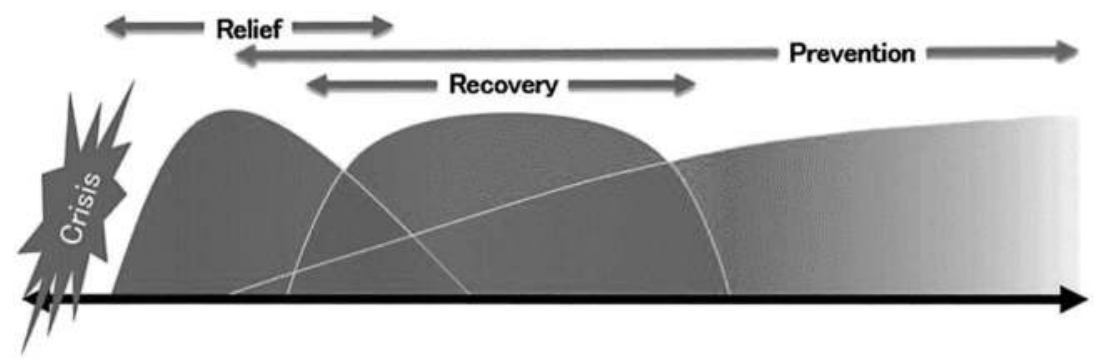

Figure 2.3 Multilayered activities model.

Source: authors, rearranged based on Wisner and Adams (2002) and FEMA (2011). 
To keep phases to a minimum compatible to all crises, the model is made up of only three of them. Relief relates to emergency activities to guarantee short term survival, while recovery covers activities oriented to restore or improve living conditions before the crisis. We then include prevention - including mitigation and preparedness - as a different phase demanding explicit attention, as in the case of natural disasters. Prevention here includes actions beyond recovery that are devised to stop or attenuate the occurrence or effects of future crisis. However, contrary to the common practice, we suggest that the prevention activities that are necessary after the crisis, even from day one, are the ones in need of recognition from the point of view of the continuum and crisis management.

\section{Issues and limitations of the model}

The discussion above suggests only a minimum common understanding, so what the model can explain is limited. Our model suggests a frame for the continuum through humanitarian crisis management, but does not cover all the issues we found through the above examination in terms of strategy, coordination and funding. Therefore, it is necessary to highlight explicit issues and limitations of the model that need to be explored empirically.

First, it should be verified whether our decision to frame the model in terms of phases and strategies is the most convenient way to study the continuum; especially because the most basic division of phases may not be good enough to cover all types of crises. This is critical in armed conflicts, where relief is not part of the peacebuilding agenda, and a different arrangement of armed and unarmed relief is preferred. A general model of the continuum must therefore allow for different configurations of phases to exist. Besides, protracted crises require the inclusion of several episodes of crisis in the model, something that the World Bank (2011) has attempted with 3D spiral representations. This approach is also used for recurrent disasters (JICA 2015). We could do the same with our model, but those models either sacrifice clarity or the contiguity of phases, so we stick to the simple 2D version, which can be combined to represent other types of crises as in Figure 2.4.

Also in relation to phases, it has to be stressed that the position of prevention as part of the management process was not clear through the approaches reviewed. Case studies should explore how in the long term prevention activities are included and given priority after relief and recovery. The models reviewed suggest that scrutinizing the relationship between prevention and development is key to understand the existing dynamics, although it should be noted that a framing of prevention - mainly as preparedness - has been also present among discussions of humanitarian actors work, particularly after disasters.

The compendium of EU experiences on resilience (EC 2015) also makes clear that there are strategy issues at different levels in the management of humanitarian crises. So far we have presented visions or concepts that cover the 


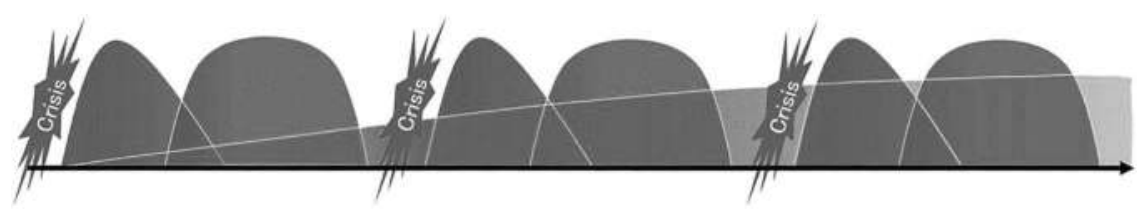

Figure 2.4 Multilayered activities model applied to a protracted crisis.

Source: authors.

headquarters of the agencies and somehow their implementing partners, but strategies have to be updated and adapted for the situation of each specific crisis in which it is to be implemented, at least to the extent that local ownership is aimed to. It is at this point when the continuum model should match or become subordinated to a different strategy or vision: that of local governments or integrated missions in charge. In other words, the continuum strategy cannot be seen in isolation for a single actor, but should be placed in context of the umbrella strategy of each specific crisis.

In this sense, the centrality of local actors that we imply through our model should be understood as an invitation to avoid approaches to the continuum that are focused exclusively on how each organization or donor links its own humanitarian and development activities. In the worst-case scenario, mighty actors may attempt to supplant locals in commanding the process, which is a recipe for failure. In the best case, achieving continuity between each external organization action would be meaningless in the midst of local disarray. This is, we believe, why assessments about continuum approaches always paint a dismal picture. Contributions to specific components of the continuum are of course welcome, but they will not shine without progress on the bigger picture. And that bigger picture is beyond what a single actor can influence.

Still coordination and actor-based approach would remain important, perhaps not in general, but in particular sectors and through different means of implementation. Relationships internal to donors or to the recipient society, as well as between multilateral actors and local offices are also of particular interest. Inside of donors, there are different ministries and agencies which deal with different function of the crisis management, such as diplomacy, security, development and humanitarian. Other important dimension for coordination relates to the actual implementation of aid, namely: at the executive level for policy decisions, at the managerial level for the distribution of tasks, and/or at the operational level for the actual implementation. Each of these levels implies the interaction of different actors, for instance inside governments, between cooperation agencies, with local authorities, or with implementation partners. Not all the dimensions and levels of coordination may have the same level of importance in realizing the continuum, yet this is a question to be solved empirically. 
Funding seems to have been slow in reflecting the overlapping of phases, and how actors can actively bridge those phases regardless of budgetary constraints. Matters of principle underlie funding arrangements that undermine the realization of the continuum. The 1991 resolution created structures explicitly exclusive for relief, resulting in differentiated structures, even within donors. Different pots of money were originally created not to overlap, and thus structurally the system started, if not against the continuum, then without it in mind. Changes of leadership derived from the strategy (e.g., moving, at least nominally, from the relief phase to the recovery phase) may also have implications on the way resources flow: criteria for allocation, procedures required, actors involved, and so. An additional problem is whether strategies and coordination tools bring along resources, or if funding mechanisms rather constraint proposed solutions. Empirical evidence of whether this is the case needs to be looked at through the case studies.

Separate humanitarian and development budgets reinforce the identities of actors. This separation is rooted not only in multilateral institutions but also in donors, who theoretically have no single mandate, but both through funding and operations sustain parallel systems. Nonetheless, in practice several actors do move across phases, and so do their bit in the general continuum. Multi-mandate actors abound and put forward different strategies on the field, but somehow the policy dialogue remains one about humanitarian and development assistance. However, the multi-mandate approach does not mean that actors do not specialize on specific activities, a potential problem that authors such as Smillie (1998) and White and Cliffe (2000) expressed skepticism about, but means that the sectors within which they work are covered across phases. This is the direction the Humanitarian Cluster System seems to be evolving towards, dovetailing with national sectors that should lead recovery and preventive development. Case studies should verify whether humanitarian and developmental identities actually are important on the ground and whether they are relevant in addressing the continuum.

Finally, it must be observed that issues outside the model will certainly arise through the case studies and should be used to correct and enrich the model. Differences between types of crises are of especial concern. Besides, it should be also tested whether the multilayered nature of the model has any practical implications on the face of linear transitions between phases and actors.

\section{Conclusion}

Through this chapter, we put forward a model to study the continuum of humanitarian crisis management based on a critical review of existing approaches by bilateral and multilateral actors. We suggest that the best way to visualize the process is as a multilayered sequence of phases to which the multiple actors involved commit. Issues of strategy, coordination and funding are also stressed as fundamental to understand how this process of crisis management takes place, which need to be investigated empirically. From this analytical perspective, the 
following case studies will tackle the questions: to what extent different actors' approaches have addressed the continuum in managing humanitarian crises? How phases are defined in each of their strategies? What factors or conditions promote and hinder these strategies and cooperative actions among actors? Through the book conclusion, we will come back to all these questions.

\section{Notes}

1 The European Union External Action does recognize, at least in principle, the full picture of the continuum as part of crisis management (see Tercovich 2014).

2 ECHO's name changed to the Directorate-General for European Civil Protection and Humanitarian Aid Operations in 2009, but kept its acronym. Besides, inside DEVCO, the Fragility and Resilience Unit was created in 2013 partly to be in charge of LRRD.

3 A commended tool to make available resources from existing projects for disaster response in crisis-prone countries is the 'crisis modifier' (Yoshikawa 2013).

4 According to Halperin and Michel (2000), from all major donors only Japan and the EU do not implement all aid by a single organization.

5 The word in Japanese is also not the same as the one used in JICA (2015), which is at the same time different from that on JICA strategy home page. The idea is nonetheless the same.

6 The Development Cooperation Charter revised in 2015 (MOFA 2015) is the first time that relief is included as part of the implementation of development cooperation.

7 At the field level this works between ECHO and the EU delegation.

\section{References}

ADE and Humanitarian Futures Programme. 2014. Evaluation of the Implementation of the European Consensus on Humanitarian Aid. Analysis for Economic Decisions and Humanitarian Futures Programme. http://ec.europa.eu/echo/files/evaluation/2014/ european_consensus_main_en.pdf.

Bailey, Sarah, Sara Pavanello, Samir Elhawary, and Sorcha O’Callaghan. 2009. Early Recovery: An Overview of Policy Debates and Operational Challenges. HPG Working Paper. London: Overseas Development Institute (ODI).

Barnett, Michael. 2011. Empire of Humanity: A History of Humanitarianism. Ithaca, NY: Cornell University Press.

Bennett, Christina. 2015. The Development Agency of the Future: Fit for Protracted Crisis? ODI Working Paper. London: Overseas Development Institute.

Boin, Arjan, Allan MCConnell, and Paul T. Hart. 2008. Governing after Crisis: The Politics of Investigation, Accountability and Learning. Cambridge: Cambridge University Press.

Call, Charles T., and Katy Collin. 2015. The United Nations Approach to Peacebuilding. Paper prepared for 'Rising Powers and Peacebuilding' project. www.risingpowersand peacebuilding.org.

Crisp, Jeff. 2001. Mind the gap! UNHCR, Humanitarian Assistance and the Development Process. International Migration Review 35(1): 168-191.

Development Initiatives. 2014. Global Humanitarian Assistance Report 2014. Bristol: Development Initiatives.

DFID. 2011. Defining Disaster Resilience. A DFID approach paper, London: Department of International Development. 
DHA. 1995. Relief and Development in an Unstable World. Geneva: United Nations.

EC. 1996. Linking Relief, Rehabilitation and Development (LRRD). COM (96) 153 Final. European Commission. http://eur-lex.europa.eu/LexUriServ/LexUriServ.do?uri=CO M:1996:0153:FIN:EN:PDF.

- 2001. Linking Relief, Rehabilitation and Development - An Assessment. COM (2001) 153 Final. European Commission. https://ec.europa.eu/europeaid/sites/devco/files/ communication-naturaldisastersandcrisismanagement-com2001153-20010423_en.pdf. 2007. Towards a European Consensus on Humanitarian Aid. COM (2007) 317 Final. European Commission. http://ec.europa.eu/echo/files/policies/consensus/acte_en.pdf. - 2012. The EU Approach to Resilience: Learning from Food Security Crisis. COM (2012) 586 Final. European Commission. http://ec.europa.eu/echo/files/policies/resilience/ com_2012_586_resilience_en.pdf.

. 2013. Action Plan for Resilience in Crisis Prone Countries 2013-2020. SWD (2013) 227 Final. European Commission. http://ec.europa.eu/echo/files/policies/resilience/ com_2013_227_ap_crisis_prone_countries_en.pdf.

-2015. EU Resilience Compendium: Saving Lives and Livelihoods. European Commission. http://ec.europa.eu/echo/files/policies/resilience/eu_resilience_compendium_en.pdf.

ECHO. 2014. Resilience Marker: General Guidance. Ares (2014) 3883617-21/11/2014. European Community Humanitarian Aid Operations. http://ec.europa.eu/echo/ files/policies/resilience/resilience_marker_guidance_en.pdf.

FEMA. 2011. National Disaster Recovery Framework Strengthening Disaster Recovery for the Nation. Federal Emergency Management Agency. www.fema.gov/media-library-data/20130726-182025045-5325/508_ndrf.pdf.

Fengler, Wolfgang, Ahya Ihsan, and Kai Kaiser. 2008. Managing Post-Disaster Reconstruction Finance: International Experience in Public Financial Management. Policy Research Working Paper 4475. http://elibrary.worldbank.org/doi/pdf/10.1596/1813-9450-4475.

Gómez, Oscar A. 2014. What Can the Human Development Approach Tell Us about Crisis? An Exploration. International Fournal of Social Quality 4(2): 28-45.

Halperin, Morton H., and James Michel. 2000. Interagency Review of U.S. Government Civilian Humanitarian and Transition Programs. http://pdf.usaid.gov/pdf_docs/Pdabw490.pdf.

IASC. 2006. Implementing Early Recovery. Inter-Agency Standing Committee. http://reliefweb.int/ sites/reliefweb.int/files/resources/26FB981DE9BEE0E3852571C000560D35-iascearlyrecovery-jul2006.pdf.

- 2012. Reference Module for Cluster Coordination at the Country Level. Inter-Agency Standing Committee. www.humanitarianresponse.info/system/files/documents/ files/iasc-coordination-reference $\% 20$ module-en_0.pdf.

- 2015. Preference Module for Cluster Coordination at Country Level. Inter-Agency Standing Committee. www.humanitarianresponse.info/en/system/files/documents/files/ cluster_coordination_reference_module_2015_final.pdf.

- 2017. Grand Bargain (Hosted by the IASC). Inter-Agency Standing Committee. https://interagencystandingcommittee.org/grand-bargain-hosted-iasc.

Inter-Agency Team on Rapid Transitions from Relief to Development. 1996. Linking Relief and Development in the Greater Horn of Africa: USAID Constraints and Recommendations. Report for the President's Greater Horn of Africa Initiative. http://pdf.usaid.gov/ pdf_docs/pnaby652.pdf.

JICA. 2015. Toward Mainstreaming Disaster Risk Reduction: Building Disaster Resilient. Japan International Cooperation Agency. http://gwweb.jica.go.jp/km/FSubject0301.nsf/ff4e b182720efa0f49256bc20018fd25/3958a0a725aba98549257a7900124f29/\$FILE/E.pdf. 
Kaldor, Mary, Mary Martin, and Sabine Selchow. 2007. Human Security: A New Strategic Narrative for Europe. International Affairs 83(2): 273-288.

Kamidohzono, Sachiko G., Oscar A. Gómez, and Yoichi Mine. 2016. Embracing Human Security: New directions of Japan's ODA for the 21st Century. In Fapan's Development Assistance: Foreign Aid and the Post-2015 Agenda, edited by Hiroshi Kato, John Page and Yasutami Shimomura, 205-222. Basingstoke: Palgrave Macmillan.

Kent, Randolph C. 1983. Reflecting Upon a Decade of Disasters: The Evolving Response of the International Community. International Affairs 59(4): 693-711.

Koddenbrock, Kai, and Martin Büttner. 2009. The Will to Bridge? European Commission and U.S. Approaches to Linking Relief, Rehabilitation and Development. In Humanitarian Assistance: Improving US-European Cooperation, edited by Julia Steets and Daniel S. Hamilton, 117-143. Washington, DC: Center for Transatlantic Relations (CTR)/Berlin: Global Public Policy Institute (GPPi).

Macrae, Joanna. 2001. Aiding Recovery? The Crisis of Aid in Chronic Political Emergencies. London: ODI.

Macrae, Joanna, and Mark Bradbury. 1998. Aid in the Twilight Zone: A Critical Analysis of Humanitarian-Development Aid Linkages in Situation of Chronic Instability. A report for UNICEF. London/New York: ODI, UNICEF and Brown Univeristy.

McAllister, Ian. 1993. Sustaining Relief with Development: Strategic Issues for the Red Cross and Red Crescent. Dordrecht: Martinus Nijhoff Publishers.

Mendelson-Forman, Johanna. 2014. Gender and Peace. In Advanced and Challenges in Political Transitions: What Will the Future of Conflict Look Like?, by Roberrt D. Lamp and Johanna Mendelson-Forman, 26-29. Washington, DC: Center for Strategic and International Studies.

MOFA. 2011. Humanitarian Aid Policy of Japan. Ministry of Foreign Affairs. www.mofa. go.jp/policy/emergency/pdfs/aid_policy_japan.pdf.

- 2015. Development Cooperation Charter. Tokyo: Ministry of Foreign Affairs.

Morazan, Pedro, Francois Grunewald, Irene Knoke, and Tobias Schafer. 2012. Stengthening LRRD in the EU'S Financial Instruments. Brussels: European Union.

OCHA and DARA. 2014. Saving Lives Today and Tomorrow: Managing the Risks of Humanitarian Crises. OCHA Policies and Studies Series. New York: OCHA.

OCHA, UNDP and DOCO. 2015. Lessons Learned and Good Practice Tool: Adapting Coordination Mechanisms to Support National Transitions. New York: UNDP.

OECD. 2014. OECD Development Co-operation Peer Reviewes: United Kingdom 2014. Paris: Organisation for Economic Co-operation and Development.

Olson, Richard Stuart. 2005. The Office of U.S. Foreign Disaster Assistance (OFDA) of the United States Agency for International Development (USAID): A Critical Juncture Analysis, 1964-2003. http://pdf.usaid.gov/pdf_docs/Pnadc353.pdf.

Otto, Ralf. 2013. Linking Relief and Development: More than Old Solutions to Old Problems? Amsterdam: Policy and Operations Evaluation Department (IOB), Ministry of Foreign Affairs.

Rebelle, Bruno. 1999. Combining Skills. In Responding to Emergencies and Fostering Development: The Dilemmas of Humanitarian Aid, edited by Claire Pirotte, Bernard Husson and Francois Grunewald, 35-65. London: Zed books.

Shaw, John D. 2011. The World's Largest Humanitarian Agency: The Transformation of the UN World Food Programme and of Food Aid. Basingstoke: Palgrave Macmillan.

Smillie, Ian. 1998. Occasional Paper 33: Relief and Development: The Struggle for Synergy. Providence, RI: Thomas J. Watson Jr. Institute for International Studies, Brown University. 
Steets, Julia. 2011. Donor Strategies for Addressing the Transition Gap and Linking Humanitarian and Development Assistance: A Contribution to the International Debate. Berlin: GPPi.

Steets, Julia, et al. 2010. Cluster Approach Evaluation 2 Synthesis Report. Berlin: GPPi, Groupe URD.

Suhrke, Astri, and Arve Ofstad. 2005. Filling 'the Gap': Lessons Well Learnt by the Multilateral Aid Agencies. CMI Working Paper WP 2005:15. Bergen: Chr. Michelsen Institute.

Tanaka, Akihiko. 2015. Toward a Theory of Human Security. JICA-RI Working Paper No.91. JICA Research Institute.

Taylor, Glyn, et al. 2012. The State of the Humanitarian System. London: ODI.

Tercovich, Guilia. 2014. Towards a Comprehensive Approach: The EEAS Crisis Response System. Fournal of Contingencies and Crisis Management 22(3): 150-157.

UNDP. 2008. UNDP Policy on Early Recovery. New York: United Nations Development Programme.

- 2013. Livelihoods and Economic Recovery in Crisis Situation. New York: United Nations Development Programme.

United Nations General Assembly. 1991. Strengthening of the Coordination of Humanitarian Emergency Assistance of the United Nations. A/RES/46/182. United Nations.

USAID. 2012. Building Resilience to Recurrent Crisis: USAID Policy and Program Guidance. Washington, DC: United States Agency for International Development.

White, Philip, and Lionel Cliffe. 2000. Matching Response to Context in Complex Political Emergencies: 'Relief', 'Development', 'Peace-Building' or Something In-between? Disasters 24(4): 314-342.

Wisner, Ben, and John Adams. 2002. Environmental Health in Emergencies and Disasters: A Practical Guide. Geneva: WHO.

World Bank. 2011. World Development Report 2011: Conflict, Security, and Development. Washington, DC: World Bank.

Yoshikawa, Lynn. 2013. From Crisis to Recovery: Lost in Transition. Washington, DC: InterAction. www.interaction.org/sites/default/files/InterAction $\% 20$ Transition $\% 20$ report $\% 20-\% 20$ February $\% 202013$.pdf. 


\section{Part II}

Humanitarian crisis

management in armed conflicts 


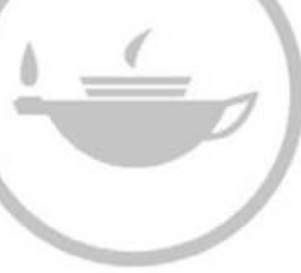

Taylor \& Francis Taylor \& Francis Group

http://taylorandfrancis.com 


\title{
3 The continuum in \\ the management of armed conflict
}

\author{
An overview
}

\section{Toshiya Hoshino and Chigumi Kawaguchi}

\section{Advancing the 'continuum' in post-conflict transitions to peace}

At his first formal appearance at the United Nations Security Council on January 10, 2017, Secretary-General António Guterres, who had just assumed the position of chief administrator of the world body, took the opportunity to make what he believed to be a critically important appeal. He called on members of the most powerful organ of the UN to jointly advance efforts 'to build and sustain peace across the continuum, from prevention, conflict resolution and peacekeeping to peacebuilding and long-term development' (Guterres 2017). Two outright concerns are likely to have motivated this plea: firstly, today's armed conflicts have become more complex, intractable and interconnected than ever; and secondly, the continued lackluster performance of the international community, which has remained largely fragmented in addressing multiple crises. In his speech, the notion of the 'continuum' was used by Mr. Guterres to highlight the need to bring together all the relevant actors, necessary policy tools and funds - ensuring their effective integration and sequencing in a proper strategic context - in order to promote peacebuilding and sustaining peace.

In the case of armed conflict, developing the right model to describe the continuum is not an easy task. All armed conflicts are violent, political and tragic. Each conflict, however, has its own historical background, underlying socioeconomic causes, and unique power dynamics. Most parties involved do not trust each other and may disagree in their interpretations of the issues at stake - thus a 'one size fits all' prescription is difficult to apply. Moreover, the conflicts of today can be exacerbated by global threats such as terrorism, transnational crime, climate change and massive population movements. Consequently, past failures to implement the kind of policies necessary to address the root causes and effects of conflicts have led to missed opportunities and wasted resources.

In this overview, we attempt to critically review some previous international efforts and practices to support the transition from conflict to peace. Under the notion of a strategically conceived 'continuum,' we identify key factors required to help bring relevant actors, necessary resources and useful policy instruments together for the purpose of better managing local processes to advance selfsustaining peace in post-conflict states or regions.

Figure 3.1 illustrates eight different sets of intervention models in the transition between conflict and peace, providing an overall picture of the activities 


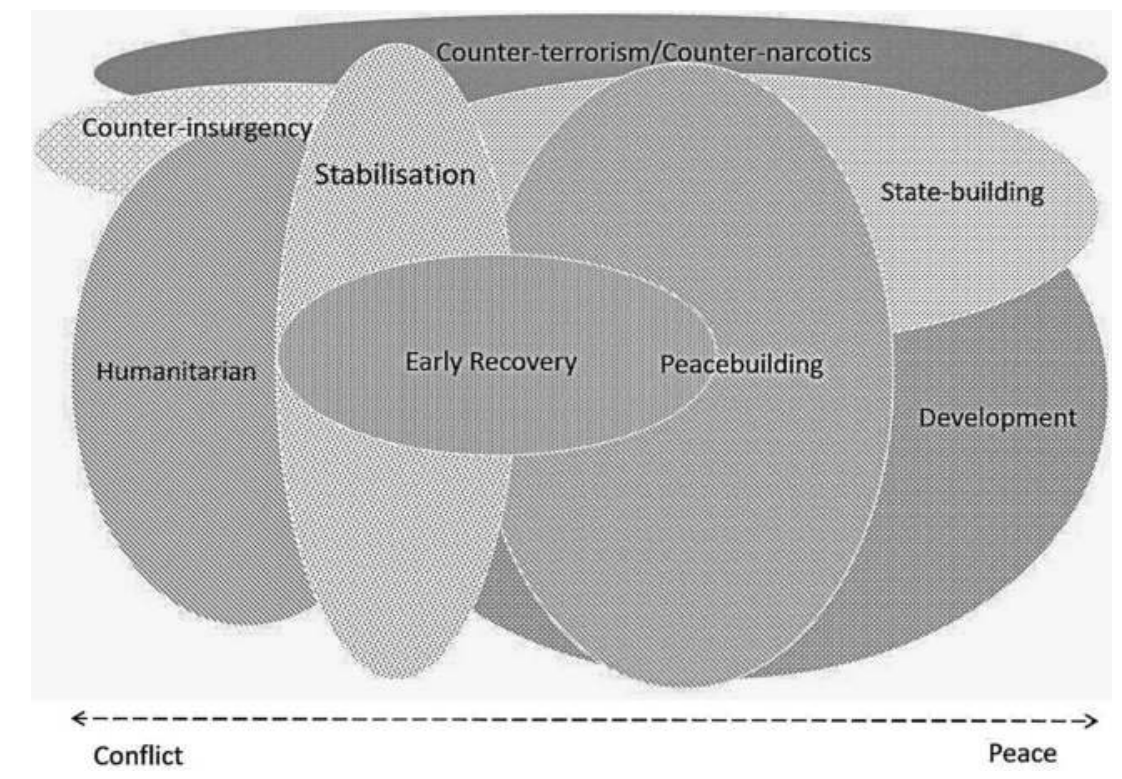

Figure 3.1 Overlapping intervention models between peace and conflict.

Source: authors, based on $\operatorname{OECD}(2010,2)$ and Bailey et al. (2009, 8).

that tend to be employed in countries emerging from armed conflict (OECD 2010; Bailey et al. 2009). Among these, stabilization normally includes rapid reaction and military activities, but it also can include humanitarian assistance, recovery, and development activities (Rotmann and Steinacker 2014; Collinson, Elhawary, and Muggah 2010, 3). Figure 3.1 also shows the central role that peacebuilding occupies in post-conflict countries in their transition from conflict to peace. For example, state-building is recognized as an essential aid for supporting fragile states in transition, which allows a stronger role for peacebuilding but places a lower emphasis on relief. On the other hand, early recovery emerges from relief activities, but may also be an activity that can contribute to peacebuilding. As we will see below, recent discussions regarding peacebuilding have enlarged its scope to encompass other approaches, something those other approaches may not have. Therefore, peacebuilding seems to provide a promising avenue for examining how the international community can realize the continuum after armed conflict. We explore this in more detail in the following sections.

\section{What is peacebuilding?}

The notion of peacebuilding has been developed mainly through the UN. In 1992, the Report of the Secretary-General, 'An Agenda for Peace Preventive Diplomacy, Peacemaking and Peacekeeping' (widely known as An Agenda for Peace), introduced the idea of peacebuilding as a UN approach to address the issue of armed conflict, 
following preventive diplomacy, peacemaking, and peacekeeping. Peacebuilding is described as post-conflict 'action to identify and support structures which will tend to strengthen and solidify peace to avoid a relapse into conflict' (BoutrosGhali 1992, para. 21). Before peacebuilding, preventive diplomacy aims to avoid armed conflict through confidence building, early warning, fact-finding, preventive deployment and demilitarized zones. However, when conflict breaks out, mutually reinforcing efforts at peacemaking and peacekeeping come into play. Peacemaking embraces a wide range of measures such as mediation and negotiation efforts, sanctions and the use of military force. Peacekeeping is primarily limited to maintaining ceasefires and providing crucial support for political efforts by peacemakers. Once these have achieved and sustained their objectives, cooperative work in peacebuilding to deal with the underlying economic, social, cultural, and remaining humanitarian problems can take place. Post-conflict peacebuilding primarily overlaps with development activities, and is also referred as 'post-conflict recovery' and 'reconstruction.' In terms of phases, An Agenda for Peace showed a fundamentally linear understanding of crisis management.

Later, the 'Report of the Panel on United Nations Peace Operations' in 2000 (UN 2000) refined the four UN approaches to armed conflict, reducing the number to three: conflict prevention and peacemaking, peacekeeping, and peacebuilding. In doing so, the UN avoided a linear presentation of the approaches, emphasizing instead how they overlap. The 'United Nations Peacekeeping Operations: Principles and Guidelines' document (referred to as the Capstone Doctrine) in 2008 further reaffirmed this overlapping nature by developing new categories of approach: conflict prevention, peacemaking, peacekeeping, peacebuilding and peace enforcement, noting that they rarely occur in a linear or sequential way but mutually reinforce each other (UNDPKO and DFS 2008, 18-19). As can be seen in Figure 3.2 from the Capstone Doctrine document, there are no relief or prevention phases. However, the model emphasizes how relevant actors, including international financial institutions and other donors, UN agencies, and civil society organizations, can work together throughout all phases and share the same tasks, such as DDR (disarmament, demobilization, and reintegration of former combatants). However, the timeline of the three phases of transition in Figure 3.2 - stabilization, peace consolidation, and long-term recovery and development - still demonstrates a linear understanding, with a focus that is exclusively on the recovery phase (UNDPKO and DFS 2008).

In the policy area of peacebuilding, yet another reform endeavor was developed for the sixtieth anniversary of the UN in December 2005. The UN Peacebuilding Commission (PBC), a dedicated intergovernmental advisory body in the UN system, was established as a subsidiary organ of the General Assembly and the Security Council in order to bring forward a more strategic and integrated support for peacebuilding efforts in conflict-affected countries. As its founding resolutions stress, the $\mathrm{PBC}$ was mandated to:

1 bring together all relevant actors to marshal resources and to advise on and propose integrated strategies for post-conflict peacebuilding and recovery; 


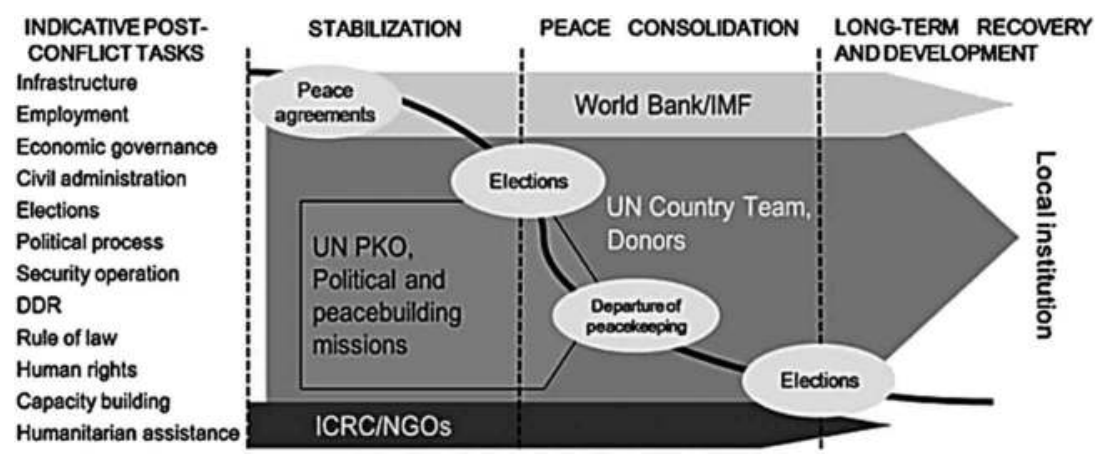

Figure 3.2 The core business of multi-dimensional United Nations peacekeeping operations. Source: adapted from UNDPKO and DFS $(2008,23)$; timeline and details added by the authors.

2 focus attention on the reconstruction and institution-building efforts necessary for recovery from conflict and to support the development of integrated strategies in order to lay the foundation for sustainable development; and

3 provide recommendations and information to improve the coordination of all relevant actors within and outside the United Nations, to develop best practices, to help to ensure predictable financing for early recovery activities and to extend the period of attention given by the international community to post-conflict recovery (UN 2005).

The PBC was established based on the premise that peacebuilding is essentially a political process as much as an operational challenge. While it is often underestimated, the basic approaches and directions that the commission prescribed to support post-conflict states were well structured and reasonable. What constrained the PBC's performance was its weakness, both institutionally and politically, to play the role expected of it in the process. For example, the powerful Security Council was not yet accustomed to hearing the advice from the commission, which is just one of its subsidiary bodies. In guiding policy discussions, the newly created secretariat, called the Peacebuilding Support Office (PBSO), was very small and no match for the well-established Department of Peacekeeping Operations (DPKO) nor the Department of Political Affairs (DPA) in the UN bureaucracy. North-South divisions often penetrate PBC political debates, in which members from wealthy states tend to represent the donor-side views while the members from developing countries are sympathetic to the recipient side. If the commission had been equipped with sufficient political clout, many of the indicative post-conflict tasks laid out in Figure 3.2, along with the many actors, might have been coordinated more effectively from within the PBC platform. Contributions from bilateral donors could also have been guided to better synergize with the strategic priorities set by the PBC on a country-specific basis.

It was therefore unfortunate that this ideal was unsuited to the political realties both at the UN headquarters in New York and in the field within post-conflict 
countries. Even so, as seen in Figure 3.2, there is a need to implement those indicative tasks and manage key political processes, as indicated by circles. This can be accomplished by involving all of the different stakeholders, with sufficient respect for ownership of local government and stakeholders, in appropriate sequencing of activities from stabilization to peace consolidation, moving eventually to long-term recovery and development. This is necessary if we are to help bring peace successfully to the target country or region.

\section{Bridging peacebuilding and humanitarian relief in the continuum}

Recognizing the inherent limitations of the PBC, the Advisory Group of Experts reviewed the UN peacebuilding architecture, leading to a report titled 'The Challenge of Sustaining Peace' (UN 2015). The report, issued on the occasion of the tenth anniversary year of the commission, presented a number of key analyses and recommendations that were later incorporated into additional concurrent resolutions adopted unanimously by both the Security Council and General Assembly in April 2016 (UN 2016). In relation to our discussion of the peace continuum, the following two developments should be given particular attention as we elaborate an effective strategy and policies to manage the post-conflict transition to peace.

The first is the expansion of the notion of peacebuilding. Indeed, the Advisory Group experts came to conclude that the scope of peacebuilding should no longer be limited to the post-conflict context. Based on this new understanding, UN members now agree that 'peacebuilding is an inherently political process aimed at preventing the outbreak, escalation, recurrence or continuation of conflict' and it 'encompasses a wide range of political, developmental, and human rights programmes and mechanisms' of the United Nations (UN 2016, preamble). Here, the idea of peacebuilding comes to be more closely associated with conflict prevention.

The second is the introduction of the new notion of 'sustaining peace.' To draw the definition from the above concurrent General Assembly and Security Council resolutions, member states of the UN now agree that 'sustaining peace' should be broadly understood as 'a goal and a process to build a common vision of a society, ensuring that the needs of all segments of the population are taken into account, which encompasses activities aimed at preventing the outbreak, escalation, continuation and recurrence of conflict, addressing root causes, assisting parties to conflict to end hostilities, ensuring national reconciliation and moving towards recovery, reconstruction and development.' They also stress that 'sustaining peace is a shared task and responsibility that needs to be fulfilled by the Government and all other national stakeholders, and should follow through all three pillars of the United Nations engagement at all stages of conflict, and in all its dimensions, and needs sustained international attention and assistance' (UN 2016, preamble). This is indeed an extensive and even expansive understanding of the goal and the process that we are encouraged to manage in our pursuit of 
peace. Furthermore, the above definition of 'peacebuilding is fully embedded in the text. In this respect, what is expected of the novel notion of 'sustaining peace' can be interpreted as the joint efforts to advance peace in the 'continuum,' cutting across prevention, conflict resolution and peacekeeping, peacebuilding and long-term development.

In fact, the resolutions encourage 'the importance of a comprehensive approach to sustaining peace' and enumerate all the following tasks, namely:

the prevention of conflict and addressing its root causes, strengthening the rule of law at the international and national levels, and promoting sustained and sustainable economic growth, poverty eradication, social development, sustainable development, national reconciliation and unity including through inclusive dialogue and mediation, access to justice and transitional justice, accountability, good governance, democracy, accountable institutions, gender equality and respect for, and protection of, human rights and fundamental freedoms.

(UN 2016, preamble).

Thus the continuum for sustaining peace is expected to cover at least these tasks and approximately overlap with the contents of peacebuilding.

One clear deficiency of peacebuilding as a continuum strategy is the difficulty of encompassing humanitarian relief. For example, Eide et al. (2005) pointed out how a humanitarian dilemma, especially focused on UN integrated missions, arose from the relationships between humanitarian, political, security and development actors. Humanitarian principles - especially neutrality and impartiality - make it possible to access all conflict areas and ensure communication with all actors in order to save lives. These principles are, however, sometimes incompatible with the political position of the UN and donors. This is due to the requirement for these parties to remain neutral and impartial, which necessitates refraining from taking sides in hostilities or engaging at any time in controversies of a political, racial, religious or ideological nature. In practice, the UN and donors need to rely on internationally recognized transitional governments to push the process towards peace. Linking the phases of the continuum may be desirable, yet these two approaches to armed conflict crisis management - peacebuilding and humanitarian assistance - cannot easily overcome such dilemmas and integrate relevant actors into one single strategy. This is why extra attention needs to be paid to this specific disconnect, to ensure that post-conflict policy management tools are placed in the full 'continuum.' For that purpose, it would prove to be useful, both conceptually and practically, to learn that the recent international discourse has broadened the scope of peacebuilding to include a prevention perspective. Moreover, the introduction of the concept of 'sustaining peace' enables us to link policies and activities for peace and security, sustainable development and human rights, and humanitarian relief, bringing them closer together into one big strategic picture.

Managing a transition across this wide spectrum of the continuum does indeed constitute a challenge. However, we need to align our divergent supportive 
activities as much as possible to mutually enhance their effects and avoid hindering each other in order to maximize the outcome of collective efforts. Toward that purpose, it is always important to plan support for projects not only from 'supply side' logic (i.e. the views from aid providers), but also from a 'demand-side' perspective, namely, the standpoint from the people who seek protection and assistance. It may of course be argued that no action can be taken without thinking about the welfare of the recipients. However, it is the prerogative from the side of the providers to eventually decide whether to limit or widen the choices of means to intervene. On top of that, there are certainly dos and don'ts for each provider of troops and contributions from their technical and operational standpoints or as a matter of policy. But in the final analysis, all these actions are undertaken for the people and populations on the ground, particularly the most vulnerable ones in dire need. Peace is only truly sustainable if it includes this people-centered point of view. This is probably the fundamental reason why the notion of 'sustaining peace' is, and should be, introduced in order to achieve the continuum from relief to recovery and prevention in a way that makes sustainable development possible.

\section{Actors and financing for continuum after armed conflict}

The multiplicity of approaches to armed conflict suggests the presence of a constellation of actors that find it difficult to work under a single roof. Besides the UN and its agencies, the World Bank and regional development banks also fund development programs, while the International Committee of the Red Cross (ICRC) and international non-governmental organizations (INGOs) provide humanitarian and development assistance as final implementers. The role of the private business sector has also been attracting more attention recently. Bilateral donors are now involved as mediators, personnel providers for peace operations, funders to multilateral organization, and implementers working parallel through bilateral assistance programs.

Coordination appears to be the more critical issue for realizing the continuum in armed conflict crises. At the multilateral level, there have been discussions about coordination among humanitarian actors in the relief phase, including protracted relief, and between humanitarian actors and others in both relief and recovery phases through the Humanitarian Coordinator/Resident Coordinator (HC/RG) and the Civil-Military Coordinator. Also, there have been discussions within donor governments, such as the EU and the US, about whether they should link humanitarian assistance and development, security, foreign, and economic policies or not, due to concerns over humanitarian principles (Steets 2009). Donors are not restricted by a single humanitarian or development mandate, but they still have independent humanitarian structures, such as the European Commission's Directorate General for Humanitarian Aid and Civil Protection (ECHO) and the Office of US Foreign Disaster Assistance (OFDA), partly to maintain neutrality through distinct portfolios. Separate portfolios allow bilateral donors to provide humanitarian funding to multilateral agencies 
and NGOs, which to a certain point avoids the need to raise the humanitarian dilemma. Those portfolios, however, increase the demand for coordination between implementing partners and even inside donor governments.

The peacebuilding strategies reviewed above, such as An Agenda for Peace and Capstone Doctrine, primarily focus on how to coordinate international actors. These strategies assume that peacebuilding initiatives will occur later, following the handover from international actors to local governments. In this sense, local governments are passive recipients in peacebuilding. However, the review of UN peacebuilding architecture highlights a broad inclusivity of national stakeholders - not only of national elites but also of people and actors who are stationed in conflict-affected areas. Since peace cannot be imposed from the outside, locals are the best actors to understand the dynamic context of any conflict (UN 2015). In other words, 'national ownership' has been enlarged to cover local people as well as government. Still, in conflict-affected societies, promotion of national ownership is not an easy task, as local governments are often authoritarian and mistrusted by people, and local capabilities have not been extensively developed.

Many donors have developed domestic strategies and coordination mechanisms as a solution to this problem. They have done this in order to provide more effective and efficient humanitarian crisis management, particularly for conflicts and are thus deserving of mention. On paper, the so-called 'whole-of-government' approach (WGA) implies that a long-term perspective of development and prevention is embedded in responses. However, cross-governmental decision-making in the capital has yet to translate well in the field (Bennett 2015). The most advanced form of WGA for addressing armed conflict is the UK's Stabilization Unit. Under 'the Building Stability Overseas Strategy,' the Department for International Development (DFID), the Foreign and Commonwealth Office (FCO), and the Ministry of Defense (MOD) jointly work to provide expert staff at short notice, and to support interdepartmental analysis and planning for practical implementation on armed conflict and stabilization (DFID, FGO and MOD 2011). As Rotmann and Steinacker $(2014,16)$ point out, the Stabilization Unit is designed to link activities for pre-crisis prevention, response, and recovery to build structural stability. However, Rotmann and Steinacker show that this objective remains far from realized in field operations. Other examples of WGA are the Danish Whole of Government Board, and the Canadian Stabilization and Reconstruction Task Force (START), while the Australian government is now developing a new humanitarian strategy able to combine preparedness, relief, and recovery together under the newly formed Department of Foreign Assistance and Trade (DFAT).

Issues related to financing in post-conflict contexts are most visible in the segmentation of the aid architecture from a macro perspective, as well as in the prioritization of peacebuilding sectors from a micro perspective. There is a great imbalance between allocations available for peacebuilding and global funding, either for humanitarian responses or for peacekeeping operations (UN 2015; 
OECD 2010). An OECD analysis of aid flows in 2010 demonstrates that donors provide substantial financial support to post-conflict countries, and that the resources are drawn from different budgetary lines, humanitarian, development and defense. Due to the segmentation of such aid architecture - including the separation of ODA and non-ODA funding and the different mandates and remits of aid instruments and agencies - critical activities in the early peacebuilding period may go unfunded (OECD 2010).

From the micro perspective, ODA spending on conflict, peace and security is relatively small, comprising only 2.5 percent of total ODA (Development Initiatives 2015). Funding for some activities like governance, demobilization of former soldiers, and security-sector reform remains a challenge for donors, while funding for traditional development sectors such as health, education, infrastructure, and agriculture receive most of the donor attention. Activities occurring early in the peacebuilding process receive much less funding than humanitarian or development activities, mainly because of the limitations of the different instruments available during the period, and a lack of flexibility to shift such funding between different instruments once donors have allocated money (OECD 2010). To address the issue, some donors have developed specific funds for transition activities, using pooled funds combining ODA and non-ODA financing to offer a flexible response in crisis situations requiring a more holistic view of peacebuilding. There are several examples of this, such as the UK's Conflict, Stability and Security Fund, the Peace and Stability Fund of Denmark, and the EC's Instrument for Stability.

It is worth adding that there have been various attempts to embed national ownership through different aid modalities, such as peacebuilding funds, multi-donor trust funds, and quick impact projects, for instance, in Afghanistan, Central African Republic, Timor-Leste, and South Sudan. They are all important initiatives to ensure more predictable and sustained financing for peacebuilding activities. These and other diverse efforts on the part of international community should be explored across the peace continuum. At the same time, frequently faced with a lack of recipient government capacity to absorb and operationalize these resources promptly, it is also urgent that the international community provides much-needed capacity-building opportunities, including financial management skills and expertise in an accountable way.

\section{Implementing the continuum in armed conflict contexts}

In this chapter, we have critically reviewed the international efforts and practices to support post-conflict countries in their transition from conflict to peace, placing particular emphasis on peacebuilding, and identified key elements that are required to help bring together relevant actors, resources and policy instruments for the better management of local processes for self-sustaining 
peace on the ground. In this process, consolidating local ownership and international support in the form of the 'continuum' for peace is no longer a matter of choice but of necessity. Therefore the question to be asked is not whether to implement the continuum but how it can be done and finding ways of doing it better.

The following chapters take up three case studies, namely Timor-Leste South Sudan and the Syrian crisis, which look at the process of realizing the continuum in conflict-affected countries. These case studies allow us to examine the connections of different phases of crisis management, as described in Chapter 2. Moreover, they offer further evidence of how such a managerial process is not linear at all. Close attention is given to the roles played by the various bilateral donors, such as the United States, the European Union, Australia and Japan, as well as to other international organizations and NGOs.

First, in the case of Timor-Leste Yukako Sakabe Tanaka and Tomoaki Honda (Chapter 4) analyze the interplay among the newly established Timorese Government, its local civil society, and international actors such as the UN and bilateral donors. The activities of three donor agencies from Australia, Japan and the United States are reviewed to examine how they performed to realize the continuum for sustaining peace at the local level. Through interviews and surveys of local civil society members and community participants, the authors find a major gap between prevention needs felt by local civil society and the attention provided by international actors and government, which they highlight as an important obstacle for the continuum.

The second case examines South Sudan and is written by Chigumi Kawaguchi (Chapter 5). This is a challenging example of linking humanitarian relief and development assistance in an extremely volatile situation. Among the many international actors involved, three key donor agencies from the US, the EU and Japan are selected. By careful examination over a 20 -year period from a reliefcentered period in the 1990s to peacebuilding after the comprehensive peace agreement in 2005, and after the conflict relapse in December 2013, the chapter offers a detailed comparative analysis of different phases, highlighting how donor agencies address the dilemma of often-competing imperatives between political and purely humanitarian-oriented perspectives while maintaining the continuum for peacebuilding.

The final case discusses the Syrian crisis, which has become one of the most significant humanitarian crises in recent years. Ryoji Tateyama (Chapter 6) examines international efforts to realize the continuum, especially by the UN, UK, EU and US. He highlights three obstacles to the continuum: the humanitarian dilemma of the UN humanitarian operation, the difficulty of remote management, and the relationships between humanitarian relief and political objectives set by donors. All of these are related to the question of politicization of aid. The challenge is enormous but we should recognize that even inside Syria, many actors are trying to implement both emergency relief operations as well as undertake mid- and long-term activities for building resilience, despite many obstacles. 
The case studies allow us to explore how international donors, including multilateral and bilateral organizations, have conducted (or ignored) multi-layered approaches to peacebuilding in different contexts - both during and after conflict. Their detailed descriptions help us to understand how the post-conflict peacebuilding approach has been used, as well as its strengths and weaknesses. The cases suggest we need to have a more comprehensive and non-linear understanding of peacebuilding in order to realize sustaining peace. Unfortunately, humanitarian crises caused by armed conflicts persist, with little likelihood that they will end soon. In this regard, these case studies offer some useful lessons for the future.

\section{References}

Bailey, Sarah, Sara Pavanello, Samir Elhawary, and Sorcha O’Callaghan. 2009. Early Recovery: An Overview of Policy Debates and Operational Challenges. HPG Working Paper. London: Overseas Development Institute.

Bennett, Christina. 2015. The Development Agency of the Future: Fit for Protracted Crisis? ODI Working Paper. London: Overseas Development Institute.

Boutros-Ghali, Boutros. 1992. An Agenda for Peace: Preventive Diplomacy, Peacemaking and Peace-keeping. Report of the Secretary-General. A/47/277-S/24111, June 17. New York: United Nations.

Collinson, Sarah, Samir Elhawary, and Robert Muggah. 2010. States of Fragility: Stabilization and its Implications for Humanitarian Actions. Humanitarian Policy Group Working Paper. London: Overseas Development Institute.

Development Initiatives. 2015. Global Humanitarian Assistance Report 2015. Bristol: Development Initiatives.

DFID, FCO and MOD. 2011. Building Stability Overseas Strategy. London: Department for International Development, Foreign and Commonwealth Office and Ministry of Defence.

Eide, Espen Barth, Anja Therese Kasersen, Randolph Kent, and Karen von Hippel. 2005. Report on Integrated Missions: Practical Perspectives and Recommendations. Independent Study for the Expanded UN Executive Committee on Humanitarian Affairs (ECHA) Core Group. https://docs.unocha.org/sites/dms/Documents/Report_on_Integrated_ Missions_May_2005_Final.pdf.

Guterres, Antonio. 2017. Remarks to the Security Council Open Debate on 'Maintenance of International Peace and Security: Conflict Prevention and Sustaining Peace.' 10 January. www.un.org/sg/en/content/sg/statement/2017-01-10/secretary-generalsremarks-security-council-open-debate-maintenance.

OECD. 2010. Transition Financing: Building a Better Response. Paris: OECD Publishing.

Rotmann, Philipp, and Lea Steinacker. 2014. Stabilization: Doctrine, Organization and Practice: Lessons for Germany from Canada, the Netherlands, the United Kingdom and the United States. Berlin: GPPi.

Steets, Julia. 2009. From B-Envelopes to the F-Bureau: Understanding Transatlantic Approaches to Humanitarian Assistance. In Humanitarian Assistance: Improving US-European Cooperation, edited by Julia Steets and Daniel S. Hamilton, 11-28. Washington, DC/ Berlin: Center for Transatlantic Relations (CTR)/GPPi.

UN. 2000. Report of the Panel on United Nations Peace Operations. A/55/305-S/2000/809. August 21. New York: United Nations. 
2005. The Peacebuilding Commission. A/60/180-S/RES/1645. December 20. New York: United Nations.

. 2015. Challenge of Sustaining Peace. Report of the Advisory Group of Experts on the Review of the Peacebuilding Architecture. A/69/968-S/2015/490. June 30. New York: United Nations.

- 2016. Review of the United Nations Peacebuilding Architecture. A/70/262-S/RES/2282. April 27. New York: United Nations.

UNDPKO and DFS. 2008. United Nations Peacekeeping Operations: Principles and Guidelines. New York: United Nations Department of Peacekeeping Operations (UNDPKO) and Department of Field Support (DFS). 


\title{
4 Should the 'continuum' for peacebuilding focus on development or conflict prevention?
}

\author{
The case of Timor-Leste
}

\author{
Tukako Sakabe Tanaka and Tomoaki Honda
}

\section{Introduction}

'Goodbye conflict, welcome development' is a symbolic message that was promoted by the Timorese Government in 2010. The message reflects the 'wish to ensure that the current transit[ion] toward longer-term development be sustained without a reversion to conflict' (RDTL 2010). Prime Minister de Araújo shared this view, adding that 'we are inheriting a country that is stable, safe and peaceful' and 'with strong economic growth' (RDTL 2015). These messages are underpinned by an ample state budget in which over 90 percent of the government's revenue is derived from petroleum products and relevant tax revenue. This would seem to indicate that financial contributions from donors are no longer expected. Managing the revenue from petroleum in a sustainable way is crucial to planning a healthy budget, and, therefore, the Petroleum Fund of Timor-Leste was established in order to manage oil revenues in a financially sustainable manner.

Given that Timor-Leste has now persevered through a 15-year post-conflict situation, it might appear that Timor-Leste seems to be on track towards development after overcoming crises and establishing a sustainable peace, yet this transition could be undermined as a result of vulnerability to several factors. The Timorese government has used oil revenue to finance veterans' pensions and the Program of Integrated District Development. Both programs have provided a peace dividend to the population and reduced the chances of conflict (RDTL 2014). However, it is a rather striking statement to say that peace and stability can be achieved as a result of abundant financial resources. As Peake (2013) has argued, new industries must be established to take the place of petroleum production. In other words, it is doubtful whether peace in today's Timor-Leste is sustainable. In fact, as of 2014, half of the country's population still lives under the national poverty line while Timor-Leste's Gross Domestic Income per capita is US $\$ 2,680$ (World Bank 2016). In order to boost the economy to reduce poverty, the government expects growth in non-oil sectors such as agriculture, tourism, and downstream petroleum production (interview with RDTL Vice-Minister of Finance, H. E. Helder Lopes, March 10, 2016). 
Peacebuilding has been a challenge not only for domestic actors but also international actors. Timor-Leste achieved its independence only after 25 years of war against Indonesia and through a referendum under the authority of the United Nations (UN) in 1999. The international community grappled with multiple tasks within the fledgling new country, from building a new state to promoting peace and supporting people's needs. After just four years of independence, renewed political turmoil in 2006 resulted in ten percent of the population once again becoming internally displaced persons (IDPs). This demonstrated that the country's peacebuilding efforts were off-track. The clash between the police and the army showed that externally led peacebuilding efforts needed to be reconsidered. As of 2016, the peacebuilding path is once again perceived differently, with some actors believing that 'money has bought peace' (Peake 2013).

This chapter considers whether there is a gap in the peacebuilding 'continuum' between bilateral aid agencies and other stakeholders, arguing that international actors, the government, and local actors all have distinctive perspectives how to address issues of peace/conflict prevention into humanitarian-development continuum. The concept of peacebuilding can be interpreted broadly. The Organisation for Economic Co-operation and Development (OECD 2008, 13) definition, for example, is 'actions undertaken by international or national actors to institutionalize peace, understood as the absence of conflict and at least a modicum of political process.' While the UN interim authority focused on peacebuilding from a security perspective and the core functions of administration, the donors' views were attributed 'to institutionalize peace' through 'recovery' or 'reconstruction.' Bilateral agencies, sharing the view that Timor-Leste was aiming towards building a new state, were able to visualize 'development' as designed to fulfill social needs and economic growth beyond 'recovery' and 'reconstruction.' However, the political turmoil in 2006 reminded the international community that the government was not yet at full capacity in its ability to conduct rule of law practices, and that there was still embedded potential for social conflicts. Backsliding into 'prevention,' bilateral agencies attempted different approaches in order to realize the continuum from their own perspectives. Alternatively, civil society was concerned with possible on-the-ground conflicts and thus established community-based systems aimed directly at conflict prevention.

We selected Australian Aid (Australia), the Japan International Cooperation Agency (JICA), and the United States Agency for International Development (USAID) from among the six primary donors to Timor-Leste to analyze bilateral agency approaches. These agencies commenced Official Development Assistance (ODA) disbursements prior to 2002 and have continued to support Timor-Leste's national strategy. After 2006, Australia doubled its disbursements in response to the crisis, while USAID and JICA maintained their funding volumes. Other countries, such as the United Kingdom, decreased support (see Figure 4.1).

The following section provides an overview of the humanitarian crises in Timor-Leste and the strategies of the Timorese Government. It also describes how the country attempted to manage peacebuilding with international support. Subsequent sections analyze the programs of the three agencies, revealing that 


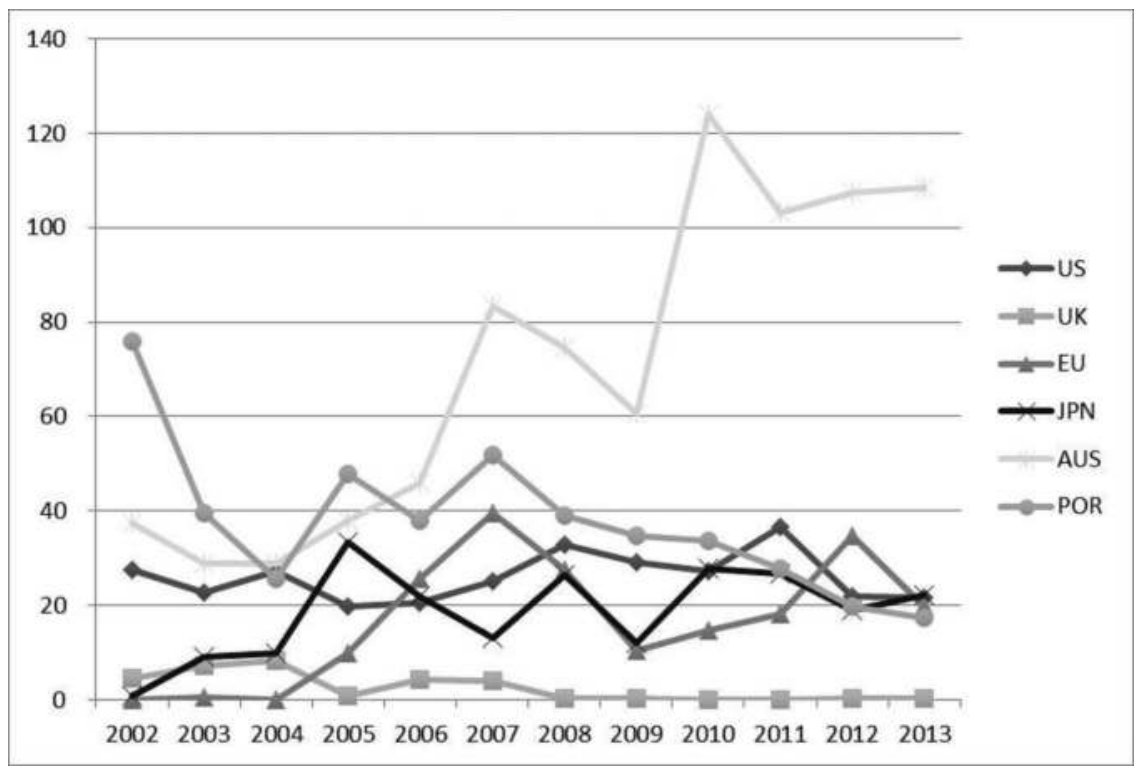

Figure 4.1 ODA disbursements to Timor-Leste (US\$ millions).

Source: authors, based on data generated from OECD QWIDS

Notes: US (United States), UK (Untied Kingdom), EU (European Union),JPN (Japan), AUS (Australia), POR (Portugal).

each agency has its own perspective regarding the continuum. After this, we argue that civil society has a distinctive view of the country's situation and has established its own system for conflict prevention. We then discuss the distinctive approaches to realize the continuum that have been adopted by the government, international actors, and local counterparts. Such a gap emerged from varied perceptions toward peacebuilding in Timor-Leste. The chapter concludes with a discussion of the implications of crisis/aid management in a post-conflict situation based on the experience of Timor-Leste.

\section{Overview of the humanitarian crises and strategies in Timor-Leste}

\section{Humanitarian crises}

Since the 1970s, the Timorese people have experienced insecurity as a result of the resistance movements that emerged against the Indonesian invasion as well as conflicts between Timorese political actors over the position of Timor-Leste. This strife resulted in the deaths of over 102,800 people through violence, hunger, and illness in an area with a population of less than one million (GAVR $2005,44)$. While attention to this crisis increased as a result of international 
media coverage in the early 1990s, the popular consultation backed by the UN in 1999 resulted in yet another humanitarian crisis. As soon as the results were released indicating that over 78.5 percent of the people had voted for independence, Indonesia declared martial law, authorizing militias and the Indonesian military to carry out 'scorched earth plans' (Molnar 2010). This resulted in over 1,400 casualties and the forcible displacement of 300,000 (CAVR 2005, 110). While humanitarian crises have persisted in Timor-Leste for more than two decades, the 1999 crisis was the first crisis in which bilateral donors responded to support the needs of the Timorese people. This included not only assisting with safe return home, as well as food and shelter, but also the delivery of services to help them rebuild their lives in this new country.

Four years after achieving formal independence in 2002, Timor-Leste experienced another humanitarian crisis. The immediate cause of the 2006 crisis was a demonstration by petitioners from the army that escalated into riots and looting, mainly in the capital city of Dili. The most severe incident was the collision between the Forças de Defesa de Timor Leste (FDTL) and the Policia Nacional de Timor-Leste (PNTL) in late May. This second crisis resulted in 38 casualties and 150,000 IDPs (OHCHR 2006, para. 100). The UN concluded that the 2006 crisis stemmed from the vulnerability of state institutions and the rule of law (OHCHR 2006, para. 2). Yamada (2015) further noted that the leadership did not follow the rule of law, while Hasegawa (2013) attributed it to the elite competition between President Gusmão and Prime Minister Alkatiri. The violent actors, scattered throughout Dili, consisted primarily of youth, members of gangs and martial arts groups (MAGs), many of whom were unemployed (e.g., Scambary 2006). Geographical and social divisions, such as those between east and west, and urban and rural, as well as ethnic divisions within communities are said to be the causes of increased violence (e.g., Kingsbury 2008).

While intense support was provided to IDP camps in Dili, for the 70 percent of the population residing outside the capital, poverty reduction has remained a challenge. Therefore, relevant stakeholders faced multiple challenges as a result of the 2006 crisis: stabilizing security, restoring the rule of law, responding to the needs of IDPs, as well as continuing to address development through economic growth.

\section{National and international strategies}

It was generally recognized by donors that the immediate response to the 1999 crisis was insufficient because it was also necessary to support the building of a new country. In essence, the goals were to assist with both peace and development.

From 1999, two international devices functioned to provide direct support to Timor-Leste; the UN missions/multilateral forces and the national/international strategy. The UN Transitional Administration in East Timor (UNTAET) was responsible for the interim government up until independence. Later, it supported the country's core administration and maintenance of law and order. In response to the 2006 crisis, the UN Integrated Mission in Timor-Leste (UNMIT) was mandated to restore the police service. UNMIT ended its mandate in 2012 when the 
PNTL regained full responsibility for internal security. In the very early stages of the crisis, multilateral forces led by the Australian Defence Force were dispatched to stabilize the situation. In other words, peacebuilding efforts-especially security - were primarily led by multilateral forces, while the UN missions played the core role of building and sustaining the functions of the new governance.

The task of formulating strategies for relief and development was initially led by the international community and then, gradually, the Timorese Government assumed the primary responsibility. Responses to the humanitarian needs that emerged after the 1999 crisis were made by the Consolidated Inter-Agency Appeal for East Timor Crisis (CAP), composed of international organizations and non-governmental organizations (NGOs). For recovery and development issues, the World Bank-led Joint Assessment Mission (JAM), composed of bilateral donors, international agencies, and Timorese representatives, was dispatched in late 1999 in order to assess mid- and long-term needs (JICA 2002). Following this, the Timor-Leste Government provided a descriptive account of the National Development Plan (NDP) road map (for the reconstruction of Timor-Leste).

In the middle of 2000, donors quickly shifted their focus from relief to recovery matters by pledging US $\$ 30$ million for Timor-Leste's recovery and development projects at a second donors' meeting held in Lisbon (JICA 2002). ${ }^{1}$ Donor countries also agreed that the program must be conducted under an efficient aid coordination system and must accept the independence of Timor-Leste. Such activities indicate that most international donors shared an awareness that it would be necessary to support the state-building process for Timor-Leste through development assistance. As an example of humanitarian crisis management from the perspective of the continuum, Timor-Leste is considered to be one of the first attempts to integrate the recovery and development process in the early stages of peacebuilding.

In December 2002, the government and donors communicated about implementing the NDP (RDTL 2002). The NDP was formulated based on nationwide consultations and had two development goals: to reduce poverty and to promote economic growth while improving health and education (Planning Commission 2002), an approach that was also linked to the Millennium Development Goals (MDGs). Following this, 17 Sector Investment Programs (SIPs) were formulated to coordinate government policy, the budget, and donor support with a mechanism known as Sector Working Groups (SWGs). However, operating SWGs in line with SIPs was a burden to some line ministries whose capacity was not fully functioning (e.g., Sakabe 2008).

The total amount of international support to Timor-Leste was drastically decreased from US $\$ 500$ million in 2000-2001 to US $\$ 150$ million in 2005-2006 (RDTL 2006). Nevertheless, international assistance, per capita, was high at US\$189 in 2005 compared to US\$17, the average for low-income countries (World Bank 2005). Humanitarian aid during the 2006 crisis was coordinated first through a UN Flash Appeal requesting US\$24 million. Thereafter, the Central Emergency Response Fund (CERF) began contributing; and they eventually received 103 percent of the requested amount. The largest donor was Australia 
followed by Japan and the European Commission/the Directorate-General of European Civil Protection and Humanitarian Aid Operations (EC/ECHO), disbursing US\$4-5 million each (Hidalgo 2007).

In response to the multiple needs that emerged following the 2006 crisis, the government launched the National Priorities Process (NPP), a coordination mechanism for diplomatic, defense, and development actors (the ' $3 \mathrm{Ds}$ ') to work together to ensure the sustainability of peace. As appropriately stated by RDTL (2010), 'TimorLeste would have to first identify and address the most pressing issues hampering the safety of its citizens and devise solutions to address both the root causes of these issues and their immediate effects.' While the NPP encompassed food security and rural development, social services, access to justice, and good governance issues, in 2008, the government initiated the NPP with the goal of enhancing the interactions of actors to downgrade 'safety and security' from being the highest priority to the lowest (7th) priority by 2010 (RDTL 2010). Although there was an assassination attempt against the president and the prime minister in 2008, the government's operational services continued and the rebels from the 2006 crisis surrendered. This outcome brought confidence to stakeholders that Timor-Leste was stabilizing.

The Strategic Development Plan (SDP) was then launched in 2011 to promote mid- and long-term plans for the country's development. The SDP is composed of four subsections (social, economic, infrastructure development, and governance) that comprehensively cover all relevant national development sectors. The Development Policy Coordination Mechanism (DPCM) is currently in operation to facilitate the implementation of the SDP between donors and line ministries in accordance with the New Deal principles endorsed at the 4th High-level Meeting for Aid Effectiveness in 2011 (MoF RDTL 2014).

In sum, the international community was the dominant force behind the formation and coordination of peacebuilding strategies as well as state-building. Accordingly, the international community responded swiftly to emerging needs after the 2006 crisis. While the Timorese Government gradually took the initiative in leading building strategies while maintaining a close relationship with the international community, international organizations divided up the roles to address multiple needs. Multilateral forces were tasked with security issues, the UN concentrated on state-building, and bilateral aid agencies subsequently supported development issues. Under such circumstances, bilateral agencies launched their activities based on a shared concept that their role in Timor was to contribute to state-building by conducting recovery and reconstruction projects.

In the next three sections, we analyze the actions of the bilateral agencies from the perspective of the continuum for peacebuilding.

\section{USAID}

\section{Aid to Timor-Leste from the perspective of the continuum}

Since 2002, USAID has continuously earmarked approximately US $\$ 2.5$ million per year (see Figure 4.2), mainly focusing on the governance sector. In fact, a 


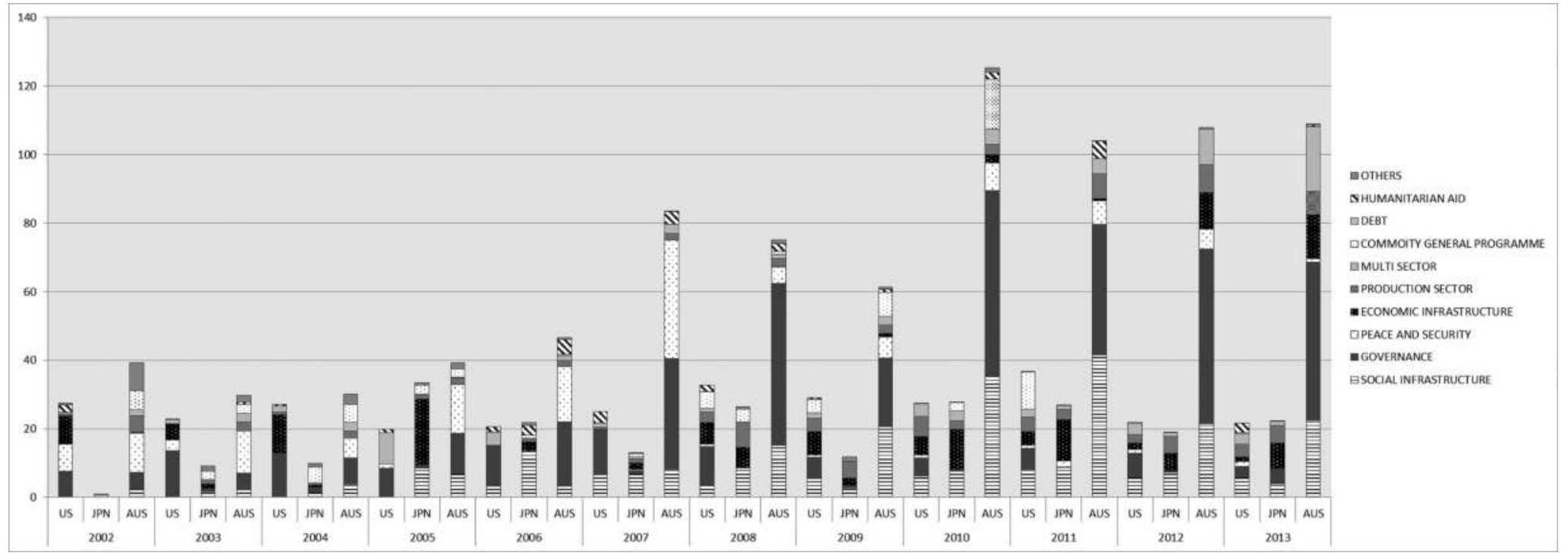

Figure 4.2 ODA sectoral disbursements by $\operatorname{donor}^{2}$ (US $\$$ millions).

Source: authors, based on data generated from OECD QWIDS. 
governance-centered approach is a characteristic of USAID's strategy, as described below. In addition, following the 2006 crisis, USAID made efforts to build social infrastructure such as establishment of a comprehensive land tenure system.

In December 1999, USAID and the Office of US Foreign Disaster Assistance (OFDA) sent staff members to Timor-Leste to monitor the situation and coordinate assistance with other humanitarian aid organizations. At that time, the US Government pledged US $\$ 41$ million in response to Timor-Leste's humanitarian crisis. USAID and OFDA provided nearly US\$11 million, primarily for the provision and transport of relief commodities such as humanitarian aid. This is a significant point for this section because it shows that the continuum does not simply link one phase to another. Instead, it shows that both humanitarian and recovery phases were incorporated into the early planning stages.

In parallel with emergency assistance, in 2000, USAID commenced mid- and long-term support toward advancing peace and democracy by establishing the Office of Transition Initiatives (OTI) in Timor-Leste. OTI is not just a USAID in-house organization but was strategically designed to support US foreign policy objectives to achieve peaceful democratic change. ${ }^{3}$ OTI was mandated to identify and recruit national commissioners, to plan and implement logistical aid projects, and to act as a liaison for donors with longer-term funding support. The concrete programs that OTI initiated involved the following tasks: supporting community development; supporting reconstruction and employment projects; enabling key local civil society organizations to participate as equal partners in relief, reconstruction, and state-building activities; providing in-kind 'startup' assistance and technical assistance to independent media outlets; and supporting East Timor's political leadership and reconciliation (USAID 2000, 64). The roles played by OTI simply indicate that USAID and the US Government supported Timor-Leste under a clear strategic aim: that is, democratic state-building.

In 2004, USAID drafted a new aid strategy to support Timor-Leste in place of the TSP (Transition Support Program), in conformity with Timor-Leste's NDP. Simultaneously, USAID conducted a Conflict Vulnerability Assessment (CVA) to provide recommendations for USAID support to Timor-Leste over the following ten years (USAID 2004). The key recommendations in the GVA were as follows:

- to apply a dialogue-building, conflict prevention approach as a cross-cutting theme; and

- to prioritize the districts most vulnerable to conflict as a function of their economic situation.

The CVA concluded that the top-priority risks leading to conflict were 'poverty, unemployment, and limited access to basic services' (USAID 2004). Based on this assessment, USAID formulated a new strategy in 2005 entitled the 'USAID Strategic Plan for East Timor: A New Nation Moving Forward.' USAID then allocated its budget to three development sectors: economic growth $(50 \%)$, 
democracy and governance $(30 \%)$, and health $(20 \%)$. This strategic document provided the starting point for the successive and unchanged USAID program for Timor-Leste through 2012.

After the re-occurrence of conflict in April 2006, USAID conducted a survey that focused on clarifying the causes of the conflict and considered a new approach (USAID 2006). USAID reiterated that its primary strategy involved a long-term development approach for a stable country and therefore, it was therefore unable to utilize this directly in responding to the crisis of April 2006. However, USAID also emphasized the results of conflict provided an opportunity for allocating additional resources for conflict management and stabilization as well as reconciliation and peacebuilding. While the results of the GVA in 2006 were not groundbreaking compared to the CVA two years before, USAID staff emphasized the continuity of the USAID approach both before and after the 2006 crisis (interview with USAID staff, March 10, 2016).

In 2012, USAID publicized a new strategy titled the 'Country Development Cooperation Strategy: 2013-2018' (CDCS), which focused more specifically on development issues. The goal of the new strategy was a more prosperous, healthy, and democratic Timor-Leste (USAID 2012). Despite several revisions, there has been little change in USAID's approach in Timor-Leste and the US has undertaken every project in accordance with this strategy. This is a consequence of the particular situation of Timor-Leste. Briefly stated, the situation involved shortterm humanitarian assistance and mid- or long-term recovery support existing in parallel.

\section{Conflict prevention focusing on the daily lives of the local people}

Staff members at the USAID office in Dili who were engaged in support from the early period emphasized that, from the perspective of the continuum, OTI was a key in-house USAID organization. In fact, the USAID East Timor Planning Framework (USAID 2000) mentioned OTI's contribution to a smooth transition along the continuum through its coordination of relevant stakeholders in a timely manner. For example, the Transitional Employment Program (TEP), the largest program sponsored by OTI with a budget of US\$254,000, provided immediate employment to locals in public works facilities. The program was implemented in conjunction with UNTAET District Administrators in all thirteen districts and created jobs for approximately 50,000 Timorese people by July 2000. Through this effort, USAID helped to provide income sources to local people through coordination of projects to repair basic social infrastructure such as houses, roads, and community centers.

In parallel with those transitional projects, USAID also tackled issues relating to land disputes. The lack of a land tenure system was recognized as a bottleneck in Timor-Leste's development. Without an established land ownership system and legally protected rights to land based on a legitimate land registration system, local people were restricted from engaging in related economic activities. 
For this very reason, USAID initiated the Land Law Program (LLP) from 2002 in conjunction with the Ministry of Justice. The LLP was designed to provide informed policy recommendations and to support the development and implementation of transparent and representative land laws. The LLP contained two objectives: the first was lasting economic development and the second was conflict prevention. According to USAID's evaluation of the LLP, the role of transitional land law is to provide a legal basis for registration (Lopes 2008). It involves the following four issues:

1 recognizing the ownership rights of consensual owners (in undisputed cases);

2 establishing criteria to resolve disputed cases where overlapping rights exist;

3 converting previous property rights and long-term peaceful possession into ownership rights according to established legal criteria; and

4 establishing the administrative mechanisms and processes that will allow the Timorese state to manage the regularization of property rights in an effective and efficient manner.

In the first program, LLP 1 (2003-2004), USAID conducted a comprehensive basic survey regarding land disputes in Timor-Leste. The survey concluded that complex land authorization, the foundation of which is derived from various sources, placed limitations on private and public investments. Therefore, USAID helped to create a land law system that would relieve the bottleneck and facilitate economic development. LLP 1 included policy proposals with drafts of legislative bills targeted at the centralization of land asset management by the Timor-Leste Government and to build a system to address formal land disputes and other issues. Following the results of the LLP 1 report, USAID implemented LLP 2 from 2004 to 2006 with the goal of developing a legal infrastructure and facilitating capacity-building. One of the new goals of LLP 2, which USAID staff members highlighted in their interviews, is to assist in the establishment of pilot projects for an electronic land registration system in certain districts.

In 2007, the electronic land registration system was placed under the authority of the National Directorate of Land and Property in the Ministry of Justice. The LLP continued through a project titled 'Ita Nia Rai' (Strengthening Property Rights in Timor-Leste Project, or SPRTL), which was managed by the Timor-Leste Government and local associations. USAID reached the conclusion that Ita Nia Rai and the LLPs made meaningful contributions to the development of laws related to land and real property. With this outcome, USAID believes that the program achieved the transition of the initiatives to local organizations in 2007. These successful efforts by USAID, which focus on building an effective land tenure system, can be viewed as USAID's approach to 'covering the continuum.' The approach was centered on the issue of the type of governance that directly affects people's economic situations and on the belief that such an issue should be primarily addressed by nationals. This is why the LLP was swiftly transferred to the government and local organizations. 


\section{JICA}

\section{Aid to Timor-Leste from the perspective of the continuum}

JICA is not an organization with a mission to conduct humanitarian or recovery efforts in post-conflict situations. At the time when Timor-Leste experienced its humanitarian crisis in 1999, it was very rare for JICA to conduct recovery assistance activities in post-conflict situations. Conflict prevention and peacebuilding efforts were not given explicit status in JICA's mandate because JICA is a bilateral 'development' agency. Nevertheless, JICA engaged in providing support to Timor-Leste in 1999 by dispatching staff with the goal of preparing recovery projects and providing some humanitarian assistance. This staff deployment was the most significant part of JICA's approach to addressing the continuum in Timor-Leste. Because JICA concentrated on development activities in 1999, it did not have a concrete strategy to connect the humanitarian phase with the development phase at that time.

JICA also had an inherent interest in Timor-Leste as the site of its first practical engagement with peacebuilding. Japan began to look for a way to contribute to the field of peacebuilding and conflict prevention in 1999. In other words, Japan's support for Timor-Leste was provided in the context of its initial goal of supporting post-conflict or conflict-affected countries. Under these circumstances, JICA started to provide early recovery assistance in Timor-Leste.

In December 1999, donor countries, international aid organizations, and NGOs participated in the first meeting of Timor-Leste donors in Tokyo. Japan, as the host nation for the meeting, pledged more than US\$130 million over the subsequent three years to rebuild Timor-Leste. At the same time, Japan proposed three areas that to be addressed in JICA's basic aid policy in Timor-Leste: human resource development, rebuilding of infrastructure, and agricultural and rural development. In 2002, during the sixth donors' meeting held in Oslo, Japan pledged approximately US\$60 million over the subsequent three years and to contribute to 'the consolidation of peace' (heiwa no teichaku in Japanese) as the fourth focus area of aid to Timor. Japan further renewed its commitment to Timor-Leste in 2005 at the donors' meeting in Dili to continue its support, pledging approximately US\$20 million per year.

In response to the 2006 crisis, while Japan ceased nearly all of its efforts, including NGO projects commissioned by the Japanese ODA, it donated approximately US $\$ 1$ million in food relief through the World Food Programme (WFP) for emergency assistance. ${ }^{4}$ Following this disruption in aid assistance, Japan recommenced its development assistance in Timor-Leste with the objective of maintaining continuity. However, efforts toward enhancing security and conflict prevention - the focus of other donors who took the 2006 crisis seriously - were not addressed by JICA. This is simply because such projects require multilateral coordination, including coordination with UN missions and multinational forces, and because JICA, in principle, was not permitted to perform militaryrelated activities as per Japan's ODA Charter. ${ }^{5}$ 


\section{Infrastructure and economic sectors}

At the commencement of its activities in 2000, during the humanitarian assistance period, JICA dispatched a number of assessment teams to examine the infrastructure, economic, and agricultural sectors. For example, for the rehabilitation of the social infrastructure sector, JICA conducted a 'Study on the Urgent Rehabilitation Plan in East Timor' (SURPET) from February to August 2000. Because over 70 percent of infrastructure in Timor-Leste had been damaged or destroyed during the 1999 crisis, there was a huge need for infrastructure rehabilitation. Under such circumstances, JICA conducted a survey with the goal of designing a concrete rehabilitation strategy in the infrastructure sector. The concrete objective of SURPET was 'restoring the roads, bridges, ports, irrigation and power of East Timor' (UNTAET and JICA 2000, 57). Thus, during the humanitarian assistance period, JICA's primary goal was the urgent development of a rehabilitation plan to address these issues. JICA assessment teams also considered small-scale development projects, including plans for small-scale agricultural community development.

A report prepared by the JICA Timor-Leste Office, 'JICA Cooperation in Timor-Leste' (JICA 2015) stated that JICA had concentrated on 'nationbuilding' support through the urgent rehabilitation of various infrastructures in its initial efforts in Timor-Leste. ${ }^{6}$ The Ministry of Foreign Affairs (MOFA) also provided an emergency aid grant through the United Nations Office for Project Services (UNOPS), focusing on the rehabilitation of infrastructure from 2000 to 2001. JICA's third assistance period was from 2004 to 2006 and included fullscale development projects through the commencement of a grant scheme. In this period, several projects were launched, such as the power supply rehabilitation project in Dili in 2004, the water supply improvement project in Dili in 2004, the capacity-building project for road maintenance in Timor-Leste in 2005, the capacity-development project for the training of personnel and preparation of road guidelines and manuals in 2006, and other projects. In addition to these aid projects, JICA began to dispatch experts for long-term technical cooperation projects in 2004. For this aid scheme, JICA sent two advisors to the Ministry of Transport Communications and Public Works (MTCPW), a policy advisor on infrastructure-building and a road sector advisor.

JICA summed up these approaches in the above-referenced document (JICA 2015), articulating that 'JICA is one of the oldest development partners to Timor-Leste since before its independence' and emphasized its long-term and continual support for Timor-Leste. According to JICA, its 15-year efforts in Timor-Leste can be divided into three phases as follows:

1 2000-2006, support for reconstruction and rehabilitation;

2 2006-2011, sustainable development for building self-reliance; and

3 post-2012, development cooperation emphasizing an end of the rehabilitation stage of Timor-Leste.

JICA discussed its activities conducted from 2000 to 2006 from the perspective of the continuum. Japan provided numerous aid projects with a focus on 
rehabilitation from an early stage. Following this stage, based on these achievements, JICA continued with management and maintenance projects through its technical cooperation scheme (JICA 2008). With the sudden shift in April 2006, most of these projects were interrupted and, instead, MOFA provided US\$5 million to support IDPs through other international organizations. In the autumn of that year, JICA resumed operations on all projects.

In the context of Timor-Leste, the continuum as viewed by bilateral donors spans all the points from humanitarian crisis and rehabilitation or recovery to development. In fact, JICA is the first donor that began providing loan aid to Timor-Leste. JICA initiated a supply road rehabilitation project (120 kilometers from Dili to Baucau at approximately US\$500 million) with a five-year aid scheme beginning in 2012. JICA and Japan began considering providing loan aid to Timor-Leste in around 2008. The goal of providing loan aid was not only to carry out large-scale projects but also to restore confidence in Timor-Leste as an established country. Indeed, Mr. Kitahara, the Japanese ambassador to Timor-Leste at that time, emphasized that Japan's loan aid project would deliver a message to the international community that the 'Timor-Leste Government deserved the confidence of loan projects because they have the capacity to repay.'

\section{Australian aid/Australia}

\section{Aid to Timor-Leste from the perspective of the continuum}

Australia became the highest contributing donor after 2006 and has disbursed over US $\$ 100$ million since 2010 (Figure 4.2). ${ }^{7}$ Australia's financial contributions to Timor-Leste were the third largest during the relief and recovery phase after the 1999 crisis. Following the 2006 crisis, the contributions were especially devoted to social infrastructure and governance. Additionally, Australia provided AU $\$ 75$ million towards the UN mission and an additional AU $\$ 20$ million for humanitarian support. These contributions emerged from Australia's national interest in Timor-Leste's prosperity and peace as one of its nearest neighbors (ODE 2014).

While its financial contributions have been considerable, Australia evaluated its own aid performance as having mixed results due to the lack of an overriding strategy. Australia had no clear country program until 2009 and instead, it responded to the acute needs of Timor-Leste. It is therefore difficult to assess the outcomes. Immediately after the 1999 crisis, the aid program focused on humanitarian responses and recovery, especially in the areas of health, education, water supply, and food production, which were delivered through multilateral institutions and NGOs. After 2002, the program shifted to development, with the goal of building the government's capacity (AusAID 2011). The 2006 crisis was a challenge for Australia to plan and manage aid programs - which had doubled - while staff were under-resourced (ODE 2014). Since 2007, the program has aimed to align itself with Timorese policy planning. In 2011, when the country's political stability allowed for the establishment of a policy-level agreement, the '2009-2014 Australia and Timor-Leste Country Strategy' was 
finalized. This strategy clarified its earlier focus on rural development, such as rural roads, water, and sanitation, health, education, governance, and security, which falls within the scope of the SDP.

Interestingly, Australia speculated that continuous efforts are needed to develop an appropriate strategy and operational skills in low-capacity, conflict-affected settings such as Timor-Leste: 'As the largest donor in Timor-Leste and as a close neighbor, Australia has been under considerable pressure to assist every sector' (NDAE 2012a, 5). Consequently, 'Australia's flexibility and responsiveness in the post-conflict phase has pulled the program in many different directions' (AusAID 2009, 6).

\section{The police program}

Among many other projects, the Australian Federal Police Timor-Leste Police Development Program (AFP-TLPDP) is a long-standing Australian assistance program. AFP-TLPDP was launched to assist the PNTL in building a more effective and accountable police service for the people. Initially organized in 2004, AFP-TLPDP was a four-and-a-half-year program co-funded by the UK with a relatively optimistic view of security development. The program overcame several challenges and became one of the main programs articulated in the 2009 country strategy (ODE 2014). At the beginning, the annual disbursement was US $\$ 750,000$. Following the 2006 crisis, it was increased to US $\$ 28$ million, reaching its peak in 2010 as a part of ODA (data from OECD QWIDS 2015).

From Australia's perspective, the program was a result of a whole-government approach driven by the strong national interests of Timor-Leste. At a strategic level, the launch of the International Deployment Group (IDG) in 2004, a standing police team with an initial capacity of 550 personnel, has developed into a main unit under the AFP and was given approval for expansion to 1200 personnel in 2008 (McFarlane 2007). Hameiri (2009) argues that this revolution of IDG has been enabled by the structural shift of the National Security Council under the Howard government to involve the chiefs of military, intelligence, and police to form security policies, concerning the security risks to Australia. So far, the IDG has dispatched personnel to the UN mission in Cyprus, the Solomon Islands as part of the Regional Assistance Mission to the Solomon Islands (RAMSI) as well as Papua New Guinea, Nauru, Vanuatu, Samoa, and Tonga for policing capacity-development programs/ missions (AFP undated). In other words, policing assistance has become Australia's mainstream method of support for fragile states in the region.

In Timor, Australia was one of the primary contributors to the UN mission to send AFP personnel as UN police officers. Between 1999 and 2004, the UN mission had two mandates for the police sector: maintain law and order and police-building. After the 2006 crisis, the UN authorized UNMIT to support police functions as well as to rebuild and mentor the PNTL. At the same time, the original programs were designed for capacity-building in investigation, operations, training, and development, in collaboration with a contracting company focused on crime prevention, community safety, and administration issues (Edwards and O'Donnell 2011). 
In principal, the AFP-TLPDP program is recognized as a 'training program' in the Police Training Centre (PTC), but Edwards and O'Donnell (ibid.) emphasize that the program does more than just provide formal training. In short, the program included mentoring and the provision of advice, tools, and support for infrastructure, as well as the provision of advice and support for the Secretary of State-Security (SoSS) and the Office of the Prosecutor General (NDAE 2012b). After the 2006 crisis, Australia resumed training in December of that year and eventually reorganized its program under a leadership group to address issue of capacity-building and networking between relevant stakeholders including senior government officials, PNTL counterparts, and donors between 2008 and 2010. This process was considered vital to the TLPDP program, although it was occasionally 'under-appreciated' (Edwards and O'Donnell 2011). The TLPDP also faced a changing donor environment and organizational structure in the security sector. For example, UNMIT had the primary task of supporting the PNTL through 2008 (UNSG Resolution no. 1704), and then withdrew in 2012 (NDAE 2012b). The promulgation of the new PNTL organic law entitled the 'Career, Salary and Promotion Regime' between 2008 and 2009 also presented challenges for the AFP-TLPDP to reflect these capacity development changes on an operational level.

While doubts were cast on the skills of AFP to implement these capacitybuilding projects (e.g., Wilson 2008), the experience gained from other missions facilitated a convergence between the TLPDP and other aid programs, such as those in the justice sector (ODE 2014). In terms of program management by DFAT and AFP, the gap between aid philosophy and its approach to capacity development has shrunk after many years of coordination. Edwards and O'Donnell (2011) opined that by utilizing a structured evaluative process, the AFP-TLPDP's efforts and flexibility to respond to the changing needs and priorities were enhanced by including a variety of experts in the team. Furthermore, the program has the potential to play a complementary role in other aid programs, such as those in the justice sector, supported by Australian Aid.

Strategies for coordination with other stakeholders were in place, yet evaluations of such coordination vary among researchers. The Portuguese Gendarmerie Guarda Nacional Republicana (GNR) conducts police training at the police academy and community policing is developed in cooperation with the New Zealand police force, the Asia Foundation, as well as JICA and Singapore (Deniz 2015). Funaki (2009) and Wilson (2012) were concerned about the lack of meaningful coordination between donors because of the lack of an overall strategy in the Police and Security Sector Reform (SSR). After the withdrawal of UNMIT, dialogue increased between Australia, New Zealand, US, UN Development Programme (UNDP), and Japanese support systems within the government-led coordination mechanism. However, non-traditional donors such as Portugal, Brazil, China, and Indonesia have continued to work individually with the government (Dewhurst, Saraiva and Winch 2016).

Overall, the notable performance of the AFP-TLPDP can be attributed to the constant efforts to build long-term relationships with Timorese counterparts as 
well as relevant stakeholders in the rule-of-law sector. Building relationships can bring about a consensus regarding aid objectives, which can lead to an alignment with the recipient government and can close the strategic, coordination, and funding gaps. Simultaneously, the Australian experience suggests that internal management of aid programs is expected to meet the shifting needs of a post-conflict environment. Coordination with other donors in supporting police development is another challenge. These lessons imply that long-term involvement and focused attention on the changing needs are conditions that enable the continuum initiative but at the same time, such initiatives may also require further integration of actions by the government and donors.

\section{Local perceptions and reactions}

The efforts of these three bilateral donors were undertaken in close cooperation with the government. As a result, bilateral donor programs have been established in line with national strategies. However, as discussed in the introduction, attributing the current peace to government payments to veterans and disbursements to local programs is questionable.

With such questions in mind, the following section articulates some perceptions of local in relation to peace and order. While local perceptions of externally led peacebuilding efforts have already been explored in a separate research article (Tanaka 2018), the following section considers the concerns of Timor-Leste's civil society that the government's outlook on peace and order is largely oblivious to the fragile situation among some Timorese communities.

\section{Concerns of local NGOs}

One of main concerns for local NGOs is the country's diminishing revenue from petroleum production (interview with the Director of La'o Hamutuk, September 5, 2015; interview with the Director of Fundasaun Mahein, November 23, 2015). The rapid and continuous decline in international oil prices from 2014 to 2017 had seriously undermined the oil-based Timor-Leste economy. In the course of receding oil prices, Timor-Leste's oil income (per month) has been cut in half (La'o Hamutuk 2005). Furthermore, the volume of petroleum production has almost consistently declined over the last five years, and there is a prediction that Timor-Leste's oil yield will be exhausted within ten years (interview with the director of La'o Hamutuk, September 5, 2015). Civil society echoes the opinion that Timor-Leste must develop new industries for economic growth and must emphasize education as well as the continuing expansion of international support (ibid.).

Civil society is also concerned with the quality of the government's performance and the need for additional efforts to improve the security sector. Local NGOs are aware that there is broad support from the public to respect the rule of law, including government officials themselves, and laws for addressing local disputes are vital to stable development with lasting peace. In addition, as there are no quick solutions to such fundamental problems, local NGOs have stressed 
the importance of grass-roots efforts and the necessity for accurate monitoring of government policy (interview with the members of Fundasaun Mahein, March 9, 2016).

Further, members of civil society have pointed to land disputes and veteran issues as potential sources of conflict in current Timorese society. Citizens in both urban and rural areas share these concerns, saying that, upon returning to their homes after fleeing violence, they found others occupying their land, thus leading to disputes because no effective legal documents had been filed (Tanaka 2018). A member of a local NGO feels this issue will continue because of the lack of attention by the government and stated:

Any citizen in this country needs a piece of land. In my opinion, if the land issue is not resolved right now, the issue could bring instability to the country in the future. Land conflicts can happen almost anywhere in a post-conflict country, so it would be wise for the government to resolve this. Big persons, the authorities, own large parcels of land in Timor-Leste. That situation could also lead to social jealousy.

(Interview with the director of Fundasaun Mahein, March 9, 2016)

Another concern derives from the verification process for pension payments for retired soldiers. Citizens feel that pension funds and support for the children of veterans - such as scholarships - are not distributed in a fair and appropriate manner (Tanaka 2018). A local NGO member pointed out that veterans have played an important role in the country's independence. Therefore, they are influential and can even bring instability if the government does not pay attention to their requests for payment (interview with the director of Belun, November 26, 2015; ETLJB 2014).

\section{Efforts toward 'on-the-ground' conflict prevention}

Regarding the fragility of peace in Timor-Leste, local NGOs have engaged in bottom-up conflict prevention efforts. For instance, a local NGO known as Fundasaun Mahein (FM) was established in 2009 with the purpose of preventing violence in the daily lives of Timorese people. FM has also set its sights on influencing security-related policymaking based on grassroots viewpoints through monitoring and advocacy. ${ }^{8}$ As a practical matter, FM works with the PNTL and the FDTL by advocating and advising on improvements regarding the performance of these institutions. It also acts as a watchdog for officials.

Another notable mechanism launched by the initiative of local NGOs is the 'Early Warning System' (EWS). ${ }^{9}$ EWS is essentially run by communities themselves to monitor the security situation, thereby preventing potential disputes from escalating. The system is supported by NGOs to gather information and solve problems promptly. The system advises and warns the government of potential conflicts via information-sharing. In this regard, the FM Director, Mr. Belo, 
stated: 'With the power and authority that the government has, we believe that it can use the information we provide to prevent conflict.' These activities of local NGOs stem from on-the-ground concerns regarding social conflict and can be referred to as 'grass-roots conflict prevention.'

\section{Discussion}

Bilateral development agencies have been able to focus on 'development' from an early stage because of the international red-carpet assistance provided to Timor-Leste. First, UN missions in Timor-Leste focused on security and governance issues. While enhancing security was the responsibility of multilateral forces, both UNTAET and UNMIT were mandated to create stable and sustainable state functions for Timor-Leste, including police functions in the security sector. Here, the UN missions faced 'some of the choices, challenges, and dilemmas encountered in development' (Morrow and White 2002). Second, Timor-Leste has been considered a blessed country due to generous assistance and a sufficient income from the oil industry. In spite of being a small country, as far as bilateral donors, there are approximately 50 organizations that provide development services in Timor-Leste. ${ }^{10}$ For this reason, Timor-Leste is referred to as a 'Beloved Land' (Peake 2013). Third, the aid environment in Timor-Leste has been structured primarily by the international community, followed by the Timorese Government, to establish 'a multi-layered model' that has incorporated stakeholders in development efforts since 1999. Similarly, after the 2006 crisis, in order to address the strategy gap, the government established the NPP as a means of aligning the development efforts of internationals.

At the agency level, bilateral aid donors had their own strategies and means to achieve development along the continuum for peacebuilding. USAID carried out projects utilizing an uninterrupted approach, with solid assistance strategies for Timor-Leste based on its original assessments. In concrete terms, the OFDA engaged in emergency relief at the first stage but OTI put forth a strategy targeting transition in early 2000 to avoid a coordination gap. OTI took on a crucial role from USAID's continuum perspective because OTI led the USAID strategy in promoting mid- and long-term economic development, with periodical assessments. That strategy provided a platform for USAID's assistance during the transition period, which was a period that would continue until Timor-Leste reached a stage of absolute development where no risks of conflict were confirmed. In acknowledging that the transition period ended when UN missions withdrew, USAID handed over their programs, including the LLPs, to local organizations.

There have also been some criticisms of USAID's approach. Neves (2011), for example, pointed out that USAID has not produced or promoted good results through its land management projects. Another criticism indicates that USAID did not consider the impact of aid, that the draft law lacked community consultation, and that the government was insufficiently ready to take over the program. ${ }^{11}$ Thus, the USAID's continuum approach may take into account of 
smooth transition from relief, recovery to development by transferring initiatives to local at the earliest opportunity.

JICA consistently followed its basic aid policy for Timor-Leste focusing on three to four sectors, namely, infrastructure, the economy (including agriculture), human resource development, and the consolidation of peace. Since early 2000, JICA has adopted two methods for realizing the continuum: a gradual and evolutionary approach to developing projects by coordinating several schemes for humanitarian and recovery phases. In other words, JICA's basic approach to realizing the continuum was to apply existing developmental aid schemes to relief and recovery. Additionally, JICA's projects have been implemented under a fundamentally unchanged principle from the beginning of the post-crisis period and with careful internal management. Thus, JICA's 'continuum' approach is likely to value warily preparing and conducting development projects since humanitarian phase following the 'do no harm' principle.

Australia self-evaluated that they have offered significant amounts of assistance - especially after the 2006 crisis - yet management suffered due to the lack of an aid strategy. However, backed by strong national interest, the police support program evolved over time in volume and quality in accordance with accumulation of capacity-building skills within the IDG. It was a success in terms of building cordial relationships between government officials, communities, and donors so that the program could assimilate voices and eventually enhance the program's quality. Nevertheless, Australia also emphasized that sufficient staff and a structured management system are vital to being sensitive to shifting demands. Further, coordination among donors is challenging because no overall SSR strategy was launched in the country. Also the IDG's role in building police capacity can be critically evaluated, as its impact on local government as well as communities is enormous (Harris and Goldsmith 2012).

Concerns and the reaction of civil society have highlighted deep perception gaps regarding Timorese leadership and the aid community, which have focused on development issues. Civil society has warned that current public peace is vulnerable due to the 'buying of peace' policy, backed by an unsustainable budget and low public service performance, including within the security sector. Because of the government's reluctance to fully deal with land disputes and veterans issues, people are concerned about potential resource conflicts. In response, civil society has taken on an advocacy role in monitoring the government. In addition, locals have adopted their own mechanisms such as EWS to mitigate potential conflicts at the community level. We conclude that actions taken by civil society are signs that the conflict prevention perspective has been absent from ongoing Timor-Leste assistance projects.

\section{Conclusion}

The international community assigned multiple tasks to various organizations supporting peacebuilding in Timor-Leste; however, the division of labor seemed to neglect an important issue. Bilateral aid agencies were in a position to incorporate 
programs for reconstruction (or rehabilitation) and, eventually, 'development' from the initial phase of a humanitarian crisis with the established mechanism of aid management and a substantial inflow of funding. Because Timor-Leste was aiming to build a new state, crisis management has not only targeted people's immediate needs but also provided livelihood support from scratch. A shared mindset among stakeholders in the early phase of the crisis drove aid agencies to support the long-term needs of the people directly, while the UN missions and the multilateral forces were primarily in charge of peace and security issues.

In parallel, bilateral aid agencies adopted their own perspectives and strategies to respond to changing needs. In other words, each agency used its instruments to act on the continuum to support Timor-Leste's national development. The OTI of the US led to the formation of a strategy at the country level and programs accordingly fit into both Timor-Leste's needs and the US strategy of focusing on governance. In contrast, JICA had no specific mechanism to respond to the needs of weak states or strategies for peacebuilding at that time, and therefore maximized its contribution by utilizing development schemes. Australia eventually fostered the police capacity-building program along with the institutional evolution of the IDG. As a result, while agencies had shared understanding on Timor-Leste's development, their challenges to realize the continuum in peacebuilding differed in terms of organizational goals, structures, and values.

Alternatively, the concentration of development efforts by the government and donors invoked a range of alternative local actions from civil society following the 2006 crisis. To fill in the gap of perception toward peace, local NGOs have focused, a priori, on alleviating possible on-the-ground conflicts.

The findings in this chapter imply that adopting the approach to realize the continuum towards development in a new, post-conflict, fledgling state was not sufficient to address the conflict prevention perspective at a grass-roots level. Concerns regarding the fragility of peace raised by civil society show a contrasting view of the government's positive view of peace. In Timor-Leste, the developmentoriented approach has been successfully linked with relief, recovery and development efforts through donors' selections of specific sectors but this approach left an important need aside. Bilateral donors may continue to face difficulties with the task of corresponding to needs and demands in post-conflict situations.

\section{Acknowledgements}

We appreciate the generous support of the Japan International Cooperation Agency Research Institute in conducting this research. This chapter is partially supported by JSPS KAKENHI, grant numbers 15KT0049 and 15K16990.

\section{Notes}

1 Donors had already pledged over US $\$ 500$ million over three years for Timor-Leste in the first Donor Meeting held in Tokyo on December 17, 1999. 
2 For convenience, the components of the graph are reorganized from the original OECD QWIDS. In concrete terms, the CRS purpose code (for the 100s group) for 'social infrastructure and services' is divided into 'social infrastructure' components, such as education, health, water, and sanitation sectors in code 110 through to the $140 \mathrm{~s}$, and the $160 \mathrm{~s}$, 'governance' in code section 151, and 'peace and security' in code section 152.

3 The US defines its support to Timor-Leste in terms of realizing US national interests such as (1) promoting democracy internationally and in Southeast Asia, (2) being a part of Indonesia's democratic transformation, and (3) as successfully completing a UN-directed undertaking (USAID 2000, 2).

4 The Ministry of Foreign Affairs of Japan holds jurisdiction over the ODA regarding international organizations.

5 Japan's first Official Development Assistance Charter (established on June 30, 1992) www.mofa.go.jp/policy/oda/summary/1999/refl.html

6 'Nation-building' is generally used with the sentence 'consolidation of peace' by Japanese officials. In short, the Japanese government defines peacebuilding as the consolidation of peace and nation-building ('heiwa no teityaku to kunidukuri').

7 AusAID (Australian Agency for International Development) was integrated into the Department of Foreign Affairs and Trade (DFAT) on September 18, 2013.

8 FM's vision is a Timor-Leste in which every citizen feels safe and secure in his or her own country and that this condition will be based on the Universal Declaration of Human Rights and the Constitution of Timor-Leste (see www.fundasaunmahein. org/kona-ba-fundasaun-mahein/deklarasaun-mahein).

9 For instance, details on Belun's EWS operations can be found on the website that updates security-related information (see www.belun.tl/en/early-warning-and-earlyresponse-ewer).

10 There were about the same numbers of international donors (multi-donors) as there were bilateral agencies, with both playing an active role in Timor-Leste.

11 See also the website for Habitat International Coalition (www.hic-net.org/news. php?id=pWloZA==\#.WB1Smi2LSCh).

\section{References}

AFP. Undated. International Deployment Group. www.afp.gov.au/what-we-do/our-workoverseas/international-deployment-group.

AusAID. 2009. Australia-Timor-Leste Country Strategy: 2009 to 2014. Canberra: AusAID. . 2011. Submission No. 22, Inquiry into Australia's Relationship with Timor-Leste. Joint Committee on Foreign Affairs, Defence and Trade, Foreign Affairs Sub-Committee. Canberra: AusAID.

CAVR. 2005. Chega! The Report of the Commission for Reception, Truth and Reconciliation in Timor-Leste, Executive Summary. Dili: Commission for Reception, Truth and Reconciliation, Timor-Leste.

Deniz, Kocak. 2015. Timor-Leste: The Continuing Challenge of Police-building and Security Governance. August 19. www.ssrresourcecentre.org/2014/08/19/timor-lestethe-continuing-challenge-of-police-building-and-security-governance.

Dewhurst, Sarah, Joana Saraiva and Bronwyn Winch. 2016. Assessing the Impact of Orthodox Security Sector Reform in Timor-Leste. CSG Paper No.12, September. Kitchener, Ontario: Centre for Security Governance.

DFAT. 2015. Aid Program Performance Report 2014-15. November. Canberra: DFAT/Australian Government. 
Edwards, Grant, and Tess O'Donnell. 2011. Timor-Leste Police Development Program: Lessons in Capacity-building Approaches. In Security, Development and Nation-Building in Timor-Leste: A Cross-Sectoral Assessment, edited by Vandra Harris and Andrew Goldsmith, 148-162. London: Routledge.

ETLJB. 2014. Veteran's Payments in Timor-Leste: A Source of Conflict? East Timor Law and Fustice Bulletin, November 4.

Funaki, Yoshino. 2009. The UN and Security Sector Reform in Timor-Leste: A Widening Credibility Gap. New York: Center on International Cooperation.

Hameiri, Shahar. 2009. Governing Disorder: The Australian Federal Police and Australia's new Regional Frontier. Pacific Review 22(5), 549-574.

Harris, Vandra, and Andrew Goldsmith. 2012. Police in the Development Space: Australia's International Police Capacity Builders. Third World Quarterly 33(6), 1019-1036.

Hasegawa, Sukehiro. 2013. Primordial Leadership: Peacebuilding and National Ownership in Timor-Leste. Tokyo: United Nations University Press.

Hidalgo, Silvia. 2007. Timor-Leste: Relapse and Open Wounds. In The Humanitarian Response Index 2007: Measuring Commitment to Best Practice, edited by Silvia Hidalgo and Augusto López-Claros, 135-141. Madrid: DARA.

JICA. 2002. FICA no tai Higashi Timor fukkou/Kaihatushien Soukatu Houkokusho. Kokusai Kyouryoku Figyoudan ajia dai Ichibu [A General Report of JICA's rehabilitation and development support for Timor-Lestein]. Tokyo: JICA.

JICA. 2008. FICA Higashi Timor Katsudou Houkoku [The FICA Statement of Activities in Timor-Leste]. Timor-Leste Office, September. Dili:JICA Timor-Leste Office.

- 2015. FICA Cooperation in Timor-Leste. October. Dili: JICA Timor-Leste Office.

Kingsbury, Damien. 2008. East Timor's Political Crisis: Origins and Resolution. In Democratic Governance in Timor-Leste: Reconciling the Local and the National, edited by D. Mearns, 33-51. Darwin: Charles Darwin University Press.

La'o Hamutuk. 2005. Timor-Leste Petroleum Fund/Fundu Petroliferu. September. www. laohamutuk.org/Oil/PetFund/05PFIndex.htm.

Lopes, Ibere. 2008. Ita Nia Rai. Technical Framework for a Transitional Land Law for East Timor, USAID / ARD Strengthening property Rights in Timor Leste. Dili: Ita Nia Rai Project.

McFarlane, John. 2007. The Thin Blue Line: The Strategic Role of the Australian Federal Police. Security Challenges 3 (3), 91-108.

MoF, RTDL. 2013. Summary Report: Fragility Assessment in Timor-Leste. February 26. Dili: Fragility Assessment Team at Ministry of Finance.

— 2014. 2014 Development Cooperation Report for Timor-Leste Overview. Dili: Development Partnership Management Unit, Ministry of Finance, Government of the Democratic Republic of Timor-Leste.

MOFA, Japan. 2000. Indonesia and East Timor. Diplomatic Bluebook 2000, Chapter 1: General Overview. Tokyo: MOFA.

- 2011. Heiwa Kouchiku notameno Shien no Hyouka [A Policy Evaluation for Peacebuilding Assistance] (in Japanese only). Tokyo: MOFA. www.mofa.go.jp/mofaj/gaiko/oda/ shiryo/hyouka/kunibetu/gai/easttimor/hs10_01_index.html

Molnar, Andrea Katalin. 2010. Timor Leste: Politics, History, and Culture. New York: Routledge.

Morrow, Jonathan, and Rachel White. 2002. The United Nations in Transitional East Timor: International Standards and the Reality of Governance. Australian Year Book of International Law 22, 1-45.

NDAE. 2012a. Development Partner Handover Report 2012 Australia. Dili: National Directorate for Aid Effectiveness. 
2012b. Development Partner Handover Report 2012: Australian Federal Police Timor-Leste Police Development Program. Dili: National Directorate for Aid Effectiveness.

Neves, Guteriano. 2011. Timor: Where Has All the Aid Gone? Money Has Been Pouring into Timor-Leste, but It Has Not Translated into Meaningful Development. Foreign Policy in Focus, June 20. http://fpif.org/timor_where_has_all_the_aid_gone.

ODE. 2014. Evaluation of Australian Aid to Timor-Leste. Canberra: Office of Development Effectiveness, DFAT.

OECD. 2008. Concepts and Dilemmas of State Building in Fragile Situations: From Fragility to Resilience. Fournal on Development 9(3), 61-148.

OECD QWIDS. 2015. OECD Query Wizard for International Development Statistics. https://stats.oecd.org/qwids/.

OFDA. 2000. Humanitarian Assistance in Fiscal Year 2000. Washington, DC: Bureau for Humanitarian Response, Office of U.S. Foreign Disaster Assistance, USAID.

OHCHR. 2006. Report of the United Nations Independent Special Commission of Inquiry for TimorLeste. October 2. Geneva: Office of the High Commissioner for Human Rights.

Peake, Gordon. 2013. Beloved Land: Stories, Struggles, and Secrets from Timor-Leste. Brunswick, VIC: Scribe Publications.

Planning Commission. 2002. National Development Plan. May. Dili: Planning Commission. RDTL. 2002. Timor-Leste Development Partners Meetings. Transcript/Minutes. December 9. Dili: Democratic Republic of Timor-Leste.

- 2006. Combating Poverty as a National Cause, Promoting Balanced Development and Poverty Reduction. March. Dili: Democratic Republic of Timor-Leste.

- 2010. Timor-Leste Development Partners Meetings. Background Paper. Dili: Democratic Republic of Timor-Leste.

- 2014. State Budget 2015: Budget Overview Book 1. Dili: Democratic Republic of Timor-Leste.

- 2015. Speech by His Excellency the Prime Minister Dr. Rui Aria de Araujo on the Occasion of the Swearing-In of the Sixth Constitutional Government. February 15. http://timor-leste.gov.tl/wp-content/uploads/2015/02/Swearing-in-of-the-SixthConstitutional-Government-16.2.20151.pdf. Dili: Democratic Republic of Timor-Leste.

Sakabe, Yukako. 2008. International Assistance to Nation-Building Efforts of TimorLeste. In Democratic Governance in Timor-Leste: Reconciling the Local and the National, edited by D. Mearns, 229-231. Darwin: Charles Darwin University Press.

Scambary, James. 2006. A Survey of Gangs and Youth Groups in Dili, Timor-Leste. Canberra: AusAID.

Tanaka, Yukako Sakabe. 2018. A 'Local' Response to Peacebuilding Efforts in Timor-Leste. Working Paper No. 169. March. Tokyo: JICA-RI.

UNTAET and JICA. 2000. Scope of Work for the Study on the Urgent Rehabilitation Plan in East Timor (SURPET). January 12. UNTAET and JICA.

USAID. 2000. East Timor Planning Framework: Transition to Independence. June. Washington DC: USAID.

- 2004. Conflict Assessment: East Timor. May 18. Washington DC: USAID/East Timor and USAID Office of Conflict Management and Mitigation.

2006. The Crisis in Timor-Leste: Causes, Consequences and Management and Mitigation. Report for USAID Timor-Leste Based on a foint USAID-AusAID Conflict Vulnerability Assessment. November 12, 2006. Washington DC: USAID. USAID. 


\section{Y. S. Tanaka and T. Honda}

Wilson, Bu V. E. 2008. Smoke and Mirrors: Institutionalising Fragility in the Polícia Nacional Timor-Leste.' In Democratic Governance in Timor-Leste: Reconciling the Local and the National, edited by D. Mearns, 98-115. Darwin: Charles Darwin University Press. . 2012. To 2012 and Beyond: International Assistance to Police and Security Sector Development in Timor-Leste. Asian Politics \& Polity 4(1), 73-88.

World Bank. 2005. World Development Indicators. Washington, DC: World Bank. . 2016. Timor-Leste Data. http://data.worldbank.org/country/timor-leste\#cp_wdi.

Yamada Mitsuru. 2015. Heiwa-kouchiku to Funsou-Yobou Governance [Peacebuilding and Governance on Conflict Prevention]. In Ningensonzai no Kokusaikankeiron [HumanCentered International Relations], edited by Ryuhei Hatsuse and Satoru Matsuda, 213-237. Tokyo: Hosei University Press. 


\title{
5 Comparative analysis of donor approaches to the continuum under a fragile peace
} The case of South Sudan

\author{
Chigumi Kawaguchi
}

\section{Introduction}

South Sudan is a challenging to realize the links between relief, recovery, and development under the conditions of a fragile peace. As Sudan has been plagued by crisis for more than half of the century, debates among aid communities have persisted on how to provide more-than-relief aid to create the conditions for a sustainable peace. As Maxwell, Santschi, and Gordon (2014, 3) noted, aid programs in Sudan are necessary in order to build capacity: regardless of the outcome of the war, when peace eventually comes and whoever is in charge, skills and capacities and infrastructure will be required. This leads to the question of how donors can provide such aid programs. The aim of this case study is to examine donor approaches to 'realizing the continuum' in South Sudan before the signing of the Comprehensive Peace Agreement in 2005 (hereafter, the 2005 CPA) up to the beginning of 2016. The approaches implemented by United States of America (US), the European Union (EU), and Japan were selected because as the key humanitarian and development assistance donors, they have realized the relief-to-development continuum at policy and operational levels.

The basic notion of the continuum concerns how humanitarian and development strands (normally seen as opposing ends of the continuum) can be intertwined to simultaneously address both humanitarian needs and deeply rooted socio-economic and political issues (van Dijkhorst 2013, 241). In the context of a protracted humanitarian crisis in Southern/South Sudan, 'more-than-relief' activities are required. Donors utilize different names in referring to this process, including 'developmental,' 'rehabilitation,' 'recovery,' and 'reconstruction.' In particular, 'rehabilitation' programs before the 2005 CPA typify a reliefdevelopment continuum. After 2005, 'peacebuilding' becomes the overarching concept in crisis management, embracing 'relief,' 'recovery' and 'state-building' (which also includes development) rather than 'gap-filling.'

This case study focuses on three donors in particular: the US, EU, and Japan. As introduced in Chapter 2 of this volume, among all donors to South Sudan, these three donors have incorporated general continuum approaches into their humanitarian or development aid strategies. The US has supported South Sudan's 
independence and peacebuilding and is now its largest financial donor. The characteristics of US approaches to the continuum relates to the promotion of its own geo-political interests in Southern/South Sudan. Two agencies, USAID and the humanitarian-mandated USAID-OFDA have cooperated from the early 1990s in furthering their political goals through activities in gray areas - or in other words, activities that lie between humanitarian aid and development.

The EU, as a long-time leader of approaches for linking relief, rehabilitation and development (LRRD), has started its assistance before the 2005 CPA and has been the second-largest humanitarian donor to South Sudan. The EU's main driver is the humanitarian-mandated agency, the European Community Humanitarian Operations (ECHO), in cooperation with the development agency, the Commission's Directorate-General for International Cooperation and Development (DEVCO). The EU's approach is characterized by the incorporation of humanitarian principles.

Japan has supported humanitarian relief and development on a comparatively large scale since the 2005 CPA. Interestingly, among the three donors, Japan is the only one that does not have a humanitarian-mandated agency for conflict situations. Thus, relief comes only in the form of aid provided by the Ministry of Foreign Affairs through international organizations and non-governmental organizations (NGOs). The Japan International Cooperation Agency (JICA), as a development-mandated agency, covers a gray area from the both perspective of development and peacebuilding. Comparative analysis of these three large donors should provide some illustration of the varieties of continuum approaches by bilateral donors. It is important at the outset to examine each of the bilateral donors' motivations to start gray area activities in South Sudan, how they have been implemented, and finally, how each donor's approach towards the continuum could be characterized.

This case study is based on literature review, 16 semi-structured interviews in Juba in February 2016 with donors, multilateral agencies, NGOs, and correspondences with donor government officials, aid workers, and academics. ${ }^{2}$ Unfortunately, I was unable to conduct interviews directly with South Sudanese government officials for this chapter.

The structure of this chapter is as follows: a brief overview of the crisis in South Sudan followed by a chronological examination of donor approaches to the continuum in different periods. The last section provides a comparative analysis of donor approaches and examines possible factors that could promote or prevent better realization of the relief-to-development continuum.

\section{Overview of crisis and aid in South Sudan}

\section{Treo armed conflicts and independence of the South}

South Sudan gained its independence from the Republic of the Sudan (hereafter referred to as $\operatorname{Sudan}^{3}$ ) in July 2011. For more than fifty years since its independence in 1955, Sudan has been riven by armed conflict between the government in 
Khartoum and rebel groups. The conflict was most marked between the North and the South on the grounds of religion (Muslims and Christians) and ethnicity (Arabs and Africans). Additionally, many people in the South believed they were being exploited by the North and desired to see this relationship transformed. The first armed conflict took place from 1955 to 1972; the second began in 1983 and ended with the signing of the 2005 CPA in January 2005. The 2005 CPA was signed between the Government of Sudan $(\mathrm{GoS})$ on the one hand, and the Sudanese People's Liberation Movement/Army (SPLM/A) and other rebel groups on the other. The agreement was also supported by the regional organization IGAD (Intergovernmental Authority on Development) and by Western countries as well as Japan. Terms of the agreement included ensuring administrative autonomy for the South, a new Government of South Sudan (GoSS) headed by the SPLM/A, and a six-year interim period until a referendum for independence was held in 2011.

Underpinning the North-South conflict was a mixture of different types of conflicts in the region. These include disputes over resources between local groups, challenges against the government, and conflicts between states. Another conflict - in Darfur - began in 2003 when rebel groups backed by the South fought against the government in the North. This resulted in large-scale forced movement, starvation and death. The Darfur conflict and its outcomes embody the complexity and dynamics of conflict in Sudan.

The GoS - the regime in Khartoum - was able to count on a state apparatus with considerable strengths, including centralized control over wealth, resources, and security forces (Haslie and Borchgrevink 2007, 12-13). However, this was not the case for the South, where there were no modern, democratic governmental structures prior to signing of the 2005 CPA. Historically, southern Sudan has been a severely under-developed area with very limited infrastructure and administrative capacity. In SPLM/A-controlled areas, during the period of conflict, there were traditional authorities and a military administration, with service delivery provided largely by NGOs. According to the OECD/DAC (Organisation for Economic Co-operation and Development/Development Assistance Committee) Report, Sudan (both North and the South) encompassed all dimensions of fragility: it could be variously grouped with countries undergoing a post-conflict/crisis and political transition, facing deteriorating governance environments, demonstrating gradual improvement, as well as countries in prolonged crisis or impasse (Haslie and Borchgrevink 2007, 13). The 2005 CPA, rather than marking the beginning of recovery or reconstruction, is widely considered to mark the point at which the South began to build a state from scratch (Harvey 2009). This perspective implies that agenda for the continuum in the South is not to fill the gap between relief and recovery but to generate synergies between relief and state-building.

\section{The third conflict in 2013}

Two-and-a-half years after the Republic of South Sudan became independent, violence recurred in December 2013, leading to a deterioration of the humanitarian 
situation. Before the new conflict broke out, the humanitarian community forecast that the situation in South Sudan showed the potential for improvement in 2014 and beyond: it was the first time since 2011 that humanitarian needs had not increased (OCHA 2013). However, even though South Sudan was regarded as having positive development prospects before the conflict (AfDB, OECD, and UNDP 2015, 3), significant humanitarian needs and a chronic lack of development persisted (OCHA 2013). Unfortunately, the violence that started in Juba spread across eastern and northern South Sudan. Nearly 1.4 million people were forced from their homes and tens of thousands were killed (OCHA 2014).

A ceasefire agreement was signed in August 2015, but clashes have continued. The strife has progressively adopted the characteristics of an inter-communal conflict, with government forces under President Salva Kiir Mayardit, allied to the Dinka tribe, fighting against the Nuer tribe, which is loosely allied with former and current Vice-President Riek Machar. ${ }^{4}$ The conflict is concentrated in the Greater Upper Nile states of Jonglei, Upper Nile, and Unity, with the central counties of Unity State the most severely affected. Food insecurity and malnutrition rates are alarming, and insecurity is hampering the delivery of assistance. OCHA (UN Office for the Coordination of Humanitarian Affairs) reports widespread violations of human rights and targeted violence against civilians, and 6.1 million people were reported to be in need of humanitarian assistance in 2016 (OCHA 2015). The number of affected people has declined since its peak of 7.3 million in 2014 (OCHA 2014); however, more than 69 percent of the total population is still suffering as a result of the conflict.

Between the independence in 2011 until December 2013, South Sudan has received more than US $\$ 4.3$ billion in humanitarian and development assistance

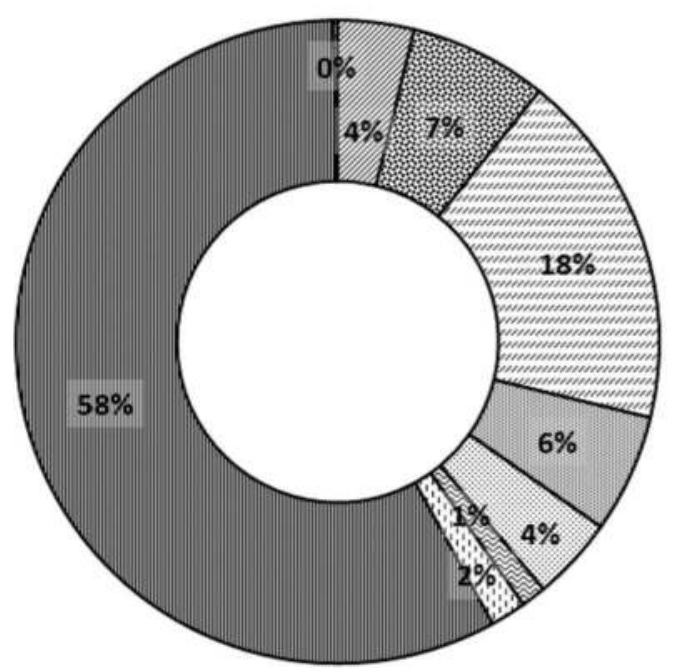

๒Education

国Health and Population

DOther Social Infrastructure and Service

$\square$ Economic Infrastructure and service

Mroduction

Multisector

๒Programme Assistance

$\square$ Humanitarina Aid

๑Other and

Unalocated/Unspecified

Figure 5.1 Bilateral ODA by sector for South Sudan, 2013-2014 average.

Source: authors, based on data from OECD/DAC (www.oecd.org/dac/stats). 
from the international community (Osborne 2014, 2). It was the fourth-largest recipient of international humanitarian assistance (US\$664 million) in 2013. In 2013-2014, 58 percent of bilateral ODA was designated as humanitarian aid, leaving nearly 42 percent for development (see Figure 5.1 ). ${ }^{5}$ The conflict has redirected resources away from development funds to humanitarian relief, following a structure similar to the pre-CPA period. On the other hand, the shift in world attention to the Syrian crisis has dramatically decreased the amount of humanitarian assistance to South Sudan, falling by US\$210 million in 2014 (Development Initiatives 2015).

\section{Humanitarian crisis management in the pre-CPA period: commencing with rehabilitation}

\section{Operation Lifeline Sudan}

Due to major violations of human rights in Sudan from the late 1980s to the early 1990s, donors withdrew official development assistance to Sudan. The US suspended development assistance in 1990, as did the EU. Japan ceased providing development assistance to Sudan in October 1992. Up until the 2005 CPA, aid for southern Sudan was limited to humanitarian relief resources, with the few possible recovery and development activities carried out under the guise of relief activities. The approach to realizing the continuum during this period was using humanitarian aid to achieve longer-term, recovery and development goals.

Operation Lifeline Sudan (OLS), the largest-ever humanitarian coordination mechanism, was coordinated by United Nations agencies and NGOs under the lead of UNICEF. OLS was established in 1989 to respond to the most severe war-created famines (e.g. 1988 in Bahr el Ghazal). The specific characteristics of OLS were arrangements for humanitarian access negotiated with both sides of the conflict - the GoS and the SPLM/A - by creating separate administrative sectors in the government-controlled 'North' and non-governmentcontrolled 'South.' Each NGO had an area of responsibility and worked closely with local Sudanese authorities and UN-funded agencies such as the World Food Programme (WFP). OLS started as an emergency relief operation for famine, but after 1993 it sought to implement relief-to-development projects, especially in the South (Karim et al. 1996; Macrae et al. 1997, 223; Maxwell 2014, 3).

The continuum approach used in the North was oriented toward development, the development-oriented continuum, and was driven by the governmentdevelopment agenda. In the case of the South, however, donors, UN agencies, and NGOs were the main promoters of the relief-to-recovery approach to the continuum, with the SPLM/A showing a positive and cooperative attitude. As Macrae et al. (1997) pointed out, there was no clear working definition of the continuum at that time. The largest component of OLS was food deliveries; however, with UNICEF in the leading role, they also focused on capacity- and institution-building as well as promoting food security to increase self-reliance. UNICEF capacity-building projects included cash payments to the Sudanese 
Relief and Rehabilitation Association (SRRA) and the Relief Association of Southern Sudan (RASS) ${ }^{6}$ to cover salaries, rents, and office expenses (Macrae et al. 1997, 234). Some authorities were critical of the OLS approach to the South, maintaining that too much support was given to SPLM/A for human resource development, institution building, and to securing resources for sustainability of SPLM/A. Operational issues during OLS included legitimacy of the recipients and the politicization of aid.

\section{Donor engagement}

\section{United States of America}

From 1983 to 2003, the US provided US\$2 billion in humanitarian assistance, mainly in the form of food assistance. The majority of US assistance was channeled to the South with the recognition of the SPLM/A as the main 'authority' (Harmer 2004, 14). It was administered mainly through the Bureau for Humanitarian Response (BHR), the Office of US Disaster Assistance (OFDA), and Food for Peace (FFP). This makes it difficult to identify activities as being specifically development or humanitarian relief, with most activities lying somewhere in between the two.

Hostile relations between the US and the GoS led to the concentration of USAID activities in the SPLM/A-controlled southern area. ${ }^{7}$ Under the Clinton administration, the USAID headquarters in Washington and the Sudan Field Office in Nairobi, (established in March 1993 for US relief assistance in the South) created a new strategy together to undertake 'rehabilitation-oriented activities that did not fall under the conventional definition of "emergency assistance"" (O'Toole Salinas and D'Silva 1999, 7). The distinctive feature of the strategy was to start 'rehabilitation' in relatively secure opposition-held areas alongside the countrywide civil war. Such an approach would traditionally be considered as lying within the 'relief' aid phase. The other feature of the strategy was its methodology: small grants were provided to NGOs with the aim of reducing costs. For the 1994 fiscal year, OFDA estimated US\$28 million would be needed as emergency grant aid for fifteen NGOs (Anderson et al. 1995, 1, 7). Of that amount, about 81 percent went to three sectors in the South for building local health capacity (approximately US $\$ 12.6$ million), small-scale agriculture programs (US $\$ 8.7$ million), and road rehabilitation projects (US $\$ 1.5$ million). The smallest amount of funding was allocated to food aid $(15 \%)$ and water and sanitation projects $(3 \%)$.

The Sudan Transitional Assistance for Rehabilitation (STAR) program, which began in 1998, is considered a US model for a 'developmental' program in an area that is relatively stable but in the middle of conflict. The STAR program components were designed to:

- strengthen Sudanese grassroots organizations working to solve local rehabilitation problems, thereby reducing their heavy reliance on relief and strengthening self-reliance; 
- $\quad$ provide governance training to the nascent civil administration in order to improve transparency, accountability, public financial management and respect for human rights; and

- $\quad$ provide a forum that can contribute to the development of policies (O'Toole Salinas and D'Silva 1999).

The STAR program was introduced after debate in the US Congress and a change of policy in the White House in 1997. This allowed the provision of development assistance - US $\$ 7$ million over three years - in addition to humanitarian assistance. It was intended to be used for promoting participatory democracy and good governance while reducing reliance on relief in the South. The Bureau for Population, Refugees, and Migration (PRM) of the US Department of State, the USAID Regional Economic Development Services Office in the Sudan Field Office, USAID Khartoum, and the US Embassy in Nairobi planned and monitored STAR together (OFDA 1998, 49).

STAR consisted, for the most part, of relatively small amounts of funding provided in related to capacity- and institution-building within the SPLM. At the same time, it also promoted a grassroots people-to-people reconciliation process, small-scale economic recovery activities, and rehabilitation of roads and agricultural systems. The STAR program was intended to provide a bridge between relief and development as well as create a foundation for the eventual transition from conflict. It is important to note the SPLM was not a passive recipient but a participant in the program development and implementation processes in capacity-building for civil administration. However, STAR had underlying political objectives in moving towards state-building, by linking together not only relief and development but also capacity-building.

\section{The European Union}

From 1992 to 2002, the EU disbursed approximately US\$488.25 in humanitarian assistance to both the North and the South (Harmer 2004, 15). Ever since the suspension of development cooperation, ECHO had been a major player in Sudan and had tried to provide humanitarian relief and rehabilitation.

ECHO managed its activities in the North from Khartoum, withdrawing from the South when the SPLM asked NGOs belonging to OLS to sign a Memorandum of Understanding (MoU) in March 2000. As a humanitarian-mandated agency, ECHO took a strong stance against the arbitrary taxes imposed by the SPLM/A and suspended ECHO's humanitarian flights, but continued to provide support outside the SPLM/A-controlled area. As a humanitarian agency, ECHO was reluctant to accept the SPLM/A as the local 'authority' governing the South while at the same time, the EU as a political entity was adopting a foreign policy approach of 'constructive engagement' toward normalizing relations with the GoS. This shows a clear distinction between ECHO and USAID, whose support for capacity- and institution-building in SPLM/A-controlled areas virtually confirmed US recognition of the SPLM/A as the local authority as part of the US government's strategy. 
Despite its strict humanitarian mandate, ECHO recognized it needed to move beyond relief activities. In the absence of development funding, ECHO had to 'dress up' developmental activities as 'relief' in NGO funding proposals (Lehtinen 2001, 21). In this regard, ECHO strongly advocated for the Director General (DG) of DEVCO ${ }^{8}$ and DG Relex ${ }^{9}$ to start developmental activities. In November 2000, the EU agreed on the implementation of its 'Humanitarian Plus' program from the 6th European Development Fund. It aimed to address the lack of a legal framework for development cooperation and provided US\$16 million in grants for programs that extended beyond relief. The Humanitarian Plus program provided multi-year funding and focused on re-establishing 'selfreliance' in sectors related to food security, basic health, water, and sanitation to strengthen the delivery of basic services at the local community level. This was the first time in Sudan that local NGOs could access EU development-assistance funding. Humanitarian Plus was implemented by NGOs rather than by the GoS or SPLM/A; however, EU member states were still concerned that such a program would send the wrong political signal to the Sudanese government.

DG DEVCO is responsible for the Humanitarian Plus program in close coordination with ECHO. The European Commission (EC) disbursed assistance through Humanitarian Plus to both the North and the South as humanitarian aid, though ECHO provided assistance only to the North and not to SPLM/Acontrolled areas (Harmer 2004, 14-15). It was managed by a special Programme Management Unit (PMU) within the Commission, in close cooperation with the EU delegation and ECHO in Sudan. This was partly due to the result of an influential evaluation of ECHO's work in 1999, which criticized its increasing role in more-than-relief areas (Randel, Cordeiro and Mowjee 2004, 56).

\section{Japan}

Until Sadako Ogata became the president of JICA in 2003, Japan had not developed any initiatives related to the continuum. JICA is in charge of providing bilateral aid in the form of Technical Cooperation, and Loan and Grant Aid, for which the main purpose is development. The Ministry of Foreign Affairs (MOFA), on the other hand, manages multilateral aid, including humanitarian funding to international organizations and NGOs. In comparison to EU and US, Japan does not have a humanitarian agency for conflict-affected situations. ${ }^{10}$

Japan has been providing ODA to Sudan since the 1960s. In 1976, Japan provided loans for the first time; however, the main aid scheme for Sudan was grant aid to the North. The JICA Sudan office, which opened in Khartoum in 1989, was closed in January 1993 following a Japanese government decision to suspend development assistance. Following this, JICA sent a mission to conduct field research and start a dialogue with the SPLM in Nairobi in November 2004. At this time, more than 90 percent of aid to Sudan was humanitarian assistance via international organizations, such as the WFP and UNICEF. Up until 2004, Japan disbursed a total of US\$73 million as grant aid including humanitarian assistance (MOFA 2005). 
As the aid project titles show, Japanese aid was not intentionally used for rehabilitation purposes. With the suspension of aid for development programs implemented through the GoS, disbursement of humanitarian aid through international organizations and NGOs was the only way for Japan to continue engaging with the humanitarian crisis in Sudan. There were no rehabilitation-purposed programs for achieving relief-to-development continuum activities such as STAR and Humanitarian Plus. Japan's engagement in gray area activities in relation to the continuum commenced after Ms. Ogata was appointed to the JICA presidency. This occurred well before 'seamless assistance' - the Japanese approach to the continuum — was formally adopted as JICA's strategy in 2008.

\section{Comparative analysis}

'Rehabilitation,' 'capacity-building' and 'long-term objectives' were used as well as the word 'developmental' to show the need to extend assistance to the gray area between relief and development in the literature and donor reports during the period. The phase shift in donors' strategies from 'relief' to 'developmental' activities started around 1994 along with the expansion of OLS activities in the South. It is useful to examine why such a shift took place at this time.

One reason for the expansion of OLS was the 1993 famine, but there were other reasons. The most obvious explanation is that donors began to realize that 'relief is not enough' in a humanitarian crisis with no end, and that locals should be empowered to become self-reliant (Maxwell et al. 2014, 3). Moreover, prolonged and expensive humanitarian assistance led to a requirement by donor governments for cost reductions and decreases in aid dependency levels among recipient populations. Realization of the need for these reductions can be seen as prompting modifications of previous relief-focused policies.

Another reason was the unforeseen changes in diplomatic relations between donors and the GoS - especially for the US - which occurred simultaneously to the building of closer relations with the SPLM/A (Akol 2005; Bradbury, Leader and Mackintosh 2000). Despite the establishment of OLS, without any visible progress from the GoS on the peace process, respect for human rights, or democratization, donors were unlikely to change their policies.

On the other hand, relationships between donors and the SPLM/A changed dynamically following the establishment of RASS as the civilian counterpart in the South and agreement on new Ground Rules with the SPLM/A for negotiated access. This created a humanitarian space that could also be used for more developmental activities. Bradbury, Leader and Mackintosh (2000, 24) noted that the establishment of the OLS and the signing of the Ground Rules in early 1993 signaled a process of rehabilitation for the SPLM/A and the area it controlled. This clearly shows that development aid is a highly political instrument, and that political goals take precedence over needs at the local level. In this regard, the rehabilitation program implemented in the OLS period, which was funded by donors as humanitarian assistance, could be regarded as the relief-to-developmental continuum approach under a humanitarian umbrella (Macrae et al. 1997). 
There were no special coordination mechanisms during the OLS period towards realizing the relief-to-development continuum. There were six UN agencies, 30 international NGOs, and 11 local NGOs under the auspices of OLS Southern Sector. Some constraints on the effective coordination of the complex structure of the OLS at different levels led to insufficient strategic coordination and poor joint planning. Within the OLS, frequent meetings often appeared limited to exchanges of information regarding security and ongoing projects rather than joint strategic coordination and the planning of activities (Lehlinen 2001, 15). There was the notion of the need for a strategy for realizing the continuum; however, it did not become a specific strategy for OLS.

As Lehtinen (ibid., 12-13, 17) observed, the contrast between the US and the EU shows that the donors' approaches differed according to their mandate between the politically mandated humanitarian OFDA and the humanitarian-mandated ECHO. In the case of Japan, JICA was restricted by its development-only mandate. The rehabilitation program in the South was strongly linked to OFDA's foreign strategy; in this regard, OFDA worked jointly with other governmental offices and agencies. On the other hand, ECHO was faithful to its humanitarian mandate even though ECHO pressured DEVCO to develop a rehabilitation program. Compared with the US and the EU, Japan had to rely on multilateral engagement during this period, and did not seek to utilize the relief-to-development continuum at this time. It is unsurprising that each donor approach toward the continuum corresponds to the differences between agencies' mandates. It also depends on whether each donor has a clear political strategy for engaging with such fragile states.

In addition, with regard to local issues, the case of Sudan highlights the problem of how to deal with local 'illegitimate' authorities such as the SPLM as counterparts. There were many critics of this approach because, 'whilst not challenging Sudanese sovereignty directly, OLS conferred international recognition on the SPLA' (Harmer 2004, 12). Although the US started rehabilitation activities before others in the southern area, thereby providing an important contribution towards realizing the continuum, the one-sided nature and the backing of the SPLM/A as a part of an anti-GoS policy also received some criticism (Deng and Morrison 2001).

\section{CPA period to the 2013 crisis: the continuum in a linear peacebuilding model}

\section{Foundation of the continuum: CPA, JAM, MDTFs}

The 2005 CPA symbolized the beginning of a 'recovery' for all donors (Harvey 2009, 146). This is clearly based on a linear peacebuilding model. For the first time, the Government of South Sudan (GoSS) was recognized as a legitimate recipient, enabling donors to resume development assistance in the South. The process of setting a course for recovery (which consisted of state-building in the South) and the prospect of improved security helped to broaden the kinds of programs 
on offer and boosted the motivation of aid workers. However, the special interim measures, such as 'one government, two systems' (meaning two counterparts), two coordinating teams, and two cluster teams for both the GoS and SPLM/A, during the 2005 CPA transition period until the referendum on independence, created an enormously complex situation. The international environment was dominated by the war against terrorism, leading to the continuation of strained relations between some western donors and the GoS in Khartoum. On the other hand, positive support for the newly recognized authority, the GoSS in Juba, was driven by the expectation of building the world's newest country (Hemmer and Grinstead 2015). DAC countries almost doubled the amount of their aid in 2005, as a result, after the 2005 CPA, international aid engagement in Sudan (including the South) increased dramatically.

Aid coordination mechanisms established in the 2005 CPA period could be regarded as an experiment in how and to what extent donors and aid organizations could work jointly to provide effective assistance. There was a clear need to assist the emerging governance structure of the GoSS in maintaining the peace process, address the issue of the fragility of the damaged and vulnerable economy and society, and to save the lives of people at risk. As a result, the structure of donor intervention in South Sudan became multi-layered. Political support for the peace process was provided by the troika (US, UK, Norway) and IGAD (Intergovernmental Authority on Development); security and election preparation assistance was undertaken by United Nations Mission in Sudan (UNMIS); and humanitarian relief and recovery was implemented by international organizations, NGOs, and donor agencies.

The 2005 CPA, the Joint Assessment Mission (JAM) process, and the MultiDonor Trust Funds (MDTFs) were important elements in donor engagement. The 2005 CPA was an ambitious time-bound political process, leading to a referendum on the South's self-determination in 2011 (Fafo Institute 2013, 7). As a member of the troika, the US took a strong initiative in the process. The JAM report was developed as a foundation plan for the six-year 'recovery,' focusing mainly on post-conflict development. Key donors, including the US, EU and Japan, provided critical technical and financial support to cluster works, such as governance, economic policy and infrastructure. The GoS and SPLM/A were also comprehensively included the JAM process, with careful consideration given to ensuring a balance between local ownership and donor interventions. A multinational pooled fund for Southern Sudan (MDTF-SS) was already embedded in the Protocol on Wealth Sharing (2004) to ensure donors' financial and technical support; this was formally decided at the Oslo Pledging Conference (2005) when the 2005 CPA and JAM reports were in place. The purpose of JAM was to provide an assessment of rehabilitation and transitional recovery needs focused on the first two years of the interim period, and an outline framework for reconstruction and recovery over the full six-year interim period (UNDG/World Bank 2006). JAM envisioned that it could use these pooled funds - mainly from MDTFs - to enable aid coordination. ${ }^{11}$ However, the MDTFs were not the sole funding channel; donors directly funded their own programs bilaterally (JAM 2005). The 2005 
CPA, JAM, MDTFs, and bilateral funding were the foundation of a continuum 'picture' for drawing up a strategy envisaging humanitarian and security assistance. They also provided a basis for donors' large flagship development projects, financed through separate channels (Davies, Smith and Williamson 2011).

During this process, JAM tried to create links between other planning processes such as the UN \& Partners Work Plan of 2005 and 2006, the UNAMIS and UNMIS mission planning process, the Poverty Eradication Strategy concept note, and the joint GoS/SPLM document 'Urgent Needs in Sudan' (UNDG/World Bank 2006). The document was developed as an alternative to the Consolidated Appeals Process (CAP), which normally involves the development of a strategic plan for humanitarian action and the fostering of cooperation between the host government, donors and aid agencies. These linkages were a noteworthy experiment in adopting a comprehensive approach, especially for the UN \& Partners Work Plan 2006, which included a humanitarian component and a recovery and development component based upon the outcomes of JAM, and could be regarded as a continuum strategy. In the case of South Sudan, it is noteworthy that the planning process was originally based on separate humanitarian, security (peacekeeping) and development communities working together, as in the Work Plan and Poverty Reduction Strategic Paper (PRSP) and in the UNMIS integrated planning process.

The JAM report requested funds for a coordinated response to development and recovery needs. Consequently, US $\$ 4.6$ billion was pledged by donors at the Oslo Conference in 2005. This provided a financial base for implementing the JAM report. The humanitarian needs did not directly respond to JAM but were included in the Work Plan for 2005 (UNDG/World Bank. 2006). However, about 60 percent of these pledges were actually provided for humanitarian relief. The PGNA review pointed out the need for integration of humanitarian relief, recovery, and development planning tracks and that more attention should be given to 'early recovery' activities with careful coordination of projects geared towards 'medium-term reconstruction' (ibid.). Overall, the challenge of merging political, humanitarian and development approaches by combining CPA, JAM and MDTFs under a state-building umbrella in order to realize the continuum may inevitably lead to the creation of a complex and un-manageable situation.

\section{Donor engagement}

\section{United States of America}

The US was an interesting exception among the donors due to its deep involvement in peace negotiations as a member of the troika, the large scale of its aid, and the human capacity available in the field. For example, while the 2005 CPA and its aid approaches tied donors to cooperating within the 2005 CPA framework, its most important element was to 'make unity attractive.' The peace process strategically focused on different approaches depending on the area - the North, the South, and the Three Areas ${ }^{12}$ — with the latter two exempted from 
sanctions beginning in 2006. USAID provided activities for relief and promoting peace in the Three Areas, and supported the South in its moves towards anticipated independence with a range of large projects covering humanitarian, recovery, and development activities. In this regard, they coordinated activities closely with other donors of development projects, but did not necessarily act in concert with the 2005 CPA's aim for unity.

At the Oslo Donors' conference in April 2005, the US pledged the largest amount of funding: about US $\$ 1.7$ billion for the two years 2005 and 2006. The US has been the leading donor to Sudan, providing more than US\$3.5 billion between 1983 and 2006. Among all contributions made by the US government, Sudan was the largest recipient of OFDA humanitarian funding up until 2012, when the Syrian crisis became the major problem. However, due to legislative constraints and remaining suspicions about effectiveness, USAID's large resources were only channeled bilaterally and did not support any pooled funds (Harvey 2009, 158).

From November 2007, OFDA Sudan (except Darfur) shifted the focus of its aid from relief to long-term assistance, with the goal of reducing humanitarian funding (OFDA 2007b). According to the OFDA annual report in 2007 and 2008, OFDA worked with OTI, FFP and USAID/Sudan to transfer its activities from relief programs to more development-oriented programs that could be handed over to other agencies and local authorities in Southern Sudan (OFDA 2007a, 2008). This indicates a clear phase-centric logic. This shift may have arisen as a result of the recognition that the peace dividends were proving to be slow in realization. This resulted from the fragility of GoSS service delivery systems and, if unaddressed, it could consequently become a source of conflict. In 2009, USAID/Sudan started funding the Building Responsibility for Delivery of Government Services (BRIDGE) Program, which aimed to support CPA by delivering tangible peace dividends through building the capacity of state and county governments in the South to plan and deliver essential services as well as empower communities. The BRIDGE program serves as an important link in USAID's strategy to transition efforts from relief to development.

After independence in 2011, USAID generated the 'Transition Strategy between 2011 and 2013,' which was aimed at increasing stability in South Sudan (USAID 2011). The strategy stated, 'the experience of the last six years demonstrates that moving humanitarian to development programs and approaches is not a simple or linear process' (ibid., 4). This strategy recognized the importance of synergies between the development and humanitarian programs led by OFDA and FFP, and other US government initiatives such as the DOS Bureau of International Narcotics and Law Enforcement Affairs (INL), the Office of the US Special Envoy to Sudan (USSES), and the stabilization team mobilized by the State Department's Office of the Coordinator for Reconstruction and Stabilization (S/CRS).

In South Sudan, OFDA provides its funding mainly through international NGO partners, preferring to put funds into NGOs rather than the UN. NGOs are considered more flexible, cost effective, capable of showing a stronger presence 
on the ground, and better able to reach remote and isolated populations (Harvey 2009, 151). Interviews by Harvey, showed that coordination between the three offices within the Bureau for Democracy, Conflict and Humanitarian Assistance (DCHA) worked well based on strong personal relationships and long experience in the South and the Three Areas. Harvey also found that internal coordination with USAID development assistance was generally seen as strong (ibid., 152).

\section{The European Union}

The EU recommenced development assistance to Sudan in 2005. At the Oslo Donors' conference, the EU pledged about US\$734 million for the three years from 2005-2007. The total amount of EU assistance to Sudan between 2005 and 2011 was more than US $\$ 827$ million, with more than half provided to the South in the areas of agriculture, food security, education, stabilization, and human rights. The EU was required to work only through the Government of National Unity (GoNU), which was created following the 2005 CPA as an interim government between the GoS and the SPLM/A, and not directly with the GoS unless the GoS ratified the EU's Cotonou Partnership Agreement with the African, Caribbean and Pacific (APC) states, which included requirements for good governance based on human rights and democracy. However, the EU provided extensive funding for CPA implementation, which was channeled to pooled funds such as MDTF-SS, the Common Humanitarian Fund and the Basic Service Fund.

The European Commission Juba sub-office has played an important role in information sharing with ECHO and other Commission DGs to implement particular projects with awareness of the need to link relief and longer-term objectives. The Recovery and Rehabilitation Program - co-funded by UNDPprovided funding to 48 national and international NGOs to build water points, health care units, schools, and sanitation systems. ECHO started allocations to implementation partners (IPs) for humanitarian projects in the South in 2005, including early recovery programs for internally displaced persons (IDPs) who had fled their homes but not crossed an international border. In order to realize the continuum, funding for the recovery phase (the European Commission's Recovery and Rehabilitation Program, the Humanitarian Plus Program, the Food Security Thematic Program, and the Water Facility) could take over from the ECHO funding.

The EU published a Single Country Strategy Paper aligned with South Sudan's 2011-2013 Development Plan in January 2012. The strategy stated that a coordinated transition from a humanitarian approach to a government-owned development based on Linking Relief, Rehabilitation and Development (LRRD), the relief-to-development continuum concept for the EU, was the core (EU 2012, 3, 28). In addition to the LRRD, the EU Comprehensive Approach - encompassing political and diplomatic issues, security, rule of law, stabilization, development, human rights, and humanitarian and trade aspects in the EU's policy - was a guiding principle. The EU developed the strategy as a pilot case for the EU Joint Programming approach, which aims to improve the effectiveness and efficiency 
of EU aid by reducing fragmentation among EU donor aid programs and projects through joint preparation of country strategies with EU bodies, EU countries, recipient governments, and non-EU donors. As a result, the EU decided to focus on rule of law, health, education, and infrastructure for WASH, as well as food security. LRRD was embedded as a core principle for implementation with these sectors.

\section{Japan}

Japan pledged US\$100 million at the 2005 Oslo Conference for the first phase of JAM for both North and South, including the Three Areas. Japan channeled aid bilaterally not to MDTFs, but via JICA and through UN agencies. ${ }^{13}$ The total amount of technical cooperation provided to South Sudan by JICA from 2005 to 2011 was about US $\$ 58.97$ million (JICA 2013, 68).

The Japanese government recommenced development aid to Sudan in April 2005. JICA started discussions with SPLM officials in Nairobi in 2004, and formal engagement recommenced in May 2005 following an international cooperation seminar in Japan to which administration officers from the North and South were invited. The final report of the emergency study on planning and support for 'Basic Physical and Social Infrastructure in Juba Town and Surrounding Areas' suggested 25 projects in 8 areas, mainly infrastructure, such as road networks, water supply facilities, education facilities, and health centers (JICA, Katahira \& Engineers International and Japan Engineering Consultants 2007). Along with these infrastructure projects - JICA's traditional area of expertise-JICA started a vocational training capacity-building project in the Juba Multi-Service Training Center. One of the features of JICA's continuum approach in the 2005 CPA period was ensuring 'visible and tangible results' by combining fast onset (vocational training) and slow onset projects (infrastructure), with a central focus on infrastructure projects, so South Sudanese people could become aware of a tangible peace dividend (JICA 2013, 69).

\section{Comparative analysis}

Until the 2013 Crisis, to a large extent, donors repeatedly invested aid in South Sudan's development and state-building with great enthusiasm (Harvey 2009), 'blind optimism' (Maxwell et al. 2014) or 'the mantra that only development could bring peace' (Hemmer and Grinstead 2015). Especially in terms of development assistance, donors funded infrastructure, basic services, and social protection through the GoSS and provided capacity- and institution-building projects for government officials. As international engagement ultimately shapes state-building, shifting never-ending humanitarian relief to recovery came to be an important issue; however, considerable effort was put into state-'frame' building and development as the main drivers of recovery. This foreseeable 'state' is considered essential in preventing relapse into conflict and precipitating another humanitarian crisis. 


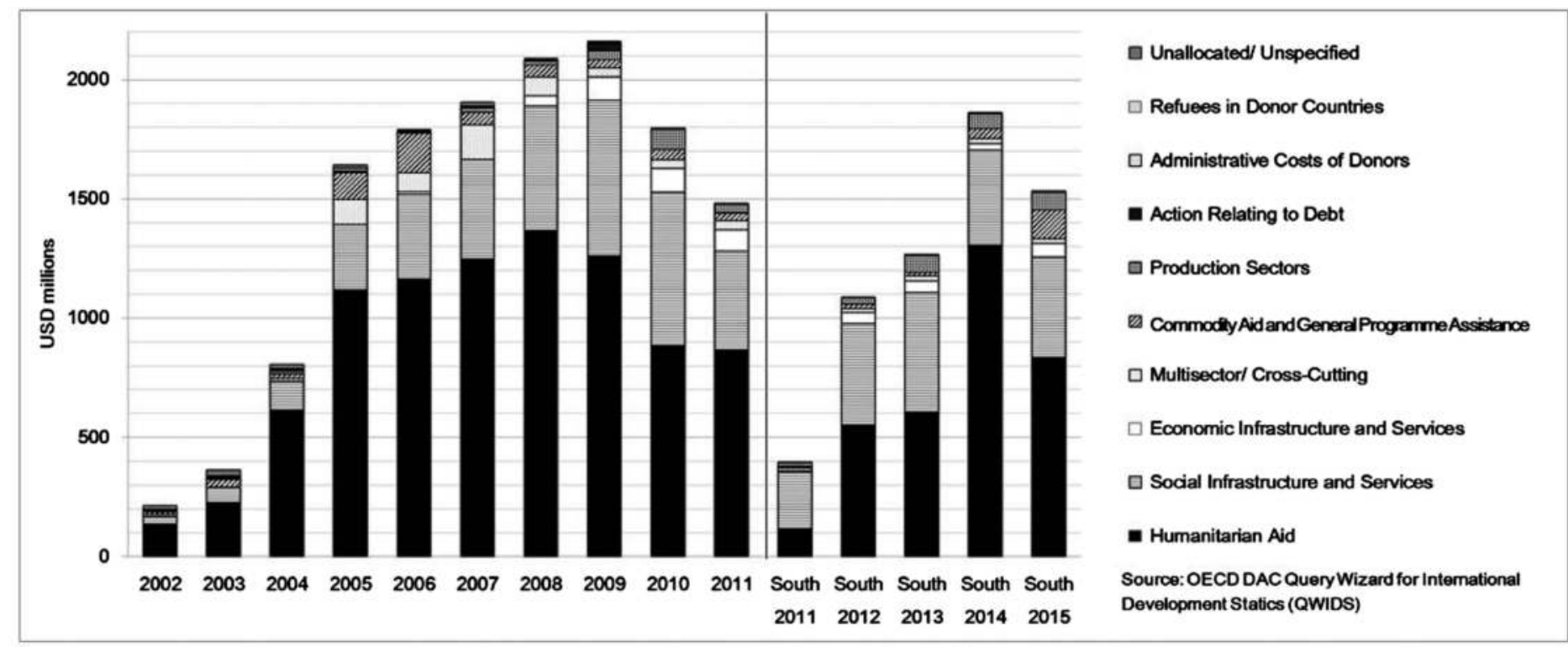

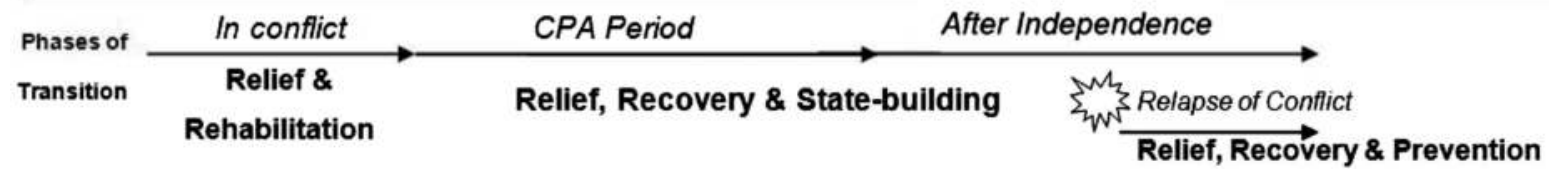

Figure 5.2 Total assistance to Sudan (2001-2011) and South Sudan (2011-2014) by DAC countries and EU institutions across phases of transitions. Source: authors, based on data from OECD QWIDS. 
Besides the mainstreaming of state-building, the fact that focus of aid changed constantly over a short period of time was a characteristic of this phase. Humanitarian assistance made up the largest part of the total amount of donor commitment up until 2010; however, the focus gradually shifted to development assistance after independence in 2011, especially in the terms of social infrastructure (Figure 5.2). However, the suspension of oil production in January 2012 and ensuing financial crisis caused another shift as the focus of donor assistance returned to humanitarian issues. With the resumption of oil production in September 2012, donor focus reverted to development. Donors responded well to the changing nature of complex emergencies like South Sudan; however, the changing nature of the conflict itself made it difficult to implement consistent aid programs.

Although the 2005 CPA aid mechanism explained in the section above was prepared by JAM and backed by MDTFs, many criticized the strategic gap in the early recovery phase. There was little evidence of a strategy that encompassed political, security, development, and humanitarian tools across bilateral and multilateral actors (Chandran, Jones and Smith 2008; Harvey 2009). As time has passed, JAM has lost its importance as an operational strategy. If it is assumed that one voice is ideal, a myriad of complex bilateral and pooled fund mechanisms with too many leaders was an obstacle to greater strategic coherence. However, looking at each donor's approach, there were relatively useful strategies for linking relief and development in coordination and funding mechanisms. The US and Japan did not use pooled funds but provided 'early recovery' programs for the continuum bilaterally, while the EU tried to realize the continuum through pooled funds and coordination among EU players.

\section{Donor engagement in the post-2013 crisis: the state-building to community approach?}

\section{After the relapse into conflict}

Many of those interviewed for the study in January 2016 noted that it was very important that the humanitarian and development communities agree on addressing the continuum in South Sudan. In spite of more than 20 years of support provided to the government for capacity-building and long-term development, they have been disappointed by the unbreakable vicious cycle of delayed peace processes, recurring violence, and worsening humanitarian crises (Hemmer and Grinstead 2015).

Bilateral donors other than Japan have adopted the stance of not recognizing the South Sudan government as a credible development partner, and full-scale development aid mediated by the central government is currently in abeyance. The US, along with the UK and Norway, has continuously supported peace negotiations. However, on March 28, 2015, the Security Council adopted Resolution 2206, condemning the flagrant violations of the Cessation of Hostilities Agreements in 2014 signed between the GoSS and the SPLA-IO 
(SPLA-in-Opposition) and decided on targeted sanctions against individuals and entities who engaged in violent acts. The US had been working on the resolution out of frustration with the lack of progress in the 14-month-long peace process. As a result, they had no choice but to continue with mainly humanitarian aid. While donors in Juba are sharing information, as of January 2016, they are not yet in a position to coordinate development aid.

\section{Donor engagement}

\section{United States of America}

Regarding coordination within donor countries, the US being the largest aid donor, has adopted a comprehensive approach to 'crisis response.' The cooperation made between USAID staff that deal with diplomats within the embassy, OFDA staff within USAID that specialize in humanitarian aid, various specialists in public order, humanitarian aid, and conflict analyst and DART (Disaster Assistance Response Team), has been activated since the 2013 crisis. DART provides the spearhead for crisis management, coordinating directly with OFDA Washington. By authorizing independent decision-making for relief, DART strengthens the American government's crisis response capability. According to a DART staff member, the system does function more flexibly and effectively in times of crisis. As such, they endeavor to make parallel relief and recovery work feasible, hoping to turn in results that constitute a single comprehensive and coherent USAID approach.

\section{The European Union}

Within the EU, it appears difficult to adapt the model for the relief-to-development continuum for natural disasters and food security to a complex emergency like South Sudan. The traditional recognition of organizational differences between development approaches and ECHO's strategy, rules, funding, mindsets and philosophy persists. According to some interviews, aid workers in the field recognize there are organizational gaps - in principles, program cycles, and organizational culture - between the humanitarian and development communities. Acting on an EU headquarters initiative, ECHO and the EU delegation of South Sudan carried out a Joint Humanitarian and Development Framework (JHDF) to promote strategic talks between the humanitarian wing (ECHO) and the development/political wing of the EU delegation. The JHDF tried to create a framework for information sharing and common assessment and identify possibilities to complement programs in a cooperative manner. However, this approach was found to be too systematic. One interviewee said that, especially in a complex emergency like South Sudan, phases are non-linear and issues differ from place to place; thus, the attempt to systematize the collaborative work between humanitarian and development aid is ideally good but, in practice, would not work easily in the field. Moreover, as the example of the JHDF shows, the gap between 
the headquarters and field offices is far from small. For the field officers, attempts to systematize collaborative work between independent actors in foreign policy, development, and humanitarian areas are ideally good but not easily applied in practice. Since the suspension of development aid, ECHO has resumed its role as the main EU actor, the same role it undertook in the OLS era.

\section{Japan}

Japan has a small number of officers in the embassy - with no special analysts for conflict, humanitarian relief, or development - while the JICA office is sited elsewhere in Juba. There are coordination meetings and ODA task force meetings between JICA and the embassy, but these are for information-sharing rather than working collaboratively to integrate relief and development work across the continuum. The approach is divided into humanitarian aid, dealt with by the embassy through allocation of the supplementary budget to international organizations, and development programs implemented by JICA. A pilot project of concerned parties in communal conflict analysis - started as a part of JICA's agricultural master plan - has the potential to become a project aimed at conflict prevention.

In contrast to the stance of the Western donors, the Japanese government has taken a long-term perspective, emphasizing patient association with the South Sudanese government. Japan has adopted a different, independent response compared to the 1990s when it acted in concert with Western donors and suspended its support. Without a specialized government agency for humanitarian relief in cases of armed conflict Japan is attempting to include a perspective on implementing the continuum when the Japanese Embassy in Juba processes aid proposals by international organizations. It does this by trying to take into account both short-term relief and medium-to-long-term recovery and prevention perspectives when the Japanese Embassy in Juba processes aid proposals by international organizations. On the other hand, development assistance has been implemented through the continuing support of JICA, which particularly emphasizes 'economic development' by providing high-quality infrastructure and detailed agriculture master plans. As a result, Japan could be regarded as supporting the continuum through the demarcation between MOFA's grant aid for international organizations and JICA's humanitarian relief and development support.

\section{Comparative analysis}

Donor plans for closing the gap between relief and recovery are moving toward a focus on community-centered livelihood improvement and conflict prevention. This is the first time that conflict prevention has become the main focus since the CPA, with donors adopting similar ideas to those employed during the OLS period. As a decision on assistance through the central government is still pending, program targets have turned to the improvement of 'resilience' at 
the community level. Unlike what has been done since the 2005 CPA period, this is not a state-building approach through the central government, but what is now referred to as 'resilience' support, intended to boost the inherent coping abilities of people living in regional communities. It implies an understanding that future shocks will occur. In particular, USAID, International Organization for Migration (IOM), WFP, and JICA are taking an approach that combines food security and livelihood improvement support with conflict prevention and resolution. 'Conflict' here does not refer to the disputes between the SPLA and SPLA-IO, but to community-level conflicts (resource-dependent communal conflicts such as cattle raiding). Actions aimed at increasing self-reliance through improvements in food-security show similarities to the OLS period but, in their more recent incarnation, they are designed to prevent communal conflict and combine livelihood and peacebuilding at the community-level. It could be said that these efforts have been developed in response to the criticisms of previous aid programs, which paid insufficient attention to the connections between relief, recovery, and conflict prevention, rather than just relief.

Such community-based approaches show donor awareness of the dangers of aid dependency through large and continuous aid investment and service delivery by NGOs. As a result, while the humanitarian needs are not acute, conditional approaches such as 'food for assets' or 'food for education' have also been adopted. Moreover, community-based approaches are expected to encourage an improvement of local governance (bottom-up governance reform) through community support. These approaches have broadened the relief-to-development continuum into donor funding, such as the WFP's Food for Assets and the IOM's Abyei Rehabilitation Initiative funded by USAID (USAID and IOM 2014, 2015) and the Peace and Stabilization Quick Impact Fund financed by the EU. Currently, a new call for papers is being issued, and the ECHO Humanitarian Implementation Plan (HIP) Sudan and South Sudan, as well as the UK, the US, Germany, Switzerland, and Canada, are contributing to the South Sudan Conflict Sensitivity Programme. ${ }^{14}$ This fund is receiving attention for its 'not business as usual' awareness and due to the need for a special approach different from that taken until now in South Sudan (Hemmer and Grinstead 2015). There are plans to share conflict analysis data and a conflict resolution framework, and to start a Conflict Sensitivity Resource Facility and Conflict Sensitivity Forum. In other words, relief, recovery, and development, along with conflict prevention, are the trend of movement along the continuum in South Sudan.

According to some interviewees, there is also hesitation to form resilience programs and program cycles. Resilience programs should target medium- to long-term objectives, but humanitarian agencies should - ideally — not stay long. In addition, there are differences between donors in how key concepts, such as humanitarian relief and resilience, are understood and applied. For example, in terms of the meaning of 'localization,' humanitarian agencies tend to think of this as being based in local 'communities' or 'people'; one the other hand, the development sector often takes 'local' to mean 'state authorities.' There are other examples of considerable variances in basic perceptions. 
In order to narrow the differences in mandates and policies between donor countries, understanding and cooperation at the ministerial level is essential. For example, in Japan, in order to acquire a supplementary budget, it is necessary to lay the groundwork with the Africa Bureau and the Economic Cooperation Bureau of the Ministry of Foreign Affairs, and to persuade the Ministry of Finance. In the United States, there is the USAID/OFDA Rapid Response Fund that works as a fund to close the gap between relief and recovery. As it is able to direct quick funding to IPs, the fund has been praised as especially useful by IPs. The maximum amount allowable under the fund is US\$300 million with a very rapid three-week screening process. The DART mechanism enables it to adapt to many programs at once, and the standard length of a project is three months - with further extensions possible after review. Close cooperation between Washington and DART, bypassing the regional office in Nairobi, is an arrangement that gives decision-making power to the local DART and increased flexibility to the Rapid Response Fund approval process. Furthermore, cooperation with and implementation of FFP relief within DART has increased responsiveness and flexibility during crisis responses. The EU diplomatic mission has an officer to manage the Instrument contributing to Stability and Peace ( $\mathrm{IcSP})$ but this is not a position that coordinates the EU's development and humanitarian sectors.

\section{Conclusion}

This chapter conducted an analysis of the US, the EU and Japan's approaches to realizing the continuum in South Sudan from the early 1990s until after the 2013 Crisis. As already mentioned, approaches to the continuum were referred to as 'rehabilitation' in the early 1990s, 'rehabilitation,' 'transitional or early recovery,' and 'reconstruction' in the 2005 CPA period under a state-building process, then 'resilience' and 'conflict prevention' in the post-2013 crisis period. Thus, it is clear that bilateral donors have implemented some 'more-than-relief programs' over these past 20 years and how they were implemented.

To conclude, I would like to highlight two aspects of my findings: firstly, ways that donors introduced activities into gray area activities in South Sudan; and secondly, the motivations for bilateral donors to start such activities, or in another words, what the differentiating factors were in each donor's approach to the continuum. I will conclude by characterizing each donor's approach and describing the implications of the study.

The US was the first donor to start the rehabilitation program for the continuum in the Southern area, during a time that it was experiencing conflict. The distinctive feature of the strategy in 1993 was to undertake 'rehabilitationoriented activities' in relatively secure opposition-held areas in the South, with the goal of building the capacity of the SPLM. Adopting a different approach to the US, the EU started a rehabilitation program in 2000 for both the North and South. This was organized under the 6th European Development fund, Humanitarian Plus. A key aim of the program was to fill the gap in the legal framework for development cooperation towards Sudan. When Japan began to 
focus on the relief-to-development continuum approach - around the time of the 2005 CPA - it was somewhat behind the other two donors. Compared to the US and EU relief-to-development 'rehabilitation' programs, which consisted of many small grant projects for capacity-building related with livelihood, a feature of Japanese approach was the utilization of a development-to-recovery continuum focusing on vocational capacity-building along with an infrastructure program.

The second aspect concerned donor motivations and differentiation of each donor's approach to the continuum. Despite understanding the needs on the ground, domestic political dynamics in each donor country influenced decisions on how and when to establish a continuum program. For USAID, the commencement of the rehabilitation program was reflected in changing the strategy towards the Horn of Africa. Of course, hostile relations between the US government and the Khartoum government led to USAID activities being concentrated in SPLM/A-controlled areas. For the EU, in addition to ECHO's pressure on DEVCO and DG Relex, the assessment of the Council of Europe in 1999 could be regarded as one of the causes of the decision to use the development fund to set up the 'more-than-relief' program. In the case of Japan, it was difficult to implement recovery or development activities during the 1990s following the suspension of ODA, the lack of a humanitarian implementation agency, and the region's high sensitivity to operational safety concerns. As well as addition of 'reconstruction' in its mandate, JICA has changed its internal procedures to deliver quick impact projects in the early recovery phase. As a result, the independence of the South in 2005 provided an opportunity for JICA to realize the continuum.

Comparing approaches to realizing the continuum by the US, the EU and Japan, it could be concluded that the US's approach was dependent on its political interests, the EU's approach reflected the humanitarian principles of ECHO, and in contrast to both, Japanese approach showed empathy related to their own past experiences of development in the post-conflict phases. This explains each bilateral agency's mandate but does help to determine when bilateral donors have realized the continuum and how it should be implemented. While the purpose of the continuum is to ensure that people's needs can be responded to dynamically, donor motivations for realizing the relief-to-development continuum are primarily driven by domestic political dynamics and policy changes. When state-building becomes the central item on the agenda of international actors and governments, the goal of addressing suffering among people is likely to be neglected, as donors prioritize the development end of the continuum over humanitarian activities.

It is obvious from the above examination that we should consider the political sensitivities involved in humanitarian crisis management, especially in the case of fragile states such as South Sudan. This is particularly so in areas not controlled by the government or when the government is not regarded as a credible actor. The different attitudes of donors to Sudan and southern/South Sudan are, of course, reflected in their aid approaches. Unfortunately, from the 1990s up until the present, the growing recognition of the importance of conducting morethan-relief programs has been insufficient to prompt donors to introduce such 
programs. Bilateral donors cannot retain a focus on achieving their own political goals while providing purely people-centric assistance. Donors should work towards ensuring that aid best meets the needs of the people while protecting the dignity of those who suffer the most.

\section{Update (2018)}

As mentioned in the introduction, the analytical target of this chapter covers the period of the aid situation in Southern/South Sudan before the signing of CPA in 2005 to the beginning of 2016. This chapter excluded the analysis of the situation after the violent clash between the government forces and the SPLA-IO forces during the 5 th year anniversary of their independence. According to the South Sudan Humanitarian Needs Overview for 2018 by OCHA (United Nations Office for the Coordination of Humanitarian Affairs), more than 2 million people have fled South Sudan as refugees and about 1.9 million people are internally displaced. Needless to say, the humanitarian needs for both inside and outside of the country have continued to intensify and expanded. However, it should be noted that South Sudan has various needs including that of peacebuilding and further development. Unfortunately, development aid by western donors is still suspended and humanitarian aid to support South Sudan continued to decline. At that beginning of 2018, South Sudan remains to be one of the most challenging environments for humanitarian and development actors. Therefore, the significance of realizing the continuum should take into account the assistance for those who fled from South Sudan as refugees and those who opted to stay.

\section{Notes}

1 At the end of the 1990s, Macrae et al. $(1997,224)$ defined that 'relief' operations are primarily concerned with the physical survival of individuals lives, 'developmental' activities are usually planned with respect to the sustainability and appropriateness of social and economic systems, and 'rehabilitation' assistance is assumed to have a developmental concern for promoting livelihoods and reducing future vulnerability, as well as maintaining a concern for the preservation of life.

2 The author wishes to thank all interviewees she met in Juba in February 2016.

3 Please note that the term 'Sudan' refers to the present-day Republic of the Sudan, and 'South Sudan' to the Republic of South Sudan established in 2011, whereas terms such as 'northern Sudan' or 'southern Sudan' refer to the relevant geographical regions.

4 Riek Machar was Vice-President of the Republic of South Sudan from 2005 to July 2013 and is considered to have remained in the position until replacement by Taban Deng Gai after the July 2016 violence in Juba. As of April 2017, he was in exile.

5 The data are from the table 'Bilateral ODA by Sector for South Sudan, 2013-14 average' on the OECD/DAC webpage 'Aid at a Glance: Chart for South Sudan' (https:// public.tableau.com/views/OECDDACAidataglancebyrecipient_new/Recipients?: embed $=y \&$ :display_count $=$ yes\&:showTabs $=y \&:$ toolbar $=$ no? $\&$ :showVizHome $=$ no).

6 The Sudanese Relief and Rehabilitation Association (SRRA) was established to act as the humanitarian arm of the SPLM; the Relief Association of Southern Sudan (RASS) was established in 1994 as part of the SPLM civil administration. 
7 The Clinton administration added Sudan to the list of states supporting terrorism in August 1993 and, in August 1998, a US missile hit Khartoum in retaliation for the terrorist bombing of the US Embassy in Nairobi.

8 The Commission's Directorate-General for International Cooperation and Development (DEVCO) is responsible for designing European international cooperation and development policy and delivering aid throughout the world (see http://ec.europa.eu/ europeaid/general_en).

9 The Directorate-General for the External Relations (DG Relex), which was responsible for the external policy, was merged into the European External Action Service in 2010.

10 As shown in Chapter 1, JICA has a system for dispatching disaster relief teams during natural disaster situations.

11 There are other pooled funds: the Common Humanitarian Fund, the Capacity Building Trust Fund, the Strategic Partnership Arrangement, the Emergency Response Fund, the Global Fund for HIV/AIDS, tuberculosis, and malaria, and the Basic Services Fund.

12 The Three Areas consist of Abyei, South Kordofan, and Blue Nile, located along Sudan's volatile North-South border.

13 JICA implemented the vocational training project funded by MDTFs.

14 This is being led by DFID, with a two-year pilot starting in early 2016 and the possibility of an extension to three years.

\section{References}

AfDB, OECD and UNDP. 2015. South Sudan. In African Economic Outlook 2015: Regional Development and Spatial Inclusion, 81. Paris: OECD Publishing.

Akol, Lam. 2005. Operation Lifeline Sudan: War, Peace and Relief in Southern Sudan. Accord 16, 52-55.

Anderson, Don, Barbara Herwaldt, Richard Huntington, Richard Longhurst and Brad Michaels. 1995. Evaluation of U.S. Humanitarian Assistance Strategy for Southern Sudan. Final Report. Washington, DC: Office of Foreign Disaster Assistance, USAID.

Bradbury, Mark, Nicholas Leader and Kate Mackintosh. 2000. The 'Agreement on Ground Rules' in South Sudan. Humanitarian Policy Group Report. London: ODI.

Chandran, R., B. Jones, and N. Smith. 2008. Recovering from War: Gaps in Early Action. NYU Centre on International Cooperation for the UK Department for International Development. New York: New York University.

Davies, Fiona, Gregory Smith, and Tim Williamson. 2011. Coordinating Post-conflict Aid in Southern Sudan. ODI Background Note, September. www.odi.org/sites/odi.org.uk/ files/odi-assets/publications-opinion-files/7291.pdf

Deng, Francis M., and Stephen J Morrison. 2001. US Policy to End Sudan's War. Report of the C.SIS Task Force on U.S-Sudan Policy, February. Washington, DC: CSIS.

Development Initiatives. 2015. Global Humanitarian Assistance Report 2015. Development Initiatives. www.globalhumanitarianassistance.org/wp-content/uploads/2015/10/ GHA2015P_Friendly2.pdf

EU. 2012. EU Single Country Strategy (Response Strategy) for South Sudan 2011-2013. EU. January. https://ec.europa.eu/europeaid/sites/devco/files/single-country-strategy-south-sudan2011-2013_en.pdf

Fafo Institute. 2013. Independent Evaluation of the Multi-Donor Trust Fund-South Sudan (MDTF-SS): Final Report. July 25. Oslo: Fafo Institute for Applied International Studies. Harmer, Adele. 2004. Aid to Poorly Performing Countries: Sudan Case Study. Background Paper 5 for ODI study on Poor Performing Counties, March. www.odi.org/sites/odi.org.uk/ files/odi-assets/publications-opinion-files/6153.pdf 
Harvey, Paul. 2009. South Sudan: European Commission and U.S. Approaches to Linking Relief, Rehabilitation and Development-A Case Study. In Humanitarian Assistance: Improving U.S.-European Cooperation, edited by Julia Steets and Daniel S Hamilton, 145-166. Washington, DC: Center for Transatlantic Relations, Johns Hopkins University and Global Public Policy Institute.

Haslie, Anita, and Borchgrevink, Axel. 2007. International Engagement in Sudan after the 2005 CPA: Report on the Piloting of OECD/DAC's 'Principles for Good International Engagement in Fragile States' for the Case of Sudan. Paper No.714. Oslo: Norwegian Institute of International Affairs.

Hemmer, Jort, and Nick Grinstead. 2015. When Peace is the Exception: Shifting the Donor Narrative in South Sudan. Conflict Research Unit Policy Brief, June 2015. The Hague: Netherlands Institute of International Relations.

JAM. 2005. Volume I Synthesis: Framework for Sustained Peace, Development and Poverty Eradication. March 18. Joint Assessment Mission Sudan.

JICA. 2013. Minami Sudan Kyowakoku FICA Kunibetsubunseki Pepar [JICA Country Analytical Work for the Public of South Sudan]. Tokyo: JICA.

JICA, Katahira \& Engineers International and Japan Engineering Consultants. 2007. Emergency Study on the Planning and Support for Basic Physical and Social Infrastructure in Fuba Town and the Surrounding areas in the Southern Sudan. Final Report: Executive Summary, March. Tokyo: JICA.

Karim, Ataul, Mark Duffield, Susanne Jaspars, Aldo Benini, Joanna Macrae, Mark Bradbury et al. 1996. OLS Operation Lifeline Sudan: A Review. Juba: UNICEF.

Lehtinen, Terhi. 2001. The European Union's Political and Development Response to Sudan. European Center for Development Policy Management (ECDPM) Discussion Paper 26. Maastricht: ECDPM.

Macrae, Joanna, Mark Bradbury, Susanne Jaspars, Douglas Johnson, and Mark Duffield. 1997. Conflict, the Continuum and Chronic Emergencies: A Critical Analysis of the Scope for Linking Relief, Rehabilitation and Development Planning in Sudan. Disasters 21(3), 223-243.

Maxwell, Daniel, Martina Santschi, and Rachel Gordon. 2014. Looking Back to Look Ahead? Reviewing Key Lessons from Operation Lifeline Sudan and Past Humanitarian Operations in South Sudan. Working Paper 24. Somerville, MA: Feinstein International Center, Tufts University.

MOFA, Japan. 2005. ODA Data Book by Country 2005. Tokyo: Ministry of Foreign Affairs, Japan. www.mofa.go.jp/mofaj/gaiko/oda/shiryo/kuni/05_databook/index.html

OCHA. 2013. South Sudan Consolidated Appeal 2014-2016. November 14. https://docs.unocha. org/sites/dms/CAP/CAP_2014-2016_South_Sudan.pdf

- 2014. South Sudan Crisis Response Plan 2014. June 14. https://docs.unocha.org/ sites/dms/CAP/Revision_2014_South_Sudan_CRP_June_2014.pdf.

2015. South Sudan: Humanitarian Response Plan (January-December 2016). http:// reliefweb.int/sites/reliefweb.int/files/resources/2016_hrp_SS_Final_WEB.pdf

OFDA. 1998. BHR/OFDA Annual Report for Fiscal Year 1998. Washington, DC: USAID.

- 2007a. Annual Report for Fiscal Year 2007. Washington, DC: USAID.

2007b. OFDA Sudan (Excluding Darfur) Public Guidance for Potential Partners 2008 Program Approach and Priorities. November 15. Washington, DC: USAID. http://pdf.usaid. gov/pdf_docs/Pdack431.pdf.

2008. Annual Report for Fiscal Year 2008. Washington, DC: USAID.

Osborne, Anna. 2014. South Sudan: Donor Response to the Crisis. Global Humanitarian Assistance, January. Bristol: Development Initiatives. 
O'Toole Salinas, A., and B. C. D'Silva. 1999. Evolution of a Transition Strategy and Lessons Learned: USAID-Funded Activities in the West Bank of Southern Sudan, 1993 to 1999. Washington, DC: USAID.

Randel, Judith, Maya Cordeiro and Tasneem Mowjee. 2004. Financing Countries in Protracted Humanitarian Crisis: An Overview of New Instruments and Existing Aid Flows. In Beyond the Continuum: The Changing Role of Aid Policy in Protracted Crises, Humanitarian Policy Group Report 18, edited by A. Harmer and J. Macrae, 54-70. London: ODI.

UNDG/World Bank. 2006. PGNA Review: Phase One. Sudan Joint Assessment Mission (JAM) Case Study 10. www.undg.org/documents/8882-Sudan_PGNA_Case_ Study___Lessons_Learned_Annex_-_Sudan_JAM_Case_Study.doc.

USAID. 2011. South Sudan Transition Strategy 2011-13. June. Washington, DC: USAID.

USAID and IOM. 2014. Abyei Rehabilitation Initiative: Project Update Fuly 2013-August 2014. Washington, DC: USAID.

- 2015. Abyei Rehabilitation Initiative: Project Update September 2014-March 2015. Washington, DC: USAID.

Van Dijkhorst, Hilde. 2013. Post-conflict Recovery and Linking Relief, Rehabilitation and Development in Angola: From Crisis to Normality?' In Disaster, Conflict and Society in Crises, edited by Dorothea Hilhorst, 241-257. New York: Routledge. 


\title{
6 The Syrian Givil War \\ Politicization of the crisis and challenges and dilemmas for humanitarian response
}

\author{
Ryoji Tateyama
}

\section{Introduction}

The civil war in Syria has become protracted, and many actors, both internal and external, have waged armed confrontations to further their own interests and agendas. The humanitarian situation continues to deteriorate. The report of the United Nations Secretary-General of September 2016 to the Security Council describes the humanitarian situation: 'month by month, as hospitals, schools and markets are destroyed and doctors, teachers and shopkeepers are killed, the Syrian Arab Republic increasingly becomes a shell of its former self' (UNSG 2016, 16). A report of the Independent International Commission of Inquiry on the Syrian Arab Republic ${ }^{1}$ issued in August 2016 states that 'there has been a marked upsurge in the fighting, with indiscriminate and disproportionate attacks on civilian-inhabited areas, particularly through pounding aerial bombardments' (UNHRC 2016).

The international community has tried to respond to the deep on-going crisis, with various humanitarian actors - including United Nations (UN) agencies, major donors, international and local non-governmental organizations (NGOs) - engaging in large-scale assistance operations. However, as no political solution is in sight, the response by the international community has been far from adequate. The war-torn and fragmented reality in Syria hinders and complicates aid operations, and humanitarian actors face a wide range of challenges.

One salient challenge is that humanitarian actors need to conduct two different types of aid operations in parallel - emergency humanitarian relief along with mid- and long-term assistance for recovery and future development. Since the early 1990s, the concept of a continuum has led to wide discussions on the utility of providing humanitarian relief in sequential phases. A. Gómez and Chigumi Kawaguchi, however, argue that in responding to a huge scale humanitarian crisis, a multi-layered approach is required rather than a linearly sequential approach, because the two phases of relief and development overlap each other and cannot be clearly separated (Gómez and Kawaguchi 2016, 30-31). In a large-scale crisis such as in Syria, indeed, affected people need both emergency relief and mid- and long-term assistance simultaneously in parallel rather than in a linear sequence. 
In order to bridge phases of emergency relief with mid- and long-term assistance, humanitarian actors began incorporating the concept of resilience into humanitarian relief about ten years ago. The Organization for Economic Co-operation and Development (OECD) defines resilience as the opposite of fragility and as 'the ability to cope with changes in capacity, effectiveness, or legitimacy' (OECD 2008, 12). Thus, resilience is not a phase-oriented approach; rather it implies that 'all activities occur in parallel' and 'a commitment to resilience pursues contiguous participation during the entire crisis' (Gómez and Kawaguchi 2016, 10).

Indeed, in responding to the Syrian crisis, the UN called for the strengthening of resilience from the early stage. In its revised version of the 2013 Syria Humanitarian Assistance Response Plan (SHARP), the UN emphasized the necessity of livelihood interventions 'in order to retain and strengthen community resilience' (UN 2013, 30). Since then, the UN has called on humanitarian actors to achieve two goals simultaneously: extending 'a lifeline to the most vulnerable people' and enhancing 'protection and strengthen individual- and community-level resilience' (UN 2015, 8).

As the crisis has deepened and become increasingly prolonged, however, the funding gap has remained huge, and demands for emergency assistance have continued to increase because of the unbroken crisis. Therefore, it is quite challenging for humanitarian actors to decide how to divide limited resources between the two types of responses.

Another difficult challenge relates to politicization. In humanitarian conflicts, almost all actors - both internal and external - politicize everything, even humanitarian access, for their own tactical and strategic interests and advantages. In the Syrian case, the regime and other armed actors deliberately restrict aid access for political and tactical gain. Consequently, apolitical organizations, such as UN humanitarian agencies and international NGOs, are obliged to operate in a highly politicized environment. Major donors also provide assistance within political contexts, particularly with the goals of facilitating a political transition and state-building. These political objectives may obscure the primary goal of humanitarian relief operations.

In this chapter, I first provide an overview of the Syrian civil war and the humanitarian crisis. In the following sections, I explore responses to the crisis inside Syria by UN agencies, major donors (mainly the United States (US), European Union (EU) and United Kingdom (UK)), and their bilateral agencies. I focus particularly on restrictions on humanitarian access, cross-border assistance and remote management, and issues relating to emergency relief assistance and resilience building. Finally, I discuss three issues:

1 dilemmas between adherence to the humanitarian principles and continuation of aid delivery;

2 obstacles caused by the remote management approach; and

3 political objectives set by major donors and their impacts on humanitarian relief. 
In doing so, I try to explore tensions and dilemmas caused by conflicting relationships between humanitarian relief and politicization. The mass influx of Syrian refugees has had enormous impacts on host countries and communities. However, because the refugee crisis has already been widely discussed, I will not explore refugee issues in this chapter.

My study is based on literature research in related fields, plus field research in Lebanon and Jordan in September 2015 and in Turkey in March 2016. During my field research, I conducted 43 semi-structured interviews with officials from UN agencies, government departments, and bilateral agencies, staff of international NGOs, and academics. Corresponding to the time of my field research, this chapter mainly covers the situation until 2016.

\section{The civil war in Syria and humanitarian crisis}

\section{Prolonged armed conflict and fragmentation}

The so-called 'Arab Spring' in Tunisia at the end of 2010 triggered popular social movements in many Arab states, which demanded social justice, economic and political reforms, and democratization. Syria was not an exception. Since March 2011, protest movements against the regime under Bashar al-Assad spread rapidly across the country. Violent suppression by the regime led to the widespread-armed conflict between government forces and opposition groups. In April 2011, the UN Human Rights Council adopted a resolution condemning 'the use of lethal violence against peaceful protesters' by the Syrian authorities and requested the Office of the United Nations High Commissioner for Human Rights to dispatch a mission to investigate alleged violations of international human rights law (UNHRC 2011).

The armed confrontation inside Syria, however, continually escalated to the extent that, in June 2012, the UN Under-Secretary-General for Peacekeeping Operations, Herve Ladsous described the situation in Syria as a 'civil war.' It was the first time that a senior UN official used a term 'civil war' to characterize the situation in Syria (Reuters 2012).

There have been some diplomatic attempts to bring about cease-fires or cessations of hostilities among major external actors. In line with negotiations between the US and Russia, the UN Security Council adopted Resolution 2254 in December 2015, expressing support for a political transition program based on the agreement of the International Syrian Support Group (ISSG). ${ }^{2}$ Nevertheless, attempts to implement cease-fires and a political transition have failed to bring about the intended results. Rather, the crisis in Syria has prolonged and increasingly deteriorated mainly for the following reasons.

First, government forces have never been strong enough to overcome opposition forces despite the support provided by Iran and Hezbollah. Since Russia started its military intervention, taking the side of the regime in September 2015, the regime has been on the offensive. Even so, the regime faces serious weaknesses, including lack of legitimacy and insufficient human resources. 
Second, anti-regime groups have never been united; rather they pursue their own interests. Anti-regime groups organized the Syrian National Council (SNG) in October 2011 as an umbrella organization. Defectors from the national army also formed the Free Syrian Army (FSA). In November 2012 in Doha, Syrian opposition factions formed another umbrella organization, the National Coalition for Syrian Revolutionary and Opposition Forces, also known as the Syrian Coalition. In a meeting of the Group of Friends of the Syrian People in December 2012, the US, most European countries, Japan, and other regional states acknowledged the Syrian Coalition as 'the legitimate representative of the Syrian people and the umbrella organization under which Syrian opposition groups are gathering' (Group of Friends of the Syrian People 2012, para.13). The Syrian Coalition established the Syrian Interim Government in March 2013.

However, opposition groups and forces have remained deeply divided along various lines, such as tribes, localities, ethnicities, sects, and different interpretations of Islam. Therefore, almost all opposition groups have retained a strong local orientation and do not share common ideologies, objectives, or even strategies. Support by external actors has further divided anti-regime forces, with some regional actors - including Saudi Arabia, Qatar, and Turkey - providing different rebel groups with funds and, in all likelihood, weapons for their own agendas.

Third, the UN Security Council is not functioning well because of the deep disagreement between the US and Russia over a possible political settlement to the crisis. For instance, in April 2012, the Security Council adopted Resolutions 2042 and 2043. Based on the resolution, the United Nations Supervision Mission in Syria (UNSMIS), an unarmed monitoring team, was deployed in Syria. However, the mission could not make any substantive contribution because of its restrictive mandate and the insecure situation on the ground, and it ceased activities after four months.

Fourth, the emergence and presence of two transnational jihadist groups, the Islamic State in Iraq and Levant (ISIL) ${ }^{3}$ and the Nusra Front (Jabhat al-Nusra), ${ }^{4}$ have further complicated the fragmented situation, worsening the humanitarian crisis. Since September 2014, the US and its allied forces have been conducting air raids on ISIL positions. In addition, both the Syrian government and opposition forces have attacked ISIL. Despite being defensive, however, ISIL has continued to hold large swathes of territory and has committed atrocities against civilians.

As a result, the country has broken into many pieces, each of which is controlled by different groups, including the regime, Kurds, ISIL, the Nusra Front, and other rebel groups.

\section{Deep humanitarian crisis}

The prolonged and highly intensified violence and fighting have resulted in a very serious humanitarian crisis. According to an estimation of United Nations Office for the Coordination of Humanitarian Affairs (OCHA) over the last five years, more than 250,000 people have been killed and more than 1.2 million 
injured (OCHA 2016a, 30). Another estimation, however, puts the number of casualties at 470,000 (PBS 2016). ${ }^{5}$

Furthermore, as of December 2016, OCHA estimates that 13.5 million, including 5.8 million children, are in need of humanitarian assistance, with 4.9 million of these people living in hard-to-reach and besieged areas. OCHA estimates that the number of internally displaced persons (IDPs) has reached 6.3 million (OCHA 2016e, 7). In addition, some 450,000 Palestinian refugees registered with United Nations Relief and Works Agency for Palestine Refugees in the Near East (UNRWA) have suffered severely during the prolonged crisis.

The humanitarian tragedy has deepened further because the various armed groups have deliberately targeted civilians for tactical and political purposes. A report issued by the Independent International Commission of Inquiry on the Syria Arab Republic listed a number of different types of human rights violations and possible war crimes, such as long-term sieges, assaults on medical care, hostagetaking, torture, and sexual violence (UNHRC 2016). These violations have been committed by different armed groups, including the government, ISIL, and others. Of these, however, the Assad regime has allegedly committed the most violations of international human rights law. Ban Ki-moon, the UN Secretary-General, strongly condemned the Syrian government, saying that 'many groups have killed innocent civilians - none more so than the government of Syria, which continues to barrel bomb neighborhoods and systematically torture thousands of detainees,' in the UN General Assembly in September 2016 (AP 2016).

It has been reported that the regime forces have deliberately attacked civilian targets, including schools and health facilities, in rebel-held areas in order to prevent emergence of alternative governing bodies in territories that the regime has lost to rebels (Khaddour 2015). Between April 2011 and November 2016, according to Physicians for Human Rights, 454 attacks on medical facilities were recorded, and more than 796 health care personnel were killed. Of these, regime forces were responsible for 307 attacks on facilities (68\%), with 675 personnel killed (85\%) (Physicians for Human Rights undated).

The regime has also been responsible for imposing sieges on hundreds of thousands of civilians. In his statement to the UN Security Council in May 2016, Stephen O'Brien, the UN Undersecretary General for Humanitarian Affairs and Emergency Relief Coordinator, announced the breakdown of people under siege: 452,700 , or 76.4 percent, were besieged by regime forces. In addition, 110,000 were besieged by ISIL and 20,000 by non-state armed groups and the Nusra Front (OCHA 2016b, 2). The Syria Institute, however, estimated that as of July 2016, the number of civilians under siege was more than one million in at least 40 besieged areas (Syrian Institute and PAX 2016, 8). Due to these different estimations, which I will discuss later, OCHA has been criticized on the grounds that it has deliberately underestimated the number of people under siege due to pressure from the Assad regime (Sparrow 2016). ${ }^{6}$

The refugee crisis in neighboring and European countries has also caused serious problems, both for refugees themselves, and for host countries and communities (see Table 6.1). The magnitude of the mass refugee influx into neighboring 
Table 6.1 Number of Syrian refugees in neighboring countries (thousands).

\begin{tabular}{lrrrrrr}
\hline & 2012.1 & 2013.1 & 2014.1 & 2015.1 & 2016.1 & 2017.1 \\
\hline Turkey* & 9.5 & 174 & 560 & 1,553 & 2,504 & 2,855 \\
Lebanon & 6.3 & 131 & 811 & 1,148 & 1,069 & 1,011 \\
Jordan & 2.9 & 120 & 582 & 623 & 635 & 655 \\
Total** & 18.7 & 520 & 2,332 & 3,718 & 4,595 & 4,855 \\
\hline
\end{tabular}

Source: author, based on data from UNHCR (http://data.unhcr.org/syrianrefugees/country. php?id=107).

Note: *Numbers of registered refugees with the Turkish government.

** Numbers include refugees in Iraq, Egypt, and other part of North Africa.

countries has exceeded the capacity of host countries and communities to manage the refugee crisis.

While the refugee crisis is beyond the scope of this paper, I do need to point out one negative impact that the refugee crisis may create in a post-conflict process. While many refugees will most likely help by contributing financially or by other means to a reconstruction process, the outflow of millions of people means that Syria will be deprived of significant human resources for a very long time to come. There is a general tendency towards increasing numbers of refugees living in exile for many years, with the average length of exile around 17 years (Betts and Collier 2015, 92). The Syrian refugees are unlikely to be an exception to this trend, and it is therefore estimated that a majority of refugees will remain in host or third countries. In addition, many children of refugees and IDPs receive neither formal nor informal education. The growing number of the lost generation of unschooled children is likely to be a serious problem for a long time.

\section{Response by the international community inside Syria}

\section{UN operations and constraints caused by politicization}

Assistance operations inside Syria conducted by various humanitarian actors can be categorized into three types based on targeted areas:

1 regime-held areas from Damascus;

2 cross-line assistance to opposition-held areas from Damascus (i.e. across lines between conflicting parties); and

3 territories held by either the regime or opposition groups from neighboring countries as cross-border assistance.

A large portion of cross-border assistance is carried out from two major hubs: Gaziantep, Turkey, and Amman, Jordan. In addition, a small portion of crossborder assistance is also conducted from Lebanon and Iraq.

From the outset of the violence in Syria, UN humanitarian agencies, the International Organization for Migration (IOM) and international NGOs began humanitarian relief operations in order to provide affected people with emergency 
relief. In December 2012, they launched the 2013 Syria Humanitarian Assistance Response Plan (SHARP), which was later revised in order to address further large-scale humanitarian needs inside Syria. From the Syrian side, the Syrian Arab Red Crescent (SARC) has played an important role in humanitarian assistance by providing volunteers for aid deliveries. SARC also approves and oversees all operations and acts as an implementing partner for international humanitarian organizations in government-controlled areas (Howe 2016, 13).

UN agencies have faced a wide range of difficulties and obstacles caused not only by intense armed confrontations and constant changes in the situation but also by politicization of the humanitarian crisis. As discussed in the previous section, the humanitarian crisis in Syria has been highly politicized by warring forces and external actors. The Assad regime, in particular, has been criticized on the grounds that it has 'weaponized' humanitarian needs by withholding access and preventing aid from reaching those in need in order to 'punish and weaken opposition groups' (Berti 2016).

In territories under its control, the regime has tended to give consent to, and even provide, cooperation for humanitarian operations in order to mobilize popular support. As a deliberate strategy, however, the regime restricts aid deliveries to territories controlled by opposition forces, causing a serious dilemma for UN agencies: between respecting Syria's sovereignty or attempting to continue their full operations outside of government-held areas.

The UN system has an established principle of respecting the sovereignty of any affected country where UN agencies provide humanitarian assistance. UN General Assembly Resolution 46/182 of 1991, which governs humanitarian emergency assistance by the UN, explicitly states the importance of respecting the sovereignty of the affected country as one of the guiding principles, as follows:

The sovereignty, territorial integrity and national unity of States must be fully respected in accordance with the Charter of the United Nations. In this context, humanitarian assistance should be provided with the consent of the affected country and in principle on the basis of an appeal by the affected country.

(UN 1991, Annex I, para. 3)

In fact, SHARP was prepared 'in collaboration with the Government of Syria,' with the agreement further stating that 'humanitarian partners renew their commitment to deliver humanitarian aid with full respect to the sovereignty of the Syrian Arab Republic' (UN 2013, 8). Therefore, UN agencies should conduct operations with the consent and cooperation of the Assad regime not only for safe operations but also for respecting Syria's sovereignty.

In order to reach the people in need, the UN and other humanitarian agencies have repeatedly demanded that the Assad regime provide its consent and guarantee humanitarian access, and to lift obstructions to relief access. For instance, the third report of the Independent International Commission of Inquiry on Syria of August 2012 asked the Syrian government to 'grant the international community immediate access to the affected areas to provide humanitarian assistance' (UNHRC 2012, para. 153). In October 2013, the UN Security Council issued 
a Presidential Statement urging Syrian authorities to 'take immediate steps to facilitate the expansion of humanitarian relief operations, and lift bureaucratic impediments and other obstacles.' The statement further urges the Syrian authorities to promptly facilitate 'safe and unhindered humanitarian access to people in need, through the most effective ways, including across conflict lines and, where appropriate, across borders from neighboring countries in accordance with the UN guiding principles of humanitarian emergency assistance' (UNSC 2013, 3).

However, the Assad regime has maintained strict restrictions on UN agencies' operations and the situation has continued to deteriorate.

\section{UNSC Resolution 2165 of 2014}

In response to this situation, the UN Security Council adopted Resolution 2165 in July 2014. The resolution authorizes UN humanitarian agencies and their partners to use routes across conflict lines and two border crossings in addition to those already in use 'in order to ensure that humanitarian assistance, including medical and surgical supplies, reaches people in need throughout Syria' (UNSC 2014, para 2). The UN Security Council has renewed Paragraph 2, making use of follow-up resolutions.

With the passage of the resolution, UN humanitarian agencies launched the 'Whole-of-Syria' approach in September 2014. The main objective of the Wholeof-Syria was to integrate separate operations into a single framework, in order to 'maximize efficiency, reduce duplication, and ensure greater accountability, effectiveness and reach of humanitarian programming' (OCHA undated). Based on UN Security Council Resolution 2165 and the follow-up resolutions, UN humanitarian agencies have expanded their cross-line assistance from Damascus and cross-border assistance since July 2014.

According to OCHA, seven UNagencies dispatched 505 convoys of 13,091 trucks for cross-border assistance from July 14, 2014, to February 2017 (OCHA 2017). As Table 6.2 shows, millions of people have benefited from the UN Security Council Resolutions since the adoption of Resolution 2165.

Table 6.2 Number of beneficiaries by cross-border operations of the UN and its partners, July 2014 to February 2017 (thousands).

\begin{tabular}{|c|c|c|}
\hline Sector & Beneficiaries & Items \\
\hline Health & 12,231 & $\begin{array}{l}\text { Emergency health kits, surgical kits, reproductive health } \\
\text { kits, midwifery kits, medical consumables }\end{array}$ \\
\hline $\begin{array}{l}\text { Non-food } \\
\text { items }\end{array}$ & 3,540 & $\begin{array}{l}\text { Dignity kits, blankets, jerry cans, kitchen sets, sleeping } \\
\text { mats, mattresses, winterization kits, tarpaulins }\end{array}$ \\
\hline Food & 3,261 & Food baskets \\
\hline Wash & 2,826 & $\begin{array}{l}\text { Basic water kits for families, water purification tablets, hygiene } \\
\text { kits for families and babies, sanitary napkins, diapers }\end{array}$ \\
\hline Education & 322 & Recreational kits \\
\hline Nutrition & 28 & Supplementary spreads \\
\hline
\end{tabular}

Source: author, based on OCHA (2017). 
Even so, however, UN cross-line and cross-border operations have been constrained not only by active conflict and insecurity but also by politicization by the regime. In order to respect the sovereignty of Syria, as discussed in the previous section, the UNSC resolutions oblige UN agencies to notify the Syrian authorities in order to receive the latter's approval for aid deliveries. In many cases, however, the Syrian authorities creates 'bureaucratic blockages' (UNSC 2016, para. 39), such as rejecting approvals, demanding amendments, delaying procedural processes, and requesting additional aid deliveries to areas that the regime controls.

For instance, in August 2016, the UN requested access for inter-agency convoys to 32 locations for 991,050 people, comprising 523,550 people in hard-toreach areas and 467,500 people in besieged areas. According to the report by the UN Secretary-General to the Security Council, Syrian authorities approved access to only 505,750 of those 991,050 targeted people in 23 of the 32 locations. The Syrian authorities also requested that 41 other locations outside the plan be reached in August. As a result, the report concludes, 'all in all, the United Nations was not granted access to more than 50 percent of the requested beneficiaries' (UNSC 2016, para. 26).

\section{Cross-border assistance and remote management}

In addition to UN agencies, international and local NGOs, major donors and their bilateral agencies have provided humanitarian assistance inside Syria mainly through cross-border activities for civilians in areas held by opposition groups. Because NGOs do not necessarily have to respect the sovereignty of Syria, they commenced their own cross-border efforts from Turkey and Jordan immediately after armed confrontations erupted in 2011 in Syria. Since then, they have expanded their operations.

According to OCHA, as of February 2016, 50 International NGOs and more than 100 Syrian NGOs provided aid to Syria from Turkey (OCHA 2016c, 3). In fact, 80 percent of cross-border operations from Turkey were conducted by NGOs (author's interview with an OCHA official in Gaziantep, March 10, 2016). For instance, the Turkish Red Crescent began its cross-border operations in 2011 to provide humanitarian supplies, such as food, medicines, and tents, through local Syrian NGOs (author's interview with an official of Turkish Red Crescent in Ankara, March 9, 2016). Médecins Sans Frontières (MSF) has operated medical facilities and has supported clinics inside Syria since August 2011, mainly through Syrian medical networks and field hospitals (MSF 2015, 2).

Bilateral agencies have also conducted cross-border assistance. The United States Agency for International Development (USAID) has assisted Syrian partner organizations in different sectors, such as agriculture, food security, economic recovery, health, information management, protection, and the Water, Sanitation and Hygiene Program (WASH) (USAID 2015a, 7). The UK's Department for International Development (DFID) and EU's European Civil Protection and Humanitarian Aid Operations (ECHO) have also provided a number of actors with funds for cross-border operations. 
The Group of Friends of the Syrian People established the multi-donor Syria Recovery Trust Fund (SRTF), which funds projects inside Syria. The SRTF states that its purpose is to reduce the suffering of the Syrian people and assist the National Coalition for Syrian Revolutionary and Opposition Forces (the Syrian Coalition; Syria Recovery Trust Fund undated). As mentioned above, the Group of Friends of the Syrian People has recognized the Syrian Coalition as the legitimate representative of the Syrian people since 2012.

While cross-border operations make a vital contribution to assisting millions of civilians in need inside Syria, humanitarian organizations have faced increasing difficulties and risks to secure their operations because the situation in Syria has further deteriorated and fragmented into small territories controlled by different armed groups.

Against the backdrop of these difficulties and risks, most cross-border operations are implemented through remote management. Remote management has developed in places where international organizations cannot operate due to limited humanitarian access or lack of government permission in a conflictaffected country. Thus, international organizations, which are usually based in neighboring countries, manage operations and local staff and/or partners implement projects. Because of the physical distance between management sides and implementation sites, remote management leads to a number of serious problems, particularly relating to monitoring, reporting, and accountability. International staff may also lose touch with the reality of implementation sites over time.

In addition, constant changes on the ground further complicate remote management. Humanitarian operations through remote management are usually implemented in opposition-held areas. However, confrontation lines are not necessarily fixed but rather shift from time to time. Thus, a targeted area of operations may be captured and controlled by the regime forces or their affiliates. In such cases, operations may need to be suspended (author's interview with an official of a bilateral agency in Ankara, March 7, 2016).

Furthermore, such shifts in confrontation lines are likely to cause additional risks for local staff and partners because the regime forces or their affiliates may 'punish' local staff and partners due to the latter's collaboration with international organizations without permits from the government. As a result, there is an inevitable need for secrecy to protect local staff and partners in certain aspects of cross-border operations.

Remote management also involves the ethical issue of transferring security risks from international actors to local staff and partners, because remote management only improves the safety of the international organization, and local staff continue to operate under serious risks (Howe, Stites and Chudacoff 2015, 16; Milosevich and Jalali-Shirazi 2016, 13).

Thus, such serious difficulties and challenges involved in remote management hinder the provision of humanitarian relief in the Syrian crisis. Remote management also raises important questions about relationships between international organizations and local partners, capacity-building and local ownership. I will discuss these issues further below. 


\section{Emergency relief and resilience-building}

Major donors have contributed funds to humanitarian relief both inside Syria and in neighboring countries. In 2015, the EU provided 200 million euros, about half of which went to those in need inside Syria, both through cross-line assistance from Damascus and cross-border assistance from neighboring countries (European Commission 2015b, 3).

As Table 6.3 shows, DFID provided 249.1 million pounds through various UN agencies and international and local NGOs for humanitarian relief inside Syria from 2011 to March 2014. Among those funds, £139.8 million (56\%) was allocated to UN agencies. From the fiscal year 2013 to the fiscal year 2016, the US Department of State and USAID provided about US $\$ 2.3$ billion for humanitarian assistance inside Syria (Table 6.4). In contrast to DFID, the US Department of State and USAID contributed more funds to NGOs than UN agencies.

In responding to the Syrian crisis, many donors, including the EU and UK DFID, regard resilience building as an important goal, in addition to emergency relief assistance. According to the European Commission, resilience means 'the ability of an individual, a household, a community, a country or a region to prepare for, to withstand, to adapt, and to quickly recover from stresses and shocks without compromising long-term development prospects' (Council of the European Union 2013, 1). Based on this concept, the EU regional strategy for Syria and Iraq stresses the essentiality of linking humanitarian efforts to long-term assistance as a 'means to promote resilience, recovery and post-conflict reintegration and development' (European Commission 2015a, 11).

In its operational plan for Syria, DFID has identified four 'high level' objectives one of these is to build 'resilience at the individual, community and institutional level to enable people to cope in the short term and to provide the foundation for a future political transition' (UK DFID 2014, 4).

Table 6.3 UK DFID funding inside Syria by organizations, 2011-2014 (UK£ millions).

\begin{tabular}{lr}
\hline UN agencies total & 139.8 \\
\hline IOM & 4.7 \\
FAO & 7.0 \\
OCHA & 2.3 \\
UNDSS & 0.5 \\
UNFPA & 3.0 \\
UNHCR & 10.7 \\
UNICEF & 15.8 \\
WFP & 72.2 \\
WHO & 8.0 \\
UNRWA & 15.6 \\
ICRC & 9.0 \\
Others* & 100.3 \\
Total & 249.1 \\
\hline
\end{tabular}

Source: author, based on Development Tracker (2015). Note: *Others include undisclosed humanitarian agencies. 
Table 6.4 US humanitarian assistance inside Syria, FY 2013-2016.

\begin{tabular}{lrrrrr}
\hline & \multicolumn{1}{l}{2013} & \multicolumn{1}{l}{2014} & \multicolumn{1}{l}{2015} & \multicolumn{1}{l}{2016} & \multicolumn{1}{c}{ Total } \\
\hline NGO partners & 270,821 & 330,600 & 402,623 & 421,384 & $1,425,428$ \\
WFP & 149,284 & 185,346 & 173,209 & 79,812 & 587,651 \\
UNHCR & 58,170 & & & & 58,170 \\
UNICEF & 24,000 & 24,500 & 24,350 & 35,454 & 108,304 \\
WHO & 14,000 & 13,000 & 14,646 & 17,500 & 59,146 \\
IOM & & & 10,500 & 17,940 & 28,440 \\
UNFPA & 2,796 & 4,500 & 6,000 & 6,700 & 19,996 \\
FAO & 1,000 & 1,000 & 4,866 & 2,000 & 8,866 \\
PIO partners & 2,000 & 2,000 & & & 4,000 \\
IFRC & 500 & 5,000 & & 2,000 \\
UNDSS & 3,000 & 3,000 & 3,000 & 3,000 & 1,000 \\
OCHA & 5,100 & & & & 5,000 \\
UNRWA & 2,627 & 2,456 & 1,760 & 2,597 & 9,400 \\
Administrative and & & & & & \\
$\quad$ support costs & 583,298 & 566,912 & 642,954 & 586,387 & $2,379,551$ \\
Total & & & & & \\
\hline
\end{tabular}

Source: author, based on USAID (2014, 2015b, 2016a, 2017).

Note: The table does not include funds that cannot be distinguished from those destined for Syria or for neighboring countries.

UN agencies have also emphasized the importance of building resilience in Syria. The UN's humanitarian relief plan to the Syrian crisis regards building resilience as one of its objectives, calling for humanitarian actors to 'incorporate resilience within humanitarian programming' (UN 2015, 10).

To achieve these objectives, DFID has allocated a certain portion of funds to projects relating to building resilience inside Syria, such as rehabilitation of water supply networks, psychosocial activities for both children and adults, and providing remedial classes to children who are falling behind (UK DFID 2015, 14, 23, 25). The US Department of State and USAID have also funded projects relating to resilience building inside Syria, including education, information management, and WASH (USAID 2016a, 8, 9).

However, the reality on the ground inside Syria still requires the continuation of large-scale emergency relief operations. In fact, the EU repeatedly acknowledges in its documents that almost half of its humanitarian assistance should be allocated to 'immediate life-saving emergency humanitarian operations inside Syria,' such as providing food, safe drinking water, sanitation and hygiene, child protection activities and emergency items (European Commission 2016, 3; European Commission 2017, 3).

The US Department of State also recognizes that its humanitarian assistance inside Syria will continue to provide 'critical, life-saving support,' such as emergency food assistance, medical care, cash assistance, funding for shelters and relief supply (US Department of State 2016). Like the EU, the US allocates almost half of its assistance for emergency relief activities. For instance, in the fiscal year 2016, the US government provided US $\$ 586$ million for humanitarian operations inside Syria under the programs of Foreign Disaster Assistance and 
Food for Peace. Out of this amount, US\$301 million or 51 percent was allocated to emergency relief activities, such as emergency food assistance and air delivery of humanitarian assistance (USAID 2016b, 8). The actual portion of emergency relief activities may be higher, because some funds from the remaining US $\$ 285$ million may also have been allocated to emergency relief, although it is impossible to ascertain.

With no political solution in sight and the situation further deteriorating, major donors and UN agencies will need to continue emergency relief operations on a large scale for years to come. However, available financial and humanitarian resources are limited; in fact, the funding gap has become increasingly serious. As of the end of June 2016, only 33.4 percent of financial requirements for Humanitarian Response Plan inside Syria in 2016 were met (OCHA 2016d, 3). Therefore, decisions on how to divide available resources between emergency relief assistance and resilience-building operations will remain difficult for international assistance agencies.

Remote management approaches also hamper mid- and long-term operations for resilience-building assistance. Due to problems discussed in the previous section, such as monitoring, reporting, and security risks for local partners, many donors and international NGOs tend to implement simple projects rather than complicated and time-consuming ones. In addition, constant changes caused by movement of conflict lines often force international humanitarian actors to suspend or abandon projects before completion (author's interview with an official of GIZ in Ankara, March 7, 2016).

\section{Humanitarian relief and politics}

\section{Humanitarian principles and relief activities}

As discussed above, UN agencies are facing a dilemma concerning humanitarian principles, particularly in regard to neutrality and impartiality in their operations inside Syria. While UN agencies are expected to respect the sovereignty of the state where they engage in humanitarian activities, they are also expected to abide by humanitarian principles. However, UN agencies operating inside Syria - including OCHA, World Health Organization (WHO), United Nations Children's Fund (UNICEF), and World Food Programme (WFP) - have been heavily criticized that they do not abide by these humanitarian principles because they have been strongly concerned by the prospect of reduced cooperation from the Assad regime (Lynch 2014).

Based on their analyses of food distribution by UN agencies inside Syria, José Martínez and Brent Eng have criticized UN agencies for their food distribution from the angle of neutrality. According to them, food assistance has been disproportionately concentrated in areas held by the regime, a finding that has serious political implications because food assistance provided by UN agencies has actually supported the regime's survival (Martínez and Eng 2016, 155).

Annie Sparrow also argues that, by providing billions of dollars of assistance, 'the UN has freed Syrian government resources to be used for Syrian politicians, 
troops, security forces and allies.' Accordingly, Sparrow has urged OCHA to revisit the underlying principles and stop 'supporting the atrocities of the Syrian government' (Sparrow 2016).

While these criticisms sound persuasive on the surface, the application of humanitarian principles, particularly neutrality and impartiality, is not straightforward in a war-torn setting such as Syria, where the government deliberately manipulates humanitarian access for its own strategy and interests. In addition, millions of civilians face serious shortages of food, drinking water, medicine, and other necessities. Facing such a humanitarian crisis, it is also obligatory for UN agencies to continue humanitarian operations in order to reach as many affected people as possible, regardless of where they reside. Furthermore, assisting only certain segments of people may have other political and security implications, and may undermine overall humanitarian operations.

An official of OCHA emphasized the difficulties of balancing quantities of assistance between operations based in Damascus and cross-border operations from either Turkey or Jordan because of unstable and unpredictable circumstances. This official also admitted that UN agencies were sometimes forced to 'reconcile' their activities and announcements - including statistics such as the number of people in besieged areas - with political reality in order to continue provision of humanitarian assistance (author's interview with an OCHA official in Turkey, March 2016).

Nevertheless, criticisms of the UN have continued. In September 2016, 73 NGOs that engage in humanitarian relief in the Syrian crisis suspended cooperation with the UN. The signatories of the letter sent to OCHA said that the Syrian government had a 'significant and substantial influence on the performance of UN agencies,' and criticized that the people had suffered more because of the 'deliberate manipulation by the Syrian government and the complacency of the UN' (Gladstone 2016).

This dilemma between adhering to humanitarian principles and continuing humanitarian operations under the UN guiding principle is not limited to Syria. It is rather common with humanitarian operations in any country where the central government loses its willingness to safeguard its own people suffering from a humanitarian crisis. The ICRC faces the same dilemma. To reduce this, Claudia McGoldrick states that the ICRC should take a needs-based approach, maintain proximity to the beneficiaries, and ensure engagement with all stakeholders. McGoldrick further argues that, by doing so, the ICRC can gain 'the widest possible acceptance and respect, and, through this, the widest possible humanitarian access' (McGoldrick 2011, 974, 984).

Regarding how to meet the two requirements, i.e. adhering to both humanitarian principles and continuing humanitarian assistance in war zones, Katherine Haver and William Carter suggest a more practical approach. In order to 'find acceptable compromises,' they emphasize the need for 'a more nuanced understanding of principles, including a hierarchy of principles' with humanity at the top. According to them, humanity is 'the most important principle because it expresses the fundamental goal of all humanitarian action' (Haver and Carter 2016, 37-38). 


\section{Humanitarian relief and local actors}

As discussed above, most cross-border operations for Syria have been conducted through remote management arrangements between international organizations based in neighboring countries and local actors inside Syria. In this respect, I will explore relationships between international organizations and local partners and issues of capacity-building.

Local actors differ widely in terms of types, backgrounds, agendas, activities, financial resources, and other aspects. In government-controlled areas, local NGOs, which are registered with the Syrian government, are the only ones allowed to operate. These were usually established prior to the crisis, and are strongly controlled by the government. Thus, most of them are not regarded as NGOs rooted in civil society because civil society itself did not exist either in Syria prior to the crisis nor in government-controlled areas up to the present date (author's interview with staff of a Syrian NGO based in Gaziantep, March 10, 2016). It has been reported that in government-controlled areas, so-called popular committees have been formed for the assessment of local needs, the coordination of aid, and its distribution. These committees, however, are under the regime's tight control (Meininghaus 2016, 1467). ${ }^{7}$

In opposition-held areas, different types of local actors have emerged since the eruption of the armed conflict, including local councils, local NGOs, community-based organizations, women and youth initiatives (Swisspeace, Conflict Dynamics International and FarikBeirut.net 2016, 7-12). The emergence of local councils was a reactive response in order to fill the power vacuum and lack of social services that resulted from the closure or withdrawal of government administrative institutions. They try to meet demands of the local population by maintaining security and social order, providing basic needs, such as food, drinking water, medical care, and electricity. Both local councils and NGOs function as channels for humanitarian aid flows (Meininghaus 2016, 1467). In other words, they are indispensable partners for international actors to implement various types of projects, both emergency relief as well as mid- and longterm assistance.

Most local actors, however, suffer from certain disadvantages caused by their insufficient capacity and relatively short experience because they are still newcomers and operate in extremely difficult and insecure environments. According to Rana Khalaf, local councils are not yet well established, and are 'at different stages of development, depending on their security situation, access to routes to border areas, length of time since their establishment and existence of other competing structures or spoilers' (Khalaf 2015, 46). In addition, local actors are still weak in terms of legitimacy, efficiency, and capacity (Centre for Humanitarian Dialogue 2014, 9-11, 25-26).

Nonetheless, they have strong advantages because they are firmly rooted in their own local societies. Therefore, they are able to obtain first-hand information about their communities, and are well aware of the requirements of affected populations. They have also accumulated knowledge on how to conduct their operations in wartorn circumstances. Thus, in order to engage in both emergency relief and mid- and 
long-term recovery and future development, it is essential for international organizations to establish reliable and robust relationships with local partners.

In this context, one essential task for international organizations is to undertake capacity-building for their local partners in relevant tasks, such as needs assessment, project formation and management, and reporting. Capacity-building is particularly important in remote management, because local staff members need to make many day-to-day decisions regarding project activities (Zyck 2012 , 10). Of course, it is not an easy task to build capacity of local partners located in remote areas with limited or no access. Nevertheless, a certain number of international organizations conduct capacity-building programs in different ways, including face-to-face training if possible, training a certain number local staff members as trainers for other local members, and through the internet (Centre for Humanitarian Dialogue 2014, 27).

To implement capacity-building programs, international organizations should be careful not to give the impression that they one-sidedly push capacity-building programs on their local partners because, as Howe, Stites and Chudacoff (2015, 33) warn, capacity-building approaches are 'top-down in nature.' Due to this nature, local partners tend to have a feeling that the internationals dictate areas of capacity improvements and provide mandatory trainings for these skills.

In any case, relationships between international organizations and local partners are particularly delicate in remote management due to limited communications, sometimes leading to mutual mistrust. Referring to Syrian medical NGOs, Zedoun Alzoubi points out that international donors and NGOs fail to understand the particular situation in which Syrian partners operate. Therefore, according to Alzoubi, many Syrian NGOs have criticized some international NGOs 'for deciding on the projects they want to fund rather than tailoring the projects to the needs of the people inside Syria' (Alzoubi 2015, 5).

As discussed above, local actors also differ in many aspects, and some of them have connections with armed groups. Therefore, it is hard to define 'local' in a war-torn situation like Syria. Even so, it is a fact that local actors themselves should lead self-help initiatives at the grass-root level and navigate the reconstruction process once it starts. In this context, remote management has a positive aspect as well. It helps to increase local ownership because it may bring about greater engagement by local staff in decision-making processes and skill-transfers from international to local staff (Danish Refugee Council 2015, 3).

\section{Humanitarian relief and political objectives set by major donors}

Since the end of the cold war, the international community has responded to humanitarian crises and armed conflicts as part of security policy, particularly in the context of 'failed,' 'fragile' or 'collapsed' states because such states have been perceived as threats to global peace and stability. As Charles Call argues, a prescription for these states prioritizes reinforcement of order and stability and places emphasis on 'creating states that are foremost strong security providers,' 
although each state needs different and specified approaches (Call 2008, 6). In addition, Daniela Nascimento argues that humanitarian policy has focused on 'violence reduction and conflict prevention instead of humanitarian assistance per se,' and humanitarian action is 'increasingly conditioned on geopolitical and geostrategic interests of the main international actors' (Nascimento 2015, 5, 15).

There is no doubt that many international actors have responded to the Syrian crisis in the broader security context, not only because of its huge magnitude but also because of its significant and far-reaching political and security implications. In fact, the UK, the EU, and the US stress the linkage between their provision of humanitarian relief and their long-term political and security objectives, particularly in regard to achieving a political transition and countering extremism.

As discussed above, in its Operational Plan 2011-2016 Syria, DFID sets four 'high level' objectives in the short and medium term. One of these is building resilience to 'provide the foundation for a future political transition.' Another objective is to 'strengthen the moderate opposition's capacity to provide governance and services - and thereby an alternative to extremist groups and Assad' (UK DFID 2014, 4).

In order to achieve these objectives, the Operational Plan states that DFID will 'help to improve governance and service delivery in opposition-held areas, working closely with the moderate opposition,' and will 'build local level resilience and provide an alternative to the regime and extremists' (UK DFID 2014 , 4). These two political objectives, namely to 'build resilience to provide the foundation for a future political transition' and to 'strengthen the moderate opposition's capacity,' repeatedly appear in DFID's documents on the crisis in Syria as 'key objectives.' ${ }^{\text {, }}$

In its 2014 document regarding its response to Syria and Iraq, the EU also stresses the importance of 'supporting the resilience of individuals, communities and institutions in coping with the effects of the crisis.' For this purpose, the EU refers to achieving a 'Syrian-led transition,' emphasizing that it will continue to 'support the moderate opposition,' including the Syrian Coalition (European Commission 2015a, 13-14).

In the Quadrennial Diplomacy and Development Review (QDDR) 2015, the US Department of State clearly affirms that the Department of State and USAID 'have innovated with cross-border engagement and assistance to support the Syrian opposition' (US Department of State and USAID 2015, 60). USAID also states on its website that 'moderate opposition' groups will play 'a vital role in stabilization efforts when a transition of power occurs in Syria,' and it will assist in increasing 'the ability of moderate opposition organizations to serve the Syrian people' (USAID undated).

Thus, the three major donors clearly connect their humanitarian relief with political goals that they want to achieve. They particularly emphasize the importance of supporting 'moderate opposition.' However, the term 'moderate' is not self-explanatory in the context of the Syrian crisis. Furthermore, as discussed already, resources for responding to the crisis are limited, and remote management 
creates a very delicate and challenging situation for both implementing emergency relief assistance and mid- and long-term resilience-building operations.

The following example from DFID's underscores the tensions within this discussion. DFID allocated $£ 9.5$ million from the UK Conflict, Stability and Security Fund (CSSF) to 'support local capacity and build stability' (UK DFID 2016, 1). While the DFID document does not provide any details of how this fund will be spent, the UK parliament record shows that it was used to support the Southern Front. According to the Parliamentary record, this front was 'a coalition of moderate armed opposition groups,' and the UK government planned to provide members of the front with 'training and non-lethal equipment' in order to 'improve their casualty evacuation capabilities and their capacity to control and defend a defined section of the Syrian-Jordanian border' (House of Commons 2015). As this case shows, support for 'moderate opposition' can include security objectives.

While the concept of resilience is helpful in bridging the gap between emergency relief assistance and development aid, it has not been strictly defined. Therefore, one can expand the concept to include numerous factors, from enhancing capacity at an individual and community level to reconstructing security and state-building at a national level. However, reconstructing security and state-building are political interventions. As such, they are dependent on a number of factors, and these may not necessarily be compatible with a humanitarian intervention. As Michael Mazarr argues, outsiders simply cannot accomplish forcible state-building because state-building missions 'tend to be long, difficult, and expensive, with success demanding an openended commitment to a messy, violent, and confusing endeavor' (Mazarr 2014, 115-116).

As Somalia, Afghanistan, Iraq, and other cases show, to incorporate statebuilding efforts, such as 'supporting moderate opposition' and accelerating 'political transition,' into humanitarian intervention may blur the fundamental goals of humanitarian relief and hinder humanitarian operations, particularly in remote management settings.

In this respect, it is worth considering a critical comment on the concept of resilience raised by Jonathan Whittall and other MSF officials: the word 'resilience' is a 'new buzzword of a floundering aid system, pushed by donors increasingly looking for cost effectiveness and a way to marry all components of aid to a process of state-building. They further argue that linking resilience building to state-building may sideline 'the most vulnerable, which is exactly those people and those populations that are not resilient enough to cope by themselves' (Whittall, Philips and Hofman 2014).

I am not suggesting here that it is a good idea to exclude the notion of state-building entirely from the scope of crisis responses and resilience building, because such an approach to state-building is essential for affected people. However, state-building is a very long-term process, and the present reality inside Syria offers little room for prioritizing such a political endeavor. 


\section{Conclusion}

In this chapter, I have discussed the three major issues involved in humanitarian relief by the international community to the Syrian humanitarian crisis. All three issues relate to the question of politicization.

The first issue is the dilemma that UN humanitarian agencies have been facing in their relief operations inside Syria, either through cross-line or cross-border assistance. The dilemma exists between consistently adhering to humanitarian principles or abiding by the UN guiding principle of respecting sovereignty of the affected country. In order to continue relief operations inside Syria, UN agencies should obtain consent and corporation from the government authorities. In fact, most besieged areas can only be reached through government-held areas (Lund 2016b). Despite strong criticism, they are obliged to both continue humanitarian efforts and abide by the UN guiding principles.

Controlling humanitarian access is a common political or tactical action in a conflict setting. Although denying humanitarian access may constitute violations of international human rights law, warring actors try to control the flow of goods, including humanitarian supplies, to further their political and tactical advantages. Therefore, as far as UN humanitarian agencies are concerned, this dilemma is likely to continue unless the central government completely collapses or the international community forces a central government to allow humanitarian access based on a strong UN Security Council Resolution, which requires a broader consensus among major international actors.

The second issue concerns remote management. For the last two decades or more, intra-state armed conflicts have increased and intensified. Under such circumstances, there is little or no guarantee of security protection for humanitarian actors. Furthermore, many armed actors, including government authorities, politicize movements of staff of external humanitarian organizations in territories under their control. Remote management should not be a last resort due to its many disadvantages (European Commission 2013, 3). In many cases, however, international humanitarian actors are forced to resort to remote management, and this tendency is increasing. Therefore, further studies on remote management should be undertaken from many perspectives, such as operational hindrances, ethical issues, capacity-building and local ownership.

The third issue is related to relationships between humanitarian relief and political objectives set by major donors. Major donors tend to perceive intra-state conflicts from the perspective of their own security concerns, and prioritize recovery of security and a state-building process in an affected country. As the Syrian case shows, however, numerous political and warring actors continue to pursue their own political interests and agendas. In addition, fragmentation and localization at different levels has obscured political objectives at the national level. Remote management also hinders humanitarian relief operations.

Therefore, the inclusion of political objectives in humanitarian relief should be undertaken with care and restraint. Otherwise, humanitarian assistance, which 
is a primary objective of crisis response, will be further complicated, particularly due to limited resources, unfriendly circumstances, and remote management.

As discussed in the introduction, in order to realize the continuum in responding to a huge-scale humanitarian crisis, such as the Syrian case, a multi-layered approach is required rather than a linearly sequential approach, because the two phases of relief and development overlap with each other and cannot be clearly separated. In fact, inside Syria, many actors try to implement both emergency relief operations and mid- and long-term activities for building resilience, despite many obstacles.

The three issues raised above, however, cause additional difficulties for international organizations in realizing this continuum. Strong criticism against UN agencies in respect to humanitarian principles may undermine necessary coordination between UN agencies and international NGOs. Controlling humanitarian access by armed forces not only denies delivery of emergency relief but also hinders mid- and long-term activities. According to OCHA's report, it is difficult for international organizations to bring staff reliably to project sites either for rotation or for training, which undermines programming and efforts to strengthen local capacities (OCHA 2016e, 24). Emphasizing political objectives may also make local partners hesitate to cooperate with international organizations in implementing mid- or long-term projects because local partners understandably avoid risks of being 'punished' by the regime forces or their affiliates once a project site falls into hands of the latter.

A large-scale humanitarian crisis, such as the Syrian case, also raises doubts about realizing crisis prevention measures. With ongoing intense fighting, the needs for extensive humanitarian relief operations, and no political solution insight, there has been little room for crisis prevention activities inside Syria so far.

Humanitarian action cannot happen in a political vacuum (McGoldrick 2011, 974) and inevitably accompanies politicization. Hence, humanitarian actors should cope with problems and issues relating to and caused by politicization. Lessons presented by the Syrian crisis are common to any large-scale humanitarian crises caused by armed conflicts.

The circumstances surrounding the Syrian civil war has significantly changed since the end of 2016. The Assad regime has turned offensive and regained its control over wide areas. Partial ceasefire and de-escalation measures have been introduced in some regions. ISIL has lost its major footholds through battles in 2017. Nevertheless, hostilities still continue in various places. As a result, the large-scale humanitarian crisis is unlikely to end in the foreseeable future, and obstacles to humanitarian assistance remain a fundamental problem. The report of the United Nations Secretary-General of December 2017 to the Security Council warns 'lack of safe, sustained and unimpeded humanitarian access is a critical element compounding the fragility of civilian populations' (UNSC 2017, 14). The international community and humanitarian actors should continue their response to the Syrian humanitarian crisis and at the same time should draw lessons from their experiences in Syria as many as possible. 


\section{Notes}

1 The Commission was established in August 2011 by the UN Human Rights Council with a mandate to investigate all alleged violations of international human rights law since March 2011 in Syria. See www.ohchr.org/EN/HRBodies/HRC/IICISyria/ Pages/IndependentInternationalCommission.aspx.

2 The International Syrian Support Group (ISSG) was established in the fall of 2015 to find the way to a political settlement of the Syrian civil war. It is co-chaired by the US and Russia, and consists of 17 nations in addition to the UN, the EU and the Arab league. In November 2015, ISSG issued a statement, which calls for an 18-month timeline for a political settlement.

3 ISIL is also called as the Islamic State (IS), the Islamic State in Iraq and Sham (ISIS), and its Arabic abbreviation, 'Daesh.'

4 The Nusra Front changed its name to the Front for the Conquest of Syria (Jabhat Fateh al-Sham) in July 2016, and it changed its name again to the Organization for Liberation of the Levant (Hay'at Tahrir al-Sham) after it merged with other groups in January 2017.

5 In April 2016, Staffan de Mistra, Special Envoy of the UN Secretary-General for Syria, said that his estimation of the death toll was 400,000 (Al Jazeera 2016).

6 Later, OCHA announced a revised number of people under siege as 974,080 as of early November 2016 (data from www.unocha.org/syria).

7 According to Aron Lund, popular committees were organized by pro-Assad forces, and became part of the state-sponsored umbrella organizations to support the regime (Lund 2016a).

8 For instance, see UK DFID's 'Syria Crisis Response' summaries for August 20, 2015, October 29, 2015, and March 10, 2016 (www.gov.uk/world/organisations/ dfid-syria-crisis-response).

\section{References}

Al Jazeera. 2016. Syria Death Toll: UN Envoy Estimates 400,000 Killed. AlFazeera, April 23. Alzoubi, Zedoun. 2015. Syrian Voices on the Syrian Conflict: Syrian Medical NGOs in the Crisis: Realities, Perspectives and Challenges. October. Norwegian Peacebuilding Resource Centre.

AP. 2016. Ban Ki-moon Addresses UN General Assembly, Slams Syria Government. AP, September 20.

Berti, Benedetta. 2016. Syria's Weaponized Humanitarian Space. Cairo Review of Global Affairs, July 14. www.thecairoreview.com/tahrir-forum/syrias-weaponized-humanitarianspace.

Betts, Alexander, and Paul Collier. 2015. Help Refugees Help Themselves: Let Displaced Syrians Join the Labor Market. Foreign Affairs 94(6), 84-92.

Call, Charles T. 2008. The Fallacy of the 'Failed State.' Third World Quarterly 29(8), 1491-1507.

Centre for Humanitarian Dialogue. 2014. Local Administration Structures in Opposition-held Areas in Syria. April. Gentre for Humanitarian Dialogue.

Council of the European Union. 2013. Council Conclusions on EU Approach to Resilience. May 28. Council of the European Union.

Danish Refugee Council. 2015. Remote Management in Humanitarian Operations: Lessons Learned from Libya and Beyond. Evaluation Learning Brief 8 (September).

Development Tracker. 2015. UK DFID, Annual Review (2): To Provide Humanitarian Assistance to Those Affected by the Syrian Conflict in Syria and the Neighbouring Countries. GB-1-203216, 
December. Development Tracker. https://devtracker.dfid.gov.uk/projects/GB-1-203216/ documents (accessed March 25, 2016).

European Commission. 2013. Instruction Note for ECHO Staff Remote Management. Brussels: European Commission.

- 2015a. Foint Communication to the European Parliament and the Council: Elements for an EU Regional Strategy for Syria and Iraq as Well as the Da'esh Threat. February 6. Brussels: European Commission.

- 2015b. Syria Crisis: ECHO Factsheet. August. Brussels: European Commission.

- 2016. Syria Crisis: ECHO Factsheet. September. Brussels: European Commission.

- 2017. Syria Crisis: ECHO Factsheet. January. Brussels: European Commission.

Gladstone, R. 2016. 73 Syrian Aid Groups Suspend Cooperation with UN. The New York Times, September 8. www.nytimes.com/2016/09/09/world/middleeast/syria-aidunited-nations.html.

Gómez, Oscar A., and Chigumi Kawaguchi. 2016. The Continuum of Humanitarian Crises Management: Multiple Approaches and the Challenge of Convergence. JICA-RI Working Paper, No.136, December. Tokyo: JICA Research Institute.

Group of Friends of the Syrian People. 2012. The Fourth Ministerial Meeting of The Group of Friends of the Syrian People Marrakech: Chairman's Conclusions. December 12. www.mofa.go.jp/mofaj/area/syria/friends_kaigo/2012_12/pdfs/2012_12_01. pdf\#search='Freinds +of + Syria+2012'.

Haver, Katherine and William Carter. 2016. What It Takes: Principled Pragmatism to Enable Access and Quality Humanitarian Aid in Insecure Environments. November. Global Public Policy Institute.

House of Commons. 2015. Syria: Conflict, Stability and Security Fund. Hansard 602, November 17. https://hansard.digiminster.com/Commons/2015-11-17/debates/15111748 000008/SyriaConflictStabilityAndSecurityFund.

Howe, Kimberly. 2016. No End in Sight: A Case Study of Humanitarian Action and the Syria Confict. London: Kings College. Feinstein International Center, and the Humanitarian Policy Group at the Overseas Development Institute, January.

Howe, Kimberly, Elizabeth Stites and Danya Chudacoff. 2015. Breaking the Hourglass: Partnerships in Remote Management Settings - The Cases of Syria and Iraqi Kurdistan. Feinstein International Center.

Khaddour, Kheder. 2015. The Assad Regime's Hold on the Syrian State. Carnegie Middle East Center, July 8.

Khalaf, Rana. 2015. Governance Without Government in Syria: Civil Society and State Building During Conflict. Syria Studies 7(3), 37-71.

Lund, Aron. 2016a. Assad's Broken Base: The Case of Idlib. The Century Foundation, July 14, https://tcf.org/content/report/assads-broken-base-case-idlib/.

- 2016b. The UN Enters Syria's Moral Labyrinth. September 9. Carnegie Middle East Center.

Lynch, Colum. 2014. UN's Fear of Angering Assad Leaves Gap in Syria Aid Effort. Foreign Policy, December 30.

McGoldrick, Claudia. 2011. The Future of Humanitarian Action: An ICRC Perspective. International Review of the Red Cross 93(884), 965-991.

Martínez, José Ciro, and Brent Eng. 2016. The Unintended Consequences of Emergency Food Aid: Neutrality, Sovereignty and Politics in the Syrian Civil War, 2012-15. International Affairs 92(1), 153-173.

Mazarr, Michael J. 2014. The Rise and Fall of the Failed-State Paradigm: Requiem for a Decade of Distraction. Foreign Affairs 93(1), 113-121. 
Meininghaus, Esther. 2016. Humanitarianism in Intra-state Conflict: Aid Inequality and Local Governance in Government- and Opposition-Controlled Areas in the Syrian War. Third World Quarterly 37(8), 1454-1482.

Milosevich, Darren, and Padideh Jalali-Shirazi. 2016. Humanitarian Aid in Conflict Environments: A Case Study of Cross-Border Aid to Syria. Institute for Middle East Studies, George Washington University.

MSF. 2015. Syria Crisis Factsheet. January. Médecins Sans Frontières.

Nascimento, Daniela. 2015. One Step Forward, Two Steps Back? Humanitarian Challenges and Dilemmas in Crisis Settings. The Fournal of Humanitarian Assistance 18, February 18. http://sites.tufts.edu/jha/archives/2126.

OCHA. 2016a. Global Humanitarian Overview 2016. OCHA.

. 2016b. Under-Secretary-General for Humanitarian Affairs and Emergency Relief Coordinator, Stephen O'Brien: Statement to the Security Council on Syria. New York, 27 May. OCHA.

- 2016c. Humanitarian Bulletin Syria Operations from Turkey 15, February. OCHA.

. 2016d. Summary of Humanitarian Response Plan Monitoring Report. January-June. Whole of Syria ISCCG for Strategic Steering Group, OCHA.

- 2016e. Humanitarian Needs Overview 2017: Syrian Arab Republic. December. Strategic Steering Group, OCHA.

- 2017. Syrian Arab Republic: United Nations Cross-border Operations under UNSC Resolutions 2165/2191/2258./2332. March 9. OCHA Regional Office for the Syria Crisis.

- Undated. Humanitarian Response Overview: Whole-of-Syria. OCHA.

OECD.2008. Concepts and Dilemmas of State Building in Fragile Situations: From Fragility to Resilience. Paris: OECD.

PBS. 2016. A Staggering New Death Toll for Syria's War-470,000. February 11. PBS.

Physicians for Human Rights. Undated. Anatomy of a Crisis: A Map of Attacks on

Health Care in Syria. https://s3.amazonaws.com/PHR_syria_map/web/index.html.

Reuters. 2012. Syria in Civil War, UN Official Says. Reuters, June 12.

Sparrow, Annie 2016. Aiding Disaster: How the United Nations' OCHA Helped Assad and Hurt Syrians in Need. Foreign Affairs, February 1.

Swisspeace, Conflict Dynamics International and FarikBeirut.net. 2016. Inside Syria: What Local Actors Are Doing For Peace. January. Swisspeace, Conflict Dynamics International and FarikBeirut.net.

Syria Recovery Trust Fund. Undated. Overview. www.srtfund.org/articles/1_overview.

Syrian Institute and PAX 2016. Siege Watch: Third Quarterly Report on Besieged Areas in Syria. May-July. http://siegewatch.org/wp-content/uploads/2015/10/PAX_REPORT_ Syria_Siege_3_FINAL_digi_singlepage.pdf.

UK DFID. 2014. Operational Plan 2011-2016 Syria. Updated December 2014. http://reliefweb. int/sites/reliefweb.int/files/resources/Syria.pdf. London: Department for International Development.

—. 2015. Annual Review 2014/2015 Summary Sheet. Development Tracker, December. https://devtracker.dfid.gov.uk/projects/GB-1-203216/documents.

- 2016. Syria Crisis Response Summary. March 10. London: Department for International Development.

UN. 1991. Strengthening of the Coordination of Humanitarian Emergency Assistance of the United Nations. A/RES/46/182, December 19. United Nations.

2013. Revised Syria Humanitarian Assistance Response Plan Fanuary-December 2013. United Nations.

. 2015. 2016 Humanitarian Response Plan: Syrian Arab Republic. December. United Nations. 


\section{R. Tateyama}

UNHRC. 2011. The Current Human Rights Situation in the Syrian Arab Republic in the Context of Recent Events. A/HRC/RES/S-16/1, April 29. UNHRC.

- 2012. Report of the Independent International Commission of Inquiry on the Syrian Arab Republic. A/HRC/21/50, August 16. UNHRG.

- 2016. Report of the Independent International Commission of Inquiry on the Syrian Arab Republic. A/HRC/33/55, August 11. UNHRC.

UNSC. 2013. Statement by the President of the Security Council. S/PRST/2013/15, October 2. UNSC.

- 2014. Resolution 2165 (2014). S/RES/2165 (2014), July 14. UNSG.

- 2016. Implementation on Security Council Resolutions 2139 (2014), 2165 (2014), 2191 (2014) and 2258 (2015): Report of the Secretary-General. S/2016/796, September 16. UNSC. . 2017. Implementation on Security Council Resolutions 2139 (2014), 2165 (2014), 2191 (2014), 2258 (2015) and 2332 (2016): Report of the Secretary-General. S/2017/1057, December 15. UNSC.

USAID. 2014. Syria - Complex Emergency Fact Sheet, No. 6 of FY 2014. January 15. Washington, DC: USAID.

- 2015a. Syria - Complex Emergency Fact Sheet, No. 6 of Fr2015. June 25. Washington, DC: USAID.

. 2015b. Syria - Complex Emergency Fact Sheet, No.7 of FY 2015. August 4. Washington, DC: USAID.

- 2016a. Syria - Complex Emergency Fact Sheet, No. 2 of FY2016. February 4. Washington, DC: USAID.

- 2016b. Syria - Complex Emergency Fact Sheet, No. 5 of Fr2016. September 30. Washington, DC: USAID.

- 2017. Syria - Complex Emergency Fact Sheet, No.2 of Fr2017. March 1. Washington, DC: USAID.

- Undated. Syria. www.usaid.gov/political-transition-initiatives/syria.

US Department of State. 2016. New US Assistance to Respond to Syria Crisis. February 4. www.state.gov/r/pa/prs/ps/2016/02/252113.htm.

US Department of State and USAID. 2015. Quadrennial Diplomacy and Development Review 2015: Enduring Leadership in a Dynamic World. Washington, DC: US Department of State and USAID.

Whittall, Jonathan, Mit Philips and Michiel Hofman. 2014. Opinion and Debate: Building Resilience by Deconstructing Humanitarian Aid. February 7. Médecins Sans Frontières. www.msf.org.uk/article/opinion-and-debate-building-resilience-deconstructing-hum anitarian-aid.

Zyck, Steven A. 2012. Remote Control Project Management in Insecure Environments. Series on Afghanistan in Transition. Norfolk, VA. Civil-Military Fusion Centre. 


\section{Part III}

Humanitarian crisis

management of disasters 


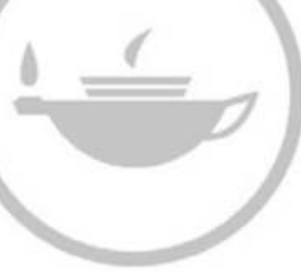

Taylor \& Francis Taylor \& Francis Group

http://taylorandfrancis.com 


\title{
7 The continuum in the management of disasters
}

\author{
An overview
}

Hiroshi Higashiura and Oscar A. Gómez

\section{A cycle or a spiral? Visualizing disaster management}

In almost all textbooks and training tools for disaster management, the image of a disaster management cycle - shown in Figure 7.1 - is used to illustrate how actions related to disasters are organized (e.g., Carter 1991; Wisner and Adams 2002; Akashi et al. 2013). Immediately after a disaster strikes, the response starts, followed by rehabilitation and reconstruction - often referred to as 'recovery' in recent international frameworks. Prevention, mitigation and disaster preparedness should ensue, after which disaster may strike once more.

This simplified depiction of the cycle presents the continuum as a sequential process of activities that is easy to teach and assimilate, which explains why it is still frequently used. Nevertheless, the linear cycle is far from an accurate representation of disaster management. The cyclic representation can give the incorrect impression that the same or similar disasters may occur, even after making maximum efforts towards prevention, mitigation and disaster preparedness. It can therefore be seen as pessimistic about what can actually be achieved by activities for confronting hazards. It also obscures the fact that actions described at each stage largely overlap, or work can be undertaken that contributes to multiple phases simultaneously. When disasters occur, disaster management actors and inter alia humanitarian organizations become involved not only in the immediate response and long-term recovery phases but also in developing community resilience against future disasters. In this sense, the interphase between relief and recovery is easier to grasp: activities for recovery generally include 'the social sectors (housing, land and settlements, education, health, and nutrition), production sectors (employment and livelihoods, agriculture, commerce and trade, and industry), [and] infrastructure sectors (community infrastructure, water, sanitation and hygiene, transport and telecommunications, and energy and electricity)' (GFDRR 2015, 17). All of these sectors are also attended to during the relief phase, and it is easy to foresee how actions can be undertaken in parallel - for example, by providing temporary and permanent housing solutions as they become available, as well as in sequence, by shifting from relief to recovery mode, or being integrated as part of comprehensive livelihood support. 


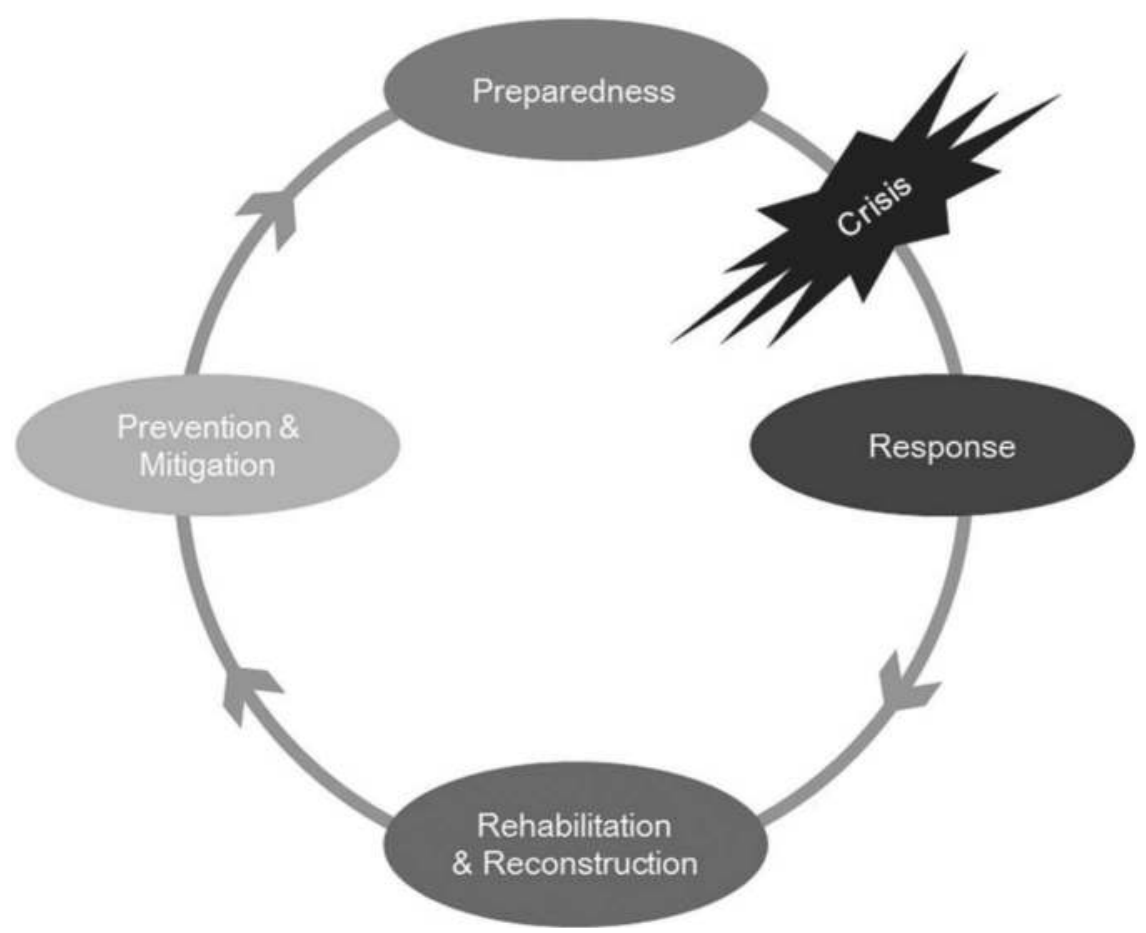

Figure 7.1 The disaster management cycle.

Source: authors.

The case for the prevention phase overlapping with recovery is similar, as the latter can provide an opportunity to build back better (BBB) by introducing measures against similar future events as the recovery phase progresses. Prevention, understood as integrating mitigation, risk reduction and preparedness, is also connected to relief, as it encompasses 'strengthen[ing] disaster preparedness for response, taking action in anticipation of events, integrating disaster risk reduction in response preparedness, and ensuring that capacities are in place for effective response and recovery at all levels' (UN 2015). Activities include structural and non-structural measures such as construction codes, disaster-conscious construction planning, risk assessments, risk governance, mitigation (e.g. through land use controls), early warning systems, community disaster risk reduction (DRR), and other mitigation/preparedness measures (JICA 2015).

Besides this, developmental considerations also play a key role in contributing to the mitigation and preparation of a community to effectively confront a disaster. Prevention activities are different from other parts of the cycle in as much as they are not transitory, but need to become part of everyday life. In this sense, this project suggests a progressive model that changes over time (see Figure 7.1). ${ }^{1}$ Disaster management diagrams should not be visualized as a circle but should 
reflect the possibility of enhancing community capacity towards future disasters instead. This has formed the basis by which understandings of the continuum have evolved through the influence of international organizations involved in managing disasters. In order to grasp this evolution, two strands of experience are described in this chapter: first, the humanitarian perspective as fleshed out by the International Federation of the Red Cross and Red Crescent Societies (IFRC) and, second, a developmental perspective from global agreements ensuing from the International Decade for Disaster Reduction(IDDR) in the nineties.

\section{Principles and rules of disaster relief and their evolution within the Red Gross}

The Red Cross was born of a desire to bring assistance without discrimination to those wounded on the battlefield. The organization endeavored, in its international and national capacities, to prevent and alleviate human suffering wherever it may be found (ICRC 1996, 2). The Red Cross/Red Crescent Societies (hereafter referred to as 'National Societies') are auxiliary bodies tasked with providing humanitarian services for their governments under national laws or by Presidential decree. They are subject to the laws of their respective countries; yet, they must always maintain their autonomy. National Societies are thus not non-governmental organizations (NGOs), although they are considered to be the largest relief agency. That said, the principles and rules that they apply to disaster relief have been evolving as experience around the world has accumulated.

The 1953 North Sea floods were the worst disaster in Europe in modern times. During relief operations, National Societies gathering in Geneva raised nineteen questions about their role, including the following: Should international Red Cross disaster relief actions be limited to meeting the immediate emergency or should they carry over into rehabilitation? If a decision is taken against actions for rehabilitation, how should any surplus funds be disposed of? After a series of discussions, a set of principles for the work of the Red Cross was adopted in Oslo in 1954. These stated simply that, while the primary aim of the Red Cross was to meet emergencies, additional funds might be used for rehabilitation of the neediest individuals.

These 'Oslo Principles' were reviewed by the Relief Advisory Committee in Istanbul in 1960. Henry W. Dunning, the Deputy Secretary General in charge of relief operations at the League of Red Cross Societies (now IFRC), reported that when all immediate needs had been met, the status of surpluses remained one of the biggest issues. Following discussions, it was established that the surplus could be utilized for rehabilitation, but that this work should only be undertaken by the private sector. In other words, rehabilitation should not include any project that is normally a governmental responsibility. However, exceptions were made for hospitals, clinics, kindergartens, schools or community centers, provided that prior agreement was reached between the donor and recipient National Societies. Elaborating a rehabilitation program in consultation with a specific National Societies was included as one of the duties of the League delegates to be dispatched to the 
affected National Society. This plan was to be submitted through the League to the National Societies in a position to contribute to such a program.

The new Principles and Rules for Red Cross/Red Crescent Disaster Relief were adopted in Resolution XXIV at the 21st International Red Cross/Red Crescent Conference (IRCG) in Istanbul, 1969. The IRCG gathered not only the representatives of the International Red Cross/Red Crescent Movement but also the representatives of the state's parties to the Geneva Conventions. The resolution affirms that prevention of disasters, assistance to victims and reconstruction are first and foremost the responsibility of public authorities. The General Provisions state that, 'in principle Red Cross help is of an auxiliary and complementary nature and operates basically in the emergency phase. However, if circumstances required and provided that the Red Cross is assured of the necessary resources and means, it may undertake longer-term assistance programmes.'

Since their adoption in Istanbul, the principles and rules have been modified and/or supplemented based on lessons learned through undertaking international relief operations. For instance, after famine relief operations in Africa in the mid-eighties, the report 'Prevention Better than Cure,' on human and environmental disasters in the Third World, was prepared for the Swedish Red Cross by Hagman, Beer and Swedish Red Cross (1984). Based on that report, the National Societies in Sweden, West Germany and Japan formed a consortium for a five-year integrated community development program in drought-affected areas in northern Ethiopia. There is also evidence from efforts of the IFRC to consolidate its accumulated experiences and broker global action, as in the work of McAllister (1993) and the ongoing series of World Disasters Reports commencing in 1993.

In the summer of 1994, the Code of Conduct for the International Red Cross Movement and NGOs in disaster relief, was also developed and agreed upon by eight of the world's largest disaster response agencies - Caritas International, Catholic Relief Services, IFRC, International Save the Children Alliance, Lutheran World Federation, Oxfam, World Council of Churches and International Committee of the Red Cross (ICRG). The Code of Conduct is a voluntary one, to which NGOs are signatories. ${ }^{2}$ The Code lays down ten points of principle, with the first four relating to the humanitarian principles of humanity, impartiality, neutrality and independence. The following four are particularly relevant for the continuum:

- We shall attempt to build disaster response on local capacities.

- Ways shall be found to involve programme beneficiaries in the management of relief aid.

- Relief aid must strive to reduce future vulnerabilities to disaster as well as meeting basic needs.

- In our information, publicity and advertising activities, we shall recognize disaster victims as dignified human beings, not hopeless objects.

(IFRC 2017)

A subsequent groundbreaking event was the adoption of the 'Agenda for Humanitarian Action' during the 28th IRGC in 2003. The agenda focuses on 
the main theme and overall goal of the IRCG, namely Protecting Human Dignity, and sets out action-oriented goals and measures that member states and the components of the International Red Cross and Red Crescent Movement can undertake to protect human dignity (ICRC 2003). Among the four humanitarian concerns addressed in the agenda, the inclusion of the reduction of 'the risk and impact of disasters and improve preparedness and response mechanisms' is evidence of further internalization of the full continuum into the organization's activities (ibid., 11).

As one of the deadliest disasters in recorded history, the 2004 Indian Ocean earthquake and tsunami resulted in further changes. The plight of the affected people and countries prompted a worldwide humanitarian response, which resulted in more than US $\$ 14$ billion of donations in humanitarian aid. Given the abundance of resources, the International Red Cross representatives met in a Forum held in Hong Kong in March 2005, and committed to delivering rehabilitation and recovery programs based on the needs of the communities affected; carrying out recovery programs in the affected countries in line with the regional strategy, ranging from re-establishing and diversifying livelihoods to reconstructing health institutions, housing and social infrastructure; strengthening national and transnational disaster response capacity and supporting DRR programs through building community resilience to prepare for and respond to disasters; and developing the disaster management skills of volunteers and staff in the National Societies in a sustainable manner that increases local to global emergency response capacities. The meeting was followed up by a Tsunami Forum in Kuala Lumpur in 2007, where 15 wide-ranging recommendations were made and directed toward the IFRC's Governing Board. Great emphasis was placed on the problems of coordinating large-scale operations covering relief, recovery and prevention activities by different National Societies in the same affected areas.

Mention should also be made that in 2011, the 31st IRCC adopted a resolution encouraging states, with support from their National Societies, IFRC, United Nations Development Programme (UNDP), and other relevant partners to review existing legislative frameworks in light of the key gap areas related to DRR identified in an IFRC report to the conference. The resolution called for states to assess whether their laws made DRR a priority (including through resource allocation and accountability); involved communities, civil society and the private sector; and facilitated the implementation of land-use planning and building codes (IFRC and UNDP 2015).

After the overview of progress and lessons learned from implementing major operations over the last few years - such as the Haiti earthquake, Pakistani floods and the Japan triple disaster - recent discussions have focused on commitment to the allocation of a firm percentage to activities for preparedness within major disaster appeals. The 24th Session of the Governing Board of the IFRC in 2011 adopted the approach that every appeal for international disaster response should include, as far as possible, a provision of at least 10 percent for longer-term disaster preparedness and risk reduction work. However, this important decision was not included in the 2013 revisions and remains an issue. 
The Principles and Rules Preamble drafted in 2013 describe how they encompass preparedness for response, disaster relief and early recovery activities. They complement commitments to DRR and seek to encourage National Societies to link relief, recovery and development. Accordingly, Principle 9 mentions that IFRC supports the transition from relief to recovery for disaster-affected people, and Principle 10 describes how the societies provide international assistance that builds upon local capacities and complements local response mechanisms, contributing to preparedness for possible future disasters and strengthening longterm resilience. There are even specific instructions for connecting relief and recovery.

In sum, it is clear how the challenge posed by the continuum has crept into the IFRC Principles and Rules since they were first adopted in 1954. Availability of resources and pressure to respond to the changing needs on the ground have been the major driving forces. Much emphasis is placed on the central role of local communities and authorities, who are the main responders. This also plays a role in the evolution of the second strand of efforts through the United Nations (UN) that we describe in the next section.

\section{From Yokohama to Sendai: Strategies for the continuum and disaster risk reduction frameworks}

The process of mainstreaming comprehensive action against disasters through the UN started with the International Decade for Natural Disaster Reduction (IDNDR) in the nineties. ${ }^{3}$ This was mostly a scientifically propelled initiative that tried to raise awareness of the possibilities of prevention, in opposition to the shock-driven response facilitated by the GNN effect. These seminal experiences profoundly influenced the way that agreements concerning disaster reduction were framed. From the outset, the DRR movement was inspired by the premise that 'prevention is better than cure,' and it therefore focused on ways to avoid disasters before they occur, primarily by mainstreaming DRR as part of development. In consequence, the frameworks adopted for action had (and still have) little to say about relief. Indeed, until the last version was agreed on in 2015, there were few references to recovery. The outcomes of the first World Conference on Disaster Risk Reduction, held in Yokohama in 1994, acknowledged the importance of the continuum but quickly emphasized that 'notwithstanding the full continuum, disaster prevention is better' (IDNDR 1994, 10).

The next World Conference took place in 2005 in Kobe, Hyogo, Japan. In the list of outcomes of this meeting (UN 2005), preparedness was included as one of five priorities, and recovery was acknowledged as a 'window of opportunity,' but the emphasis remained on prevention, now on its present formulation as 'risk reduction.'

As noted above, the Indian Ocean tsunami of 2004 was a turning point because it was the first time in history that there was enough money for cooperation to look beyond relief on such a massive scale. In 2011, the first World Reconstruction Conference was held, and the BBB mantra became a major 
trend inside DRR. This was reflected in multiple side events related to recovery during the Third World Conference in Sendai in 2015, giving way to one of four new priorities being framed as: 'Enhancing disaster preparedness for effective response, and to Build Back Better in recovery, rehabilitation and reconstruction' (UN 2015). In principle, the continuum is fully recognized through the outcomes, but the framing suggests two things: the emergence of a strong recovery focus group inside the DRR community, and the continuation of the traditional sidelining of relief, which did not manage to maintain its own standalone priority. In fact, the concept of crisis management has been carefully avoided, partly to underscore the importance and urgency of disaster risk management (UNISDR 2015).

There is thus competition between the main phases in disaster management, but until recently the connection between those phases has not figured prominently in major documents. Since recovery became a field of active engagement, related work by Fengler, Ihsan, and Kaiser (2008) and the Global Facility for Disaster Reduction and Recovery (GFDRR 2015) recognizes the need to start working as soon as possible after a disaster, while relief work is still ongoing, and ideally building upon humanitarian aid. From existing experience, there are two sectors that have repeatedly been shown to be the most critical in connecting relief with recovery: housing and livelihoods (Christoplos 2006; GFDRR 2015). Both areas are not only critical but extremely complex, to the point that they are a big issue not only in developing countries but also in robust societies such as Japan (Ranghieri and Ishiwatari 2014). There are multiple examples of work being undertaken and guidelines being developed in these two sectors, such as those prepared by the International Recovery Platform and several UN agencies (see IRP undated). However, since any solution is very contextual, generalization is difficult.

It is also important to note that prevention in DRR is framed as occurring prior to disasters, so the ways that prevention and preparedness enter the picture of crisis management has not been addressed (Brusset et al. 2009). Once again, the rise of $\mathrm{BBB}$ has provided a way of resolving this issue by linking prevention to recovery, but the approach does not necessarily cover the full range of prevention and, especially, preparedness activities. As in the case of the Red Cross; the interface, if any, between recovery and prevention phases/actors is yet to be made clear with a better model of the continuum. We suggest that such a model should acknowledge the overlap of phases and establish how middle and long-term activities for prevention are engendered from day one of any crisis.

One way or another, the last two world conferences resulted in frameworks for action that describe the tasks and priorities for advancing DRR in each country, and include the full cycle of crisis management. They followed an inclusive and elaborated process for the crafting of the documents, including formal inter-governmental negotiations, with the results subsequently adopted by UN member states and endorsed by the UN General Assembly. Their outcomes have thus become a global referent on this specific type of crisis and, through its intergovernmental process, highlight the importance of local ownership. 


\section{Actors and financing for the continuum after disasters}

Both historical strands introduced above converge on two major features of the continuum: a similar set of phases and the centrality of local communities and governments. While we have emphasized the fuller picture of crisis management and ways in which doing 'more than relief' has been reflected in disaster management history, the configuration of actors and the underlying flow of resources also deserve mention.

While the world conferences on DRR gather many diverse stakeholders at the global level, the process remains an inter-governmental one. Local ownership is stressed because it is the affected people and their governments who must undergo the full process. Therefore, the way external actors - mainly donors, international organizations and NGOs - come into the picture is through assessment tools and the plans derived from those assessments. This is most clear from existing recovery frameworks, for instance, the European Union (EU), World Bank, and the UN post-disaster needs assessments (PDNA) (EG 2015, 109). National officers are supported to different degrees by international partners to produce the assessments and then develop recovery plans that donors will support, depending on their capabilities. This process aims to avoid the risk of international agencies, and their development partners, appropriating control of the process (GFDRR 2015, 37).

At this point, similar mechanisms for dovetailing relief into DRR do not exist. The UN Office for the Coordination of Humanitarian Affairs (OCHA), in conjunction with national governments, coordinates emergency needs assessment based on national requests, which inform the flash appeals to the international community. However, all agencies involved in humanitarian action undertake their own needs assessments. ${ }^{4}$ For example, the United States Agency for International Development's (USAID's) Office of Foreign Disaster Assistance (OFDA) has DARTs (Disaster Assistance Response Teams), while the European Civil Protection and Humanitarian Aid Operations (ECHO) and the Japan International Cooperation Agency (JICA) also deploy their own assessment teams. The extent to which multiple needs assessments for relief can or cannot be coordinated is an issue heavily influenced by the flow of funds - that is, they are supply-side oriented. Changes to the cluster system, suggests that moving operations back to local institutions may be possible in the future when 'government capacity is adequate and not constrained' (IASC 2015). Since relief is followed by different forms of informal recovery that can interfere with BBB plans, efforts at early coordination have been encouraged.

There is, however, an important caveat to the relatively positive picture of the response to natural disasters. International attention to the DRR process has so far been very unequal. During the two decades since 1991, Japan has contributed as much as 68 percent of all financial donations for DRR (Kellett and Caravani 2013) and is the only country that addresses disasters from both its humanitarian and development branches in a very clear manner. For the remaining donors, activities related to disasters are mainly seen as part of the humanitarian aid portfolio. 
The lack of financial contributions towards DRR has resulted in an ongoing debate. This can be seen in relation to other types of crises: in the 2010 figures, DRR amounted only to about 10 percent of what is spent on peacekeeping. Lack of funding has also been criticized as a share of the Overseas Development Assistance (ODA), less than 1 percent, and as a share of humanitarian aid, 6.4 percent in 2014 (Development Initiatives 2015; Kellett and Caravani 2013). Mainstreaming DRR into development is seen as a way to address the scarcity of resources, although tracking such efforts remains difficult. The low share of resources for humanitarian assistance - just about one tenth of all ODA - also suggests limitations in addressing multiple parallel phases of the continuum through this budget line, in which relief needs override prevention needs - one of the issues addressed by the Red Cross, as explained above. Funds for DRR, as distinct from BBB, are not necessarily included in recovery plans if they are not explicitly there from the start. Funding through humanitarian portfolios makes it unclear how the goal of preventing crises from recurring can become part of the continuum in the long term. Nonetheless, it is important to keep in mind that the biggest contribution of funds actually comes from citizens, within a country and from abroad (GFDRR 2015, 42-43).

The lack of a multilayered understanding of phases contributes to tensions between relief and recovery actions. On the one hand, from the national government perspective, the ideal is to finish relief as soon as possible to provide its people with some sense of normalcy, or at least progress. This requires careful assessment of the situation, since populations under stress and the organizations supporting them could perceive this as a political decision. On the other hand, there is the perception that the humanitarian world 'often stretches out the relief phase (immediate or delayed) until the funds earmarked for relief have been exhausted' (de Ville de Goyet 2008, 32). In other words, financial sources may also be a source of conflict between implementing partners and local authorities, generating unfriendliness and reinforcing prejudices between actors. The issue is not, however, merely about funding because, as de Ville de Goyet (ibid.) recognizes, organizations receiving humanitarian resources do move into recovery projects as needs change on the ground. The work of the Red Cross is a conspicuous example, and Yoshikawa (2013), as well as the interviews conducted as part of this review, support this observation. Larger organizations without mandate constraints can internally balance different sources of funding within their evolving programs. Irrespective of this, it seems to be the case that humanitarian money is easier to obtain than development money (Buchanan-Smith and Maxwell 1994), creating a perverse incentive to apply for available funds. A strict humanitarian mandate tries to prevent this, but this actually discourages the goal of the continuum by, for instance, banning the words 'permanent' or 'reconstruction' from flash appeals (de Ville de Goyet 2008, 33), despite the fact that phases overlap and any division between them may be difficult to distinguish.

It is also important to observe that time-constrained allocations are not only an issue of relief. Support for the recovery process - as an extraordinary type of assistance - can also be limited by donors or local authorities to a certain time 
period that may or may not reflect the actual capacity of the implementing actors to absorb resources on the ground. The rush to spend money does, therefore, facilitate co-optation and waste. Moreover, there is also a trade-off between speed, quality, and control that can only be managed on a case-by-case basis (Akashi et al. 2013).

\section{Addressing the continuum in practice}

Getting a better grasp of how these changes in global frameworks and practice of crisis management are manifested in the field requires examination of particular cases. The following three chapters of this volume provide close-up accounts of major events at different points in the history of DRR efforts, illustrating how challenges and approaches have evolved, as well as the complexities inherent in each context. First, the case of Honduras after Hurricane Mitch (Chapter 8) offers a peek into how the system worked at the outset of the DRR movement. Gómez considers how prevention is engendered during the relief phase and then proceeds, partly thanks to - and partly in spite of - recovery and efforts to restart development. His chapter shows how, in the absence of common agreement on BBB, long-term visions of societies stepping back from disasters can return to business as usual because of, among other things, politically motivated time pressure and conflicting visions of how DRR works. He also highlights the impact of the general lack of specialized knowledge in DRR cooperation, a point that other chapters show has been consolidated through experience.

Next, Ishiwatari follows the epoch-making events of the Indian Ocean tsunami, using the Java earthquake that occurred two years later as a test of how much learning has taken place in Indonesia (Chapter 9). This allows an overview of the full process of disaster management, and in particular, the contributions to long-term development. Ishiwatari presents an overall positive picture, in which the commitment of the government and the generosity of donors allowed multiple initiatives that, partly through trial and error, resulted in the development of lasting institutions. He highlights advances in housing, showcasing reconstruction in Yogyakarta that ensured resilient solutions against future earthquakes. He also describes how the livelihood sector received positive support through cash programs. Indonesia was able to strengthen its DRR by developing institutions and legislation through learning from the disasters. Donors coordinated different assistance schemes to link recovery with long-term development. Another positive experience can be seen in the work of multi-donor pool funds, although the problem of donor visibility remains a major hurdle. However, weak links were found in some areas between recovery and development, particularly in the sustainability of the prevention strategies promoted through the recovery, and the decreasing attention to DRR after the recovery is no longer seen as a matter of concern.

Part III of this volume concludes with Jibiki and Ono describing the case of another major disaster in a middle-income country frequently affected by adversity (Chapter 9). The authors present a case from the Philippines following Typhoon Yolanda, in which local ownership resulted in low coordination of needs among 
donors. These organizations initially used their own existing programs to support the crisis management and then plug into national planning for the recovery. While tensions in relation to a linear, sequential conception of the relief phase remain, the authors emphasize the enormity of the challenge posed for the housing sector and the reluctance of international cooperation to engage with this. They find that the time frame for cooperation is very different from that required by the recovery process, suggesting the need to develop strategies for longer-term support, including attending to pre-existing vulnerabilities.

Despite multiple challenges, the case studies suggest steady progress in consolidating disaster management as a whole in the aftermath of disasters. A vision of crisis management shared by stakeholders on both affected and cooperating societies emerges as time passes, giving way to increased attention to the intricacies of devising DRR institutions and of specific sectors. International cooperation also moves to the background, positively as recognition of the local ownership of the process, but also revealing the difficulty of supporting more than relief through crisis management as international attention fades away. Three cases are certainly not enough to generalize, but still they offer hints on the challenge of realizing the continuum, about which the final chapter synthesizes the major findings specific for disasters, as well as those common to armed conflict case studies.

\section{Notes}

1 See Figure 7.1; see Federal Emergency Management Agency 2011; Red Cross undated.

2 As of July 20, 2018. See: http://media.ifrc.org/ifrc/who-we-are/the-movement/ code-of-conduct/signatories-to-the-code-of-conduct/

3 Before this, the UN Disaster Relief Coordinator worked as a focal point for relief since its creation 1972. Regarding its performance, see Crisp (2007).

4 The Inter-Agency Standing Committee (IASG) introduced the Multi-Cluster/Sector Initial Rapid Assessment (MIRA) in 2012 to address the lack of joint needs assessments in sudden onset emergencies. This effort is still work in progress. Lately, work on 'more joint and impartial needs assessments' as a follow up to the Grand Bargain agreed during the World Humanitarian Summit is ongoing.

\section{References}

Akashi, Yasushi, Kenzo Oshima, and Kae Yanagisawa. 2013. Daisaigai ni tachimukau sekai to nihon: Saigai to kokusaikyoryoku [The World and Japan Facing Large-Scale Disasters: Disasters and International Cooperation]. Tokyo: Saeki Insatsu Kabushikigaisha.

Brusset, Emery, Mihir Bhatt, Karen Bjornestad, John Cosgrave, Anne Davies, Yashwant Deshmukh, Joohi Haleem, Silvia Hidalgo, Yulia Immajati, Ramani Jayasundere, Annina Mattsson, Naushan Muhaimin, Riccardo Polastro, and Treena Wu. 2009. A Ripple in Development: Long Term Perspectives on the Response to the Indian Ocean Tsunami 2004. Joint Follow-up Evaluation of the Links between Relief, Rehabilitation and Development (LRRD). Stockholm: SIDA.

Buchanan-Smith, Margaret, and Simon Maxwell. 1994. Linking Relief and development: An Introduction and Overview. IDS Bulletin 25(4), 2-16. www.eldis.org/fulltext/ LinkingReliefandDevelopment.pdf. 
Carter, W. Nick. 1991. Disaster Management: A Disaster Manager's Handbook. Manila: Asian Development Bank.

Christoplos, Ian. 2006. Links between Relief, Rehabilitation and Development in the Tsunami Response: A Synthesis of Initial Findings. London: Tsunami Evaluation Coalition.

Crisp, Jeff. 2007. Humanitarian Action and Coordination. In The Oxford Handbook on the United Nations., eds. Thomas G. Weiss, Sam Daws, 479-495. New York: Oxford University Press.

Development Initiatives. 2015. Global Humanitarian Assistance Report 2015. Bristol: Development Initiatives.

De Ville de Goyet, Claude. 2008. Information Gaps in Relief, Recovery, and Reconstruction in the Aftermath of Natural Disasters. In Data against Natural Disasters: Establishing Effective Systems for Relief, Recovery, and Reconstruction, edited by Sara Amin and Markus Goldstein, 23-58. Washington, DC: World Bank.

EC. 2015. EU Resilience Compendium: Saving Lives and Livelihoods. Luxembourg: Office for Official Publications of the European Communities. http://ec.europa.eu/echo/files/ policies/resilience/eu_resilience_compendium_en.pdf.

Federal Emergency Management Agency. 2011. National Disaster Recovery Framework: Strengthening Disaster Recovery for the Nation. Washington, DC: Federal Emergency Management Agency.

Fengler, Wolfgang, Ahya Ihsan, and Kai Kaiser. 2008. Managing Post-disaster Reconstruction Finance: International Experience in Public Financial Management. Policy Research Working Paper 4475. Washington, DC: World Bank. http://elibrary.worldbank.org/doi/ pdf/10.1596/1813-9450-4475.

GFDRR. 2015. Guide to Developing Disaster Recovery Frameworks: Sendai Conference Version. Washington, DC: Global Facility for Disaster Reduction and Recovery.

Hagman, Gunnar, Henrik Beer, and Svenska Röda Korset. 1984. Prevention Better than Cure: Report on Human and Environmental Disasters in the Third World. Stockholm: Swedish Red Cross.

IASC. 2015. Reference Module for Cluster Coordination at Country Level. Geneva: Inter-Agency Standing Committee. www.humanitarianresponse.info/en/coordination/clusters/ document/iasc-reference-module-cluster-coordination-country-level-0.

ICRC. 1996. The Fundamental Principles of the Red Cross and Red Crescent. Geneva: International Committee of the Red Cross. www.icrc.org/eng/assets/files/other/icrc_002_0513.pdf.

- 2003. $28^{\text {th }}$ International Conference of the Red Cross and Red Crescent. Geneva: International Committee of the Red Cross. www.icrc.org/eng/assets/files/ other/icrc_002_1103.pdf.

IDNDR. 1994. Yokohama Strategy and Plan of Action for a Safer World: Guidelines for Natural Disaster Prevention, Preparedness and Mitigation. Geneva: UN Department of Humanitarian Affairs. International Decade for Natural Disaster Reduction.

IFRC. 1994. The Code of Conduct for the International Red Cross and Red Crescent Movement and Non-Governmental Organisations (NGOs) in Disaster Relief. Geneva: International Federation of Red Cross and Red Crescent Societies. www.ifrc.org/Global/Publications/ disasters/code-of-conduct/code-english.pdf.

2017. Code of Conduct for the International Red Cross and Red Crescent Movement and NGOs in Disaster Relief: List of Signatories. www.ifrc.org/Global/ Documents/Secretariat/Copy $\% 20$ of $\% 20$ Code $\% 20$ of $\% 20$ Conduct $\% 20$ UPDATED_ January\%202017.pdf. 
IFRC and UNDP. 2015. The Checklist on Law and Disaster Risk Reduction: Pilot Version. Geneva: International Federation of Red Cross and Red Crescent Societies/New York: United Nations Development Programme.

IRP. Undated. Guidance Notes. www.recoveryplatform.org/resources/guidance_notes_ on_recovery.

JICA. 2015. Toward Mainstreaming Disaster Risk Reduction: Building Disaster Resilient Societies. Tokyo: JICA. Japan International Cooperation Agency. http://gwweb.jica.go.jp/km/ FSubject0301.nsf/ff4eb182720efa0f49256bc20018fd25/3958a0a725aba98549257a 7900124f29/\$FILE/E.pdf.

Kellett, Jan, and Alice Caravani. 2013. Financing Disaster Risk Reduction: A 20-Year Story of International Aid. London: ODI/Washington, DG: GFDRR.

McAllister, Ian. 1993. Sustaining Relief with Development: Strategic Issues for the Red Cross and Red Crescent. Dordrecht: Springer.

Ranghieri, Federica, and Mikio Ishiwatari. 2014. Learning from Megadisasters: Lessons from the Great East Japan Earthquake. Washington, DC: World Bank.

UN. 2005. Report of the World Conference on Disaster Reduction Kobe, Hyogo, Japan, 18-22 Fanuary 2005. A/CONF.206/6. March 16. New York: United Nations.

- 2015. Sendai Framework for Disaster Risk Reduction 2015-2030. A/CONF.224/ GRP.1. March 18. New York: United Nations.

UNISDR. 2015. Making Development Sustainable: The Future of Disaster Risk Management. Global Risk Assessment Report on Disaster Risk Reduction 2015. Geneva: United Nations International Strategy for Disaster Reduction.

Wisner, Ben and John Adams. 2002. Environmental Health in Emergencies and Disasters: A Practical Guide. Geneva: World Health Organization.

Yoshikawa, Lynn. 2013. From Crisis to Recovery: Lost in Transition. InterAction Transition Report. Washington, DC: InterAction. www.interaction.org/sites/default/files/Inter Action $\% 20$ Transition\%20report $\% 20-\% 2$ 0February $\% 202013$.pdf. 


\title{
8 Prevention through the continuum of crisis management \\ The case of Honduras after \\ Hurricane Mitch
}

\author{
Oscar A. Gómez
}

\section{Introduction}

Most of the discussions about realizing the continuum of crisis management focus on how relief and recovery phases connect and overlap. As shown in Chapter 2, approaches to the continuum are generally framed in terms of the humanitariandevelopment divide, occasionally including some form of early recovery in the middle, but seldom including prevention as a specific phase of crisis management. Prevention is certainly a preoccupation, crosscutting different areas of intervention, but it is not clearly connected to the flow of actions underlying the continuum. This likely follows from the strong emphasis on pursuing prevention before crises, not after. Such emphasis can be seen in the general depiction of the humanitarian Cluster System designated by the Inter-Agency Standing Committee, the framing of the peace agenda as explained by Hoshino and Kawaguchi earlier in this volume, and even in disaster risk reduction (DRR) frameworks for action, usually depicted as having a cyclical nature as described in the introduction to this section of the book. In consequence, there has been limited attention given to documenting the ways that prevention is or can be connected to relief and recovery efforts.

In this chapter I use the case of Honduras after Hurricane Mitch to shed light on how prevention evolves as a phase of the crisis management process, pointing out different factors that can facilitate or hinder its progress. From the outset, it should be stressed that for this research, prevention is considered to include activities for mitigation, risk reduction and preparedness, which sometimes are presented as independent of each other. In order to examine the characteristics of the prevention phase as part of the continuum, I provide a historic account of relief and recovery phases conducted by national actors, as well as the United States (US), the European Union (EU) and Japan, focusing on the way they influenced and overlapped with activities related to prevention. This description allows understanding of how the prevention phase took shape from the very beginning of the emergency and evolved in parallel to other phases. Next, I concentrate on prevention-specific activities - specifically, the consolidation of a disaster risk 
management (DRM) system and the conciliation of different strands of work relevant to DRM - to identify the main challenges in advancing this phase beyond relief and recovery. Finally, I add comments on two major consequences of Hurricane Mitch that had a great impact on the crisis management process but were beyond its reach: firstly, Honduran participation in the ongoing global debt relief program at that time; and secondly, increased migration to the US.

The research explores Christoplos's (2006) observation that the job of connecting different phases and the return to normality is the core task of national actors' responses to disasters. The ideal role of international donors is to support locals in realizing the continuum of relief, recovery and prevention, not in making their individual projects connected with each other. Therefore, I present a broader account of the complex process of crisis management and the longer-term changes to the Honduran society triggered by the hurricane, through which I identify the specific contributions of external actors, particularly in relation to major donors and the promotion of a robust prevention phase.

I partly organize my presentation around the idea of 'transformation,' which warrants explanation. After Hurricane Mitch, transformation was a guiding concept pushed by the international community in order to make sure that something beyond simple reconstruction was achieved after the disaster. Transformation came to mean many different things for different actors, including disaster prevention but also civil society empowerment, decentralization, democratization, and transparency, among other things. Thus, transformation helped different actors to communicate and put forward their own plans under general coordination principles, despite each of them having their own particular agendas. This characteristic makes the pursuit of transformation an appealing option for understanding the overlap and transition between different management phases. Bearing in mind that in 1998, concepts such as recovery, disaster risk reduction and build back better (BBB) had yet to become standards for framing the disaster management cycle, transformation captured the idea of turning disasters into opportunities. This framing can still be heard today, especially in relation to BBB. Moreover, it is worth noting that I am using 'reconstruction' and 'recovery' interchangeably, with the former a concept used in national and international policies, while the latter is a term used for the model proposed in this book.

This research is based on a series of 37 semi-structured interviews, several of them with two or more people, held in Tegucigalpa in July 2015 and June 2016 with government officials, donors, multilateral agencies, non-governmental organizations (NGOs), and universities. It is complemented by a handful of other consultations undertaken in Washington DC and in Tokyo. Primary and secondary data in Spanish, English and Japanese was thoroughly reviewed, benefitting particularly from the comprehensive online collection held by the Medical Library of the National Autonomous University of Honduras, as well as copies of old reports available at local Honduran institutions. 


\section{Background}

Hurricane Mitch wreaked havoc over the whole of Honduras, Nicaragua, and to some extent other neighboring countries between October 22 and November 9, 1998. Despite its strong winds, it was the unrelenting rains that led to floods and landslides. These left 5,657 persons confirmed dead, 8,052 missing, and hundreds of thousands displaced in Honduras alone (ECLAC 1999). Losses amounted to US $\$ 3,800$ million, or 70 percent of the gross domestic product of the country. The most affected area was the productive sector, especially agriculture, while infrastructure damage equaled seven times the annual construction sector output (ibid.). About 70 percent of roads were destroyed; bridges were also particularly affected, as well as the electricity supply. The loss of access to potable water for a long period of time was critical. The disaster required building around 33,220 housing units and rehabilitating 49,500 houses (UNDP 1999). The magnitude of the tragedy overwhelmed local capacities and pushed the national government to appeal for help, a call that the international community heeded and followed up on for several years.

While phases of crisis management largely overlap, there are several key events and agreements during the process that can help in understanding the connections and transitions - a summary of these has been provided in Figure 8.1.

\begin{tabular}{|c|c|c|}
\hline National & & Intermational \\
\hline $\begin{array}{l}\text { - Start of President Fores' term (Janauary) } \\
\text { - Hurricane Mitch (October) }\end{array}$ & 1998 & $\begin{array}{l}\text { - Appeal for international } \\
\text { support (November) } \\
\text { - Washington meeting (December) }\end{array}$ \\
\hline $\begin{array}{l}\text { - Start of the Reconstruction and } \\
\text { Transformation Plan }\end{array}$ & 1999 & - Stockholm declaration \\
\hline & 2000 & - Decision point for the HIPC \\
\hline $\begin{array}{l}\text { - End of the reconstruction (third } \\
\text { amniversary) } \\
\text { - Start of the PRSP }\end{array}$ & 2001 & \\
\hline $\begin{array}{l}\text { - Start of President Maduro's term } \\
\text { (Janauary) }\end{array}$ & 2002 & \\
\hline & $\begin{array}{l}2003 \\
2004 \\
2005\end{array}$ & - Completion of the HIPC \\
\hline - Start of President Zelaya's term (Janauary) & 2006 & \\
\hline & $\begin{array}{l}2007 \\
2008\end{array}$ & \\
\hline $\begin{array}{l}\text { - Constitutional crisis } \\
\text { - Approval of the DRM law }\end{array}$ & 2009 & \\
\hline
\end{tabular}

Figure 8.1 Timeline of policy events relevant to the disaster management.

Source: author. 
The process started with a declaration from Central American leaders one week after the disaster, seeking international support. This was followed by two meetings with donors and international agencies in Washington and Stockholm, in December 1998 and May 1999 respectively, where the main plans for the reconstruction and transformation process were agreed upon.

After these meetings, the framework of the process ceased to be regional and became mostly national - thus, local politics started to play an essential role. Mitch took place in the year that Honduran President Carlos Roberto Flores commenced his four-year term. Nominally, the process of reconstruction would last throughout his term, and despite patchy progress on the ground, expire in late 2001. This would allow the newly elected President Ricardo Maduro to commence his term with new policies in 2002. Given that creating a system for DRM is considered a hallmark in the evolution of the prevention phase, I follow the process until 2009 when the law that created it was officially approved, although in 2005, 2006, 2008 and 2009 there were several emergencies that once again triggered relief and reconstruction activities (Suárez and Sánchez 2012). The approval of the DRM system law coincided with a political crisis that year when Manuel Zelaya, president since 2006, was ousted as he attempted to rewrite the constitution in order to remain in power. This event affected the relations with donors and the flow of cooperation; it therefore offers a good point at which to end the analysis.

Hurricane Mitch prompted active participation by the international community, which invested time, personnel and resources to help the beleaguered countries. After the two meetings mentioned above, a follow-up coordination group was created by five leading supporting countries, which gradually expanded to include 16 members: the group started as the G5, and ultimately became the G16, including all major donors and institutions such as the UN Development Programme (UNDP), the World Bank and the International Monetary Fund (IMF). This process is considered a very successful experience in donor coordination that heavily influenced the evolution of the management process after the disaster (Yanguas 2013).

Figure 8.2 presents the Organisation for Economic Co-operation and Development (OECD) data on major bilateral donors' aid to Honduras from 1997 to 2011. Visible leadership was provided by the US, followed by Japan. The EU, Germany, Spain and Sweden also played prominent roles. Numbers should be treated carefully though: d'Ans $(2008,152-158)$ reports that a dedicated French research team was unable to determine the actual balance of the commitments and disbursements following the Stockholm meeting. With regard to Figure 8.2, some of the peaks around the mid-2000s reflect the result of debt relief - as is the case with Japan's peak in 2005, and to some extent Spain's 1 - and so do not represent actual inflow of resources. Based on the trends of the figure, as well as available information, I focus mainly on the experience of the US, the EU and Japan in order to understand donors' roles in the process. ${ }^{2}$ 


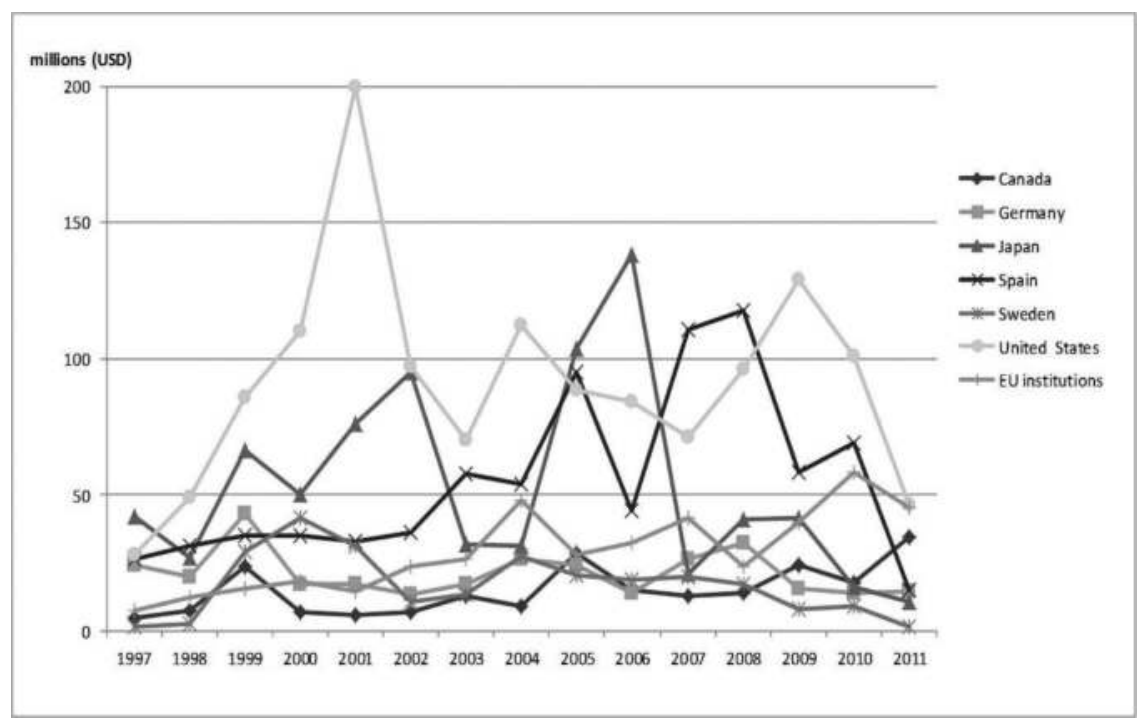

Figure 8.2 Bilateral aid to Honduras, 1997-2011.

Source: author, based on data generated from OECD QWIDS.

\section{Relief: setting the scene for recovery and transformation}

Torrential rains started affecting Central America on October 18, 1998 before a tropical depression in the Caribbean became Hurricane Mitch a week later on October 22 (d'Ans 2008). The worst period of the disaster started on October 27, sweeping the Caribbean coast of Honduras from east to west and north to south through the main corridor of the country that ends at the Pacific Ocean. Different degrees of emergency were decreed, starting with coastal regions of the north, until by October 30, the whole country was covered. A national period of mourning was declared the next day, and Tegucigalpa was placed under curfew. National and international aid started flowing in from this point onward.

On November 9, the presidents of four Central American countriesHonduras, Nicaragua, El Salvador and Costa Rica - and the Minister of Foreign Affairs of Guatemala held a hurried summit at the airport of El Salvador to make joint decisions about how to face the situation (Torres 2004). The declaration resulting from this meeting included the following appeals:

- Support for the elaboration of a Central American Rehabilitation and Reconstruction Plan through an international advisory group;

- new resources to implement such plan;

- free access to the markets of the US and the EU for products from the affected countries in order to reactivate the economy; 
- moratoria for the foreign debt of the most affected countries; and

- amnesty for undocumented migrants.

One of the most salient aspects of the declaration is that no appeal for relief or humanitarian aid was made. At the first stages of the response to the emergency, the national office in charge of the response in Honduras, the Permanent Commission for Contingencies (COPECO), played a role in providing information but it soon found itself overwhelmed (Ensor and Ensor 2008). The president then took over the operation and moved quickly into rehabilitation and reconstruction. The 1999 World Disasters Report (International Federation of Red Cross and Red Crescent Societies 1999, 42-54) suggests that most life-saving activities were undertaken by people themselves (see also d'Ans 2008). This included the provision of food, which did not become scarce because staple crops were not seriously affected by the disaster. The government decided to outsource the reception, management and distribution of relief assistance mainly to the Catholic Church, supported by some evangelical churches (Ensor and Ensor 2008, 40). COPECO was replaced by an adhoc National Commission for Emergencies, followed by the Reconstruction Cabinet (Honduras Health Secretary and Pan-American Health Organization 1999).

The lack of a dedicated appeal for relief does not imply that there was no aid, which in fact poured in like the rains. With the hurricane due to pass through Mexico before abruptly deviating towards Honduras, there were pre-positioned goods and Mexican teams that hurried to support local operations. The nine UN agencies present in Honduras worked in teams during the emergency and started early to plan for recovery and rehabilitation, an effort that was praised by the UN General Assembly (2000). ${ }^{3}$ The proximity of the US to Honduras at different levels resulted in an unprecedented high level of attention to Mitch (Halperin and Michel 2000). Starting with civil and military relief operations, multiple offices of the government, civil society organizations and private citizens supported the response. Relief operations alone totaled more than US\$300 million (USAID 2000), including civilian and military assets. More than a thousand troops were deployed from a US base in the country (Halperin and Michel 2000). The US president, the first lady and several government delegations visited the affected areas. As for the EU, the major humanitarian initiative funded by the European Civil Protection and Humanitarian Aid Operations (ECHO) was a regional response and rehabilitation projects between 1998 and 2000, which provided 39.79 million Euros.

Support from Japan after Mitch was also unprecedented: it was the first time the Japanese Self-Defense Forces were deployed after a natural disaster outside of the country. The 185 members in the mission began by installing a provisional hospital at the center of Tegucigalpa and providing support for public health activities; Japanese assistance was recognized as being among the quickest to arrive (ECLAC 1999, 29). The mission included a team of 14 Japan International Cooperation Agency (JICA) staff who undertook a survey - mainly in Honduras and Nicaragua - and developed a 'grand design' for reconstruction that was presented at the Washington DC meeting. Similar plans that may have been developed by other donors are not referred in the available accounts of the emergency response 
process, although all of them are likely to have coordinated under the umbrella of the national plan and the donor coordination group, as explained below.

It is important to note that this flood of resources benefitted civil society organizations, which became valuable implementing partners, and attracted a significant number of international NGOs. d'Ans (2008, 167-168) quotes a journalist's report in 2001 that found 1,500 NGOs had been authorized to work in the country, although official records only reported 150; later that year it was disclosed that at least 5,186 NGOs had been given legal status. Several interviewees who were working or had worked for NGOs began their roles in Honduras following Mitch. There are cases of organizations such as Oxfam, which started after Mitch with relief activities, but were not undertaking any activities related to DRR at the time of this survey. Some of these employees also moved from NGOs to international organizations or the government, as emerging disaster-related activities and institutions grew out of the tragedy. Civil society and NGOs were then able to play an important role in seeding prevention activities by implementing projects designed by them or others. d'Ans (2008) states that they shared a budget of US $\$ 70$ million dollars annually, thereby nurturing human resources that would help in managing the DRM system in later years.

Support for a greater role of NGOs and civil society during the relief phase was the result of pressure from the international community. The rationale for this was that an inclusive process would improve the planning and execution of reconstruction. The initial leaders' declaration merely mentions recovery-related actions, which was the main concern brought to the table in Washington. Fuentes (2009) describes an internal tension in Honduras between the government and civil society, with the former trying to develop a plan quickly through a closed, ad-hoc Reconstruction Cabinet, while civil society groups set out a more inclusive approach. National governments were asked by donors and international organizations in Washington DC to consult with civil society. This was the first time that 'transformation' was suggested as a leading concept for the implementation of recovery plans. The inclusion of bottom-up consultations was the first substantive undertaking that can be attributed to the 'transformation' framing, thus broadening the agenda of recovery actions under consideration.

\section{Prevention through recovery: Building back better?}

The Honduran government prepared the first draft of its Master Plan for National Reconstruction and Transformation (PMRTN) for the meeting in Stockholm in May 1999. The government projected the end date for the reconstruction in 2001 and included a vision for long-term sustainable development. There were four thematic priorities:

1 fight poverty and human development;

2 reactivate the economy through productive employment;

3 sustainable protection of natural resources; and

4 strengthening of democratic participation (Yanguas 2013). 
Priority 2 corresponded to reconstruction goals, while Priority 1 comprised the country's development plan. Priorities 3 and 4 were much more closely associated with the goal of transformation. As a concept, transformation was further explicated in Stockholm, where six principles and goals were agreed:

- $\quad$ reduce the social and ecological vulnerability of the region as the overriding objective;

- reconstruct and transform Central America on the basis of an integrated approach of transparency and good governance;

- $\quad$ reinforce the process of decentralizing governmental functions and powers with the active participation of the civil society;

- $\quad$ promote respect for human rights as a permanent objective, giving special attention to promoting equality between women and men and to the rights of children, ethnic groups, and other minorities;

- coordinate donor efforts guided by priorities set by the recipient countries; and

- intensify efforts to reduce the external debt burden of countries in the region.

The first four principles were included in the PMRTN, as is evident in the commitments published by the Honduran government with the addition of a specific mention of infrastructure. Figure 8.3 shows that around 40 percent of the budget was committed to reconstruction, 30 percent to poverty reduction. The remainder was used for transformation through promotion of DRR and several other agendas that can be loosely connected to governance and inclusive development. I will discuss the latter in the following two sections but, firstly, given the size of

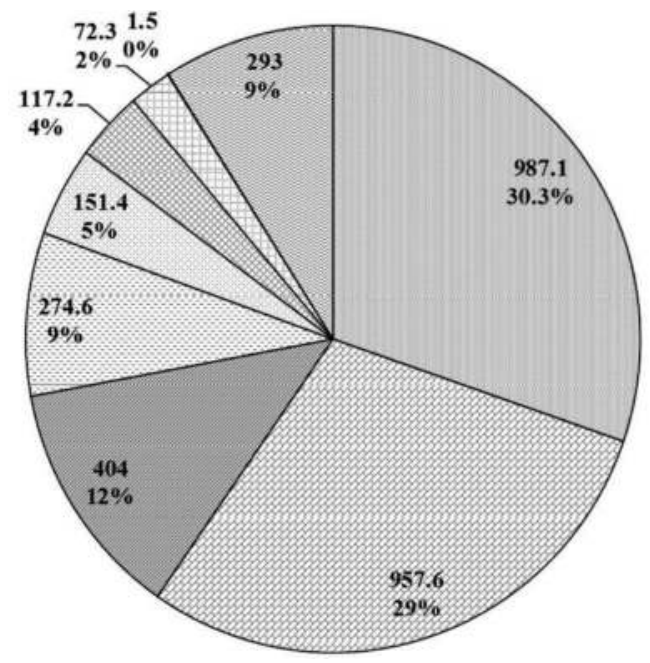

\author{
Fighting poverty \\ Infrastructure \\ Economic Reactivation \\ Natural resources and Risk \\ management \\ $\square$ Balance of payments \\ Transparency and efficiency \\ Democratic participation \\ Gender, childhood, ethnic groups \\ $\square$ Others
}

Figure 8.3 Commitments to the reconstruction process (US\$ millions, percentage). Source: author, based on data from Gobierno de la República de Honduras (2003). 
reconstruction share, it is necessary to inquire as to what extent prevention was promoted through reconstruction.

As mentioned in the introduction, the BBB mantra had still not achieved global recognition when Mitch hit Central America; however, it could be argued that it was already a shared practice. In spirit, the Stockholm principles appeal to more than merely 'building back as before' and, indeed, US assistance had previously mentioned BBB (USAID 2000), while Japanese assistance was inspired by similar ideas. Therefore, in this section, I explore some of the connections and disconnections between recovery and prevention.

From this research, at least two major factors influencing the sustainability of recovery can be identified, namely: the trade-off between speed and quality, and the lack of local and practical knowledge or capacities. One additional indirect factor specific to donors also deserves attention; namely, their previous experience in the country. These three are obviously interrelated, since lack of knowledge can be the result of not including local actors, perhaps because there was insufficient time or previous experience. However, for the sake of this analysis, I will treat them separately.

It is important to keep in mind that the recovery process was mainly supplydriven (i.e., the government adopted an 'all aid is welcome' policy) and, to some undetermined extent, the implementation was characterized by low national involvement (Telford et al. 2004). The Honduran government requested a total of US $\$ 4,000$ million at the Stockholm meeting, an amount that was received with skepticism because of doubts about the country's absorption capacity. However, the government still received commitments for US\$2,939 million. About half of this consisted of grants and the other half loans, of which 60 percent had been disbursed by November 2002 (Gobierno de la República de Honduras 2003). Another US $\$ 319.1$ million was added from local resources, comprising 10 percent of the overall total. Yet, after mining the public expenditure data, Valenzuela (2009) only finds reports of US\$63 million provided for reconstruction between 1998 and 2001, which attests to the difficulty of determining the actual flow of resources and validates the supply-driven qualification.

The trade-off between speed and quality seems to be the most prominent limiting factor. While ECLAC (1999) had already suggested that, in the ideal case, reconstruction would take seven years, the official plan was devised for only three. The final report of the reconstruction in 2003 shows that 40 percent of funds were still to be disbursed, suggesting that much work remained to be done. Yanguas (2013) suggests that transformation had replaced reconstruction by the year 2000, at least at the planning level, in as much as the preparation of the country's Poverty Reduction Strategy Paper (PRSP) was already under way. I discuss this factor further below, but it is relevant to observe here that presidential change of office was due to take place in January 2002. The hurricane obliged President Flores to devote his entire mandate in responding to the emergency, so the PRSP was an opportunity to leave a plan that extended beyond the recovery. This highlights some of the domestic political pressures underlying the planning process. 
The impact of this rush to reconstruct was mainly that a budget for maintenance was omitted from the investments. An ex-post evaluation made by the Honduran Fund for Social Investment ${ }^{4}$ (Fondo Hondureño de Inversión Social 2005, VII), with a sample of 32 from 2175 emergency projects, found that reconstruction designs included provisions against future disasters, but lacked capacities and plans to operate and maintain the work. The very same problem has been reported in regard to US cooperation. Funding from the US government was channeled through the Central American and Caribbean Emergency Disaster Recovery Fund. The fund, created in May 1999, contained a total of US\$621 million dollars, with US\$291 million to be used in Honduras alone. This generous support was initially supposed to be totally used before September 2000, but disbursement of funds did not start until January of the same year. The US Agency for International Development (USAID) managed to reach an informal agreement with the US Congress to extend the deadline to December 31, 2001 (US General Accounting Office 2002). Despite this extension, even two years and seven months were too short, and several projects had to be rushed, sacrificing technical, social quality and, in consequence, sustainability. In particular, Lichtenstein (2001) stressed that all the efforts put towards infrastructure development without corresponding resources and capacities for maintenance were due to be lost. Only 80 percent of the resources set aside for Honduras had been utilized by the extended deadline.

On the other hand, there is no evidence that Japanese aid was rushed or quality sacrificed for speed. By February 1999, a new survey team was deployed, gathering requests for help in five areas:

1 bridges and roads;

2 water, sewerage and health;

3 schools and education;

4 housing; and

5 agriculture and fisheries.

The first two sectors received special attention: seven bridges were rebuilt or reinforced around the country and the Tegucigalpa water system was rehabilitated. The Tegucigalpa water system project was completed in 2003, the new bridges were built between 1999 and 2009 (MOFA and JICA undated), and all of them have stood against subsequent disasters. It should be noted, nonetheless, that these few well-known but very expensive projects comprised most of the Japanese contribution; thus they were not expected to have many of the complications faced by USAID, which worked with 12 other US departments and agencies. ${ }^{5}$

The second problem, lack of knowledge or capacities to build back better, was also mentioned in several documents (e.g., d'Ans 2008; Telford et al. 2004; US General Accounting Office 2002). One of such capacities was the absorbing capacity of Honduran institutions, since national actors were not in a position to use all the money requested for the recovery. In the case of donors, evaluations of US assistance recognize that it was the first time USAID had confronted such 
a reconstruction process, and for many of the 12 US partners mentioned above, it was the first time to take part in international cooperation projects. NGOs are considered to have lacked the expertise required for the recovery projects, with donors suggesting that the lack of local capacities was one reason for relying on foreign contractors (Telford et al. 2004). ${ }^{6}$ The housing sector received particular attention, since provisional shelters built by local engineers and supported by the Red Cross remained functioning for more than four years, while large resettlement programs were less than successful. Still, Suárez and Sánchez (2012) show how housing was one of the most resilient sectors to disasters following Mitch, while losses to the water supply, infrastructure and education sectors were considerable. A possible explanation is that while the quality and delays in the housing component resulted in multiple criticisms, exposure to new disasters was at least addressed through relocation-housing does not suffer from maintenance problems.

Finally, regarding donors' knowledge and experience in the country, it is worth noting the contrast between the performance of the EU, US and Japan. When Mitch hit, the EU was in the process of regionalizing operations, and for Central America, this meant moving the locus of management from its Brussels headquarters to Managua, Nicaragua. However, there was no EU delegation in Tegucigalpa until 2005 (ADE-DRN 2012), so projects had to be controlled remotely. This underlies the most important weakness of the EU recovery plan: it was designed without the participation of national counterparts (European Court of Auditors 2008). In practice, the major interventions of the reconstruction plan did not start until five or six years after Mitch, and subsequent evaluations suggest it was more a development program than a reconstruction one (Barnini et al. 2009). Besides relief, ECHO undertook rehabilitation programs, making resources available for health, temporary shelter, economic reconstruction and water and sanitation for the first two years. Schrikkema (2001) presents an evaluation of the rehabilitation sector, but because it is regional and prepared right after the end of the projects, no specific details about Honduran experience and its sustainability can be found.

On the other hand, donors with a long-standing presence in Honduras, such as the US and Japan, used their established partnerships with local institutions to make the most of their contributions. The donor coordination group could have played the role of equalizer for other donors, providing opportunities to those with less experience in the country to local stakeholders, especially as it included not only diplomatic consultations but also technical and sectoral ones (Yanguas 2013). The performance of the EU suggests that solid coordination is not enough.

\section{The disaster-prevention phase}

The above sections examined many of the overlaps and connections between prevention and the other phases of crisis management. This section focuses on the prevention phase itself. The master plan for the recovery suggested that the 
prevention phase was made of two major groups of efforts: the first was composed of plans for natural resource management - basically river basins management, forestry and land planning - and the other consisted of consolidation of the DRM system, revolving around (but not exclusively about) the future role of COPECO. These two components were assigned 8.4 percent of all reconstruction commitments - 5.4 percent for natural resources and 3 percent for DRMas shown in Figure 8.3. The share of the budget seems very low, although in theory other components should have incorporated a DRR component.

The way in which the prevention phase continues after reconstruction efforts finish can be seen in how the country's PRSP — which replaced the PMRTN in 2002 - maintained natural resource management and the DRM system as part of the government agenda, at least on paper. Prevention was considered to be the 'sustainability of the strategy,' although diluted with other transformation agendas. Government and donors agreed to use the enactment of legislation and the formulation of disaster management plans as indicators of progress (Gobierno de la República de Honduras 2001, 2004, 2005). As a result laws on territorial planning, water resources, forests and DRM were promulgated between 2004 and 2009, and great efforts were undertaken to prepare municipal plans - although, as Suarez and Sanchez (2012) stress, the real challenge was and still is implementation.

There were two major issues that shaped the prevention phase, namely: the need to rethink existing institutions working on disasters based on the Mitch experience; and, underlying this, the issue of conciliating different strands of work relevant to DRM. These two partially overlap with the two groups of efforts described above. I will examine each of these in turn.

The creation and development of the DRM system in Honduras was entrusted to COPECO, the office normally in charge of emergency response and preparedness, as well as providing support during recovery (Talavera-Williams and Canales Aguilar 2008). As noted above, COPECO was overwhelmed by Hurricane Mitch and, therefore, both relief and recovery had to be managed by other ad-hoc offices. Consequently, COPECO was reformed in 1999 and the first official National Commissioner was appointed that year. ${ }^{7}$ From that point onward, a process of institutional strengthening followed, beginning with new offices, along with equipment and capacities at the central level, and gradually reaching the country's regions. All donors provided some contributions to this process of capacity-building, aimed mostly at preparedness. Levels of support reached the point that some dependence on aid - at least during the first decade - was mentioned in the interviews. ${ }^{8}$

COPECO was traditionally an emergency response office and, therefore, a good share of the resources that poured in right after Mitch were used to strengthen their response as well as early warning capacities (Arita Orellana 2003). For instance, the US invested US $\$ 16.2$ million dollars to improve the region's hydro-logical and meteorological forecasting, early warning, and preparedness capabilities, as well as improving the resilience of coastal communities at risk from the impacts of tropical storms and hurricanes' (Showstack 2001). 
This was mainly aimed at improving remote sensing and other measurements. Donors also mentioned programs for community-level preparedness, such as the Central American Mitigation Initiative, ${ }^{9}$ the Disaster Preparedness ECHO Programme and Japanese-funded BOSAI (JICA 2012), and other forms of capacity-building and equipment provision.

Capitalizing on its expertise, COPECO devoted four years of efforts (from 2002 to 2006) to developing the National System of Civic Protection in order to create a robust response structure capable of dealing with any type of disaster, while centralizing functions and authority (Talavera-Williams and Canales Aguilar 2008, 15). However, the international vision of DRM was rapidly changing, and pressure was growing to prioritize prevention and risk management over response (e.g., UNDP and CEPREDENAC 2004), thereby turning the DRM system on its head. At a meeting in Guatemala in 1999, the Central American Coordination Center for Natural Disaster Prevention (CEPREDENAC) promoted the adoption of a Strategic Framework for Vulnerability and Disaster Reduction in Central America, focusing on vulnerability and the integrated management of water resources and forests. This was precisely the other group of efforts for prevention suggested in Honduras but not the original plan of COPECO, which represented the country at CEPREDENAC. Consequently, the civil protection proposal was not welcomed by organizations involved in the meeting, including NGOs and UN agencies. The proposed legislation was subsequently dropped in 2006 and replaced with a National System for Risk Management. This law was finally approved in 2009 in the middle of the national political crisis.

COPECO's reluctance to engage in the development of a comprehensive system can be explained in terms of its existing and lacking capabilities. On the one hand, it had a tradition of response-oriented work and received a great amount of international support to continue playing that role; this capacity remains at the heart of COPECO's operations even today. On the other hand, in order to coordinate the DRM, it was necessary to be able to influence a large group of national institutions, particularly ministries, many times bigger and more powerful than COPECO. Those actors were necessary in moving forward large-scale, systematic work on mitigation and prevention, and it was evident that COPECO's position was weak. One alternative would have been to promote line ministries' ownership of DRR. Indeed, the challenge of using the crisis to commit and combine a wider set of government actors to disaster prevention is the second issue underlying this phase in Honduras.

The issue of committing and combining different strands of work relevant to DRR was problematic in Honduras from the very beginning. The two groups of prevention efforts conceived during the recovery, natural resources and the DRM system, were put together on a single coordination table in the donor coordination mechanism, which Yanguas $(2013,39)$ suggests failed to work properly because of the combination of topics. Yanguas also raises the issue of the scarcity of international cooperation staff dedicated to DRM as one of the reasons for this table not working adequately, which suggests the lack of capacity was also present from the supply side. The absence of the infrastructure sector in leading 
prevention was also a negative factor. The secondary priority of prevention in the middle of recovery, when combined with lack of experience, thus contributed to the lack of systematic approach.

Water and forestry sectors worked in parallel, each of them characterized by different institutional settings with overlapping responsibilities - and thus also conflicts. They received a greater share of the prevention budget but for this survey, I could not identify major disaster prevention-oriented capabilities developed during those years, perhaps with the exception of risk evaluation for infrastructure, mentioned as part of 'recovery.' The failure to influence local institutions was a prominent deficiency in EU support, which included an emphasis on water between 2002 and 2007, and forestry between 2007 and 2011. It assigned each of these sectors a total of around 60 percent of its recovery program, and 45 percent of the resources of its 2002-2006 strategy. However, an evaluation of this work found that the Honduran government continued to have 'no real committed policy in this sector and no policy dialogue was conducted on the causes of resource mismanagement or in support to a national agenda on natural resources management' (ADE-DRN 2012, 25). Interviews with staff at several of the involved institutions suggest that cooperation served as a means for each ministry to recover and continue with their roles prior to Mitch. Donors gave priority to the more affected areas at the beginning of operations; however, these were also areas that had better levels of human development (UNDP 1999). Therefore support was quickly moved back to poorer areas in order to promote poverty reduction and the Millennium Development Goals.

It is worth observing that, while a prevention phase that included more than preparedness can be observed in Honduras as a whole, the same is not true for donors. Particularly conspicuous is the decision of the US to forego a specific component for DRM after the recovery was over, opting instead to integrate it back into the entire program (USAID 2003). This decision made it difficult to trace back efforts towards DRM and, as the evidence suggests, it was not a successful strategy. A country goal on 'Providing Humanitarian Assistance' was included again in the 2009-2013 country assistance strategy, dealing with forestry and preparedness (USAID 2009). DRM through European development cooperation was present on paper, but an evaluation found no actions had been planned - apart from funds for strengthening COPECO (ADE-DRN $2012,51) .^{10}$

The case of Japan is a little different because prevention is something that is ingrained in JICA's vision. The JICA project formulation survey that visited affected countries roughly one year after the calamity already aimed to move 'from reconstruction to prevention' (JICA 2000). Between 2001 and 2002, a study concerning flood control and landslide prevention in Tegucigalpa city was prepared (JICA 2002), which served as a reference point for subsequent DRM activities. The 2000 formulation survey gave way to a regional project on DRM between 2007 and 2009, combining activities at the international, national and local levels in six countries at the time, with a budget of around US $\$ 4.5$ million (JICA 2012). Major mitigation projects proposed in the 2002 study commenced in 2011. 
Although somehow beyond the time frame of this chapter, it is worth noting that, since 2012, support has been given to local universities in order to create their own maps and tertiary-level expert knowledge on landslides. This is expected to ensure that the technical expertise necessary for prevention is engendered locally (JICA and IDCJ 2016).

In parallel, national and international humanitarian organizations in Honduras started their own 'humanitarian network' in 2010 to support COPECO in its preparedness work through the application of international standards and the humanitarian cluster system. This initiative was initially not seen positively by local authorities, who even now frown at the way that humanitarian resources bypass government institutions; however, collaboration has improved through the years.

In sum, the prevention phase after Mitch was a slow process through which a DRM system started to be formed in Honduras. The goal of promoting a general ownership of DRR was attempted - somewhat fruitlessly - although advances in preparedness and early warning were achieved. The conflicting visions between the expertise of local institutions and international discussions about DRM systems contributed to the poor performance, as well as lack of expertise and vision of the donors when connecting recovery and prevention. A puzzling characteristic of the emphasis on water and forestry for prevention is that this survey did not find any technical documents justifying the investment in these sectors as effective measures to deal with disasters in Honduras, except for the technical study conducted by JICA in Tegucigalpa. Not all floods and landslides can be prevented by river basin management and planting trees. This dimension, concerning the impact of the investments, requires much greater attention but was beyond the scope of this research.

\section{Beyond the continuum}

Before closing, it is important to mention some additional phenomena that were deeply connected to the disaster, but that do not fit into our proposed model of the crisis management continuum - overlapping phases of relief, recovery and prevention. These are the cancellation of Honduran foreign debt and a steep rise in migration to the US. The two show how the continuum is itself part of a wider range of processes under way in each society that do not evolve in isolation but heavily influence each other.

Perhaps the most important of these phenomena at the political level was how the Honduran government used the disaster as a means for inclusion in the Heavily Indebted Poor Countries (HIPG) initiative. The issue of foreign debt moratoria and possible debt cancellation was central to the aftermath of Mitch, as it was clear in the first joint declaration in 1998. The government of Honduras had been negotiating with the US, the Banks and the International Monetary Fund (IMF) since 1991 but in 1998, before the disaster, its debt was declared sustainable, and thus it was ineligible for debt relief under the HIPG (UNDP 1998, 71-73). 
Mitch reversed this situation, not only because of the foreseeable worsening of the fiscal situation but also because the successful donor-coordination strategy, which included the IMF, gave impetus to calls for renewed negotiations. In July 2000 the World Bank and the IMF decided that Honduras could be included in the HIPC and so, less than two years after the catastrophe, preparations to realize the benefits of the program had already started. Proof of the relevance of this process for donors can be seen, for instance, in the reports of the Ministry of Foreign Affairs of Japan about assistance to Honduras (MOFA 1999, 2000, 2001, 2002), which paid much greater attention to debt relief and its monitoring, with only passing mention of the reconstruction efforts.

A major requirement for this was the preparation of the country's PRSP (Gobierno de la República de Honduras 2001), which replaced the recovery plan in 2001. The PRSP merged the Stockholm principles with IMF requirements, thus diluting the focus on prevention, as discussed in the previous section. The formulation required a large-scale consultation process between civil society, the government and the then G-12 donor coordination group. Since the PRSP was to be adopted at the end of the Flores presidency, donors understood from the outset that handing off the plan to the next government would not be easy and tried to involve all the presidential candidates in the process. Nonetheless, the new presidency did not deliver as expected, a point which is reflected in the statements of the donor coordination group (Yanguas 2013) and a report of the World Bank experience after Mitch (Telford et al. 2004). Regardless, the new government focused on culminating the HIPG process, which finally happened in 2005.

In relation to the prevention phase, it is important to note how the PRSP displaced crisis management from the agenda. While it is true that the components of prevention from the reconstruction plan were maintained, they were combined with other elements of the 'transformation' agenda into a single item titled 'Guaranteeing the Strategy's Sustainability.' The budget allocation was 8.5 percent, similar to the previous one. While the total budget of the PRSP was around 80 percent of the recovery commitment, it was now distributed among many more interventions, including transparency, democratization, rule of law and public security (Gobierno de la República de Honduras 2004). Furthermore, the experience shows how the recovery agenda gradually became a development plan - already inserted from the start as poverty reduction - while sectors linked to DRR were displaced and combined with other agendas, diluting its importance both in visibility and in monetary terms.

Second, another phenomenon that became significant in the long run was the petition for amnesty for illegal migrants, mainly in the US - which was also included in the very first declaration of the Central American governments. The US has a legal provision to offer temporary protected status (TPS) or relief from removal for foreign nationals coming from places suffering from humanitarian crises (Seghetti, Ester and Wasem 2015). On December 30, 1998, undocumented Hondurans and Nicaraguans were granted TPS, a status that has been extended since then until January 2018. ${ }^{11}$ In fact, Hurricane Mitch is seen as a watershed in the migration of Hondurans to the US. The expatriate community has kept 
growing to the point of becoming close to 10 percent of the population and, consequently, remittances have become one of the largest sources of income, totaling 20 percent of GDP by 2007 (Inter-American Development Bank 2008). The amount of remittances is three times larger than foreign direct investment, and over five times international cooperation funds received in 2008, as reported by the OEGD. This money is expected to play a crucial role in self-help and recovery after disasters, considerably greater than international cooperation, yet it has received limited attention until recently.

\section{Conclusions}

The aim of this chapter was to examine the prevention phase of crisis management after Hurricane Mitch in Honduras and its overlaps and connections with relief and recovery in order to understand the challenges underlying the continuum. The review showed that the core of the prevention phase consisted of crystalizing and making operational the country's DRM system - a particularly intricate challenge (Ishiwatari 2015). This challenge included two overlapping issues, one related to the evolution of COPECO, the existing institution mostly in charge of response to disasters, and the other to intertwining the different strands of work relevant to DRM - mainly, water resources, forestry, and infrastructure - in a way that resulted in wider scale ownership of the government.

Given the existing capabilities, advances in preparedness proved successful in the long run, but wider structural change was not possible for the first ten years after the disaster, although it is an ongoing process. Since there was no shared vision about the role of COPECO after Mitch, it took eight years to agree on how to reconcile existing capabilities for response with the all-embracing coordination needs of the DRM system. ${ }^{12}$ COPECO, as the visible coordinator of all DRM activities, has helped to push forward the agenda, but one cost of this is that no line ministries have developed ownership of it, losing the opportunity to promote the mindset change required for DRM at other levels. Therefore, during the period investigated, most of the sectoral work seems to have moved from an emergency mode during recovery to business as usual, while donors pour resources into sectors and COPECO without concrete links to building the DRM system. Only Japanese support seems to have had a more structural impact on the consolidation of the DRM system by linking expertise to long-term vision, and undertaking projects more than a decade after being proposed.

I also showed that the prevention phase has roots in relief and recovery activities. The latter is particularly important as the seeds of prevention have been planted as part of reconstruction plans, while the task of making the recovery more resilient still constitutes a huge challenge. In this sense, the trade-off between quality and speed resulted in an accelerated reconstruction process that is likely to be wasted in subsequent disasters. This was particularly salient locally and for US support, which was under political pressure to finish recovery activities quickly, despite awareness of scarce absorption capacity and unaccountedfor maintenance needs. Yet the Japanese and EU experiences show that it was 
possible to support sectors related to prevention despite official declarations of phase change. Again, longer term planning for recovery - which, in the case of the EU, happened by accident - seems to explain different performances by donors. For local actors, however, the (political) need to return to normality seemed inescapable.

The difference between EU and Japan suggests that lack of expertise in DRM was also a limiting factor, which was not exclusive to donors but to all the actors, including implementing partners. These entered the scene during the relief phase and then attempted activities for recovery and even prevention, learning from their experiences and, thus, making mistakes in the process. ${ }^{13}$ Particularly problematic is how promoting civil society participation in planning for recovery contributed to displacing prevention from the agenda, since other 'transformation' agendas also diluted prevention as a focus for action. If the civil society view reflects what the general public thinks, then the great potential of remittances for relief and recovery will not have an impact in promoting prevention. It is worth stressing that at least the response capabilities in Honduras have been indeed strengthened and the loss of lives after subsequent disasters has been reduced, so moving to structural measures seems to be where the challenge remains.

Therefore, perhaps the most striking finding of the research is how prevention plays a minor role in the initial plans made during the emergency for the recovery, and how easily it gets displaced from the agenda afterwards. The opportunity to join the HIPC program was a perverse incentive against mainstreaming prevention. This shows that from the outset, the possibility of a robust link between disaster relief, recovery and prevention was greatly constrained. Retaining the momentum for prevention was mostly beyond COPECO and donor capabilities, but at least the latter were in the position of changing incentives. Actors involved in the promotion of BBB need to learn this lesson, and try to resist the temptation of attempting broader social transformations, when mainstreaming DRM is difficult enough.

\section{Notes}

1 By that time, Spain had also started major projects in relation to the Millennium Development Goals. Clarification on this point was kindly obtained from Maria Bella and Fernando Bonilla of Spain's Cooperation Office in Tegucigalpa.

2 Despite a notable initial push and remaining a top donor, there is scarce information about Japan's support after Mitch. An external effort in 2001 to gather information about JICA activities had already led to difficulties in accessing it (Challenge One Associates 2001). Aid provided from the embassy is particularly difficult to trace: the Ministry of Foreign Affairs (MOFA) prepares yearly data books on Official Development Assistance (ODA) but these contain only very basic information. Besides this, reports of individual projects by JICA are available online - mostly in Japanese. The first available document about Mitch as a whole is a pamphlet for the tenth anniversary (MOFA and JICA undated). This pamphlet, for instance, reports that contributions were made through multilateral agencies of close to US\$30 million, which cannot be traced. The only other publication after this pamphlet is a review by JICA 
and IDCJ (2016). Therefore, information about the interaction between the Honduran government plans and Japanese ODA is very limited.

3 This was one of the first operations of the newly created Office for the Coordination of Humanitarian Affairs. The first UN House (i.e., a single building where all local UN agencies share offices) in the world was constructed in Tegucigalpa following the emergency.

4 The FHIS is a national agency that helped in implementing reconstruction process.

5 These were: the Environmental Protection Agency, the Centers for Disease Control and Prevention, the Federal Emergency Management Agency, the National Oceanic and Atmospheric Administration, the US Department of Agriculture, the US Geological Survey, the Department of Housing and Urban Development, the Department of Transportation, the US Department of State Bureau for International Narcotics and Law Enforcement Affairs, the Export-Import Bank, the Overseas Private Investment Corporation and the Peace Corps.

6 Telford et al. (2004) criticize this justification for using foreign contractors, affirming that competent local companies existed in Honduras. An interviewee from the office in charge of infrastructure suggested that, depending on the technologies used, foreign support for infrastructure construction was necessary, yet agreed with Telford et al.

7 See http://copeco.gob.hn/que-es-copeco. According to an interviewee, before this, COPECO was still under military management, although in 1990 it was separated from the armed forces.

8 The share of the national budget for DRM has reportedly increased in recent years, seemingly connected to greater participation from the Ministry of Finance.

9 CAMI was a US $\$ 11$ million program that provided trainings between 2001 and 2004 to a wide spectrum of stakeholders, particularly at the community level (USAID Office of Inspector General 2005). Funds came from the Mitch initiative. The project inspired subsequent work on risk management by OFDA.

10 Fruhling (2002) found the same disconnect with prevention in Swedish cooperation projects.

11 This is only a small fraction of all Hondurans in the US (Suárez and Sánchez 2012), but it is likely to have played a role as a pull factor for subsequent migrants.

12 A different question - beyond this study - would concern whether the decision to put everything under COPECO's roof was the best solution.

13 One interviewee working on a NGO for the community DRR told me: 'if you are not in the disaster area in the three first months, you would not get the contracts.'

\section{References}

ADE-DRN. 2012. Evaluation of the European Commission's Cooperation with Honduras - Country level Evaluation. Two volumes. Rome: Joint Evaluation Unit for External Relations.

Arita Orellana, J. C. 2003. El Caso de Honduras [The Case of Honduras]. In Gestión de Riesgos en Centroamérica: Iniciativa, Actores y Experiencias Locales en El Salvador, Guatemala, Honduras y Nicaragua [Risk Management in Central America: Initiatives, Actors and Local Experiences in El Salvador, Honduras and Nicaragua], edited by G. Gellert, 143-185. Ciudad de Guatemala: FLACSO.

Barnini, M., L. Boccardi, M. Demare, and T. Pijnenburg. 2009. Evaluación Global del Programa Regional para la Reconstrucción de América Central (PRRAC) [Global Evaluation of the Regional Programme of Reconstruction in Central America (PRRAC)]. Final Report. Louvainla-Neuve: ADE.

Challenge One Associates. 2001. Response Capabilities During Natural Disasters at USAID/ OFDA and Applied Issues for FICA. Final Report. Washington, DC: Challenge One Associates. 
Christoplos, Ian. 2006. Links Between Relief, Rehabilitation and Development in the Tsunami Response: A Synthesis of Initial Findings. London: Tsunami Evaluation Coalition (TEG).

D’Ans, A. M. 2008. Honduras Después del Mitch: Ecología Política de un Desastre [Honduras after Mitch: Political Ecology of a Disaster]. Tegucigalpa: Centro de Documentación de Honduras.

ECLAC. 1999. Honduras: Assessment of the Damage Caused by Hurricane Mitch, 1998. LC/ MEX/L.367. April 14. Economic Commission for Latin America and the Caribbean.

Ensor, B. E., and M. O. Ensor. 2009. Hurricane Mitch: Root Causes and Responses to the Disaster. In The Legacy of Hurricane Mitch: Lessons from Post Disaster Reconstruction in Honduras, edited by M. O. Ensor, 22-46. Tucson, AZ: University of Arizona Press.

European Court of Auditors. 2008. European Commission Rehabilitation Aid Following the Tsunami and Hurricane Mitch. Special Report No. 6. Luxembourg: European Court of Auditors.

Fondo Hondureño de Inversión Social. 2005. Evaluación Ex-post del Fondo Hondureño de Inversión Social [Ex-post Evaluation of the Honduran Social Investment Fund]. Tegucigalpa: FHIS.

Fruhling. P. 2002. Turning Disasters into Opportunities: Swedish Contributions to Reconstruction $\mathcal{E}^{\circ}$ Transformation in Central America after Disaster Mitch. A Review Commissioned by Sida. Stockholm: SIDA.

Fuentes, V. E. 2009. Post-Disaster Reconstruction: An Opportunity for Political Change. In The Legacy of Hurricane Mitch: Lessons from Post Disaster Reconstruction in Honduras, edited by M. O. Ensor, 100-125. Tucson: University of Arizona Press.

Gobierno de la República de Honduras. 2001. Estrategia para la Reducción de la Pobreza: Un Compromiso de Todos por Honduras [Poverty Reduction Strategy: Everyones' Commitment to Honduras]. Tegucigalpa: Gobierno de la República de Honduras.

- 2003. Informe Final de la Reconstrucción Nacional: Logros y Lecciones del Proceso [National Reconstruction Final Report: Achievements and Lessons from the Process]. Tegucigalpa: Gobierno de la República de Honduras.

2004. Honduras: Poverty Reduction Strategy Paper Progress Report. International Monetary Fund Country Report No. 04/30. Tegucigalpa: Gobierno de la República de Honduras.

- 2005. Honduras: Poverty Reduction Strategy Paper Progress Report. International Monetary Fund Country Report No. 05/82. Tegucigalpa: Gobierno de la República de Honduras.

Halperin, M. H., and J. Michel. 2000. Interagency Review of US Government Civilian Humanitarian and Transition Programs. http://pdf.usaid.gov/pdf_docs/Pdabw490.pdf.

Honduras Health Secretary and Pan-American Health Organization. 1999. El Huracán Mitch en Honduras [Huricane Mitch in Honduras]. In Crónicas de Desastres-Huracanes Georges y Mitch [Chronicles of Disaster-Hurricanes Mitch and Georges]. Washington, DC: Honduras Health Secretary and Pan-American Health Organization.

Inter-American Development Bank. 2008. International Remittances in Honduras. Mexico D.F.: Centro de Estudios Monetarios Latinoamericanos. Inter-American Development Bank.

International Federation of Red Cross and Red Crescent Societies. 1999. World Disasters Report. Geneva: IFRC.

Ishiwatari, M. 2015. Disaster Risk Management at the National Level. In Disaster Risk Management in Asia and the Pacific, edited by I. Davis, 232-251. Abingdon: Routledge.

JICA. 2000. Chuubei 'harike-n Fukkou-bousai Taisaku' Purojekutokeiseichousa [Central America 'Hurricane Recovery-Disaster Reduction Countermeasures' Project Formulation Survey]. Tokyo: JICA. 
2002. Study about Flood Control and Landslide Prevention in the Metropolitan Area of Tegucigalpa, Honduras. Tokyo: JICA.

- 2012. Chuubeikouiki Bousai Nouryoku Koujou 'BOSAI': Shuuryouji Hyouka [Central America Regional Project on Disaster Risk Reduction Capacity Improvement 'BOSAI': Terminal Evaluation]. Tokyo: JICA.

JICA and IDCJ. 2016. Chuubeichiiki-Dominika Kyouwakoku Niokeru FICA Kyouryouku Fireibunseki Gyoumu: Chuubei Tougoukikou Kameikoku to no Kyouryoku no Ayumi [Analysis of JICA Cooperation Projects in Central America and the Dominican Republic: Steps on the Cooperation with the Members of Central America Integration System]. Tokyo: JICA and International Development Genter of Japan.

Lichtenstein, J. 2001. After Hurricane Mitch: United States Agency for International Development Reconstruction and the Stockholm Principles. Briefing paper 01, Washington DC: Oxfam America.

MOFA. 1999. Seifukaihatsuenjo Kunibetsu de-Tabukku [Data Book of Country-by-Country Official Development Assistance]. Tokyo: Ministry of Foreign Affairs, Japan.

- 2000. Seifukaihatsuenjo Kunibetsu de-Tabukku [Data Book of Country-by-Country Official Development Assistance]. Tokyo: MOFA.

- 2001. Seifukaihatsuenjo Kunibetsu de-Tabukku [Data Book of Country-by-Country Official Development Assistance]. Tokyo: MOFA.

- 2002. Seifukaihatsuenjo Kunibetsu de-Tabukku [Data Book of Country-by-Country Official Development Assistance]. Tokyo: MOFA.

MOFA and JICA. Undated. Mitch+10: Trayectoria de Desarrollo después del Mitch. Tegucigalpa: MOFA and JICA.

Schrikkema, B. 2001. Central America Hurricane Mitch, Global Plans 1998, 1999 and 2000: Rehabilitation Sector. ECHO/EVA/210/2000/01007. Brussels: European Commission.

Seghetti, L., K. Ester, and R. E. Wasem. 2015. Temporary Protected Status: Current Immigration Policy and Issues. Washington, DC: Congressional Research Service.

Showstack, R. 2001. NOAA Set to Wrap up Most of its Hurricane Assistance to Central America. Eos 82(36), 396-398.

Suárez, G., and W.J. Sánchez. 2012. Desastres, Riesgo y Desarrollo en Honduras [Disasters, Risk and Development in Honduras]. Tegucigalpa: UNDP.

Talavera-Williams, C. G., and S. Canales Aguilar. 2008. La Gestion de Riesgos contra Inundaciones y el Cambio Climático en Honduras [Flood Risk Management and Climate Change in Honduras]. Tegucigalpa: Christian Aid.

Telford, J., M. Arnold and A. Harth, with ASONOG. 2004. Learning Lessons from Disaster Recovery: The Case of Honduras. Washington, DC: World Bank.

Torres, M. 2004. Huracán Mitch 1998-2003: Retrato Social de una Tragedia Natural [Hurricane Mitch 1998-2003: Social Portrait of a Natural Tragedy]. Tegucigalpa: Centro de Documentación de Honduras.

UNDP. 1998. Informe sobre Desarrollo Humano Honduras 1998: Por un Desarrollo Incluyente [Honduras Human Development Report 1998: For an Inclusive Development].Tegucigalpa: United Nations Development Programme.

- 1999. Informe sobre Desarrollo Humano Honduras 1999: El Impacto Humano de un Huracán [Honduras Human Development Report 1999: The Human Impact of the Hurricane]. Tegucigalpa: UNDP.

UNDP and CEPREDENAC. 2004. Memoria Foro Regional Mitch +5: ¿Dónde estamos y para dónde vamos? [Mitch+5 Regional Forum Report: Where are We and Where are We Heading?]. Panama City: UNDP and Centro de Coordinación para la Prevención de los Desastres Naturales en América Central. 
UN General Assembly. 2000. International Cooperation on Humanitarian Assistance in the Field of Natural Disasters from Relief to Development. A/RES/54/233. Geneva: UNGA.

USAID. 2000. Hurricanes Mitch and Georges: From Relief to Reconstruction. The United States'Response. Washington DC: United States Agency for International Development. http:// cidbimena.desastres.hn/docum/crid/Marzo2004/pdf/eng/doc13799/doc13799.htm.

- 2003. Regional Strategy for Central America and Mexico FY 2003-2008. Volume 2: Annex B: Honduras Country Plan. Washington DC: United States Agency for International Development.

. 2009. Honduras: Country Assistance Strategy. Fiscal Years 2009-2013. Washington DC: United States Agency for International Development.

USAID Office of Inspector General. 2005. Audit of the Central America Mitigation Initiative. Audit Report No. 1-515-05-006-P. San Salvador: USAID.

US General Accounting Office. 2002. Disaster Recovery Program Addressed Intended Purposes, but USAID Needs Greater Flexibility to Improve Its Response Capability. GAO-02-787. Washington DG: USGA.

Valenzuela, C. 2009. Linea de base de Gasto Público en Gestión de Riesgo [Baseline of Public Expenditure on Risk Management]. Tegucigalpa: UNDP Honduras.

Yanguas, P. 2013. Coordinación, Cooperación y Planificación: El Grupo de Donantes G-16 en Honduras (1999-2012). Tegucigalpa: World Bank, Honduras Office. 


\title{
9 How can recovery be linked with long-term development?
}

\author{
The case of Indonesia
}

\author{
Mikio Ishiwatari
}

\section{Introduction}

Disasters are unfortunate events but provide opportunities to create a resilient and sustainable society. A more disaster-resilient society can be created by linking relief, recovery, and long-term development. Recovery efforts address the needs of individuals affected by disasters, while development efforts aim to support each society's autonomous path to self-improvement (Commission of the European Communities 2001). Recovery efforts can contribute to the development of better socio-economic conditions in disaster-affected areas and strengthen disaster risk reduction (DRR). The added value of these efforts can be maximized by linking recovery and development.

The purpose of this study is to identify ways through which recovery and long-term development have been successfully linked as part of the continuum of crisis management after major recent disasters in Indonesia. The study examines (i) how disasters provided opportunities for the country to develop disasterresponse mechanisms that help to build a resilient society, (ii) how integrating recovery activities into long-term development could contribute to building a more resilient society, and (iii) how donors could support such efforts in the wake of the Indian Ocean tsunami (IOT) in 2004 and Java Earthquake in 2006. In terms of the continuum, gaps between relief and rehabilitation were generally avoided following IOT (Christoplos 2006, 80). Relief efforts following the Java Earthquake were also rapidly completed and regarded as a success. The gap between relief and rehabilitation that commonly appears in disaster responses was avoided by donors and the Indonesian Government due to the provision of large-scale, flexible, and un-earmarked funding in the wake of IOT and Java Earthquake. Therefore, this study focuses on recovery, DRR and development and, based on the findings from this, recommends practical approaches to address the challenge of the continuum by linking recovery and long-term development.

Methods for this study involved a review of project documents of donors, research papers, and studies. This was followed by semi-structured interviews with 20 experts and researchers from government and non-government organizations, local governments, international organizations, and bilateral agencies 
in Jakarta, Yogyakarta, and Aceh, Indonesia. Topics covered in the interviews included recovery activities and associated issues. Semi-structured interview surveys and group discussions were also conducted with the affected people in three relocation sites and five communities in Yogyakarta and Aceh. All interviews were conducted in December 2015.

The following section describes the damage and impact of the two disasters. In subsequent sections I outline assistance from major donors, and examine the links between relief, rehabilitation and development, and its connection to donors' support. I conclude with a discussion of the key findings and consider the policy implications.

\section{Damage and impact}

\section{Indian Ocean tsunami}

An earthquake of magnitude 9.0 occurred in the Indian Ocean off the coast of Sumatra Island on December 26, 2004, creating a massive tsunami. An estimated 230,000 people died in twelve countries across the Indian Ocean, and over 1.5 million people were displaced. In Indonesia, the devastation left some 170,000 people dead or missing and 500,000 people displaced. The tsunami destroyed or severely damaged some 140,000 houses and as many as 750,000 people lost their livelihoods (BRR 2009).

Aceh was the worst affected province in the country. The regional economy relied on oil and natural gas, which accounted for some 40 percent of the regional gross domestic product (GDP) (World Bank 2006). Aceh's GDP in 2003 accounted for some 2 percent of the GDP of the country. Damage and losses caused by the tsunami were estimated at US $\$ 4.5$ billion, which amounts to almost the same as Aceh's GDP. Housing was the largest sub-sector affected, with US\$1.4 billion damage and losses, accounting for some one-third of the total (Consultative Group on Indonesia 2005). The fisheries sector was also badly affected, with an estimated 15-20 percent of fishermen dying and many of the facilities, boats, and fishing gear destroyed. The sector accounted for 6.5 percent of Aceh's GDP in 2004 and provided employment to 100,000 people.

Before the tsunami, Aceh was also suffering from the effects of a 30-year conflict, which contributed to regional economic fragility. During the conflict, some 10,000 people were killed, with infrastructure and basic services, such as health and education, destroyed. It is estimated that 35,000 people-predominantly women, children, and the aged - were displaced by the conflict when the tsunami struck.

Vulnerable groups suffered most from the tsunami. Women were between 1.2 and 2.1 times as likely to die as men in some regions. This is because men are physically stronger and are more likely to have learned to swim, and are therefore more likely to be able to escape from a tsunami. Furthermore, many women lost their lives trying to save their children and elderly relatives (Oxfam 2014, 9). Death rates were higher for those under 15 and those over 50 (Cosgrave 
2007, 6). Damage and loss assessments are considered to have been biased, since male-dominated teams conducted the surveys and relied on information from primarily male-headed households.

\section{Java earthquake}

The earthquake killed over 5,700 people in the central region of Java Island on May 27, 2006. Damage and losses were estimated at US\$3.1 billion (Consultative Group on Indonesia 2006). The affected area was a densely populated mix of urban and rural communities. Some 154,000 houses were completely destroyed and 260,000 suffered some damage. With nearly 1.2 million people losing their homes - a greater number than in the IOT - damage to private houses made up almost half of the total destruction and losses at US $\$ 1.6$ billion.

The 2006 earthquake also had an impact on local industry in Yogyakarta. Some 650,000 workers were affected by the earthquake. Many of them worked in ceramics, furniture, textiles, weaving, silver and leather manufacturing, as well as food processing, at small and medium enterprises and home-based industries - some 30,000 enterprises were directly affected.

\section{Impacts on development}

While these two disasters had immediate socio-economic impacts on development in Aceh and Yogyakarta, in the middle term, both areas managed to avoid impoverishment and unemployment. The dashboard on major development indicators of the impacts of disasters in Figure 9.1 provides a clear indication of this.

Regional GDP was negative in Aceh in the year following the tsunami. As Figure 9.1a shows, growth rates of regional GDP were negative in five out of the seven years until 2010 and were over 3 percent lower than the National GDP. This is mainly because oil and gas production decreased. The growth rates of regional GDP excluding oil and gas were 7.7 in 2006 and 7.4 in 2007, higher than the national rates (World Bank 2008). The growth rate of Yogyakarta slightly decreased in the year of the disaster but recovered as rehabilitation works progressed.

Unemployment rates in Aceh jumped to 30 percent just after the tsunami (Oxfam 2005b, 4) and hovered at over 10 percent in 2005. Figure 9.1b shows that the rate declined from 2006 as recovery work accelerated. The unemployment rate of Yogyakarta shows a similar trend to Aceh.

Poverty rates in Aceh and Yogyakarta were stable following the disasters but soon returned to a decreasing trend. Some 1.2 million people - accounting for 28.5 percent of the population - were living below the poverty line in 2004 in Aceh. Following the tsunami, an additional 325,000 people faced risks of falling below the poverty line, but most of them were able to rise out of poverty quickly (World Bank 2006). The rates in two provinces have been higher than the national poverty rates. Figure 9.1c shows how the gap between the Aceh and national rates has been steadily decreasing. 
(a)

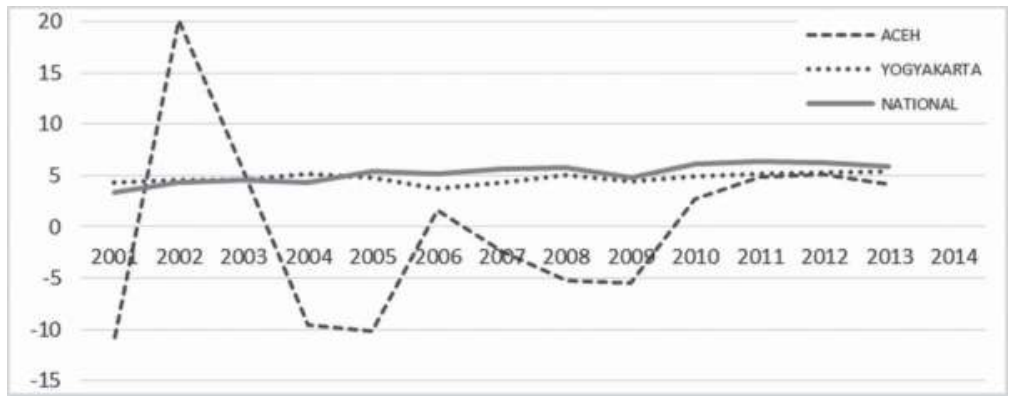

(b)

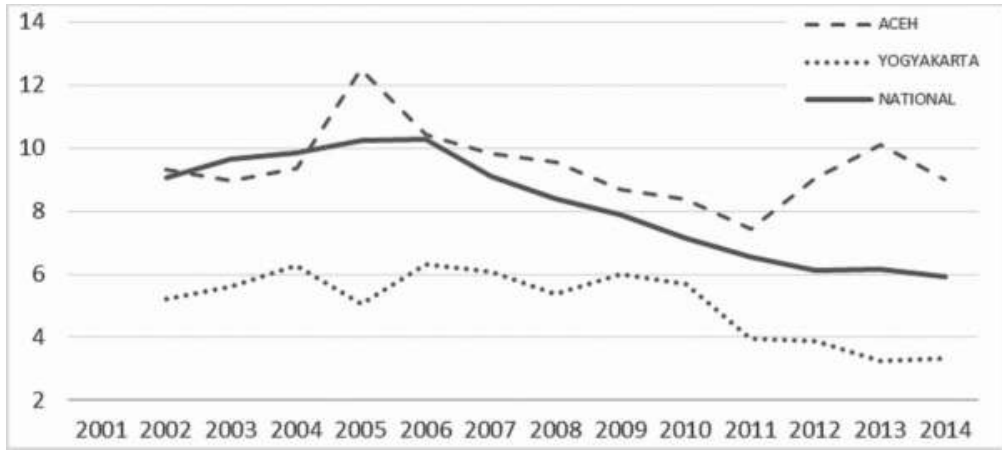

(c)

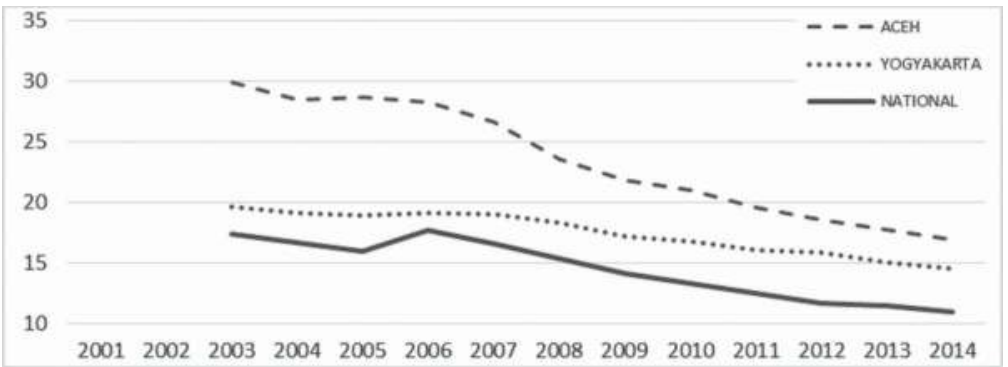

(d)

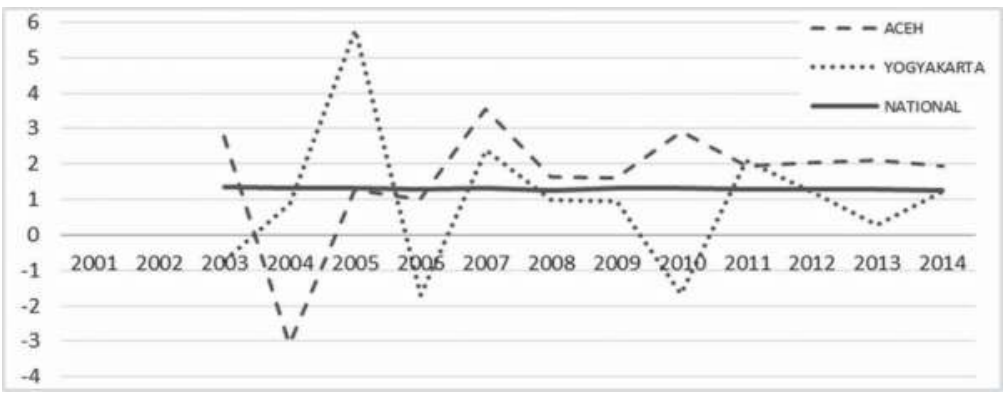

Figure 9.1 Trends and key indicators in Aceh and Yogyokarta (percent): (a) growth rate of regional GDP; (b) unemployment rate; (c) poverty rate; (d) population growth rate. Source: BPS, Statistics Indonesia. 
The growth rates of population in Aceh and Yogyakarta were negative in the year following the disasters but became positive in the subsequent years (Figure 9.1d). The population in Yogyakarta decreased in 2010 because of another disaster, the eruptions of Mount Merapi.

Overall, the data suggest that development was not seriously impacted by the disaster. While direct causality cannot be proved, the rest of this paper will explore how recovery contributed to this outcome.

\section{Donor support}

This section provides an overview of assistance by major donors by reviewing their activities following IOT and Java earthquake. This chapter focuses on the United States, Australia, Japan, and Germany, all of which actively tried to link recovery and development. Multi-donor funds were also included because of the large-scale of their assistance.

IOT is regarded as a rare case of a well-funded humanitarian emergency. The international community provided some US $\$ 13.5$ billion, with roughly 40 percent from private individuals and organizations (Telford, Cosgrave and Houghton 2006, 80). In Indonesia alone, the government and international donors provided some US $\$ 7$ billion. This stands in clear contrast with the international funding record of consistently failing to meet one-third of the humanitarian needs outlined in UN-coordinated appeals over the past decade in the world (Development Initiatives 2014).

\section{United States of America}

The US government provided over US $\$ 400$ million to Indonesia. The United States Agency for International Development (USAID) spent US $\$ 32$ million assisting over 580,000 people through the delivery of emergency food, hygiene kits, medical aid, and psychosocial assistance (Government Audit Office 2006). USAID also supported programs that provided cash-for-work to clean up debris and damaged infrastructure (USAID 2014).

The US spent a total of US\$349 million on rehabilitation programs covering the following four areas: (i) Rebuilding shelter and key infrastructure (US\$245 million), including the Aceh road project, which extended about 243 kilometers from Banda Aceh to Meulaboh, and construction of over 840 houses (USAID 2008); (ii) restoring livelihoods and enhancing employment opportunities; (iii) providing basic services and protecting the vulnerable: skills training and other educational opportunities with an emphasis on programs for women and youth; and (iv) strengthening capacity and governance: supporting capacity building of the Rehabilitation and Reconstruction Agency of Aceh-Nias (BRR) and enhancing the agency's service delivery. BRR was established in April 2005 as a specialized agency for coordinating recovery efforts. 


\section{Australia}

After IOT, Australia initially provided humanitarian relief of AU $\$ 42$ million (US\$32 million), covering food, health, medical and emergency relief coordination, logistics support, water, health, education and child protection, and shelter (AusAid 2005).

Australia subsequently established the Australia-Indonesia Partnership for Reconstruction and Development with an AU\$1 billion (US\$760 million), fiveyear assistance package to Indonesia in 2005 to support reconstruction in and beyond the tsunami-affected areas. This remains the single largest aid contribution ever made by Australia. The package consisted of AU $\$ 500$ million in grants (US\$380 million) and AU\$500 million (US\$380 million) in concessional loans for infrastructure development. The funds were allocated in three areas: (i) emergency preparedness and response, (ii) promoting broad-based economic growth, and (iii) rehabilitation (Australian National Audit Office 2006, 33).

After the Java earthquake stroke, the country supported recovery with an IDR215 billion (US\$16.1 million) program, the largest bilateral donor activity. Australia also made an immediate contribution of IDR 54 billion (US $\$ 4.1$ million) for emergency relief. The Australian Government initiated a Yogyakarta Central Java Community Assistance Program with AU\$30 million (US\$23 million) to assist affected families and communities to return as quickly as possible to normality, covering household life, income producing activities, community schooling, and health services.

\section{Japan}

Japanese bilateral grant aids mainly supported rehabilitating facilities after the IOT. The post-evaluation report (Foundation for Advanced Studies on International Development 2010) assessed fifteen grant aid projects, generally claiming high performance. The Japanese Government provided grant aids of JPY14.6 billion (US\$128 million) in January 2005. The projects were aimed at rehabilitating the water supply, roads, health posts, schools, orphanages, vocational centers, drainage, and embankments. These works were completed more quickly than projects supported by other donors.

The Japan International Cooperation Agency (JICA), as a technical assistance agency, supported a wide range of rehabilitation projects, such as infrastructure reconstruction, livelihood restoration, community empowerment, and strengthening DRR capacity. JICA implemented 12 community-based projects to restore the daily lives of the affected people. Project activities were selected from the following areas according to community needs: (i) livelihood support: providing micro-financing, vocational training, and equipment; (ii) post-trauma syndrome disease support; (iii) water supply and sanitation, public health, and education; and (iv) community capacity building (Ishiwatari 2010).

In the case of the Java earthquake, the Japanese government provided emergency assistance of US\$5 million: US\$4 million for tents, blankets, and plastic 
sheets, US\$1 million for medical support and water and sanitation through international organizations. The government allocated US\$7.7 million to support the rehabilitation of 10 schools and five health posts. JICA provided technical assistance to ensure the quality of reconstructed houses. The program covered formulation of technical standards, establishing an approval process for reconstruction of houses, and capacity development. The agency also supported eight community-based programs for medical support, trauma care, education, water and sanitation, and livelihood rehabilitation through local NGOs.

\section{Germany}

The German government had a clear strategy to link humanitarian aid and development cooperation in Aceh. Their 'Development-Oriented Emergency and Transition Aid' strategy aimed to minimize the effects of the crises on people living in affected regions and to bridge the time gap between humanitarian aid and the implementation of development projects.

German Technical Cooperation (GTZ), currently German Agency for International Cooperation (GIZ), started five programs in June 2005, six months after the tsunami: (1) health services, (2) vocational education, (3) civil and population registration, (4) economic recovery, and (5) governance. Technical cooperation programs of EUR55 million (US\$59 million) aimed at enabling the affected people to regain the base of their livelihood, and to attain self-reliance in a secure and conductive environment.

KfW Development Bank provided EUR120 million (US\$129 million) to promote the reconstruction of the devastated areas following the tsunami. It covered rehabilitation of (i) houses and roads, (ii) provincial hospitals, and (iii) vocational training centers and secondary schools.

\section{Multi-donor funds}

The Government of Indonesia established the Multi Donor Fund for Aceh and Nias (MDF) in April 2005 to coordinate donor support for the reconstruction and rehabilitation of affected areas. The fund aimed at filling gaps in reconstruction needs that other donors did not cover. MDF pooled US $\$ 655$ million in contributions from 15 donors, including the European Union (EU). MDF contributed nearly ten percent of the total recovery funds in Aceh. This included 23 projects in six outcome areas: (i) recovery of communities, (ii) reconstruction and rehabilitation of large infrastructure and transport, (iii) strengthening governance and capacity building, (iv) sustaining environments, (v) enhancing the recovery process, and (vi) economic development and livelihoods.

MDF covered crosscutting elements, such as gender inclusiveness, environmental management, and DRR. MDF achieved broad-scale capacity building of (i) communities in planning and decision-making, (ii) livelihood activities, (iii) local governments, (iv) civil society, (v) private sector, and (vi) women's groups (European Union 2014). MDF encouraged women to work in non-traditional 
wage-based jobs in three projects related to waste management, community infrastructure, and roads. The EU, BRR, and the Governor of Aceh served as cochairs of the MDF, with the World Bank also taking on the role of trustee.

Later, the Java Reconstruction Fund (JRF) was established in October 2006 to respond to the earthquake and the tsunami in West Java province in July. Seven donors supported JRF with contributions totaling US\$94.1 million. The Ministry of National Development Planning, the EU, and the World Bank jointly chaired the Steering Committee; and the World Bank served as Trustee of the fund. The closing date of the JRF was extended from December 2010 to December 2012 to assist with the reconstruction of communities impacted by the eruptions of Mount Merapi in 2011 (Java Reconstruction Fund 2012). Some US\$77.4 million or 82 percent of funds was spent on restoring housing and community infrastructure, while US\$17.2 million or 18 percent of the funds was used for recovery of livelihoods.

\section{Linking relief and rehabilitation with long-term development}

Drawing from this background of international contributions, this section reviews gaps in strategy, coordination and financing of recovery, and how recovery efforts were linked with long-term development, highlighting some of the most important challenges. Disaster-response mechanisms had advanced in the period between the IOT and the Java earthquake. In the wake of the Java earthquake, seismic-resilient houses were rapidly reconstructed within two years by taking a community-driven approach developed in Aceh. These recovery efforts and the lessons learned from the disasters themselves, contributed to long-term development by strengthening DRR. The direct support to recovery efforts and generosity of donors contributed to the success in linking recovery with long-term development by combining structural rehabilitation and capacity building. For this, strategies for housing, livelihoods and DRR were the most important, as described in the next subsection. However, weaknesses were apparent in these sectors, but also in overall strategies and coordination to realize the continuum, which suggest some lessons need to be learned. Finally, I include additional comments on permanent changes that increased resilience as a result of the development.

\section{Transition from recovery to development: resilient recovery as a strategy}

\section{Reconstructing houses}

\section{THE IOT RELOGATION PROGRAM}

The government planned to restrict housing construction in at-risk areas and relocate houses to safe higher ground. One month after the disaster, in January 2005, the government formulated a reconstruction plan, or 'Blueprint,' and issued 
the 'President Act of a Rehabilitation Master Plan' (Srivastava and Shaw 2014). This plan restricted housing construction in areas within $2 \mathrm{~km}$ of the shoreline. However, the government was unable to promote relocation programs as originally planned. By this time, donors had already started formulating reconstruction plans through participatory and bottom-up methods at the community level, and many participants wanted to be allowed to remain in their pre-tsunami villages. Fishermen preferred to reconstruct their houses on the original sites, with easy access to the ocean, and women wanted to resume their former livelihood activities, such as drying and salting fish and selling the produce at the fish markets. Thus many NGOs and local communities reacted negatively to the government's plan for a buffer zone policy, generating tensions (Birkmann et al. 2010; Nazara and Resosudarmo 2007, 12). It was therefore difficult to enforce a buffer zone policy when regulating construction.

Relocation programs were implemented at selected sites, posing various problems. It was difficult to secure safe higher sites for relocation. Constructing new infrastructure, such as the water supply, electricity, drainage, and roads, at the relocation sites required a lengthy period and enormous costs. Social networks in communities were disrupted at the relocation sites (Hiwaki and Matsuyuki 2013; Huda et al. 2014). Moreover, this approach generated new vulnerabilities related to job security. People who lost their former livelihoods were unable to easily find new livelihood options.

From a longer-term perspective, people at the relocation sites continue to experience difficulties in terms of transportation, livelihoods, education, health, and others. Some newly constructed houses have remained empty, while others were sold to people who were unaffected by the disaster (Fan 2014; Featherstone 2014, 6; Sakamoto and Kawata 2008). While the government initially arranged basic public services at the relocation sites, some services - such as the water supply and a nursery school - suspended operation. Such basic public services are necessary for improving the quality of life for the affected people

Aceh city has promoted resilient development instead of regulating it. Development in coastal areas had resulted in enormous damage and losses in the tsunami. Therefore, the governments have tried to move development centers to safer inland areas. Public facilities, such as hospitals, bus terminals, and markets were rebuilt inland and new roads were constructed to connect these areas with the city center. The facilities that have been constructed are attracting private development, such as shopping buildings and residential areas.

\section{IOT HOUSING REGONSTRUCTION}

Housing reconstruction in Aceh was slower than other sectors. The lack of progress on housing and poor accountability led to public dissatisfaction, with many of those affected unable to access information on reconstruction programs.

The affected people and government organizations faced various crucial issues, such as inflation in the price of construction materials, shortage of labor and materials, unclear land titles, and lack of established approaches for community 
involvement. The local inflation rate reached 41 percent in December 2005, compared with 17 percent nationwide. Materials and resources for the reconstruction work were brought from outside Aceh, since the conflict made it difficult to establish production bases. Besides this, some projects were completed without basic infrastructure, such as water and drainage (Asian Development Bank 2010, 14-15). The quality of materials and workmanship for some reconstructed houses was below average (Boen 2008).

Government policy was changing to respond to the needs of the affected people. Reconstruction of Aceh Land and Administration System program started in May 2005, six months after the tsunami. This program - led by communities aimed at recording land titles and boundaries. BRR announced a regulation in June 2006 that landowners would be able to obtain permanent houses with floor areas of minimum $36 \mathrm{~m}^{2}$. BRR revised this regulation latter so that tenants and non-landowners could also receive houses and land.

Formulating recovery plans is crucial for prompt recovery. There was a big difference in recovery speeds depending on the city - with differences of up to two and a half years. For example, Simeulue Prefecture completed rehabilitation of all houses within 49.8 months, the fastest among the affected areas. Banda Aceh City and Aceh Besar Prefecture took 75.3 months and 81 months, respectively, to complete rehabilitation programs. Where rebuilding houses at the original places was allowed and recovery plans were formulated at the initial stages, rehabilitation progressed more quickly than other areas. The changes to the buffer zone policies in Aceh were a major cause of the delays (Sugiyasu and Murao 2012).

A wide range of international organizations, donors, and NGOs were involved in reconstructing houses, leading to what was described as 'competition among donors' (Silva and Batchelor 2010). The donors were under pressure to spend money quickly and did not have sufficient time to produce deeper analysis (Telford, Cosgrave and Houghton 2006). Some humanitarian agencies lacked the know-how and expertise to manage mass building programs (Oxfam 2005a, 11).

The donors took two approaches: a 'community-driven' approach, and a donor-driven, 'constructed by contractors,' approach. Under the communitydriven approach, communities took the initiative by building consensus on the layout of the village and houses and supervising construction work and funding. In the donor-driven approach, aid organizations appointed construction companies to construct houses with limited community involvement.

The community-driven approach provided better living environments and higher levels of satisfaction to the affected people (Affan et al. 2015; Silva 2010). This approach was more cost-effective than construction by private companies or the donor-driven approach. The community-driven approach was pioneered under the Rekompak project in Aceh and was able to achieve transparent and cost-effective results. Community infrastructure, such as village roads, bridges, irrigation, drainage, school, and town halls, was also rehabilitated. The approach contributed to the local economic recovery as well, since workers were employed and materials were procured locally (Aysan et al. 2007). Under MDF programs, facilitators supported the communities in conducting these processes 
and ensuring the quality of the work. Nearly 20,000 houses were reconstructed or rehabilitated up until 2011 under the MDF.

The rehabilitation programs fostered community participation by involving community members in decision-making and planning processes. However, local participation in these processes is currently declining at the village level with women, in particular, increasingly excluded from participation (Thorburn and Rochele 2014, 47).

\section{HOUSING IN JAVA}

The community-driven approach, developed in Aceh, was adapted for use in Yogyakarta. Over 280,000 houses, which were more resilient to earthquakes than before, were reconstructed within two years.

Limited damage to infrastructure, strong capacities of local governments, and high levels of participation among skilled construction laborers contributed to the quick recovery. Some ten families organized a community group to receive funding from the government and to manage reconstruction work. The community groups conducted these processes by using community spirit, gotong royong, to support each other. The government provided cash subsidies to the affected people for 75 percent of the total cost of the reconstructed houses, and JRF and World Bank programs provided essential materials to the value of 11 percent of the reconstructed houses.

Under JRF some 200,000 houses, 7,300 transitional shelters, and 15,400 seismicresistant core houses were completed by March 2008 through the communitydriven approach. A total of 310 villages developed community settlement plans incorporating DRR and used them to restore community infrastructure such as the water supply, roads, bridges, and retaining walls. The quality of the housing was good, with 96 percent of the houses meeting anti-seismic standards.

A simple technical standard and monitoring mechanism functioned to ensure the quality of reconstructed housing. The government developed the standard that covers 'key requirements,' such as methods of connecting iron bars and the ratio for the water-cement ratio in concrete (Ranghieri and Ishiwatari 2014). JICA supported government agencies in developing these key requirements and in conducting training for carpenters and workers, with universities and government organizations on the ground. JICA also supported local governments in developing their capacity to monitor the construction process. The universities issued certificates to the trainees. Housing facilitators, which the government employed mainly from local universities, were expected to monitor and supervise the quality of construction work. However, in reality, housing quality varied based on experiences and skills of the facilitators (Narafu et al. 2008).

The mechanism for quality control in construction of ordinary houses did not continue after the recovery stage. The mechanisms utilized for building resilient houses functioned only for reconstruction projects and was not institutionalized. Therefore, ordinary people can currently construct their houses without 
undergoing the approval process that was applied during the reconstruction period. The level of training activities for carpenters is also declining. The university ceased conducting regular training sessions following the completion of recovery efforts.

\section{Rehabilitating livelihoods}

After the IOT, various programs for restoring livelihoods were implemented to support those who were affected, although uneven attention was given to this task within and between sectors. While in the fishery sector fishermen were able to recover lost assets, such as fishing boats, nets, and gear, limited support was provided for resuming aquaculture activities of rehabilitating fish and shrimp ponds (Featherstone 2014, 9). Furthermore, support to the wives of fishermen was delayed. Interventions designed to assist with the rebuilding of an industry or the private sector - crucial in creating job opportunities - received less support than other sectors (Fan 2014).

Follow-up support was essential in ensuring the sustainability of livelihood programs. Successful livelihood programs covered support for marketing of handicrafts, extension services for livestock, and business support for micro-, small- and medium-sized enterprises. While many women's groups received handicraft training, most of them could not explore market opportunities. A significant proportion of livelihood assistance was used for household consumption (Thorburn 2009).

Recovery work provided some job opportunities for affected people; however, many Acehnese people were unable to utilize these opportunities fully because of their low job-skills. Most of the skilled and semiskilled workers came from North Sumatra and other places in Indonesia (BRR 2009, 105).

The German Government took an integrated approach that lay between structural rehabilitation and capacity building. GTZ supported the process by creating curricula and training teachers at vocational training centers, and KfW supported reconstruction of the buildings for the training centers (Federal Ministry for Economic Cooperation and Development 2005, 15). The training courses also helped to reintegrate former combatants from the local armed groups and their family members, women, and disadvantaged youths into the society. GTZ trained 1,100 ex-combatants for a civilian career.

USAID took a similar approach to the German organizations by supporting the creation of the Aceh Polytechnic under a public-private partnership with the Chevron Corporation, Banda Aceh City, and the education ministry. The polytechnic was established to provide vocational training in applied technology, such as information technology, electronics telecommunication, and business accountancy. The polytechnic hosts 240 students per year, running three-year programs in four study streams (Boardman, Schorn and Dwatmadji 2012). The program provided assistance with curriculum development, staff recruitment and training, procurement of laboratories, workshops, classroom equipment and furniture, and economic feasibility. 
In the case of the Java earthquake, livelihood programs included capacitybuilding activities in addition to replacing assets and equipment. Experiences in Aceh provided a lesson that simply replacing assets and equipment is insufficient to secure the sustainability of restored livelihoods.

The JRF livelihood programs in Java were linked with long-term development. The programs focused on replacing assets, enhancing business skills, and improving access to finance, all of which were effective in improving beneficiaries' capacities. This program supported more than 15,000 micro-, small-, and medium-sized enterprises in total. More than 87 percent of micro and small enterprises succeeded in reaching their pre-earthquake operating capacities, sales, and profits. JRF programs targeted women and nearly 50 percent of the programs were managed by women's groups. Moreover, the programs contributed to long-term development by promoting capacity building for microfinance institutions to ensure sustainability of outcomes. The program created a revolving loan fund under the government-owned financial institution that has continued circulating funds to promote economic recovery for more than ten years.

Major support started in the two years following the earthquake, when about half of the affected entrepreneurs reached the same level as pre-earthquake capacities (Java Reconstruction Fund 2008). Since the government put a high priority on housing reconstruction, activities for livelihood support were delayed. Since resiliency to disasters varied according to the enterprise, careful measures were needed for rehabilitation. Resosudarmo, Sugiyanto and Kuncoro (2012) argue that (i) smaller enterprises are more resilient, (ii) an industrial cluster system provides necessary support, (iii) a higher quality of village infrastructure can support recovery, (iv) support should be provided as early as possible, and (v) donors should not give too much assurance of financial support.

\section{Strengthening DRR}

DRR was not properly integrated into rehabilitation programs at the early stages. In the two years following the tsunami, the Tsunami Evaluation Coalition (TEC) recommended that donors should allocate more resources toward DRR (Telford, Cosgrave and Houghton 2006, 104). TEG was an ongoing learning effort and consisted of over 40 organizations: UN agencies, donors, NGOs, the Red Cross and Red Crescent Movement, and research groups. The donors employed the recommendations issued by TEC for programs during recovery.

Government organizations gradually strengthened DRR through recovery. These government organizations promoted community-based activities, incorporating of public awareness raising and strengthening evacuation preparedness. The government has constructed earthquake-resistant schools, and the Aceh city government started DRR education in schools and conducted regular drills (Global Facility for Disaster Reduction and Recovery 2014; Oxfam 2014). DRR has been integrated into curricula from elementary to high schools. This is regarded as a practical approach considering the scale of tsunamis and limited budget for investment. The Government constructed three evacuation buildings, 
which are now also used during non-disaster periods as dual-use locations for the tsunami museum, the disaster research center of a university, and a polytechnic.

JICA supported a community-based recovery program covering structural measures and capacity development in Ulee Lheue area, which is located along the ocean and was severely damaged by the tsunami. JICA constructed evacuation centers where people in high-risk areas can escape from tsunamis. The local communities conduct evacuation drills and use the evacuation centers for various occasions including livelihood programs and community meetings during non-disaster periods. At the center, JICA is currently conducting an exchange program of practitioners and knowledge between Aceh and Higashimatsushima City, which was severely damaged by the Great East Japan earthquake and tsunami in 2011.

The Tsunami Museum is playing a crucial role in DRR in Aceh. The museum opened in 2011 to (i) keep the memory of the disaster alive and raise public awareness regarding DRR, (ii) provide a recreation space for people, and (iii) provide evacuation places during times of disaster. The museum conducts exhibitions on the tsunami disaster, recovery processes, and education on DRR. It has organized evacuation drills with local schools. The museum also contributes to local economic development, with some half a million people, including foreign tourists, visiting the museum annually.

Nonetheless, levels of DRR activities are declining following recovery. While various initiatives on DRR education have commenced, not all schools are providing DRR education. Some teachers still have limited knowledge and awareness of DRR. In Aceh, wider roads were constructed in newly developed areas to allow evacuation routes and better protection from fires. However, recently narrow roads have been constructed in newly developed areas.

Similar educational efforts to mainstream DRR followed the earthquake on Java. Programs designed to build community capacity, which were initiated in Aceh, were implemented on a large scale in Java. The program started in the Bantul Region - the area most severely affected by the Java earthquakecovering awareness-raising, DRR education in schools, and DRR planning. Each village established a DRR forum consisting of community-based organizations, Red Cross, civil society organizations, and volunteers to respond to disasters. Moreover, the Gadjah Mada University started the Iza Kaeru Caravan program. This program covers disaster-management drills, which were developed based on lessons from the Great Hanshin-Awaji Earthquake in 1995, Japan.

\section{Coordination for the transition}

Coordination was a complicated task in Aceh, since a large number of organizations contributed in relief and rehabilitation. Some 300 NGOs were involved in the first two months of the response, while only 12 NGOs were engaged in Aceh before IOT (Bruset et al. 2009, 36). In the recovery phase, 463 organizations conducted over 2000 projects. In particular, some 120 organizations implemented 266 programs related to housing reconstruction (Masyrafah and McKeon 2008). 
Local governments were expected to coordinate these activities but had limited capacity. They were already severely strained by the 30 -year armed conflict and devastated by the loss of more than 4,000 lawmakers, civil servants, and village leaders. Some 20 percent of local government staff died as a result of the tsunami (Thorburn and Rochele 2014; Christoplos 2006, 39). The donors competed to secure resources, such as construction materials, local contractors, and transportation (Chang et al. 2011).

Immediately following the tsunami, the Ministry of National Development Planning coordinated various organizations and formulated a recovery plan. The government created a special ministry-level agency, BRR, in April 2005, which took over the coordinating roles from the ministry. The agency aimed to design policies, strategies, and action plans; and to coordinate domestic and international assistance. Since the housing construction was behind schedule, BRR took over management of housing programs from the Ministry of Public Works. Overall, BRR is regarded as one of the best practices of specialized agencies for coordinating recovery efforts, having coordinated more than 12,500 projects involving some 60 bilateral donors and multilateral organizations as well as 700 NGOs. In addition, it also carried out more than 5,000 of its own reconstruction projects.

BRR improved project implementation of MDF with strong leadership provided by the top management. BRR was a co-chair of the MDF Steering Committee and supported the MDF in coordinating the reconstruction. At an initial stage, project implementation of MDF was delayed because of the time-consuming process of donors' disbursements to the fund, and the processing time for project approval and implementation by government organizations (US Department of State 2015).

Donors also undertook their own coordination efforts. AusAID coordinated with Australian NGOs. AusAid established a humanitarian partnership agreement with six major NGOs and the Red Cross Society to respond quickly to disasters and strengthen community resilience and preparedness in Australia (Joint Standing Committee on Foreign Affairs, Defense and Trade 2006, 27; Mander-Jones, Collins and Besley 2015). The Australian National Audit Office (2006) reported that AusAID was able to avoid duplication with other donors. AusAID coordinated with other programs by closely monitoring activities of other major donors and collecting information. For example, AusAID financed collaborative programs for road reconstruction with the World Bank and hospital reconstruction with Germany. Regarding Japanese assistance with other donors, a Japanese evaluation reported that no duplication was found - a result that can be attributed to the Indonesian Government's coordination role (Foundation for Advanced Studies on International Development 2010).

Acquired capacities were evident in the aftermath of the Java earthquake. The Yogyakarta State Government played the leading role in coordinating recovery efforts, and no specialized agencies were established. The state government had sufficient capacity to implement recovery programs.

Strong community spirit contributed to recovery. Interviewees repeatedly pointed out the important role that local culture played in furthering the recovery. 
Community members helped each other to reconstruct their communities and houses by drawing upon community spirit, gotong royong. The culture of gotong royong promoted positive values such as social harmony and mutual support during the recovery (Mardiasmo and Barnes 2015). Moreover, Sultan, the Governor of Yogyakarta, provided spiritual support and leadership to the affected people during the recovery period.

\section{Financing the transition}

As mentioned above, IOT was an exceptional case of a crisis funded in all its phases. The outpouring of international support meant that pooled funds played a major role in supporting the process. MDF successfully coordinated donor and government support in Aceh. Thus, the same mechanism - the JRF - was established in the wake of the Java earthquake. This helped to reduce duplication and minimize transaction costs. MDF and JRF are regarded as effective post-crisis funding mechanisms. The EU and UK provided the majority of funding through the multi-donor funds of MDF and JRF. These funds also functioned as policy forums where donors and the government could discuss and harmonize their rehabilitation policies. The government provided strong leadership for coordinating the funds.

Limited visibility and information by using channels from MDF were issues for the EU, which did not manage its programs directly. Since programs were conducted under the name of the MDF, this reduced the visibility of the EU for beneficiaries and organizations undertaking activities in the field. Quantifying output targets and generating information on the efficiency of implementation were challenges. Later the European Commission required the fund to improve the quality of information received from MDF (European Court of Auditors 2008, 19-20).

Some other donors were reluctant to participate in the multi-donor trust funds. These donors had their own agendas and approaches, or were concerned over limited visibility in the field. They preferred to provide direct assistance through their own channels.

\section{Discussion}

\section{Evolving recovery mechanisms}

Recovery mechanisms have evolved through learning from the disasters in Indonesia as shown in Table 9.1. Strategies for three sectors (i.e., housing, livelihoods, and DRR) observed in detail, allow a clearer understanding of their changes. In relation to the first disaster, there were two different challenges: relocation from tsunami-affected areas and actual reconstruction. The latter is mostly considered a success story. The Indonesian government, through the National Disaster Management Agency (BNPB), applied a community-driven approach as its national standard approach for reconstructing houses damaged by disasters. 
Table 9.1 Evolving recovery mechanisms in Indonesia.

\begin{tabular}{|c|c|c|c|}
\hline & IOT & fava & Permanent \\
\hline $\begin{array}{l}\text { Strategy } \\
\text { House } \\
\quad \text { reconstruction }\end{array}$ & $\begin{array}{l}\text { Community-driven } \\
(\mathrm{CD}) \\
\text { Donor-driven }\end{array}$ & CD & $\mathrm{CD}$ \\
\hline Needs assessment & $\begin{array}{l}\text { PDNA supported by } \\
\text { donor agencies }\end{array}$ & $\begin{array}{l}\text { PDNA supported by } \\
\text { donor agencies }\end{array}$ & $\begin{array}{l}\text { - I-PDNA } \\
\text { - Early recovery } \\
\text { needs assessment }\end{array}$ \\
\hline Livelihood program & $\begin{array}{l}\text { Cash for work } \\
\quad(\text { CFW })\end{array}$ & $\begin{array}{l}\text { - CFW } \\
\text { - Involving a long- } \\
\text { term perspective }\end{array}$ & \\
\hline $\begin{array}{l}\text { Buffer zone and } \\
\text { relocation }\end{array}$ & Changing policies & Not applied & $\begin{array}{l}\text { For landslides and } \\
\text { volcano disasters }\end{array}$ \\
\hline $\begin{array}{l}\text { Technical standard } \\
\text { for housing }\end{array}$ & Not applied & Key requirement & Not applied \\
\hline DRR & $\begin{array}{l}\text { Tsunami museum, } \\
\text { education, drills }\end{array}$ & $\begin{array}{l}\text { Community-based } \\
\text { activities }\end{array}$ & $\begin{array}{l}\text { Law, institutions; } \\
\text { some declining }\end{array}$ \\
\hline Coordination & $\mathrm{BRR}$ & $\begin{array}{l}\text { Provincial } \\
\text { governments }\end{array}$ & $\begin{array}{l}\text { Provincial } \\
\text { governments }\end{array}$ \\
\hline Financing & MDF & $\mathrm{JRF}$ & IDF \\
\hline
\end{tabular}

Source: author.

Community members including women were involved in development planning and decision-making of recovery work. The Aceh and Yogyakarta experiences demonstrate that this approach contributes to resilient and quick recovery.

However, the Indonesian government did not succeed in regulating development in risk areas in Aceh. Nowadays, the government is promoting relocation programs to cope with volcano eruptions and landslide disasters. These disasters change physical features, and those affected cannot return to the original sites. Moreover, local governments have not applied the mechanism of ensuring quality for new housing construction in Yogyakarta now that the recovery phase has been completed.

A potential livelihood crisis in Aceh was averted, and most issues of poverty that resulted from the tsunami were resolved, as discussed above. This was due to the following factors (Telford, Cosgrave and Houghton 2006, 67): (i) rehabilitating livelihoods for those affected by the disaster, (ii) engaging in reconstruction work, and (iii) using cash distributed in cash-for-work programs. Recipients were satisfied with the quick assistance in the early months after the tsunami. Short-term livelihood initiatives, such as distributing fishing boats, seeds, and large cash grants helped to provide prompt support for the affected people. Fishermen received fishing boats, nets, and gear. When donor organizations did not engage in a consultation process with the fishermen or involve cooperatives in producing the fishing boats and equipment, some items became unusable because of poor craftsmanship and the use of sub-standard raw materials (BRR and World Bank 2005, 113).

The cash distribution program, as a short-term measure, provided effective support for those who lost their livelihoods. The program contributed to 
community rehabilitation as well. Various organizations implemented quick assistance including cash-for-work (CFW). The CFW programs, which mainly focused on clearing debris, had never before been implemented on the scale following the IOT. CFW conducted by the international aid organization Mercy Corps reached nearly 18,000 participants at its peak and disbursed over US $\$ 1$ million a month in 2005 (Doocy et al. 2006). Oxfam involved some 40,000 people in CFW by October 2005 (Oxfam 2005b, 7). Livelihood programs included capacity-building activities in addition to replacing assets or equipment in Yogyakarta based on lessons from IOT.

For DRR, Indonesia has been developing mechanisms for recovery by learning from previous disasters. This has been visible at the local level with an emphasis on the creation of local capacities and different educational efforts at the community level, as well as technical assistance in relation to building codes. Local governments started DRR education and drills in Aceh and Yogyakarta. The level of these DRR activities has declined as time has passed.

Underlying these efforts, there was governmental leadership to internalize lessons and coordinate the different actors and tasks that converged after the emergencies. The government has improved legislation and institutions for DRR. The Indonesian parliament passed a new disaster-management law in 2007. This law shifted the policy paradigm away from emergency response following the disasters to covering preparedness and prevention. BNPB was founded in 2008, and local agencies have subsequently been established throughout the country (Ishiwatari 2013).

BNPB has strengthened the capacity for disaster recovery. The agency developed its methodology and tools in the Indonesia-specific Post Disaster Needs Assessment (PDNA), which assessed damages and formulated rehabilitation and reconstruction plans for when future disasters occur. A ministerial decree was issued in 2011 to ensure that the Indonesian-specific PDNA will be conducted. Following IOT and the Java earthquake, they used a standardized international methodology. In addition, the agency is developing a mechanism for early recovery needs assessment with the support of United Nations Development Programme (UNDP). This assessment aims at promptly rehabilitating people's daily lives covering (i) governance, (ii) livelihood, (iii) community infrastructure, (iv) debris management, (v) DRR, and (vi) social coherence.

Provincial governments play leading and coordination roles for recovery. Organizations that were located in disaster areas could effectively coordinate a wide range of recovery programs in Aceh and Yogyakarta. BRR is regarded as an exceptional case, since local governments have limited capacities in Aceh because of prolonged conflicts. Based on the success of the multi-donor funds, the Government established a permanent disaster fund, the Indonesian Multi-Donor Fund Facility for Disaster Recovery (IDF), in 2010. With UNDP and the World Bank function as fund trustees, this fund will mitigate operational gaps that may occur during the several months required for the trust fund to establish operations. 


\section{Reconsidering donor approaches}

Good practices for linking recovery and long-term development by donors are summarized in Table 9.2. These practices cover the combination of structural rehabilitation and capacity building at the facility reconstructed and inclusion of DRR into the programs. Capacity building and DRR contribute to long-term development efforts.

The German government had a clear strategy with its 'Development-Oriented Emergency and Transition Aid' for linking humanitarian aid and development cooperation in Aceh. This strategy contributed towards minimizing the effects of disasters on those affected and bridging the gap between humanitarian aid and development projects. The technical-assistance agency of GTZ and lending agency of KfW from Germany jointly supported vocational, health, and education sectors. German organizations have integrated long-term development into these programs. For example, GTZ supported not only rehabilitating vocational training centers but also creating vocational skills. It supported capacity-building programs and DRR while KfW supported rehabilitating buildings. It was a different approach from other major short-term intervention programs, such as cash-for-work or fishing boat distribution.

USAID partnered with an energy company to develop a post-secondary institution for vocational training. The institution building is used for evacuation shelter from tsunamis. JICA implemented a capacity-development program for community members in DRR with the construction of evacuation centers in Aceh. JICA also supported capacity building to reconstruct resilient housing by formulating a simple technical standard and establishing a monitoring mechanism following the Java earthquake. JRF programs covered both structural rehabilitation and capacity building to reconstruct houses and restore livelihoods in the wake of the Java earthquake. Strong community spirit supported these successful activities at the community level. The experience suggests that providing support for local government plans, when they are capable and committed to recovery and DRR, is the best way to link the phases of crisis management.

Table 9.2 Good practices of linking recovery and long-term development.

\begin{tabular}{lll}
\hline Recovery activities & $\begin{array}{l}\text { Combined between structural } \\
\text { rehabilitation and capacity building }\end{array}$ & Including DRR \\
\hline
\end{tabular}

\section{Indian Ocean tsunami}

GTZ: Vocational training center

USAID: Polytechnic

JICA: DRR at Ulee Lheue

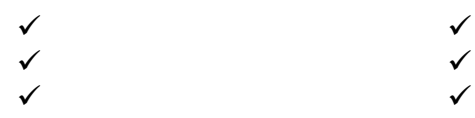

\section{Java earthquake}

JICA: Capacity development for housing reconstruction

JRF: Housing reconstruction

JRF: Livelihood restoration 


\section{Conclusion}

The IOT and Java earthquake provided opportunities for Indonesia to create a resilient and sustainable society. Indonesia has strengthened DRR and response mechanisms in legislative, institutional, and practical measures through learning from the disasters. Recovery activities in rehabilitating livelihoods and housing were integrated into long-term development. Different strategies to link recovery and DRR through development were evident through donor support but, above all, supporting the local government in the long term was the most important feature. The specialized recovery agency and provincial governments, which were located in 'local' disaster areas, were able to coordinate a wide range of programs with strong leadership and high-capacity institutions. Multi-donor funds were effective in coordinating donor organizations and filling gaps in financial sources.

Weak links were found in some areas between recovery and development. While programs to rebuild housing were successful, relocation remains a major challenge. Local governments have not applied the mechanism of ensuring quality for new housing construction in Yogyakarta since the recovery phase was completed and the level of DRR education activities is declining as time passes.

Donors can help to maintain the momentum of local initiatives by including a development perspective in recovery policy. Donors should provide recovery assistance from a longer-term perspective and formulate recovery projects to contribute to long-term development. Moreover, donors should provide support for the establishment of mechanisms to promote integration between recovery and development. Depending on the level of commitment, donors can further explore cooperation through multi-donor funds and promote education efforts to improve sustainability. This implies going one step beyond the present coordination through the PDNA. Current post-disaster needs assessments mainly cover estimates of costs and assets destroyed in disasters. In addition to PDNA, other assessments can be conducted to identify programs and formulate a master plan to link recovery and long-term development, ensuring the prevention of future disasters.

\section{References}

Affan, Muzailin, Shunichi Koshimura, Fumihiko Imamura, Hizir Sofyan, Sylvia Agustina, Nizamuddin, and Nur Fadli. 2015. Lessons Learned from Two Villages in the Tsunami Most Affected Area of Banda Aceh City: A Review of the Housing Reconstruction and the Current State of Village Development. In Post-Tsunami Hazard: Reconstruction and Restoration, edited by V. Santiago-Fandino Y. A. Kontar and Y. Kaneda, 59-72. Springer International Publishing.

Asian Development Bank. 2010. Rebuilding Lives and Homes in Aceh and Nias, Indonesia. Mandaluyong City: Asian Development Bank.

AusAid. 2005. Australia's Response to the Indian Ocean Tsunami: Report for the Period Ending 30 Fune 2005. Barton ACT: Commonwealth of Australia.

Australian National Audit Office. 2006. Arrangements to Manage and Account for Aid Funds Provided Under the Australia-Indonesia Partnership for Reconstruction and Development. Australian 
Agency for International Development, Department of Foreign Affairs and Trade. Canberra: Australian National Audit Office.

Aysan, Y., M. Aheeyar, P. Harvey, and S. Satchithanandam. 2007. External Evaluation Report on the Cash for Repair and Reconstruction Project Sri Lanka. Consortium of Swiss Organisations.

Birkmann, J., P. Buckle, J. Jaeger, M. Pelling, N. Setiadi, M. Garschagen, and J. Kropp. 2010. Extreme Events and Disasters: A Window of Opportunity for Change? Analysis of Organizational, Institutional and Political Changes, Formal and Informal Responses after Mega-Disasters. Natural Hazards 55(3), 637-655.

Boardman, G., Schorn F., and Dwatmadji. 2012. Indonesia University Partnership and Aceh Polytechnic Programs: Final evaluation of The Aceh Polytechnic Program. USAID.

Boen, T. 2008. Lessons from the Reconstruction of Houses in Aceh After the Dec. 26, 2004 Tsunami. Proceedings of the International Symposium on Earthquake Safe Housing, Tokyo. National Graduate Institute for Policy Studies (GRIPS), Building Research Institute (BRI) and United Nations Centre for Regional Development (UNCRD).

BRR. 2009. Economy: Turning the Wheel of Life. Banda Aceh: BRR.

BRR and World Bank. 2005. Rebuilding a Better Aceh and Nias: Stocktaking of the Reconstruction Effort: Brieffor the Coordination Forum Aceh and Nias. Jakarta: BRR and World Bank.

Bruset, E. et al. 2009 A Ripple in Development? Long Term Perspectives on the Response to the Indian Ocean Tsunami, 2004. Swedish International Development Cooperation Agency.

Chang, Y., S. Wilkinson, R. Potangaroa and E. Seville. 2011. Donor-Driven Resource Procurement for Post-Disaster Reconstruction: Constraints and Actions. Habitat International 35(2), 199-205.

Christoplos, I. 2006. Links between Relief, Rehabilitation and Development in the Tsunami Response. London: Tsunami Evaluation Coalition.

Commission of the European Communities. 2001. Communication from the Commission to the Council and the European Parliament: Linking Relief, Rehabilitation and Development-An Assessment. Brussels: Commission of the European Communities.

Consultative Group on Indonesia. 2005. Preliminary Damage and Loss Assessment, The December 26, 2004 Natural Disaster. Jakarta: BAPPENAS and International Donor Community.

- 2006. Preliminary Damage and Loss Assessment, Yogyakarta and Central Fava Natural Disaster. Jakarta: BAPPENAS, the Provincial and Local Governments of D. I. Yogyakarta, the Provincial and Local Governments of Central Java, and International Partners.

Cosgrave, J. 2007. Synthesis Report: Expanded Summary. Foint Evaluation of the International Response to the Indian Ocean Tsunami. London: Tsunami Evaluation Coalition.

Development Initiatives. 2014. Global Humanitarian Assistance Report 2014. Bristol: Development Initiative.

Doocy, S., M. Gabriel, S. Collins, C. Robinson and P. Stevenson. 2006. Implementing Cash for Work Programmes in Post-Tsunami Aceh: Experiences and Lessons Learned. Disasters 30(3), 277-296.

European Court Of Auditors. 2008. European Commission Rehabilitation Aid Following the Tsunami and Hurricane Mitch. Luxembourg: Office for Official Publications of the European Communities.

European Union. 2014. Multi Donor Fund for Aceh and Nias. Delegation of the European Union, Indonesia.

Fan L. 2014. Aceh's Unfinished Recovery. IRIN. www.irinnews.org/report/100972/aceh.

Featherstone A. 2014. Tsunami Ten Years on, Stories of Change 2004-2014: Community Perceptions of the Indian Ocean Tsunami Response and Recovery. London: Save the Children. 
Federal Ministry for Economic Cooperation and Development. 2005. Review of German Government Funding for the Tsunami Relief Operations. Federal Ministry for Economic Cooperation and Development.

Foundation for Advanced Studies on International Development. 2010. Post-Evaluation Report for Grant Aid Assistance for Indian Ocean Tsunami. Tokyo: Ministry of Foreign Affairs. Global Facility for Disaster Reduction and Recovery. 2014. Resilient Recovery: An Imperative for Resilient Development. Background Paper prepared for the 2015 Global Assessment Report on Disaster Risk Reduction. Geneva: UNISDR.

Government Audit Office. 2006. Foreign Assistance: USAID has Begun Tsunami Reconstruction in Indonesia and Sri Lanka, But Key Projects may Exceed Initial Cost and Schedule Estimates. GAO.

Hiwaki, T. and M. Matsuyuki. 2013. Indonesia Aceh Syuniokeru Indoyootsunamisaigaikarano Fukkojutakuti Saiteijuchiniokeru Teijuishikito Sonoeikyoyoinni Kansuru Kenkyu [Study on Factors Influencing Attitudes Toward Settling in Rebuilt Settlement Sites and Resettlement Sites after the Indian Ocean Tsunami in Aceh Province, Indonesia]. Toshikeikakuronbunsyu [Journal of the City Planning Institute of Japan] 48(3), 867-872.

Huda, K., N. Yamamoto, M. Tanaka and N. Maki. 2014. 2004nen Indoyootsunamini Indonesia Banda Acehshito Sonokinkoni Kensetsusareta Saiteijuchino Kyojusyarirekito Seikatusaiken [Profiles of Residents and Their Livelihood Rehabilitation in the Resettlements Developed in and around Banda Aceh Municipality, After Indian Ocean Tsunami 2004]. Nihonkenchikugakkaikeikakukeironbunsyu [Journal of Planning of Architectural Institute of Japan] 79(697), 597-606.

Ishiwatari, M. 2010. Review of Disaster Rehabilitation Methodologies Following the Indian Ocean Tsunami from a Human Security Perspective. Asian Fournal of Environment and Disaster Management 2(3), 275-288.

2013. Disaster Risk Management at the National Level. ADBI Working Paper 448. Tokyo: Asian Development Bank Institute.

Java Reconstruction Fund. 2008. Two Years After the Fava Earthquake and Tsunami: Implementing Community Based Reconstruction, Increasing Transparency. Jakarta: Java Reconstruction Fund.

- 2012. Final Report 2012: Disaster Response Ë Preparedness: From Innovations to Good Practice. Jakarta: Java Reconstruction Fund.

Joint Standing Committee on Foreign Affairs, Defense and Trade. 2006. Australia's Response to the Indian Ocean Tsunami. Canberra: The Parliament of the Commonwealth of Australia.

Mander-Jones, Z., M. Collins and M. Besley. 2015. Review of the DFAT-NGO Humanitarian Partnership Agreement 2011-2016. Strategic Development Associates.

Mardiasmo, D. and P. H. Barnes. 2015. Community Response to Disasters in Indonesia: Gotong Royong; a Double Edged-Sword. In Proceedings of the 9th Annual International Conference of the International Institute for Infrastructure Renewal and Reconstruction, edited by P. H. Barnes and A. Goonetilleke, 301-307. Queensland University of Technology, Brisbane.

Masyrafah, H. and J. M. McKeon. 2008. Post-Tsunami Aid Effectiveness in Aceh: Proliferation and Coordination in Reconstruction. Wolfensohn Center for Development Working Paper No. 6. Washington, DC: Brookings Institution.

Narafu, T. et al. 2008. Kaihatsutojoukokuno Jisinisaigaifukkojigyoniokeru Jutakuno Anzenseikojono Kanoseini Kansuru Kenkyu [A Study on Possibility of Enhancement of Seismic Safety of Housing in Reconstruction Procedures in Developing Countries: A Case Study of Central Java Earthquake 2006 in Indonesia]. Chïkianzengakkai Ronbunsyu [Proceedings of Institute of Social Safety Science] 10, 457-464. 
Nazara, S. and B. P. Resosudarmo. 2007. Aceh-Nias Reconstruction and Rehabilitation: Progress and Challenges at the End of 2006. Tokyo: Asian Development Bank Institute.

Oxfam. 2005a. A Place to Stay, a Place to Live. Oxford: Oxfam. 2005b. Back to Work. Oxford: Oxfam.

- 2014. The Indian Ocean Tsunami, 10 Years On: Lessons from the Response and Ongoing Humanitarian Funding Challenges. Oxford: Oxfam.

Ranghieri, F. and M. Ishiwatari. 2014. Learning from Megadisasters: Lessons from the Great East Japan Earthquake. Washington, DC: World Bank.

Resosudarmo, B. P., C. Sugiyanto and A. Kuncoro. 2012. Livelihood Recovery after Natural Disasters and the Role of Aid: The Case of the 2006 Yogyakarta Earthquake. Asian Economic Fournal 26(3), 233-259.

Sakamoto, M. and Y. Kawata. 2008. Indoyootsunamisaigainiokeru Saigaifukkosienno Yuyoseito Kadai:Banda Acehno Jireiyori [The Effectiveness and Issues of Disaster Recover Assistance following the Indian Ocean Tsunami: Case of Banda Aceh]. Africa Asia Kenkyu [Research on Africa and Asia] 48(4), 49-64.

Silva, J. 2010. Lessons from Aceh: Key Considerations in Post-Disaster Reconstruction. Rugby: Practical Action Publishing.

Silva, J. and V. Batchelor. 2010. Indonesia: Understanding Agency Policy in a National Context. In Building Back Better: Delivering People-Centred Housing Reconstruction at Scale, edited by M. Lyons, and T. Schilderman, 135-161. Rugby: Practical Action Publishing.

Srivastava, N. and R. Shaw. 2014. Institutional and Legal Arrangements and its Impacts on Urban Issues in Post Indian Ocean Tsunami. In Recovery from the Indian Ocean Tsunami: A Ten-Year Fourney, edited by R. Shaw, 17-27. Tokyo: Springer.

Sugiyasu, K. and O. Murao. 2012. 2004nen Indoyotsunaminiyoru Indonesia Hisaichino Toshifukko Masterplanno Hikakuto Tatemonofukkokyokusen [Regional Comparison of Urban Recovery Master Plan and Building Recovery Curves among Damaged Areas in Indonesia due to the 2004 Indian Ocean Tsunami]. Nihonkenchikugakkaikeikakukeironbunsyu [Journal of Planning of Architectural Institute of Japan] 77(673), 609-617.

Telford, J., J. Cosgrave and R. Houghton. 2006. Foint Evaluation of the International Response to the Indian Ocean Tsunami: Synthesis Report. London: Tsunami Evaluation Coalition.

Thorburn, C. 2009. Livelihood Recovery in the Wake of the Tsunami in Aceh. Bulletin of Indonesian Economic Studies 45(1), 85-105.

Thorburn, C. and B. Rochele 2014. The Acehnese Gampong Ten Years on: A Post-Post Tsunami Assessment. Aftermath of Aid Policy Paper. Singapore: Earth Observatory of Singapore.

USAID. 2008. Audit of USAID/Indonesia's Tsunami-Related Housing Construction Activities Implemented by Cooperative Housing Foundation International. Manila: USAID Indonesia.

- 2014. Emergency Response and Reconstruction in Aceh Province (2004-2009). Manila: USAID Indonesia.

US Department of State. 2015. Lessons from the Aceh and Nias Multi-Donor Trust Fund. Washington, DC: US Department of State.

World Bank. 2006. Aceh Public Expenditure Analysis: Spending for Reconstruction and Poverty Reduction. Jakarta: World Bank.

- 2008. Aceh Economic Update (April 2008). Washington, DC: World Bank. 


\title{
10 Typhoon Yolanda in the Philippines
}

\author{
Qualitative analysis of institutional \\ and political factors influencing \\ the continuum
}

\author{
Yasuhito Fibiki and Yuichi Ono
}

\section{Introduction}

This chapter explores how donors and bilateral cooperation agencies provided assistance following Typhoon Yolanda. By comparing approaches adopted by the Japan International Cooperation Agency (JICA), the United States Agency for International Development (USAID) and the Department of Foreign Affairs and Trade (DFAT) of the Government of Australia; this chapter explores how these three agencies addressed the challenge of realizing the continuum between humanitarian aid and development activities, focusing on their strategies, coordination and funding utilized for this purpose.

The rationale for selecting these bilateral agencies is based on their total financial aid to the Philippines. The Financial Tracking Service (FTS) ${ }^{1}$ shows that the United Kingdom, the United States, Canada, Japan and Australia were the top five bilateral donors providing humanitarian assistance following Yolanda. However, the FTS only deals with humanitarian funding, so the authors referred to the OECD.Stat database to complement the FTS data. In order to analyze the continuum, an important consideration would be the time-span of donors' support to the Philippines and presence prior to Yolanda. Japan and the US were clearly the first and second donors in the provision of 'humanitarian aid' on the basis of cumulative amounts disbursed over the past ten years (see Figure 10.1). Australia, Canada and the United Kingdom have provided almost the same amount of humanitarian aid. Taking into consideration the relationship between humanitarian assistance and longer-term development, it is clear that Japan, US and Australia are the top three donors (as the data bar for Australia indicates in the 'All sectors' column in Figure 10.1), and thus this paper focuses on their experiences.

This chapter comprises seven sections. In the next section, we provide a brief chronological review of the events after Yolanda. This is followed by an overview of the strategies for addressing the 'continuum' in the selected bilateral cooperation agencies and the challenges in implementing these strategies. The next section examines the coordination efforts, including that of the Office of Presidential Assistant for Rehabilitation and Recovery (OPARR) established by 


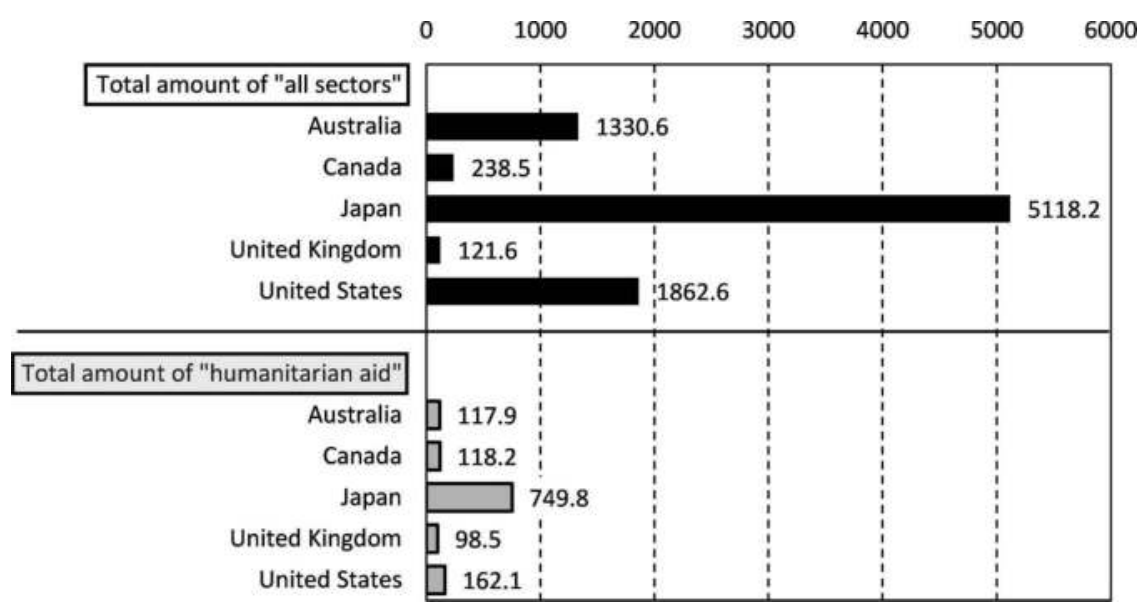

Figure 10.1 Total cumulative amount of ODA (2005-2014): comparison between 'all sectors' and 'humanitarian aid' (current prices, US\$, millions).

Note: According to OECD.Stat criteria, 'humanitarian aid total' includes 'emergency response, total,' 'reconstruction relief \& rehabilitation, total' and 'disaster prevention \& preparedness, total.' Source: authors, based on data generated from OECD. Stat.

the Government of the Philippines (GOP). OPARR was a unique, ad-hoc body, set up by the President, and was active for just one year after Yolanda. However, as a coordination mechanism for Yolanda relief efforts, the presence of OPARR cannot be ignored because of its organizational nature and relationship with bilateral cooperation agencies. We review the funding situation, incorporating some additional comments about multilateral donors.

In order to add detail to the challenge posed by the continuum, we then include a section on housing assistance in Tacloban following Yolanda and the contribution by bilateral cooperation agencies. As an issue discussed by Higashiura and Gómez (see Chapter 7), and with reference to the arguments by Christoplos (2006) and GFDRR (2015a), housing and livelihoods have repeatedly been shown to be the most critical aspect in connecting relief with recovery. This point was also emphasized by Ishiwatari (Chapter 9) who examines the challenges of housing in the chapter on Indonesia. The last section of this chapter is a discussion of our findings concerning the strategy, coordination and funding underlying crisis management. Finally, we consider how contributions by bilateral cooperation agencies started to decline considerably earlier than the ongoing efforts of the affected government.

Data for this chapter come from interviews, email communications and secondary materials such as official documents and information from online news sites and government websites. The main interviews were conducted in October 2015 and January 2016, and follow-up interviews were made in June 2016. These interviews with official representatives from bilateral cooperation agencies provided the authors an opportunity to explore the interviewee's reflections and to access 
primary documents. Interviews with the Philippine governmental organizations, the Tacloban City government and the United Nations agencies provided a varied perspective for the analysis. Although the authors were unable to conduct face-toface interviews with USAID, inquiries and communications were made by email.

\section{Chronological review of Typhoon Yolanda}

Typhoon Yolanda, known internationally as Haiyan, made landfall on Leyte Island in Philippines before dawn of November 8, 2013. As one of the strongest storms ever recorded (OPARR 2014, 7), Yolanda caused a massive amount of damage to properties and infrastructures. According to the National Disaster Risk Reduction and Management Council, the total number of dead and missing exceeded 7,000 people (NDRRMC 2013,3), and the total damage and losses were initially estimated at US $\$ 12.9$ billion (ibid., 5). The combined strong typhoon and storm surge led to a large number of people losing their homes; thereby requiring large-scale housing reconstruction. ${ }^{2}$

The extent of the devastation prompted then President Benigno S. Aquino III to declare a state of national calamity through Proclamation No. 682 on November 11, 2013 (OPARR 2014, 7). The GOP accepted the offer of international assistance through a letter to the United Nations Resident Coordinator/ Humanitarian Coordinator ad interim (OCHA 2013).

Simultaneous with the emergency response operations, the GOP had already started planning for recovery. The President agreed on a basic recovery framework presented by the National Economic and Development Authority (NEDA), which published the initial recovery vision in 'Reconstruction Assistance in Yolanda: Build Back Better (RAY)' on December 16, 2013 (Iuchi 2014). In parallel, the Office of Civil Defense (OCD) conducted a post-disaster needs' assessment (PDNA) in December 2013 (OPARR 2014, 9). The PDNA presents a strategic framework for recovery grounded on Republic Act No. 10121, known as the Philippine Disaster Risk Reduction and Management Act of 2010, and the President's social contract to the Filipino People (ibid.). The President appointed a Presidential Assistant for Rehabilitation and Recovery (PARR) on December 6, 2013 to unify the efforts of government and other agencies involved in the rehabilitation and recovery of Yolanda-affected areas (ibid., 10), and OPARR was established (JICA 2015, 1). ${ }^{3}$ On August 1, 2014, OPARR submitted the Yolanda Comprehensive Rehabilitation and Reconstruction Plan (CRRP) to the President (OPARR 2016).The CRRP was based on policy guidance developed by RAY and was designed to implement projects, programs, and activities to meet the needs identified in the PDNA (OPARR 2014, 11).

In relation to the international community's efforts, on 12 November 2013, the Emergency Relief Coordinator at the United Nations formally activated an Inter-Agency Standing Committee System-wide Level 3 (L3) emergency response to the typhoon (Hanley et al. 2014, v). ${ }^{4}$ The Philippines Humanitarian Country Team developed the Strategic Response Plan (SRP) on November 27, 2013. The SRP was designed to support the GOP's response to the immediate 
Table 10.1 Chronology of events following Typhoon Yolanda.

\begin{tabular}{ll}
\hline Data and year & Event \\
\hline November 8, 2013 & Landfall of Typhoon Yolanda \\
November 12, 2013 & Activation of IASC Level 3 response \\
November 27, 2013 & SRP developed \\
December 6, 2013 & Establishment of OPARR: MO No.62 \\
December 16, 2013 & RAY published \\
July 4, 2014 & Declaration of the end of response by President of the Philippines \\
August 1, 2014 & CRRP unveiled \\
April 22, 2015 & Termination of OPARR: MO No.79 \\
December 2015 & 30\% of projects for recovery \& reconstruction completed \\
May 2016 & (NEDA 2015) \\
& Presidential election. New president assumes office on \\
& July 1, 2016
\end{tabular}

Source: authors.

humanitarian needs of the people affected by Yolanda, and complemented the Government's RAY (Philippines Humanitarian Country Team 2013).

In implementing the SRP, twelve clusters were established. However, in the CRRP, the GOP developed another type of cluster for rehabilitation and recovery (details will be described later). There is no available information on the connection between the clusters of the Philippines Humanitarian Country Team and the clusters in CRRP. The authors did not observe any clear connection and involvement of bilateral cooperation agencies in establishing such a connection. They seem to run in parallel, separate tracks.

Although the SRP was initially planned to function for 12 months from the date of the disaster, the President declared the end of the response phase on July 4, 2014 (interview with the World Bank Manila office, October 19, 2015). Once the President of the Philippines stated that the response phase was over, some organizations with strict humanitarian mandates were caught off guard, as many relief needs remained unmet. The declaration of the President triggered the deactivation of most humanitarian clusters co-led by the UN and other international agencies, although several clusters including shelter and protection were extended until the end of November at the request of the government (Thomas 2015, 16).

\section{Strategies to address the continuum}

\section{Japan}

Assistance from Japan was provided through two major routes: the Embassy of Japan in the Philippines and JICA. These two offices collaborated with each other and shared details of their assistance. From the Embassy, emergency relief items and Emergency Grant Aid were provided. Approximately US\$30 million was allocated to nine international organizations (INGÉROSEC Corporation 2015, 45). An additional US\$20 million from the Grant Aid for recovery and 
reconstruction was disbursed to international organizations (data provided at the Embassy of Japan in Manila, October 15, 2016).

From JICA, Japan Disaster Relief (JDR) teams were dispatched, with these teams also providing emergency relief supplies. After that, an Urgent Development Study on Rehabilitation and Recovery from Typhoon Yolanda in the Philippines was conducted. This urgent development study (kinkyu-kaihatsu-chousa in Japanese) was then implemented as a Development Study-Type Technical Cooperation (JICA 2015). It aimed to comprehensively support the process of recovery and reconstruction, implement early recovery and reconstruction for areas affected by Typhoon Yolanda, and work towards establishing a disasterresilient nation/society, taking into account lessons learned from past disasters in Japan.

In addition to these settings, two new instruments were introduced in the Yolanda case: the Grant Aid Program for Rehabilitation and Reconstruction from Typhoon Yolanda, and Post-Disaster Stand-by Loans. The Grant Aid Program was implemented based on a plan formulated through the Urgent Development Study (JICA 2014a). The Post-Disaster Stand-by Loan is a type of general budget support (interview with JICA Headquarters, January 14, 2016) developed in March 2014. The Stand-by Loan encouraged the implementation of policy actions by GOP to reduce disaster risks and improve disaster-risk management capacity, as well as supporting quick restoration efforts by responding to temporary financial needs incurred when a large-scale disaster strikes (JICA 2014a). The Stand-by Loan was fully disbursed in February 2015 to support the Philippines' post-disaster reconstruction and recovery plans in the areas affected by Typhoon Yolanda (Japan Ministry of Finance 2015).

The Grant Aid Program was scheduled to be completed in February 2017. After the termination of the Urgent Development Study and the Grant Aid Program, some projects will continue to be supported by utilizing the existing JICA scheme. For example, the JICA Partnership Program will provide support to a livelihood support project for oyster farming on Leyte Island. Also, a Proposal Based Program in JICA's Partnership with the Japanese Private Sector will support the development of a fishery industry on Samar Island, also affected by the disaster.

\section{Australia}

In the relief phase, the Inter-departmental Emergency Taskforce was established by the Australian government (interview with the Embassy of Australia in Manila, January 25, 2016). The task force was composed of the Emergency Management Agency, Civil Military, Department of Health, the Federal Police and the Department of Defence. As instruments for the relief operation, an Australian Medical Assistance Team and DFAT Rapid Response Team were deployed. The Humanitarian Partnership Agreement (HPA) was activated as the primary mechanism for humanitarian funding for Australian NGOs. The agreement brings together the department and six pre-selected Australian NGOs 
(Care, Caritas, Oxfam, Plan International, Save the Children and World Vision) (DFAT 2016).

In transitioning from the relief phase to the recovery and reconstruction, the Embassy of Australia in Manila directly suggested components required for assistance to DFAT headquarters (interview with the Embassy of Australia in Manila, October 14, 2015). In other words, it is distinctive that the Embassy led initiatives in developing Australian strategy for Yolanda assistance. Additionally, almost all of the financial support for recovery and rehabilitation were delivered through programs and partnerships of the Australian Government in the Philippines that already existed prior to Yolanda.

The details of the Australian contribution are as follows:

- AU\$10 million: Construction of up to 500 classrooms through the Basic Education Support Transformation Program with the Department of Education (DepEd).

- AU\$3 million: Construction of up to 75 daycare centers through the National Community Driven Development Program with Department of Social Welfare Development (DSWD).

- AU\$1.6 million: Community small grants to help approximately 570,000 people restore livelihoods through the Philippine-Australia Community Assistance Program.

- AU\$7.3 million: To help affected communities build back better through risk assessments, updated land use planning and building codes, early warning systems and emergency response teams in 12 local government units and 150 barangays benefiting 430,000 people through the Resilience and Preparedness towards Inclusive Development Program implemented by the Philippines Climate Change Commission (CGG) and UNDP.

The utilization of these existing programs was a significant aspect of the Australian intervention after Yolanda.

\section{United States of America}

USAID's Office of U.S. Foreign Disaster Assistance (OFDA) activated a fieldbased Disaster Assistance Response Team (DART) and corresponding Washington DC-based Response Management Team (RMT) on November 9. DART conducted assessments in affected areas of the Philippines, liaised with other humanitarian and government actors in the country, and recommended appropriate response and recovery options. RMT served as a focal point to coordinate the United States Government's humanitarian response, program relief activities, and provide support for DART. On December 18, 2013, DART and RMT demobilized (USAID 2014a, 6).

On June 9, 2014, USAID/Philippines launched 'USAID Rebuild,' a multicomponent effort funded by the U.S. Government to support reconstruction and rehabilitation activities in Typhoon Yolanda-affected areas (USAID 2014b). USAID 
Rebuild has focused on restoring access to education, health services and promoting livelihood activities, as well as providing technical assistance to OPARR (ibid.). Since the overhaul of OPARR, USAID has continued to provide technical assistance to NEDA and the Department of Budget and Management (DBM) (interview with staff of USAID Rebuild Project - Technical Assistance to DBM, June 20, 2016).

\section{Challenges for 'continuum' approaches}

Interviews with bilateral cooperation agencies revealed that 'continuum' strategies faced challenges in relation to the broader context of Official Development Aid (ODA) policies of each donor country.

In the case of Japan, the affected area did not correspond to areas identified by the Country Assistance Policy for the Philippines (e-mail, JICA Manila office, November 25, 2015). Instead, Metro Manila and Mindanao Island were prioritized in the Country Assistance Policy for longer-term development. Leyte and Samar Islands, which were among the most devastated areas, received lower prioritization in the existing Japanese ODA policies - a situation that did not change after the disaster.

In Australia, a reform of ODA policies in September 2013 following the change of government influenced assistance after Yolanda (interview with the Embassy of Australia in Manila, January 25, 2016). The reforms reduced the ODA budget by 40 percent, in what was called the 'Global Cut.' While the new ODA policy emphasized Asia and the Pacific, Indonesia, Viet Nam and the Philippines were less prioritized. As a result, the total amount for recovery and rehabilitation decreased from AU\$36.3 million as of March 2014 to AU $\$ 23.0$ million as of October 2015. Furthermore, the new cabinet considered mobilization of funds for climate change issues intensively, and preferred to utilize military assets in providing assistance. In the case of the government of Australia, two things should be noted: assistance in the case of Yolanda occurred just after the change of the cabinet. Secondly, it was the first big operation following the structural reforms by which AusAID, the Australian aid organization, was merged into DFAT.

Contrary to Japan and Australia, the US showed a different tendency. USAID provided humanitarian relief and recovery assistance based on assessed needs and was not bound by limitations related to bilateral or multilateral arrangements (e-mail, USAID Manila office, February 1, 2016). In other words, USAID was not constrained by limitations on what it aimed to do in its assistance. Japanese assistance was constrained by its Country Assistance Policy and Australia ODA had just suffered from the Global Cut.

\section{Coordination for the continuum}

\section{Japan}

In terms of coordination within the Japanese government, the Ministry of Foreign Affairs, Ministry of Finance, the Embassy and JICA (both at its headquarters 
and the Manila office) participated in the relief process. However, arrangements for the recovery and reconstruction were mainly determined inside JICA and the engagement of other agencies was very weak.

There was coordination by the embassy in relation to its funding allocation. The Embassy disbursed funds to international organizations, although some Grant Assistance for Grass-Roots Human Security Projects were allocated to provide assistance such as provision of fire trucks and ambulances to the Department of Interior and Local Government, as well as school-building by the NGO IsraAid. According to the Embassy, they gathered information from other donors, but did not discuss these projects with them individually (interview with the Embassy of Australia in Manila, January 25, 2016).

In the case of JICA, it was clear that there was limited coordination with other bilateral donors. JICA made a significant effort to provide livelihood support through direct collaborations with Local Governmental Units. The authors found that such direct collaboration had nothing to do with other bilateral donors' behavior. Moreover, based on the Urgent Development Study, JICA sought to collaborate with the United Nations Food and Agriculture Organization, something that proved to be impossible (interview with JICA Manila office, October 14, 2015). There was no information on collaboration attempts with other international organizations. JICA utilized an existing program, the JICA-DOH (Department of Health, GOP) project for Strengthening Maternal and Child Health Services in Eastern Visayas, to provide equipment (JICA 2014b). This shows that JICA closely consulted with DOH, but did not discuss their operations with other agencies.

\section{Australia}

In Australia, the Inter-Departmental Task Force was organized during the relief phase. However, coordination in the recovery and reconstruction was limited between DFAT headquarters and the Embassy in Manila. Inside DFAT, several sections - such as education, gender and infrastructure - collaborated with each other.

As described in the strategy section above, it was remarkable in the case of Australia that almost all of the financial support for recovery and rehabilitation was delivered through existing programs and partnerships between the Australian Government and the Philippines. The total amount of all of recovery and rehabilitation assistance was $\mathrm{AU} \$ 23$ million. Of this, $\mathrm{AU} \$ 21.9$ million $(95.2 \%$ of the total amount) was provided through existing programs and partnerships (data provided by the Embassy of Australia in Manila, January 25, 2016). In terms of coordination, Philippines government agencies such as DepEd, DSWD and CCG, were included in the Australian assistance program. It is very clear that the Australian embassy coordinated its engagement through pre-existing programs in its Yolanda assistance.

\section{United States of America}

The US followed the strong OFDA leadership and close coordination and communication with the Department of Defense in providing relief. This allowed the 
U.S. Government to present one strategy and one united front to assist the people of the Philippines in response to the destruction of Typhoon Yolanda (USAID OFDA, 2015, 15). The 'One Team' reference indicates the close coordination between defense, diplomacy and development departments of the U.S. Government to bring about a responsive and immediate range of assistance activities to the affected populations (USAID information based on e-mail from USAID Manila office, February 1, 2016). OFDA is responsible for leading relief and response efforts by the U.S. Government and serves as the coordinator for a range of the US Government capabilities. After the relief and early recovery phase was complete, reconstruction and recovery efforts were coordinated by the bilateral USAID mission, thus while all entities continued to operate in a coordinated fashion, the reconstruction and recovery implementation were led by USAID team out of the Manila office. The same team continues to coordinate recovery and resilience activities in the affected areas, however under a less structured arrangement than DART, which was specific to the relief phase.

In the case of USAID, they utilized an existing project: Be Secure (Water Security for Resilient Economic Growth and Stability) (e-mail, USAID Manila office, February 1, 2016). According to USAID, the initial design of the Be Secure project was focused in Basilan, Iloilo, Maguindanao and Misamis Oriental Provinces and Tuguegarao City; but the project had a pre-existing disaster-recovery component included that would allow USAID to respond to a hydrological disaster in any part of the country. Under this specific activity, USAID was able to initially mobilize the project to start working with local water districts, schools, and health clinics to identify water systems that were damaged and needed repair after the typhoon. As it became clear that the Leyte Island would need longer-term assistance, USAID was able to undertake a contract modification that added Leyte as a focal site for all Be Secure activities, allowing USAID to broaden its engagement in Leyte under the project to include activities like support to the Provincial Disaster Risk Reduction Management Office, although climate change projects and a feasibility study for a bulk water supply were downscaled.

Similar to Japan and Australia, there were no clear examples of US coordination with other bilateral donors. In the relief phase, the main coordination issues were concentrated on several US governmental agencies, and the modification of the Be Secure project meant USAID did not undertake active coordination with other bilateral donors.

\section{Coordination system in the GOP}

In terms of coordination following Yolanda, the establishment of and role played by OPARR cannot be ignored, as it was mandated to provide coordination for bilateral cooperation agencies. By virtue of Memorandum Order No. 62, the President appointed the Presidential Assistant for Rehabilitation and Recovery on December 6, 2013 to unify the efforts of Government and other agencies involved in the rehabilitation and recovery of Yolanda-affected areas (OPARR $2014,10)$. To facilitate its role as over-all manager and coordinator of rehabilitation, recovery, and reconstruction efforts by government departments, agencies, 
and instrumentalities in the affected areas, five clusters on a national level were organized. GOP referred to these five clusters as the 'Rehabilitation and Recovery Clusters.' They were different from the cluster approaches used by the international community for relief. The five clusters were as follows: infrastructure (chaired by the Department of Public Works and Highways (DPWH)), livelihoods (Department of Trade and Industry), resettlement (Housing and Urban and Development Coordinating Council), social services (DSWD) and the support cluster (DBM and NEDA). OPARR was dissolved on April 22, 2015 and its functions were transferred to NEDA (President of the Philippines 2015). In addition, OPARR engaged with the provincial governors and city mayors.

Several issues in relation to the short-lived efforts of OPARR deserve mention. Based on our interviewee responses, in terms of its practical aspects, coordination led by OPARR was not as well organized as expected, and it was seen as lacking in the strong authority necessary to proceed. The head of OPARR stated in an interview that there was so much responsibility given to the position with no commensurate authority (Alpad 2015).

Additionally, as OPARR was a temporary bureaucratic setting in the national governmental system, an officer described its existence as 'not normal' (interview with a staff of Office of Civil Defense staff in Quezon, June 20, 2016). According to the existing legal framework, NEDA was appointed as an overall responsible agency in the thematic area of disaster rehabilitation and recovery (OPARR 2014, 27). In addition to our findings, local media also reported on a petition questioning the legal status of OPARR (Sabillo 2014; Torres-Tupas 2014; Rappler 2014), with the Supreme Court ultimately dismissing the petition (PNA 2014). There was also a 'squabble' between the head of OPARR and the city mayor of Tacloban, one of the most devastated municipalities. The mayor argued that the city did not receive necessary support from the national government; however, the head of OPARR denied this claim.

In terms of the relationship between OPARR and bilateral agencies, the technical support provided to OPARR by USAID, as well as JICA's approach and attitude are noteworthy. USAID funded and deployed about 100 technical staff to monitor and evaluate programs, projects and activities in recovery and reconstruction (interview with the staff of USAID Rebuild Project-Technical Assistance to DBM, June 20, 2016). OPARR had only about 20 personnel in Manila to directly support PARR. Consequently OPARR would have faced enormous difficulties in monitoring and evaluating the recovery and rehabilitation progress at regional and local level without USAID assistance. After the transfer of OPARR's functions to NEDA, USAID continued to provide support and dispatched consultants to NEDA and DBM. However, following the termination of OPARR, the scale of the USAID's assistance has gradually decreased and USAID support for NEDA and DBM ended at the end of June 2016.

JICA approached OPARR primarily as part of its preparatory process for the Urgent Development Study (interview with JICA staff member in Manila, June 20, 2016). In implementing the study's projects, one of JICA's partner agencies in the Filipino government was the DPWH. JICA closely consulted with the 
DPWH to develop these projects. Usually, consultations with the partner agency are sufficient for project preparation. In the case of Yolanda, however, DPWH communicated carefully with OPARR, and DPWH requested that JICA makes sure its plan was understood by OPARR.

The establishment of OPARR clearly demonstrated strong governmental initiative. On the other hand, the existing literature illustrates the negative reputation of OPARR. Thomas $(2015,12)$ argued that OPARR had not been empowered. Pedrosa $(2016,53)$ concluded that the Government's creation of OPARR, meant setting up an additional yet unnecessary bureaucracy to the entire rehabilitation effort. GFDRR (2015b, 31) stated that OPARR did not possess the full authority and mandate to influence outcomes. Although it is too early to comprehensively evaluate OPARR's performance, and further discussion on the existence and meaning of OPARR is necessary, it might be concluded that OPARR did not have a big impact on the continuum following Yolanda, with reference to existing documents and findings by the authors in this chapter.

\section{Summary of coordination}

Japan, Australia and the US all utilized pre-existing programs for the purpose of coordinating their strategies beyond relief. When compared to JICA and USAID, however, it is remarkable that the Australian government mainly used pre-existing programs and partnerships in terms of budget allocation, so coordination was organized within a limited number of agencies. The existing programs and partnerships included the Philippines governmental bodies as counterparts for each bilateral cooperation agency. This means that coordination with the affected government was fluid and active. Instead, coordination between bilateral agencies was relatively passive.

\section{Funding}

\section{Bilateral funding}

In total, Japan provided approximately US\$630 million to relief efforts (data provided by the Embassy of Japan in Manila, the Philippines, October 15, 2016), while Australia contributed approximately US $\$ 50$ million (data provided by the Embassy of Australia in the Philippines, January 25, 2016), and the US allocated approximately US $\$ 143$ million (e-mail, USAID Manila office, February 1, 2016). The GOP has already disbursed approximately US\$2,300 million from FY 2013 to FY 2015, based on data as of October 31, 2015 by the Department of Budget Management. Although it is very difficult to find a summary of all the costs of recovery, the CRRP estimated the summary of cluster funding requirements as the total investment requirement, and the amount is 170,916,432,664.63 Philippines pesos (approximately US $\$ 3.6$ billion; OPARR 2014, 23). Based on this temporary calculation, 22.9 percent of the amount (US\$3.6 billion) was covered by funding from these three countries and the GOP covered 63.9 percent. Compared to the amount of GOP funding 
and bilateral and multilateral funding (introduced in the next section), support by bilateral and multilateral agencies seems to be influential on the crisis management.

In terms of funding tendencies, the US and the Australian governments allocated a larger amount toward the humanitarian response. In the case of Australia, two-thirds of the total amount, including expenditures on the military and the provision of medical services, was invested in the response. In the case of the US, a detailed amount was not available to the authors. ${ }^{5}$ Based on open information by the Philippines government, almost all of the 'received' funds were categorized according to the response purpose, such as military assets, relief goods and logistics. ${ }^{6}$ In the case of Japan, except for the expenditure of JDR and Japan Self Defense Force, the funding for recovery and reconstruction was greater than that for the humanitarian response.

\section{Roles of multi-lateral cooperating agencies: the World Bank and Asian Development Bank}

In addition to bilateral assistance, the World Bank made a decision to provide credit support. The Second Disaster Risk Management Development Policy Loan with a Catastrophe-Deferred Drawdown Option (CAT-DDO 2) provided US $\$ 500$ million to strengthen investment planning and regulations to reduce disaster risks and help manage the financial impacts when disasters strike (World Bank 2015). Although the CAT-DDO 2 does not directly support recovery or reconstruction projects related to Typhoon Yolanda, it can be interpreted to allow indirect support for GOP efforts towards recovery and reconstruction. ${ }^{7}$ Moreover, the World Bank and Asian Development Bank provided funding for existing government programs and mechanisms to disburse much-needed financing to local government units in the Philippines for reconstruction and rehabilitation (GFDRR 2015b, 22). The World Bank provided US $\$ 479$ million and the Asian Development Bank provided US\$372.1 million to the National Community-Driven Development Program (ibid., 22).

The Multi Donor Trust Fund did not show any clear contribution to recovery and reconstruction. Initially, the trust fund aimed to assist RAY financially, and the secretariat was the Asian Development Bank (ADB 2014, 7). However, it did not work as planned. One of the reasons for this malfunction was that contributions from DFID (Department for International Development of the United Kingdom) were earmarked for investment in micro, small and medium enterprises (based on information provided by World Bank Manila office, October 19, 2015). The US, Japan and EU showed some interest in pledging support for the fund. However, as the documentation process was delayed, and each organization was facing the end of the fiscal year, they ultimately did not pursue this.

\section{Close-up on housing and the continuum in Tacloban Gity}

Typhoon Yolanda caused huge human losses. It also resulted in a large number of internally displaced persons with over 900,000 families displaced (OPARR 2014). 
Damage to housing was severe, with 600,000 houses completely destroyed (NEDA 2013). This damage created huge demands for new housing, including temporary shelters, as well as necessitating relocation from coastal areas in order to reduce exposure to future risks. Tacloban City was one of the areas most devastated by the typhoon and, following the disaster, a large-scale relocation was undertaken to move coastal residents into new permanent housing provided on higher land (Iuchi and Maly 2016).

The guidance note of the Global Cluster for Early Recovery described how 'for affected people the shelter recovery process starts immediately at the onset of the crisis' (GCER 2016, 38). A policy note developed by the Shelter in Recovery Working Group of the Global Shelter Cluster states that 'there is the need to ensure that there is a continuum of support throughout the entire process from emergency to recovery, and not just during the first weeks or months, when an emergency has a higher media profile. This continuum of support may need to continue over the lifetimes of different Clusters or other coordination forums, and to have clear strategic connections with national-government development policies, once there are no further humanitarian needs' (Global Shelter Cluster Working Group on Shelter and Recovery undated, 1). Also, in relation to bilateral donors, the policy note indicated:

Humanitarian organizations should ensure national ownership of the early recovery process through the fullest possible engagement of national and local authorities in the planning, execution, and monitoring of recovery actions. By doing so, they may build capacity, and also strengthen accountability systems so that the population can hold governments, local authorities, and their international donors to account in the implementation.

(Global Shelter Cluster Working Group on

Shelter and Recovery undated, 3)

These were - at least in theory - principles upon which all stakeholders could be involved in the housing sector, starting from active engagement by national and local authorities. Henceforth, these principles are somewhat contradicted by the actual practices of local actors and donors.

\section{Housing issues in Tacloban City from the local viewpoint}

This section illustrates issues in housing assistance from the viewpoint of a local government and local people. According to the city authority, over 54,000 homes were damaged by the typhoon and 48 percent of damaged houses were completely destroyed (figures presented here based on a lecture by officers of Tacloban City, October 12, 2015). As a result, about 14,500 families urgently needed housing assistance, and were tagged as having lived in unsafe zones. The city has 138 barangays, with 36 of them marked as being very high-risk. ${ }^{8}$ These are located in coastal areas, which experienced a four- to five-meter surge during Yolanda. The city prioritized the 40,500 families in the 36 high-risk barangays in order to transfer them to the Tacloban North resettlement area. 
However, significant progress has not as yet been achieved. First, transition from temporary shelters to permanent houses was delayed mainly due to lack of an adequate water system. Second, development of the resettlement area has also been delayed. The city authority has provided some reasons for that delay:

1 the water system has not been fully prepared in the resettlement area;

2 the slow pace of construction of the houses; and

3 livelihood in the resettlement area was not well provided for (from a lecture by officers of Tacloban City, October 12, 2015).

As a result, Iuchi and Maly (2016) revealed that, as of October 2015, about 80 percent of the initial target of beneficiary households had not been relocated to temporary housing or permanent houses. In addition to people living in temporary and permanent housing provided by the government or other actors, the majority of other residents from areas targeted for relocation went back to live in their original neighborhoods in self-built temporary housing.

Reconstruction endeavors are still ongoing, and the local government has struggled with many difficulties. Iuchi and Maly (2016) made the observation that the Tacloban City Government has taken on the central coordination role. They conclude that, at the time of writing, Tacloban City has coordinated and advanced housing reconstruction by managing various actors who are representing international agencies, national governments, NGOs, and civil society organizations. ${ }^{9}$ So far, they have successfully built partnerships with nongovernmental actors during both the temporary and permanent phases of housing relocation, thereby leveraging various means of support to provide housing to a larger population.

According to local people, representatives of barangays indicated that problems with the water supply and livelihood have hampered resettlement. Iuchi and Maly (2016) summarized the complicated situation from the perspective of local residents. They argued that the housing choices were not equally provided to beneficiaries, the lack of utilities such as electricity and water in resettlement areas hampers smooth relocation, and most households have decided to wait back in their communities. A resident living in a temporary house said to us that the procedures for selecting households to be relocated were unclear. Another interviewee told us that two rainy and typhoon seasons was too long to stay in a temporary house.

Furthermore, a new embankment development taking place in Tacloban negatively influenced the perception that housing issues were a priority in the city. The embankment construction (to a height of about 4.5 meters) is a project led by the national government with the aims of lessening damages from future disasters. Yet, according to the media (Philippines Today 2015; Sunstar 2015), some residents in the affected areas are worried that the construction will further delay their relocation to permanent houses. They claim that housing should be given higher priority than developing the new embankment.

In summary, as seen from the viewpoint of the local government and the local people, housing assistance needs remain largely unmet in the affected area. 


\section{Efforts by bilateral cooperation agencies}

In the relief phase, many bilateral cooperation agencies allocated funds to provide emergency shelters. Although data on this is not exclusive to Tacloban City, the FTS includes the following countries as contributing to emergency shelters: Canada, Denmark, Germany, the Hong Kong Special Administrative Region of the People's Republic of China, Ireland, Japan, Korea, New Zealand, Spain, Sweden, Switzerland, the United Kingdom, and the US (based on FTS data provided by OCHA Philippines office, October 14, 2015). However, funding for emergency shelters did not fully cover the requested amounts. Based on FTS, as of April 6, 2016, the Emergency Shelter Cluster, and the Camp Coordination and Camp Management Cluster had received 46.4 percent (approximately US\$80 million) and 55.2 percent (approximately US\$4.4 million) of their funding requirements, respectively.

In transitional housing in Tacloban City, based on Iuchi and Maly (2016), it is noteworthy that USAID provided temporary housing through funding to an NGO, CRS (Catholic Relief Service). The CRS project lasted two years, ending in December 2015 (USAID 2015). ${ }^{10}$ We did not find evidence of Japanese or Australian involvement in the provision of transitional housing assistance.

In terms of permanent housing, there was hardly any assistance provided by bilateral cooperation agencies in Tacloban City. There, the National Housing Authority is the largest distributor of permanent housing (lecture by officers of Tacloban City, October 12, 2015). While not a bilateral effort, the only example available is an EU-funded UNDP project to develop resilient houses, through which fifty-five houses are under construction. The residents of the houses will be people who lived in Barangay 61 before Haiyan. These residents are required to be involved in the construction of the houses and the houses will be provided to them for free, on the condition that they cannot sell, give or lend them to others. The residents do not need to pay land fees and are not able to own lands (interview with UNDP Tacloban Office, October 13, 2015).

In sum, while there was multilateral support for emergency shelters, there was only one example of transitional housing and no particular support for permanent solutions - although it is possible that donors have indirectly supported housing through loans. In terms of coordination, there were no active bilateral actors in Tacloban, so all efforts ran through local governments or implementing partners. Despite being one of the most crucial sectors, bilateral donors have not committed to providing permanent housing assistance, even though there is still huge demand for such assistance. In other words, it is obvious that there was no strategy, coordination, or funding for the longer-term continuum goal of providing housing assistance.

\section{Challenges underlying the housing continuum}

The finding that the housing sector is mainly coordinated by the local government (a positive finding earlier in this chapter), while at the same time unable to muster cooperation support from the major donors, deserves further attention. 
On the side of the local institutions, it is not surprising that progress of recovery and reconstruction by the Philippine government has been slow, despite being a middle-income country with a relatively strong national government (ICAI 2014, 3; Carden and Clements 2015). Several authors pointed out that the national government has faced deficiencies in disaster management (Luna 2001, 224; Victoria 2003, 1; Bankoff and Hilhorst 2009, 691). Furthermore, the problem of absorptive capacity should be considered. ${ }^{11}$ The Philippine Institute for Development Studies (2015) argues that the absorptive capacity of the Philippines government is low. Particularly, public construction projects tend to be delayed (Manasan and Mercado 2001). This point is relevant to recovery and reconstruction, since a lot of activities toward recovery and reconstruction are construction efforts.

Moreover, reflections by those governmental officials interviewed for this research indicate that it takes a longer time than initially planned for the affected government to implement recovery and reconstruction efforts. An officer in the national government stated that 'many things can happen beyond the CRRP. ${ }^{12}$ Another officer in a different central government office noted that 'the CRRP goes beyond time frame of JICA.' Based on our surveys, major bilateral cooperation agencies showed scaling down of assistance to the typhoon-affected areas. Even for the best performing donor in this sector - the US - assistance finally ended in June 2016. The national authorities are required to proactively monitor and evaluate the progress by themselves. Thus, reconstruction endeavors are ongoing, and time frame - including all of the processes of response, recovery and reconstruction - requires more than the three years in the Philippines. Thus, sharing the same time-scale of the actual recovery phase is another factor that hinders support to the continuum.

Olshansky, Lewis and Laurie $(2012,176)$ noted that governmental capacity to solve problems, provide resources, and take actions is insufficient, at least compared to normal times, because of 'time compression' characteristic of the recovery. In consequence, recovery and reconstruction were likely to be delayed and take more time than expected due to the limitations in governmental capacities. In the Yolanda case, it is a reality that unmet needs still exist in the field and it will require a significantly longer period of time to solve such problems. However, three years after the disaster, the presence of external agencies in the affected area seems to be gradually falling away. While three-year efforts might be considered sufficient for transitional activities by bilateral actors, the scale of the actual recovery is much longer.

It must be acknowledged, nonetheless, that challenges specific to the housing sector are beyond the reach of donors. Discussions with the National Housing Authority and the UN-Habitat Tacloban Office revealed two constraints:

1 limitations generated by the procurement process, the capacity of constructing machine transportation and bad weather conditions; and

2 coordination problems between resettlement and programs for livelihoodanother crucial sector. ${ }^{13}$ 
The authors consider it likely that bilateral cooperation agencies in the Philippines are already aware of these challenges and this is a reason why they have hesitated to become involved in permanent housing assistance. This view is not new, but if it influences the overall time scale of crisis management plans, it is a weak point in their commitment to realizing the continuum.

Finally, as far as this survey is concerned, nobody foresaw the influence of the presidential election of 2016. ${ }^{14}$ The political situation in the Philippines is very complex and it is hard to see whether the new government will continue the CRRP strategies developed by the outgoing administration. In fact, the CRRP, described 'the medium-term phase' as covering the period the year of 2015 to 2016 (OPARR 2014, 16), coincidently timed to match the end of the previous presidential term. The timing considerations in Manila and Tacloban are therefore different as well. The important thing is that there are no detailed descriptions for guiding recovery and reconstruction activities after the period of June 2016. At the time of writing, we can hardly assess whether the presidential election had any substantial impacts on the planning of recovery by bilateral cooperation agencies. As far as we are aware, open discussions have not been held by the new presidential administration and bilateral cooperation agencies regarding the planning for Yolanda reconstruction. The on-going projects provided by the bilateral agencies were determined in the time of the former administration. Additionally, it is also difficult to consider whether bilateral cooperation agencies are able to help supporting the affected areas between the governmental administration changes, since the new administration has not presented their own guiding principles for reconstruction. We recognize these points as major topics to be further elaborated in other articles.

\section{Conclusion}

Typhoon Yolanda brought about huge losses and damage to the Philippines in November 2013. In the three years since the disaster, progress toward recovery and reconstruction has been limited, with only about 30 percent of work completed as of December 2015 (NEDA 2015). Housing assistance, in particular, has been delayed: in Tacloban City only about 10 percent of the permanent houses that are needed have been completed (based on a lecture by officers of Tacloban City, October 12, 2015).

In principle, it could be said that the three largest donors to the Philippines were well positioned to substantially contribute to achieving the continuum - at least from the viewpoint of their strategies, coordination and funding. The prompt engagement by the three donors and activities over the past three years did reduce the gap between relief and recovery. The donors studied here dispatched large-scale emergency response teams and provided assistance for recovery and reconstruction by utilizing existing projects that had already been active prior to Yolanda. This use of existing projects and contacts seems to be the strongest facilitating factor from both the point of view of strategy and coordination. The balance of the allocated funding between the response and the recovery phases 
was not equal, and most of the funding by Australia and the United States of America went to the response. However, all of the donors presented in this chapter have substantially invested resource and paid careful attention to ensure that the phases were not fragmented.

In the cases of USAID and DFAT, most of the support for the recovery process ran smoothly through their existing programs. By so doing, they supported the strategy put forward by the government in the PDNA. The main feature of JICA's strategy was a strong awareness of the importance of seamless assistance. JICA developed its own assessments following the results of its own assessment. In comparison to the Australian Government's approach, the JICA scheme utilized pre-existing JICA instruments but this does not mean JICA used activities that existed before Yolanda - with the notable exception of the health project. JICA's own plan was closely discussed with line ministries with which it holds close relations, so there are no reasons to think that there was interference between their strategies. The difference in the size of the contributions for the recovery may explain the need for JICA's own assessment.

Following on from this strong relationship with local institutions, other types of coordination seem to lose relevance. The authors did not observe specific coordination mechanisms for achieving continuum in any of the three agencies. In other words, coordination was minimal, and took place within the existing national framework. However, coordination in relation to the relief phase seems to still require meaningful contact with relevant agencies in each government. On the other hand, the establishment of OPARR clearly showed that the Philippines government took strong initiatives towards coordination; however OPARR did not have any big impact on the continuum of crisis management. USAID directly gave assistance to OPARR and JICA contacted it individually. But, it cannot be said that OPARR played any notable roles in coordination between bilateral actors.

There were some additional factors that inhibited contributions toward realizing the continuum. Some were internal to the donors: for example, political changes affected the scale of assistance in the case of Australia ('Global Cut'). It is also noteworthy that the mega-disaster did not affect the priorities of JICA in the country. In that sense, by utilizing a close-up focus on one of the most crucial sectors in connecting phases of crisis management (i.e., housing), it became evident that strong commitment was not necessarily followed by support. USAID showed a certain degree of contribution in providing transitional housing, and multilateral support was available for relief housing, yet bilateral agencies did not provide any remarkable assistance in working towards permanent solutions. In other words, while the overall picture of working for the continuum seems positive, specific sectors seemed to have been left behind. While the intricacies of the housing sector may explain the lack of support, it seems that a variety of different factors and preconceptions of the lengthier time scale required for the recovery play against the possibility of more realistic planning. Assuming that future crisis management in other parts of the world is also likely to take place in middle income countries with unconsolidated governance capacities, as in the Philippines, it would be pertinent 
to explore ways for donors to push forward more realistic middle- and long-term plans, and to contribute to difficult sectors. At the same time, they need to evaluate the impact of expensive relief efforts that consumed most of the funding.

\section{Notes}

1 FTS is a web-based, searchable contributions' tracking system, which reflects all humanitarian funding reported to the United Nations Office of Coordination for Humanitarian Affairs (ReliefWeb 2008, 23).

2 According to the World Bank, the value of damaged physical assets, both public and private, accounted for 3.7\% of GDP (World Bank 2015, 12). In case of Japan, for reference, the World Bank's estimate of the direct economic losses for the Great East Japan Earthquake accounted for 4\% of GDP (Ranghieri and Ishiwatari 2014, 264).

3 The Presidential Assistant role was filled by Senator Panfilo Lacson, who had a rank equivalent to a cabinet secretary (GFDRR 2015b, 9).

4 The concept of 'levels' for categorizing humanitarian crises is new. The level concept was introduced in the agreement of the Transformative Agenda of IASC in December 2011 (IASC 2011). It was the first time that Level 3 was issued in the Philippines.

5 The figure of 'US $\$ 143$ million' was obtained from e-mail communication with USAID office. However, according to the USAID website, the latest amount for 'USG Humanitarian Assistance for Typhoon Yolanda/ Haiyan to date in FY 2014' is US $\$ 90,864,627$.

6 Information here is from the FAiTH database (Foreign Aid Transparency Hub) managed by GOP (see www.gov.ph/faith/full-report, www.officialgazette.gov.ph/faith).

7 Almost all of the CAT-DDO 2 assistance is provided in the manner of technical assistance (World Bank 2015). This assistance reduces the policy implementation costs of the Philippines government, and the government is able to divert the surplus resources toward on-going recovery and reconstruction activities.

8 'Barangay' is the smallest administrative unit in the Philippines.

9 Thomas $(2015,17)$ and Paragas, Rodil and Pelington (2016, 28) both provide support for Iuchi and Maly's (2016) argument: Tacloban City has proactively promoted the relocation and resettlements by coordinating with UNDP in provision of livelihoods.

10 For those who lost their homes completely, the CRS project provided new shelters and built up new communities for relocation. Beyond housing assistance, USAID and CRS launched water, sanitation and hygiene, and disaster risk-reduction activities throughout Tacloban City.

11 Based on the United Nations Asian and Pacific Development Institute, absorptive capacity may be defined as the ability of a country or sector of the economy to effectively use the available or additional resources given to it in a productive manner (UNAPDI 2011). The absorptive capacity is considered as an obstacle that limits aid effectiveness (ODI 2005).

12 CRRP is the official and most comprehensive guiding document issued by the Government of the Philippines. Its timeframe has three stages: the short-term (within one year after the calamity, i.e., 2014), the medium-term (covering the period 2015 to 2016) and the long-term (no specific description of the length of this time period is offered by CRRP).

13 Data from a 2012 survey demonstrate that the average household income in the severely affected provinces was only $75 \%$ of the national average (OPARR 2014, 7). Although the same data on the average household income is not available, the World Bank says that across all the affected areas, half of the income derived from the main livelihood activities was reportedly lost as a result of typhoon Yolanda, with the most affected areas experiencing $80-90 \%$ losses (World Bank 2015, 51). In particular, these vulnerable provinces require continuous external support. 
14 It has been reported by the Philippines media that President Duterte stated that he was not able to accept the delays in housing construction, and has placed strong pressure on line ministries to make great progress before the end of March 2017 to reduce delays in housing provision to affected people. At the time of writing this chapter, it is unclear if his statement has influenced bilateral cooperation.

\section{References}

ADB. 2014. Establishing the Typhoon Yolanda Multi-Donor Trust Funds. Asian Development Bank. www.adb.org/documents/establishing-typhoon-yolanda-multi-donor-trust-funds.

Alpad, C. 2015. A New Year and a New Challenge for Panfilo Lacson. Manila Times, December 26. www.manilatimes.net/a-new-year-and-a-new-challenge-for-panfilolacson/236334.

Bankoff, G., and D. Hilhorst. 2009. The Politics of Risk in the Philippines: Comparing State and NGO Perceptions of Disaster Management. Disasters 33(4), 686-704.

Carden, D., and A. J. Clements. 2015. Coordinating the Response to Typhoon Haiyan. http://odihpn.org/magazine/coordinating-the-response-to-typhoon-haiyan.

Christoplos, Ian. 2006. Links Between Relief, Rehabilitation and Development in the Tsunami Response: A Synthesis of Initial Findings. London: Tsunami Evaluation Coalition (TEG).

DFAT. 2016. Humanitarian Preparedness and Response. Department of Foreign Affairs and Trade, Australia. http://dfat.gov.au/aid/topics/investment-priorities/building-resilience/ humanitarian-preparedness-and-response/Pages/humanitarian-prepraredness-andresponse.aspx.

GCER. 2016. Guidance Note on Inter-Cluster Early Recovery. Geneva: Global Cluster for Early Recovery.

GFDRR. 2015a. Guide to Developing Disaster Recovery Frameworks: Sendai Conference Version. Washington DC: Global Facility for Disaster Reduction and Recovery.

- 2015b. Recovery Framework Case Study: Typhoon Yolanda Ongoing Recovery. Washington DC: Global Facility for Disaster Reduction and Recovery.

Global Shelter Cluster Working Group on Shelter and Recovery. Undated. Policy Note on Recovery, Reconstruction and Shelter, for Shelter Actors-DRAFT. www.sheltercluster. org/sites/.../03-PolicyNoteonShelterandRecoveryV2.docx.

Hanley, T., R. Binas, J. Murray and B. Tribunalo. 2014. IASC Inter-agency Humanitarian Evaluation of the Typhoon Haiyan Response. New York: Inter- Agency Standing Committee.

IASC. 2011. IASC Transformative Agenda. New York: Inter-Agency Standing Committee. https://interagencystandingcommittee.org/iasc-transformative-agenda.

ICAI. 2014. Rapid Review of DFID's Humanitarian Response to Typhoon Haiyan in the Philippines. London: Independent Commission for Aid Impact.

INGÉROSEC Corporation. 2015. Kinkyuu zitai ni okeru zindou shien no hyouka [Evaluation of Humanitarian Assistance in Case of Emergency]. INGÉROSEC Corporation. 2015. www. mofa.go.jp/mofaj/gaiko/oda/files/000076534.pdf.

Iuchi, K. 2014. 'Build Back Better' after Hurricane Yolanda: Initial Planning Dialogue on Land Use and Risk after the Hurricane of November 2013. Proceedings of International Symposium on City Planning 2014, Hanoi. www.cpij.or.jp/com/iac/sympo/Proceedings 2014/18-fullpaper.pdf.

Iuchi, K., and E. Maly. 2016. Residential Relocation Processes in Coastal Areas: Tacloban City after Typhoon Yolanda. In Coming Home after Disaster: Multiple Dimensions of Housing Recovery, edited by A. Sapat and A.-M. Esnard, 209-228. Boca Raton, FL: Routledge CRC Press. 
Japan Ministry of Finance. 2015. The Enhancement of Financial Cooperation between the Philippines and Japan. 3rd Fact Sheet. www.mof.go.jp/english/international_policy/financial_coop eration_in_asia/bilateral_financial_cooperation/20150503_philippines.pdf.

JICA. 2014a. Signing of Grant Agreement with the Philippines - Assistance for Recovery and Reconstruction in Areas Affected by Typhoon Tolanda. Tokyo: JICA. www.jica.go.jp/english/news/ press/2014/140521_01.html.

- 2014b. FICA Gives P1M Worth of Equipment to DOH Eastern Visayas to Help Restore Health Services in Typhoon Yolanda Disaster Areas. Tokyo:JICA. www.jica.go.jp/philippine/ english/office/topics/news/140421.html.

- 2015. Final Report of the Project on Rehabilitation and Recovery from Typhoon Yolanda. Tokyo:JICA. http://open_jicareport.jica.go.jp/pdf/12233946_01.pdf.

Luna, E. M. 2001. Disaster Mitigation and Preparedness: The Case of NGOs in the Philippines. Disasters 25(3), 216-226.

Manasan, R. G., and R. G. Mercado. 2001. An Assessment of the Absorptive Capacity of Agencies Involved in the Public Works Sector. Discussion Paper Series, No. 2001-17. Manila: Philippine Institute for Development Studies.

NDRRMC. 2013. Final Report re Effects of Typhoon 'Yolanda' (Haiyan). Quezon City: National Disaster Risk Reduction Management Council.

NEDA. 2013. Reconstruction Assistance on Yolanda: Build Back Better. Pasig City: National Economic and Development Authority (NEDA).

- 2015. Yolanda Updates: Rehabilitation and Recovery Programs. Pasig City: NEDA.

OCHA. 2013. Philippines: Typhoon Haiyan Situation Report No. 3 (as of 9 November 2013). Pasig City: NEDA.

ODI. 2005. Scaling Up Versus Absorptive Capacity: Challenges and Opportunities for Reaching the MDGs in Africa. ODI Briefing May 2005. London: Overseas Development Institute.

Olshansky, R. B., D. H. Lewis and A. J. Laurie. 2012. Disaster and Recovery: Processes Compressed in Time. Natural Hazards Review 13(3), 173-178.

OPARR. 2014. Yolanda Comprehensive Rehabilitation and Recovery Plan. Manila: OPARR.

- 2016. Who We Are. OPARR. http://oparr.gov.ph/who-we-are.

Paragas, G., A. Rodil and L. Pelingon. 2016. Tacloban after Haiyan: Working Together Towards Recovery. IIED Working Paper. London: IIED.

Pedrosa, A. M. 2016. A Portrait of Two Storms: The State of Yolanda Reconstruction Two Years After. Quezon City, Philippines: Canadian Catholic Organization for Development and Peace/Caritas Canada.

Philippines Humanitarian Country Team. 2013. Strategic Response Plan for Typhoon Haiyan. New York: UNOCHA.

Philippines Today. 2015. DPHW Consults Communities Affected by Leyte's Tide Embankment Project. July 25. www.philippinestoday.net/archives/22894.

PIDS. 2015. PIDS 2014 Economic Policy Monitor. Makati City: Philippine Institute for Development Studies.

PNA. 2014. SG Junks Petition vs. OPARR. 2014. Philippines Newes Agency, June 4. http:// metrocebu.com.ph/2014/06/sc-junks-petition-vs-oparr/

President of the Philippines. 2015. Memorandum Order No. 79: Providing for the Institutional Mechanism for the Monitoring of Rehabilitation and Recovery Programs, Projects and Activities for Yolanda-Affected Areas. Official Gazette. www.gov.ph/2015/04/22/ memorandum-order-no-79-s-2015/.

Ranghieri, F., and M. Ishiwatari. 2014. Learning from Megadisasters: Lessons from the Great East Japan Earthquake. Washington, DC: World Bank.

Rappler. 2014. SC Junks Plea vs Lacson as Rehab Secretary. Rappler, June 3. www.rappler.com/nation/59542-sc-junks-plea-lacson-rehabilitation-secretary 
ReliefWeb. 2008. Glossary of Humanitarian Terms. ReliefWeb, August. http://reliefweb. int.

Sabillo, K. A. 2014. Palace Defends Lacson Appointment as Rehab Czar. Inquirer, February 11. http://newsinfo.inquirer.net/576912/palace-defends-lacson-appointment-as-rehabczar-2.

Sunstar. 2015. JICA Cites Gains in Leyte's Tide Embankment Project. Sunstar, November 10. www.sunstar.com.ph/tacloban/local-news/2015/11/10/jica-cites-gains-leytes-tideembankment-project-440690.

Thomas, A. 2015. Resettlement in the Wake of Typhoon Haiyan in the Philippines: A Strategy to Mitigate Risk or a Risky Strategy? Washington DC: Brookings Institution.

Torres-Tupas, T. 2014. SC Junks TRO bid vs Lacson as Rehab Czar. Inquirer, February 11. http://newsinfo.inquirer.net/576744/sc-junks-tro-bid-vs-lacson-as-rehab-czar.

UNAPDI. 2011. A Glossary of Terms in Regional Planning and Development. The United Nations Asian and Pacific Development Institute. New Delhi: Abhinav Pub.

USAID. 2014a. Philippines - Typhoon Yolanda/Haiyan Fact Sheet \#22, Fiscal Year 2014. April 21. Washington DC: USAID. www.usaid.gov/sites/default/files/documents/1866/philip pines_ty_fs22_04-21-2014.pdf.

—. 2014b. USAID Rebuild - Building Resilient Communities. Washington DC: USAID. www.usaid.gov/philippines/fact-sheets/usaid-rebuild-building-resilient-communities.

- 2015. US Government and Catholic Relief Services Provide Safe Housing to Over 3,000 Families Affected by Typhoon Yolanda. Washington DC: USAID www.usaid.gov/philippines/ press-releases/dec-8-2015-us-government-and-catholic-relief-services-provide-safe.

USAID OFDA. 2015. Annual Report for Fiscal Year 2014. Washington DC: USAID.

Victoria, L. P. 2003. Community-Based Disaster Management in the Philippines: Making a Difference in People's Lives. Philippines Sociological Review 51, 65-80.

World Bank. 2015. Program Document for a Proposed Loan in the Amount of Equivalent to US\$500 Million to the Republic of the Philippines for the Second Disaster Risk Management Development Policy Loan With A Catastrophe-Deferred Drawdown Option. Report No. 96587-PH. Washington, DC: World Bank. 


\title{
11 Conclusion
}

\section{The continuum beyond the humanitarian-development nexus}

\author{
Atsushi Hanatani, Oscar A. Gómez and \\ Chigumi Kawaguchi
}

The main goal of this book was to examine the extent to which the continuum, an effort to link relief, recovery and prevention - and sometimes development as well-has been realized in managing two specific types of humanitarian crises: disasters and armed conflicts. We undertook this project from the perspective of crisis management, looking particularly at the involvement of bilateral donors. As we have seen in all of the case studies, the challenge of the continuum has been addressed, one way or another, by all stakeholders, regardless of whether they were humanitarian or developmental, multilateral, bilateral or local. They achieved this through strategies devised by each of them as well as through joint work. Therefore, it is safe to say that the continuum is a shared concern not only at the headquarters' level of organizations involved in humanitarian crisis management but also in practice.

The case studies also showed a variety of visions of and approaches to the continuum, providing evidence of important divisions between epistemic communities engaging in crisis management-i.e., humanitarians, developmental actors, peacebuilders, disaster risk reduction specialists, emergency relief specialists, sector-based institutions working on recovery, and so on. Such divisions are present even within each type of crisis, which partly explains why the continuum remains a central concern. In this concluding chapter, we will first examine the case studies for each of the two types of crises by following the framework for comparison introduced in Chapter 2-strategy, coordination and funding - to illustrate how international actors' approaches to the continuum have evolved and to classify issues specific to disasters and conflicts. Second, we contrast the two crisis contexts in order to highlight similarities and differences between international actors' approaches. Following this, we synthesize the findings of the whole project, discussing some enabling and hindering factors in pursuing the continuum. These factors, together with the multilayered model initially suggested, can be of help in advancing agreement in particular settings and, more generally, in the development of a global policy of crisis management. We also discuss some of the limitations of our research and the general model, including fundamental issues that may continue to complicate discussions about the continuum. Based on these observations, we close with some policy implications in the final section. 


\section{Grisis management after disasters: challenges for long-term prevention despite strong local ownership}

In Chapter 7, Higashiura and Gómez pointed out ways that global strategies for linking different phases of the continuum have changed over the last 20 years, particularly after the Hyogo Framework for Action in 2005. Among the three cases of disasters in Part III of this volume, only Chapter 8, on Hurricane Mitch in Honduras, deals with a period before this, when the concept of disaster risk reduction (DRR) was still in its embryonic stages. This case shows how difficult it was to integrate and mainstream prevention into the overall process of disaster management. Despite partial realization of the continuum thanks to the ownership of the government and international support in strengthening disaster management institutions, the case demonstrates how prevention can easily slip out of the post-disaster agenda of both donors and governments when there is limited knowledge and experience of how DRR should work.

Second, the case of Indonesia after the Indian Ocean tsunami and Java earthquake (Chapter 9) illustrates how the government, society and donors can learn useful lessons from earlier disasters. Drawing from the tsunami experience, the Government of Indonesia, with support from donors, developed national institutions that resulted in more effective disaster response management. They introduced livelihood support and housing programs through which recovery was linked with long-term development and DRR, thus successfully and effectively realizing the continuum. The case study, however, reminds readers of the difficulties of sustaining DRR as attention toward preventive activities tends to decline once the recovery is seen as accomplished by the public.

Finally, the case of the Philippines after Typhoon Yolanda (Chapter 10) further emphasizes the importance of local ownership-especially that of the government - in efforts toward realizing the continuum in disaster management. The establishment of specially mandated national institutions helped to link donor support directly with national programs. This also increased the efficiency of the assistance provided by donors, although relief still received most of the international attention. Recovery after Yolanda has taken a long time, particularly in relation to housing, for which bilateral donors have not been able to provide much support. The authors consider this to be an important gap between needs on the ground and the provision of support from outside.

While the impact of global action to unify strategies to disaster management is visible throughout the cases, the internalization of DRR is a vital but often-missed element in realizing the continuum in the case of disaster management. In Honduras, the disaster did not create enough momentum to internalize DRR broadly across national institutions. The case also shows that it is necessary for external actors to possess knowledge about the practice of DRR in different sectors in a way that elicits a commitment to crisis management in the long term. This should, hopefully, empower actors with deeper understanding and better 
engagement with local institutions. From this viewpoint, even if not intended, the long-term commitment of the Japanese government and Japan International Cooperation Agency (JICA) in Tegucigalpa is partly rooted in the master plan produced in 2000 for addressing landslides in the area which, after fifteen years, was still of help in informing action. Generating such long-term plans with a solid technical base can be even more helpful for bilateral actors to avoid the alternative of returning to patterns where they only provide peaks of support during expensive relief operations - as was the case in the Philippines.

The long-term approach to the management of crises caused by natural disasters thus relies on the consolidation of knowledge about how to implement DRR, particularly at the local level. In Honduras, formulating the reconstruction plan based on the idea of 'transformation' showed how ambiguity played against the intentions of reducing vulnerability to disasters. 'Build back better' became more relevant in Indonesia and then was reutilized as the paradigm underpinning the operation in the Philippines. In this way, efforts triggered by disasters have become more focused on actually preventing future disasters. Jibiki and Ono, however, find that most of the resources from bilateral donors are still concentrated on the relief phase. It seems, therefore, that efforts through the international DRR movement, as understood in the 2005 Hyogo Framework for Action, have not been sufficient to change the mindset of shock-driven action. Will the Sendai Framework for Action be any different? It remains to be seen. Nonetheless, the fact that - except for Japan - bilateral work for DRR remains mainly on the humanitarian agenda does not seem to augur well.

Looking at crisis management from the point of view of coordination underscores the fundamental role of local government. A common thread in all three cases describing disaster crises is the strong presence of local governments, which are ready to be at the forefront of management operations, allowing coordination issues to be addressed flexibly. Even in the case of Honduras, where Hurricane Mitch directly hit the capital city, the case study showed how the government was functional - at least at the level of planning - and actively coordinated with the international community during the recovery process. In practice, however, all actors were free for some time to implement programs as they wished. Chapter 9 describes how the Indonesian government used the disaster to create DRR institutions, which performed well two years later when the earthquake occurred on Java Island. The case of the Philippines showed how moving from relief to recovery was driven by local and national planning efforts, which bilateral donors supported in different ways. Such local ownership becomes an important, if not the main, driving force of the process in relation against which the realizationor not - of the continuum must be assessed, instead of the isolated efforts of each of the bilateral donors or other external actors.

This strength of local institutions has important implications for the ways that bilateral actors participate in the management of crises. In particular, the relevance of donor coordination decreases inasmuch as the government commands the process. At one extreme, research in Honduras highlights the successful story 
of donor coordination, where they consolidated a group that heavily influenced the recovery process and generated a dynamic process of frequent exchanges between major stakeholders that supported the implementation of their commitments. Given that, at the field level, there was a lot of freedom to put forward each actor's initiatives, this coordination structure was useful for distributing tasks and creating synergies. On the other extreme, the donors consulted by Jibiki and Ono (Chapter 10) said there was no need to establish any coordination mechanisms between themselves following Yolanda. The national government activated a specific institution for the reconstruction, came up with a plan for the recovery process, and donors contributed as they saw fit. No horizontal communication was necessary.

An unintended consequence of the decrease of coordination between donors appears to be that it makes it easier for external supporters to opt out from the full picture of the crisis management process. A central government officer, reflecting on his experiences of Yolanda (see Chapter 10), argued that the timeframe for action by donors was different from that of locals: donors were already moving out even though the major problem of housing had hardly been addressed. It is now common knowledge that recovery and prevention are phases that take many years - even decades - during which different complications emerge as other priorities arise and the context changes. And while it is difficult in principle to expect international agencies to be able to commit resources for such a long period, at least in the case of Honduras, the engagement in the coordination group resulted in a space for periodic conversations that has continued until today. In other words, there seems to be a trade-off between comprehensive crisis support from abroad and the strong local ownership needed to replace external coordination.

Overall, strategy and coordination issues in the case studies hint at the archetypical problem of action against disasters: how to move attention from relief to prevention or, from the point of view of funding, how to channel disaster response resources from the international community into the mid- and long-term management of crises instead of just short-term, photogenic relief. The cases showed that major donors were not particularly enthusiastic about common trust funds for longer-term action. This is an important consideration in ensuring that resources remain fungible. Instead, the focus is on supporting short-term needs, while middle and long-term planning is usually managed by multilateral actors.

In fairness, some of this multilateral support does indeed take place due to the fact that much of the recovery process is dependent on loans. This partly explains the different Japanese cooperation approach: early surveys of development needs after disasters can be used to inform future grants and loans. The logic of loans, however, does not seem to apply to the relief phase. Thus, the incompatible logic concerning the nature of funding following disasters remains at the heart of the fractured approach of donors: the Office of US Foreign Disaster Assistance (OFDA) vs. country offices in the United States, European Civil Protection and Humanitarian Aid Operations (ECHO) vs. Directorate-General for International Cooperation and Development (DEVCO) in the European Union, and the Ministry of Foreign Affairs vs. JICA in Japan. So, while acknowledging that 
the onus for success is placed on local institutions, coherence at the donor level in crisis management could be of help in generating change at the international level. In this sense, during the preparations for the 2016 World Humanitarian Summit, it was suggested that support for disaster relief should be excluded from humanitarian budgets, mostly in connection with concerns over resource scarcity. Although such a proposal did not make it to the final outcome, it is worth considering how streamlining the system according to the type of crisis - instead of dividing it up at the convenience of the supply side - would improve the way disaster management is supported worldwide.

Can local actors help in engendering this paradigm change? A factor that may be decisive seems to lie in the nature of the local institutions for managing crises and how they evolve and consolidate. Stronger local institutions could have the power to capture the resources made available during the peak of attention for relief and then distribute them better through the full process of crisis management. The Indonesian government at least managed something like this due to the abundance of resources provided for the tsunami recovery. In the three countries covered by the research, the institutions in charge of promoting DRR are particularly strong at dealing with relief, usually linked to defense or civil protection institutions. However, while they make great efforts to go beyond relief, their strength remains in providing a first response. Gathering momentum for ownership of DRR at line ministries remains an elusive quest. A change of mindset could be supported by donors through their work in development. This is an argument that has been made throughout all the years of DRR activism but, as mentioned above, the actual practice seems to favor relief and preparedness for better relief as easier options. What is more, major catastrophes, such as the ones reviewed in this volume, do not have the power to change mindsets and mandates to internalize DRR in line ministries, as might be expected. Thus, the question of how to put the full continuum at the center of crisis management remains without a definitive answer.

Finally, it is worth bearing in mind that these conclusions, like the case studies themselves, are based on the overall picture of management in the disasters analyzed. If you move the framework to the micro-management of the operation, disasters are very chaotic situations and bureaucracies take time to react so it is probable that doubts about the reduced need for coordination will persist and the optimistic view of local leadership will also be questioned. This is partly a limitation of our research design, which is centered on donors, their strategies, coordination and financial problems, and could be better supplemented with bottom-up views. Still, it also reflects the assumption that the problem of the continuum becomes a relevant preoccupation only at the macro-level.

\section{Grisis management in armed conflicts: challenges to overcome the linear peacebuilding template}

The case studies in Part II related to armed conflict discussed in this book took place between 1999 and 2017. This was a period when the concept of post-conflict 
peacebuilding had already been mainstreamed as a crisis management approach. While interventions have followed a post-conflict peacebuilding template, little attention has been given to the observed obstacles in the achievement of the continuum. First, the settings and strategies applied in the management phases for addressing these armed conflicts utilized linear peacebuilding strategies, attempting to compartmentalize each segment of the whole peacebuilding process after peace agreements were reached. However, such approaches are problematic since they go against the cyclical nature of conflict and disregard the simultaneous presence of various actors such as humanitarian, development and political and security actors.

In the case of Timor-Leste and South Sudan after the 2005 Comprehensive Peace Agreement (CPA), the international community applied a typical peacebuilding approach, starting from peacekeeping to electoral support for independence, and eventually transferring international recovery assistance to the new state development plan. These approaches closely equate peacebuilding to new state-building. In both cases, it was quite natural and necessary to build a functional state apparatus in order to promote conflict prevention. Moreover, in both cases, the same intervention template was applied: a multi-functional UN peacekeeping operation maintained security that progressed to a politically supported state-building, while humanitarian and development agencies simultaneously conducted relief, recovery and development operations with the financial support of donors. As observed in both cases, state-building transpires through peacebuilding mechanisms, and, as it becomes difficult to intertwine relief with recovery, conflict prevention is also left behind.

On the strategy level, efforts in Timor-Leste and post-CPA South Sudan were made to coordinate separate planning processes for relief (Consolidated InterAgency Appeal) and recovery (Joint Assessment Mission). However, in practice, this proved challenging, partly because of the conflict between coordination and humanitarian principles, as we discuss below. Moreover, conflict prevention at the community level in both Timor-Leste and South Sudan was not really considered in the management process. In both cases, it is assumed that development by itself will result in conflict prevention. The case of South Sudan was one exception to this, in which the USAID's STAR program was implemented at the project level, combining relief, recovery and conflict prevention. It should be noted that STAR, between 1998 and 2002, was a community-level project, aligned with US strategic interests toward new state-building. This program shows that intertwining relief, recovery and conflict prevention is not impossible, at least at the project level.

Timor-Leste is considered to be one of the first attempts to integrate recovery and development in the early stages of peacebuilding. Learning from Timor as well as Kosovo and Afghanistan, the post-2005 CPA experience of South Sudan is considered an experimental case on the nature and extent of donor and aid organization support for effective crisis management under complex aid coordination mechanisms. On the other hand, the Syrian crisis case study confirmed that applying a peacebuilding approach with new state-building is almost impossible under a strong national government and a relentless relief operation. Thus, 
the first two cases indicate that peacebuilding is based on the assumption of a state-building myth - in other words, the idea that building a liberal state is the best way of managing, mitigating and even preventing conflict. This implicitly brings some linearity, as suggested by Hoshino and Kawaguchi in Chapter 3. It is yet to be seen whether the new concept of 'sustaining peace,' which embraces all phases and actors in multilayered activities, will change this assumption in order to realize a non-linear crisis management approach to deal with armed conflict.

The second major finding concerning phases and strategies is that different variations of conceptualizing the 'transition between phases' influenced how international organizations and donors approach peacebuilding and the continuum. In the case of Timor-Leste, the term 'rehabilitation' was used in many of JICA's programs in the early intervention period as a way to define the transition. On the other hand, in South Sudan, transition activities were referred to in different terms: 'rehabilitation' during the 1990s, 'transitional or early recovery and reconstruction' in the post CPA period after 2005, and 'resilience' in the post-2013 crisis. It is interesting to see that these activities were done through joint-work inside of donor agencies. In the case of Syria, 'resilience' is a key term for the continuum. Responding to the Syrian crisis, from the early stages, the UN called for the strengthening of resilience in achieving the twin goals of providing life-saving relief and strong individual- and community-level capacity to recover quickly. The EU and DFID also recognized 'resilience building' as an important goal in parallel with life-saving relief. As suggested in Chapter 2, a resilience approach in the case of Syria could be a way to reduce the emphasis on phases but still push for a more meaningful connection between different activities. The practical consequences are, nonetheless, yet to be seen.

The last point for phases and strategies concerns state ownership of crisis management as an obstacle to realizing the continuum. For example, in the case of Timor-Leste, the exclusion of conflict prevention activities from the peacebuilding process was a result of the government's strong preference for a shift away from a post-conflict transition to a development phase - also seen in Honduras. Another example is South Sudan, where relief and conflict prevention were missing from the peacebuilding strategy before and after independence, although life-saving support was generously and continuously provided throughout. It should be emphasized that international aid allowed such exclusions as part of its encouragement of the government's ownership of the process and the pre-eminence placed on state-building. As a result, aid may be one of the contributors to greater power concentration at the central government level, which could eventually lead to power struggles. This case illustrates that, when state-centric peacebuilding approaches are adopted, respecting ownership and associating with untrustworthy governments needs to be balanced. Otherwise, it will be difficult to promote strategies encompassing multilayered relief and recovery, and conflict prevention will most likely be left behind or confused with development, as suggested above.

Another parameter for consideration is coordination of different actors towards the aim of the continuum. The existence of multiple actors is recognized in all cases. There are international and bilateral actors working on diplomacy, 
security, humanitarian relief, development and more specific segments such as children, women, health, etc. There are also military units such as the UN Peace Keeping Operations. In this respect, major coordination issues are different for conflict and post-conflict settings. In conflict, as in Syria and Southern Sudan before the 2005 CPA, international organizations such as OCHA, UNHCR, UNICEF and WFP and relevant NGOs were the main actors; hence, coordination among them was a priority. A more problematic coordination for the South Sudan and Syrian cases is the coordination with parties to the conflict. Since international organizations and NGOs have to coordinate with conflict actors to reach people, there are always concerns about the violation of humanitarian principles, particularly neutrality and impartiality. In the case of Syria, the author argued that strong criticism of UN agencies with respect to humanitarian principles may undermine necessary coordination between UN agencies and international NGOs. This was similar to Operation Lifeline Sudan.

On the other hand, post-conflict coordination includes three different systems for humanitarian action, planning recovery and national development. These were observed in the cases of Timor-Leste and South Sudan after the 2005 CPA. First, the humanitarian cluster system and the Consolidated Inter-Agency Appeal (CAP) were composed of international organizations and NGOs for humanitarian crisis response. Second, the development aid coordination systems, such as the Joint Assessment Mission, were composed of the World Bank, UNDP and other international organizations, plus bilateral donors and the provisional government for recovery and development. Third, the domestic aid coordination system gradually became the national development strategy following independence. Efforts to coordinate these coordination systems were observed, although it is difficult to conclude that they led to gains in the continuum. This is because each coordination system is already complex, and therefore additional harmonization between coordination systems without an overarching strategy becomes a burden for field staff.

Secondly, coordination within donors was a common trend, as seen in the cases of Timor-Leste and South Sudan. The US has developed, in principle, a wellsystematized inter-governmental agency and departmental coordination system. On the other hand, the EU's experience of creating a new fund for the recovery and rehabilitation program in South Sudan showed that flexible coordination/ cooperation between the humanitarian and development agencies is possible even when standardized coordination mechanisms have not been institutionalized yet. It is important to note that even a well-prepared intra-governmental coordination system does not necessarily result in realizing the continuum. In that sense, compared with the US and EU, the Japanese seamless approach does not attempt to connect governmental actors at the donor level through transition funds but rather smoothly transfers projects and programs in early recovery to development through close coordination with local government, as seen in the case of Timor-Leste and South Sudan. Moreover, the chapter on Timor-Leste also showed how Australian engagement in the early post-conflict phase was, similar to Japan, flexible and responsible in assisting every sector from relief to development, including the police training program, to make transformation smooth. 
The third finding on actors and coordination concerns the participation of the local community. The case studies found that local people-especially local NGOs and communities - are often outside the coordination mechanisms, which are controlled by local authorities and international actors. In Syria, local councils and NGOs emerged to fill the power vacuum and provided social services in the area to become indispensable partners for international actors to provide relief. The so-called 'local' popular committees were formed for the assessment of local needs, the coordination of aid, and its distribution in government-controlled areas. These committees, however, have to work under the regime's tight control. The government controls their activities through mandatory registration and taxes, as well as restricting access to certain areas. This means that international humanitarian agencies are limited to conducting operations only by remote management, leaving local actors at the center of on-the-ground coordination-yet the political and security implications of so doing deserve more attention.

The need for capacity-building training for local people has been mentioned in all case studies, confirming that the continuum requires not only the efforts of interveners but also the involvement of locals. For instance, in Timor-Leste, the establishment of an overarching coordination mechanism - the sector working groups - became a burden to some relevant ministries whose capacities were not fully functional. In Timor-Leste, as in South Sudan, it is no surprise that capacity-building assistance is essential for state-building, especially for the central government. Capacity-building projects in Timor-Leste - such as the Land Law Program by USAID, the capacitybuilding project for roads and infrastructure by JICA, and the Police Development Program by Australia - show how bilateral donors recognize the key role of this component of aid. The involvement of local actors requires embedding capacitybuilding elements into the projects from a sustaining-peace perspective.

Finally, the issue of funding is worth considering. As observed in the case of South Sudan, transition funding at the program level was provided through STAR by USAID and Humanitarian Plus by DEVCO. This case shows how bilateral donors recognized that a 'more-than-relief' program was needed. Using development funds, they prepared a multi-year funding program that contained several small projects implemented by NGOs. These were related to capacity building for service delivery, reconstructing basic health and washing facilities, maintaining livelihoods and so on. Compared with the US and EU, Japan does not have such transition funds available; however, JICA developed a kind of quick-impact project while conducting its assessment for a long-term development program. This was utilized for various infrastructure reconstruction projects in the early phase of the CPA interim period. JICA did the same in Timor-Leste during the post-conflict phase between 2000 and 2006.

Another example of transition funding can be seen in the response to the Syrian crisis. While the UN and donors called for strengthening resilience to achieve the two goals of life-saving relief and individual- and community-level resilience building, the author pointed out that dividing available resources between emergency relief and resilience building remains difficult for international assistance agencies. In this regard, DFID, as well as the US Department of State 
and USAID, have allocated a certain portion of funds to resilience-related projects inside Syria to filling the funding gaps. It is interesting to note that humanitarian aid by DFID is utilized through the UN agencies, while USAID and the US Department of State contributed more funds to NGOs to conduct resiliencerelated projects than UN agencies did. Finding ways of establishing flexible transition aid, and transferring and connecting this aid to the goal of realizing the continuum in partnership with local actors, remains an unresolved problem.

\section{Comparing crisis management in disasters and armed conflict}

From the crisis-specific analyses above and the case studies as a whole, it is evident that the management of armed conflicts and disasters presents similarities as well as differences. Making these clear is of great help in understanding the extent to which a general model of the continuum can be determined, and from which

Table 11.1 Analysis of disasters and armed conflict case studies.

\begin{tabular}{|c|c|c|}
\hline & Disasters & Armed conflict \\
\hline \multirow[t]{3}{*}{$\begin{array}{l}\text { Phases and } \\
\text { strategies }\end{array}$} & $\begin{array}{l}\text { Strategies still linear inasmuch } \\
\text { as they are politically driven }\end{array}$ & $\begin{array}{l}\text { Strategies still linear and rely on } \\
\text { the myth of state-building as } \\
\text { part of the continuum }\end{array}$ \\
\hline & $\begin{array}{l}\text { A concrete description of } \\
\text { phases exists but, without } \\
\text { the specific know-how of } \\
\text { the continuum by sector, } \\
\text { implementation is difficult }\end{array}$ & $\begin{array}{l}\text { Donors have their own transition } \\
\text { activities between phases but } \\
\text { such a transition comprises gap- } \\
\text { filling across all sectors without } \\
\text { a single definition }\end{array}$ \\
\hline & $\begin{array}{l}\text { Local ownership results in } \\
\text { support limited to relief }\end{array}$ & $\begin{array}{l}\text { Local ownership of relief may } \\
\text { hinder the inclusion of relief } \\
\text { and prevention into the } \\
\text { peacebuilding strategy }\end{array}$ \\
\hline \multirow[t]{2}{*}{$\begin{array}{l}\text { Actors and } \\
\text { coordination }\end{array}$} & $\begin{array}{l}\text { No humanitarian dilemma, so } \\
\text { competition for resources by } \\
\text { implementing partners }\end{array}$ & $\begin{array}{l}\text { Coordination with conflict actors } \\
\text { (including government/local } \\
\text { authority) is problematic; the } \\
\text { humanitarian dilemma is } \\
\text { evident }\end{array}$ \\
\hline & $\begin{array}{l}\text { Strong local ownership means } \\
\text { there is no need for other } \\
\text { coordination mechanisms }\end{array}$ & $\begin{array}{l}\text { Multiple coordination mechanisms } \\
\text { require inter-mechanism } \\
\text { coordination that leaves the } \\
\text { local community at the margins, } \\
\text { in part because of lack of } \\
\text { capacity }\end{array}$ \\
\hline Funding & $\begin{array}{l}\text { Going back to mostly relief will } \\
\text { result in fractured funding } \\
\text { and emphasis on donor } \\
\text { internal coordination }\end{array}$ & $\begin{array}{l}\text { Character of the 'transition' } \\
\text { funding still unclear (can easily } \\
\text { revert to development as usual) }\end{array}$ \\
\hline
\end{tabular}

Source: authors. 
point separate analyses are necessary. A summary of the observations is included in Table 11.1. It should be kept in mind, however, that generalizations cannot be made from just six case studies, but they do offer precious insights for future research.

As mentioned at the start of this chapter, through all the cases, it was possible to identify strategies and actions employed to advance the continuum. Such strategies comprise some of the phases included in the general model in Chapter 2, which described progress in overcoming disasters and conflicts. The empirical investigations demonstrated the overlap of the phases embedded in our model; however, the strategies for both types of crises show that some sense of linearity remains ingrained in the management of multiple phases. The linearity of phases is more evident and standardized in the way that disaster management is described. Peacebuilding also appears conceived as a linear progression between relief, transition and peace. An exception to this is the 'transition,' as an early phase of peacebuilding, that tries to embrace a non-linearity in which all kinds of state-building and relief activities are mixed. Transition remains, nonetheless, an unclear concept as a phase.

In this sense, an important finding is that the linearity of crisis management aims at normality as the final stage - not prevention. This is an outstanding commonality across both types of crises, underscoring how difficult it is to undertake any type of prevention activity in any kind of setting. In both cases, political reasons seem to play a prominent role: a post-conflict setting seeks to graduate from a position as fragile state and move into development and the prospects of a brighter future; disaster-affected governments also want to show that the emergency is over, allowing the national agenda to refocus on normal priorities such as poverty reduction and economic growth. In the case of disasters, emerging institutions specifically in charge of DRR could be identified as alternatives to make gains in prevention from relief and recovery efforts. The existence of such offices - usually mandated to cover the whole disaster management cycle - offer the possibility of gradual gains on the prevention front, despite relief remaining at the core of their work. In other words, disasters are a kind of crisis that results in the development of new institutions to manage them. On the other hand, political struggles during peacebuilding transitions seem to be the breeding ground for a relapse into conflict. Donors and international actors do not appear particularly ready to deal with such risks because they are also dragged down by political agendas. Such power struggles belong to the realm of domestic politics, in which international actors are advised to refrain from meddling. There are no new national institutions created to manage conflict prevention - state-building itself is at the center.

Interestingly, relief is also a phase that could be loosely tied to the continuum, particularly under strong national ownership. This is because national governments will push to finish relief as soon as possible. This is partly why humanitarians have traditionally opposed being integrated into UN missions, do not seek to be included in peacebuilding strategies, and the Central Emergency Response Fund forbids any project from going beyond relief. Their mandate to care for the more vulnerable indicates skepticism about the capacity of national recovery programs to leave no one behind. In the case of disasters, DRR offices are in a better position to progressively connect relief with recovery but, even in these 
cases, international relief actors may cry foul because of the duration of the relief phase - as in the Philippines. In armed conflicts, independent relief operations seem to remain the standard procedure; however, the progression through the disaster cases shows a slow but continuous process towards a locally integrated continuum.

Providing money alone for crisis management is, in most cases, insufficient and both types of crisis settings show that specific knowledge of the critical sectors and activities underlying each of the phases is required. Recent advances in the governance of disasters are particularly unambiguous in this respect, as specific tools and a knowledge-base for recovery has been consolidated through different international initiatives. The challenge in peacebuilding is that, as far as state-building is the ultimate goal, the entire spectrum of government and international organizations' activities can be included in the master plans for transition or recovery. Such settings can easily allow international actors to go back to their traditional programs and projects, without necessarily tailoring them to the post-conflict settings. This is also another reason that makes prevention particularly difficult, as some activities - such as security sector reform - can fall through gaps between relief and 'business as usual' state-building, as shown in Timor-Leste.

Regarding differences between the two types of crises, the possibility of trusting local governments and institutions seems to be the fundamental difference. Strategies and coordination structures look very different if national partners are put at the center of the operation because, if they are not, any other arrangement would almost immediately become fragmented. As mentioned above, humanitarian actions after armed conflicts are based on the assumption that local institutions lack neutrality because they are part of the problem, and thus, international organizations providing relief strive to act independently in order to remain neutral. Activities that go beyond relief in these settings are likely to be particularly difficult to accomplish either because it is impossible to conciliate differences with local regimes, or because empowering sub-national actors results in separatist movements that may fuel confrontations, as in South Sudan and Syria. In the case of disasters, there are no reasons not to partner with locals, perhaps with the exception of overwhelmed authorities at the peak of an emergency; even in those cases, however, the probity of international assistance should be carefully analyzed, as assuming by default that local governments are incapable of managing the situation can also be a cause of tensions, as described above. In consequence, disaster management can result in a competition between all types of implementing partners that are trying to obtain access to all kinds of resources - humanitarian or developmental - while donors make commitments to contribute to local plans.

The different implications of local ownership after each type of crisis deserve to be examined. The case of the Philippines suggests that coordination among international supporters will become unnecessary as everyone coheres to the government's strategy. However, the magnitude of support required after a conflict does not override the need for coordination, particularly if the creation of a new state is one of the consequences of the end of a conflict. Indeed, the full process of 
peacebuilding is usually presented as one gradually moving towards handing over full control of the state apparatus to local actors. The Syrian case seems to be an exception, since, under a strong government and without regime change, it does not seem feasible to follow a similar pattern to that of Timor-Leste or South Sudan. This suggests that, while the crisis management model seems generalizable to different kinds of fast-onset disasters, specific models for different types of conflicts may be necessary. In this sense, we suggest that a human-centered principle, such as the one underpinning our research, should be used for developing new crisis management models instead of simply focusing on a state-centric crisis management.

All in all, disasters and armed conflicts seem similar inasmuch as they are crises for which the sequential management of phases is warranted. While the details of the activities may be different, the general flow is similar and thus, it is possible to find efforts such as the World Bank applying tools originally developed for disasters to conflict recovery situations. However, the backbone of the coordination underlying such management is radically different, challenging the advancement of common tools for crisis management; that is, coordination with local actors presents fundamentally different challenges. This could partly explain why the humanitarian-development nexus remains an across-the-board issue of concern and shows little signs of progress despite decades of attention. General strategies and advances in disasters suggest that the nexus is indeed an issue that can be worked out, but coordination analysis shows that this is probably not the case. This argument may not, however, be the most important, as flows of funding are clearly keeping the conversation alive at the global apex of governance, while actors working at the local, implementation level continue to point out how irrelevant this discussion can be in the field.

\section{The multilayered model reconsidered}

\section{Enabling and hindering factors}

It is now possible to reconsider the model proposed in Chapter 2 in light of the evidence. While the broader proposition regarding the continuum as the heart of crisis management holds across the case studies, there are at least three factors that can be considered as possible guides for the study of the continuum after crises occur. These three major factors are summarized in Table 11.2.

The first major factor influencing the continuum is country ownership. The strong leadership of a local government can be a deciding factor for success in realizing the continuum. It is the government of the affected country that eventually takes charge of the situation and is expected to coordinate different sources of assistance, including their own, and tailor them according to the changing needs of suffering populations (Honduras, the Philippines, Indonesia). Without their commitment to take full responsibility for the situation, there cannot be any sustained management of each crisis.

Second, efforts to implement the full crisis management process require local capacity and a knowledge base. While the continuum framework offers an 
Table 11.2 Factors affecting success of the continuum.

\begin{tabular}{|c|c|c|}
\hline Factors & Enabling role & Hindering role \\
\hline Country ownership & $\begin{array}{l}\text { Government leadership } \\
\text { in crisis management } \\
\text { (Indonesia, the } \\
\text { Philippines) }\end{array}$ & $\begin{array}{l}\text { Politicization of assistance } \\
\text { (South Sudan, Syria) } \\
\text { Low priority given to } \\
\text { prevention due to political } \\
\text { implications and other } \\
\text { agendas (Timor-Leste, } \\
\text { Honduras) }\end{array}$ \\
\hline Local capacity & $\begin{array}{l}\text { Well-informed policy } \\
\text { based on past experience } \\
\text { of crisis management } \\
\text { (Indonesia) }\end{array}$ & $\begin{array}{l}\text { Low experience of managing } \\
\text { aid (Timor-Leste, South } \\
\text { Sudan, Syria) } \\
\text { Limitations in procurement } \\
\text { and knowledge for recovery } \\
\text { and prevention (Honduras, } \\
\text { the Philippines) }\end{array}$ \\
\hline $\begin{array}{l}\text { Multiple actors' } \\
\text { participation }\end{array}$ & $\begin{array}{l}\text { Multilayered intervention } \\
\text { (Timor-Leste, South } \\
\text { Sudan, Honduras, } \\
\text { Indonesia) }\end{array}$ & $\begin{array}{l}\text { Coordination mechanism } \\
\text { becomes too complex } \\
\text { and coordination costs } \\
\text { rise (Timor-Leste, } \\
\text { South Sudan) }\end{array}$ \\
\hline
\end{tabular}

Source: authors.

overall guide for the management process, the specific sectors and activities underlying international cooperation strategies have their own dynamics and complexities. Security sector reform in Timor-Leste and housing in Indonesia and the Philippines are examples of critical types interventions without which any talk of the continuum would be incomplete. The capacity to devise and implement specific strategies for multiple sectors in parallel is thus a fundamental challenge to the continuum, with the awareness that processes for each sector have their own phases, actors and institutions. International cooperation capacity to cover the full range of activities is seriously limited, both in the sectors that can be covered and the time-span during which support can be sustained. That is why here, as in most international cooperation, capacity building is stressed as a major component in post-disaster and post-conflict support. The main issue is whether the capacities created are the ones required, a supposition that seems dubious in both types of crises when promoting prevention is the main goal.

Finally, despite the limitations, multiple actors do come into action when crises break out. Paradoxically enough, the existence of multiple donors with varied mandates and priorities can help to establish a continuum of crisis managementif they start engaging early enough after the emergency period and make a commitment toward complementing ongoing efforts for more than the relief phase (Timor-Leste, Indonesia). This is partly a reflection of the nature of situations that exist after the crisis, where multiple needs exist in different locations at the same time. It is also a reflection of the gap between the needs on the ground and the 
priorities of governments, who are always tempted to demonstrate that situations are under control and/or things are progressing well - while this may not necessarily be the case (Timor-Leste). Some form of coordination for these multiple layers of action can be fundamental for the continuum. Once again, we can conclude that, depending on the type of crises, tools and mechanisms to promote effective coordination are likely to differ, thus limiting the possibilities of generalization.

The above-described factors can also hinder crisis management. Strong country ownership does not necessarily lead to realization of the continuum, at least in the same way as in disaster settings. This was most conspicuous in the case of Syria, where politicization of interventions from both the government and donors is a common phenomenon, thus inhibiting unlimited access to desperate populations and the need for the impartial provision of emergency relief. Recovery and development assistance, which is normally provided under 'development principles' - respect of country ownership, alignment with country strategy and priorities - is placed under even stronger strain because of such politicization (South Sudan, Syria). Even after disasters, the push for local governments to 'finish' phases instead of recognizing the overlapping nature of the crisis management can have a similar disruptive effect.

In cases where continuum is realized between relief, recovery and development, prevention is not part of the picture. Prevention is displaced from the agenda from the very beginning (Honduras), neglected (Timor-Leste, South Sudan), given a low priority as time goes by (Indonesia), or too early to discuss (Syria). Mainstreaming prevention in the process of crisis management through capacity building and know-how creation will continue to be an issue in realizing the continuum in its full spectrum. Finally, in contradiction to what was observed above, the existence of multiple actors in the post-emergency period does not guarantee success in addressing the continuum automatically. The absence of adequate coordination as well as an excess of coordination mechanisms, without deep knowledge of the multiple issues and the context can mean that good intentions easily turn into chaos, duplication and even harm.

\section{Further limitations of the model and the research}

The present research attempted to shed light on how the continuum in humanitarian crisis management has been addressed. It was informed, in particular, by bilateral donors, based on a detailed analysis of major disasters and armed conflict crises that have taken place over the past two decades. The research has elucidated that, while it is difficult to observe cases of well-managed coordination among humanitarian and development donors (i.e., the continuum of actors), it is still possible to observe cases where efforts are being made to cover ever-changing needs in the affected areas, although including prevention remains problematic. Hence, the continuum of phases has somehow been achieved.

In almost all of the cases studied here, local ownership - especially that of the legitimate government - was vitally important for the realization of the continuum, without which the continuum of crisis management is hard to achieve. 
This provides a good reason for donors to support capacity building with partner governments for better management of crises, whether this occurs prior to or after the eruption of the events in question. However, there is no guarantee that governments will always represent the needs of the society in the correct way. Sometimes the government is concerned more with national economic management (Honduras), or is tempted to show to the general public that things are back to normal and are moving forward (the Philippines, Timor-Leste) in spite of the situation for the affected communities. It is therefore important to discern what is really meant by 'local' - be it at the level of government, civil society organizations or society in general - and how local politics, culture, conditions and processes affect the continuum. Our research started with a strong focus on international cooperation actors, but only through the fieldwork did we realize how important deeper knowledge of the local process was. Although authors tried to supplement the original research, inquiries that start from the local point of view and evaluate external assistance from their perspective are required. The chapters of this book mainly focused on the government as the one that represents the 'local,' except for the case of Timor-Leste. As a result, the multiplicity of local actors still needs to be addressed.

In this sense, another limitation of this research, or a limitation of the concept of the continuum itself, is the relationship between the continuum as an input for crisis management and the resultant state of society as an outcome of such an approach. In other words, what impact would realizing the continuum have on the society if it is realized? This question relates to what is intended to be achieved, for whom, where, and in what timeframe, in the process of achieving the continuum. In the discussion of the continuum, this 'for what' question is taken for granted and seldom answered or even asked. But it deserves serious attention as all the interventions need to be evaluated against their intended objectives and goals. For instance, as the disaster cases suggest, looking only at donor activities would make little sense when the process in the affected societies shows a different time-frame for managing the crisis. Perhaps at the level of linking relief and recovery, it is easier for several stakeholders who are inquiring about the continuum to converge on a similar discussion and time-frame. However, if we are to achieve prevention as an ultimate goal, the strength of the concept seems to weaken considerably. We did not address this question squarely in our research, partly due to time limitations and also to our original focus on donors' performance. Still, the implications of moving the question to affected societies is an important part of the research agenda, which underlies efforts to localize aid in the outcome of the World Humanitarian Summit. Such research would greatly enrich future crisis management initiatives.

\section{The continuum after the 2016 World Humanitarian Summit}

The humanitarian-development nexus remains a major issue discussed in relation to crises. The outcome of the 2016 World Humanitarian Summit - as well as the interest from the new UN Secretary-General in promoting 'sustaining 
peace'-also supported the old idea of the continuum. Traditional agencies have come with good intentions to find new ways of working but a feeling of déjà vu is in the air. In order to avoid waste of resources and energy, a more cautious reading of these experiences over two decades is warranted. Chapter 2 showed that periodical reviews of the continuum usually present a dire picture of little progress despite all these years of efforts. One problem is the very definitions of terms such as the continuum, Linking Relief, Rehabilitation and Development (LRRD), and resilience. These terms can be pointing in different directions - for example, donors' performance vs. actual social process in affected societies - that are difficult to grasp from the single perspective of donors and international cooperation, as we suggested above. However, even by focusing solely on international cooperation, advances can be identified from which to extract some general lessons in order to keep moving forward. We emphasize three imperatives:

1 Recognize that crisis management is not linear.

2 Put 'local' at the center.

3 Prevention starts from crisis day one and efforts should be sustained.

We expand on each of these points below.

\section{Recognize that crisis management is not linear}

A collective approach to crisis management should not be mistaken for a linear process that leads from crisis to normality. Every person, every family, every community and every city goes through this process at different speeds and along different paths. Activities for relief, recovery and prevention of future crises do not follow a clear sequence but overlap and thus require everyone's commitment. Nevertheless, non-linearity does not mean that crisis management through phases is unnecessary because phases play a fundamental role in how societies realize progress and how actors confront recurrent hazards to prevent relapse into crisis. The balance between contiguity and continuity of phases and actors remains a central challenge that all actors should acknowledge. In order to advance on this front, non-linearity needs to be reflected in all aspects, including strategy, coordination and funding.

\section{Put 'local' at the center}

Societies affected by humanitarian crises are in the best position to respond, recover, prepare and prevent further relapses into calamity. This is not only a re-statement of the national responsibility principle but also an empirical observation. No matter how much the international community is prepared to provide external support, it will never be more than second best. Local actors should be making decisions throughout the whole crisis management cycle: assessing needs, setting objectives, and planning implementation, as well as monitoring 
and evaluating outcomes. Ownership combined with capacity building empowers people and the different institutions originally in charge (or created in response) to come up with the best possible solutions. Strategies and coordination mechanisms for external support where the local is not at the center are a recipe for trouble. It is true that, depending on the type of crisis (e.g., armed conflict), putting the local at the center can be challenging and may require very careful arrangements so as not to result in additional harm to the most vulnerable - for instance, barriers that affect humanitarian access. Nonetheless, the centrality of the local remains a fundamental guiding principle.

\section{Prevention starts from crisis day one and efforts should be sustained}

Ideally, prevention should precede a crisis but, in practice, it usually comes after. The actual institutions and capacities for dealing with future threats are formed through the process of relief and recovery. Framing crises as opportunities is very common, but the actual process of bouncing back better is not automatic. Prevention and preparedness for future emergencies in places where they have occurred in the past receives less attention across the management of all types of crises, both in terms of knowledge and funding. This trend needs to be reoriented toward promoting an understanding of how the momentum for change that crises create can be used in mainstreaming long-term prevention through institutions, technology and capacity building. It is natural for relief-recovery activities to aim toward at least restoring lost assets and rebuilding original functions to pre-crisis levels; still, the opportunity to enhance preparedness for an effective response and to build back better should not be missed.

There are two further issues for which we cannot draw any definitive conclusions, but that our study suggests are vital for understanding what crisis management supported by international actors entails. Both are related to discerning views about what crisis management implies in different contexts. One issue is the fixture of mandates and mindsets when engaging in crisis work. Through our preliminary overview, we noticed that coordination is frequently discussed, bringing along the idea that stakeholders have some fixed capabilities that need to be utilized as efficiently as possible. However, the cases here suggest that changing approaches, and innovating, despite mandates as circumstances change, may be more meaningful in the long run. Such changes can be seen in the creation of OCHA, the gradual involvement of UNDP, the World Bank and donors in crisis work, and the transformation of the WFP into a logistic powerhouse. Further transformations should not be easily discarded.

The other issue is whether it is convenient to have a single box for crisis management as a whole, or if different boxes by types of crisis would bring better prospects for improvement. The emergence of the DRR community suggests the latter, but the 2016 World Humanitarian Summit seems to maintain that separate humanitarian (and development) categories are the best way to organize international efforts for crisis management. As we have seen in theory and 
practice, localizing assistance is not compatible with a supply-side model, so we are tempted to suggest a different approach based on the specific demands of each type of crisis. Humanitarian actors argue that getting subsumed into crisis management can negatively affect the actual attention that the world gives to forgotten and protracted crises, which is a powerful reason for caution. In the meantime, what seems most feasible is a hybrid system whereby, after each crisis, nationally owned sub-systems such as those for disasters or pandemics evolve at the same time that supply-side humanitarian and development communities reinvent themselves. For the sake of advancing prevention, however, still there is no single recipe, so there is much room for innovation and experimentation. 


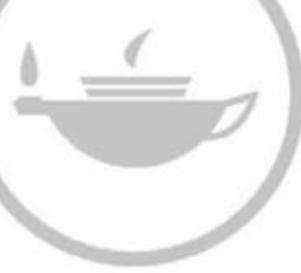

Taylor \& Francis Taylor \& Francis Group

http://taylorandfrancis.com 


\section{Index}

Page numbers in italics refer to figures. Page numbers in bold refer to tables. Page numbers followed by 'n' refer to endnotes.

Aceh: gross domestic product (GDP) 163, 164, 165; growth rates of population in 166; housing reconstruction in 170 ; impacts on development 163 , 165; potential livelihood crisis in 178 ; poverty rates in 164; Reconstruction of Aceh Land and Administration System program 171; Rekompak project in 171; resilient development 170; unemployment rates in 164

AFP-TLPDP see Australian Federal Police Timor-Leste Police Development Program (AFP-TLPDP) agencies: bilateral 11, 12, 69-70, 109; bilateral donor 185; UN 107-9, 113

'Agenda for Humanity' 8

An Agenda for Peace 40-1, 46

Alzoubi, Zedoun 116

Anderson, Mary B 12

'Arab Spring,' in Tunisia 103

armed conflict 30, 39-41, 44; actors and financing for continuum after 45-7; crisis management in 211-19; disasters and 216, 216-19; implementing continuum in 47-9; Indonesia 176; multiplicity of approaches to 45 ; in Sudan 76-7; in Syria 103-4, 115, 116, 119,120

al-Assad, Bashar 103, 107, 108

AusAID $7 \ln 7,176$

Australia 46, 52, 55, 69, 176, 214; aid to Timor-Leste 63-6, 70; Assistance to Philippines 184, 189-90, 191, 192, 195-6, 202; donor support to Indonesia 167

Australian Aid 52
Australian Defence Force 55

Australian Federal Police Timor-Leste Police Development Program (AFPTLPDP) 64, 65

Ban Ki-moon 7, 105

BBB see build back better (BBB)

BCPR see Bureau for Crisis Prevention and Recovery (BCPR)

Beer, Henrik 12, 130

BNPB (National Disaster Management Agency, Indonesia) 177, 179

Bradbury, Mark 19

Brooking Process 21

BRR (Rehabilitation and Reconstruction Agency of Aceh-Nias) 166, 171, 176,179

build back better (BBB) 128, 132, 133, 141; prevention through recovery $146-50$

Bureau for Crisis Prevention and Recovery (BCPR) 19, 23

Bureau for Humanitarian Response 10

Büttner, Martin 20

Call, Charles 116-17

CAP see Consolidated Appeals Process (CAP)

Capstone Doctrine 41, 42, 46

Carter, William 114

cash-for-work (CFW) programs 178

ceasefire agreement, South Sudan 78

Central American Coordination Center for Natural Disaster Prevention (CEPREDENAC) 152

Central Emergency Response Fund (CERF) 55

Christoplos, Ian 141, 186 
Chudacoff, Danya 116

civil war, Syria 101-3; cross-border assistance and remote management 109-10; deep humanitarian crisis 104-6; emergency relief and resiliencebuilding 111-13; humanitarian principles and relief activities 113-14; humanitarian relief and local actors 115-16; humanitarian relief and political objectives 116-18; prolonged armed conflict and fragmentation 103-4; UN operations and constraints 106-8; UNSC Resolution 2165 of 2014 108, 108-9

Clinton (President) 21, 80, 98n7

Cluster System 5, 27, 28, 134; humanitarian 32, 140,154, 214; humanitarian, early recovery $22-3, \mathbf{2 5}$; industrial 174

Cold War 3-4, 15

Comprehensive Peace Agreement (CPA) 75, 76, 212; period to 2013 crisis 84-91; in pre-CPA period, crisis management 79-84

Comprehensive Rehabilitation and Reconstruction Plan (GRRP) 200, 201, 203

conflict: 'Conflict, Security and Development' 6; Conflict, Stability and Security Fund (CSSF), UK 118; Conflict Vulnerability Assessment (CVA) 58; peace and, intervention models between 40, 40; prevention 59-60, 67-8; see also armed conflict

Consolidated Appeals Process (CAP) 86

Consolidated Inter-Agency Appeal for East Timor Crisis 55

'contiguum' model 5, 16

continuum: actors and financing for 45-7; after World Humanitarian Summit (2016) 222-5; aid to Timor-Leste from perspective of $56-9,57$; in armed conflict contexts 47-9; conceptualizing 28-32; and disaster risk reduction frameworks $132-3$; factors affecting success of 220; of humanitarian crisis management 9-13; in linear peacebuilding model $84-91$; in postconflict transitions to peace 39-40, 40; in practice, addressing $136-8$

continuum, approaches to 18-19,

25; actors and coordination 26-7; comparative analysis 24-8; early recovery through humanitarian cluster system 22-3, 23, 25; funding 27-8; gap approach 21, 25; LRRD by European Union 19-20, 25; phases and strategy 24-6; relief to development by US 20-1; resilience 23-4, 25; seamless assistance by Japan 21-2, $\mathbf{2 5}$

continuum, in linear peacebuilding model 84-91; donor engagement 86-9; foundation of continuum 84-6

COPECO (Permanent Commission for Contingencies (Honduras)) 145, 151, 152, 154, 156

'Country Development Cooperation Strategy: 2013-2018' (CDCS) 59

CPA see Comprehensive Peace Agreement (CPA)

CRRP see Comprehensive Rehabilitation and Reconstruction Plan (CRRP)

\section{Darfur conflict 77}

de Araújo (Prime Minister) 51

decision-making, cross-governmental 46

Democracy, Conflict and Humanitarian Assistance (DCHA) 10

Department for International Development (DFID) 10, 23, 46, 11 , 111, 117

Department of Foreign Assistance and Trade (DFAT) 46

Department of Humanitarian Affairs 4

Department of Peacekeeping Operations (DPKO) 42

Department of Political Affairs (DPA), UN 42

DEVCO see Directorate General for International Cooperation and Development (DEVCO)

'Developmental Relief' 18, 26

Development Policy Coordination Mechanism (DPGM) 56

de Ville de Goyet, Claude 135

DFID see Department for International Development (DFID)

Dili: IDP camps in 54; USAID office in 59

Directorate-General for International Cooperation and Development (DEVCO) 19, 26, 98n8

disarmament, demobilization, and reintegration (DDR) 41

disaster: actors and financing for continuum after 134-5; and armed conflict 216, 216-19; crisis management after 208-11; crisis management in 
216-19; in Indonesia see Indonesia, disasters in

Disaster Assistance Response Team

(DART) 92, 95, 134

disaster management: cycle 127-9, 128; principles and rules of disaster relief 129-32; Red Cross evolution 129-32

disaster-resilient society 162

disaster risk management (DRM) 140-1, $151,156,157$

disaster risk reduction (DRR) 132-4, 136, $162,174-5$

donors 6, 45, 46, 75; bilateral 11, 45, 66, 91; coordination with 66; EU institutional 11 ; humanitarian relief and political objectives set by 116-18; ODA sectoral disbursements by 57 ; OECD 6 ; policies 6; traditional 5; Western 93

donor engagement: CPA period to 2013 crisis 86-9; EU 81-2, 88-9, 92-3; Japan 82-3, 89, 93; in post-2013 crisis 91-2; pre-CPA period 80-3; US 80-1, 86-8, 92

donor support, Indonesia: Australia 167; Germany 168; Japan 167-8; multidonor funds 168-9; US 166

DPCM see Development Policy Coordination Mechanism (DPGM)

DRM see disaster risk management (DRM)

DRR see disaster risk reduction (DRR)

Dunning, Henry W. 129

Early Recovery approach: policy, UNDP 24; through humanitarian cluster system 22-3, 23, 25

earthquakes: Great East Japan 175; Great Hanshin-Awaji 175; Haiti earthquake 131; Indian Ocean earthquake (2004) 131, 163; Java 136, 162, 164, 167, 169, 174-7, 179-81; Yogyakarta (2006) 164

ECHO see European Community Humanitarian Aid Operations (ECHO) ECLAC (Economic Commission for Latin America and the Caribbean) 148

EEAS see European External Action Service (EEAS)

Eide, Espen Barth 44

Emergency Response Division (UNDP) 19

European Community Humanitarian Aid Operations (ECHO) 6, 10, 19, 20, 26, $76,81,82$

European External Action Service (EEAS) 19
European Union (EU): donor engagement 81-2, 88-9, 92-3; institutional donors 11; Linking Relief Rehabilitation and Development (LRRD) by 19-20; resilience 31

Financial Tracking Service (FTS) 185

Flores, Carlos Roberto 143

Forças de Defesa de Timor Leste (FDTL) 54

Foreign and Commonwealth Office (FCO) 46

Free Syrian Army (FSA) 104

FTS see Financial Tracking Service (FTS)

Fundasaun Mahein (FM) 67

gap approach 21, 25

GCCP see Global Conflict Prevention Pool (GCCP), UK

Germany, donor support to Indonesia 168, 176,180

GFDRR see Global Facility for Disaster Reduction and Recovery (GFDRR)

Global Conflict Prevention Pool (GCGP), UK 6

Global Facility for Disaster Reduction and Recovery (GFDRR) 133

Gómez, Oscar A. 15, 101

Good Humanitarian Donorship principles 22

Gordon, Rachel 75

Government of South Sudan (GoSS) 77,84

gray zone 10, 19, 28

Great East Japan Earthquake 175

Great Hanshin-Awaji Earthquake 175

gross domestic product (GDP), Aceh 163, 164,165

GTZ 168, 173, 180

Gulf War 4

Guterres, Antonio 9, 39

Hagman, Gunnar 12, 130

Haiti, earthquake in 131

Hasegawa, Sukehiro 54

Haver, Katherine 114

Heavily Indebted Poor Countries (HIPG) 154

Hilhorst, Dorothea 9

Honduran Fund for Social Investment 149

Howe, Kimberly 116

humanitarian: action, cluster system for coordination 5; assistance, distribution 
of international 11; cluster system 22-3; plus program 82, 83; policy 22; principles 44

Humanitarian Coordinator/Resident Coordinator (HC/RC) 45

humanitarian crisis management: continuum of 9-13; era of unprecedented 3-4; issues and limitations of model 30-2, 31; model for convergence in 28-30, 29; in pre-CPA period 79-91

humanitarian-development nexus 6-7, 222-3; coordination and 4-6

humanitarian dilemma 44, 46, 48, 216

Humanitarian Implementation Plan (HIP), South Sudan 94

Humanitarian Partnership Agreement (HPA) 189

Humanitarian Plus, EC 6

Humanitarian Reform Agenda (2005) 5

Humanitarian Response Plan, Syria 113

Human Rights Council, UN 103

Hurricane Mitch 12, 136, 140-3; bilateral aid to Honduras, 1997-2011 143, 144; commitments to reconstruction process 147; disaster-prevention phase 150-4; policy events relevant to disaster management 142; prevention through recovery, BBB 146-50; recovery and transformation 144-6

ICRC see International Committee of the Red Cross (ICRC)

IDDR see International Decade for Disaster Reduction (IDDR)

IDPs see internally displaced persons (IDPs)

IFI see International Financial Institutions (IFI)

IFRG see International Federation of the Red Cross and Red Crescent Societies (IFRC)

INCAF see International Network on Conflict and Fragility (INCAF)

Indian Ocean earthquake (2004) 131, 163

Indian Ocean tsunami (2004) 12, 15, 132, 162-4; housing in Java 172-3; housing reconstruction 170-2; relocation program 169-70

Indonesia, disasters in 162; cash-for-work (CFW) programs 178; coordination for transition 175-7; donor support 166-9; evolving recovery mechanisms $177-9$, 179; financing transition 175-7; impacts on development 164, 165; Indian Ocean tsunami (2004) 163-4;
IOT housing reconstruction 170-2; IOT relocation program 169-70; Java earthquake 164; linking recovery and long-term development 180; linking relief and rehabilitation 169; reconsidering donor approaches 180; reconstructing houses 169-70; strengthening DRR 174-5; transition from recovery to development 169-75

Indonesian Multi-Donor Fund Facility for Disaster Recovery (IDF) 179

INGOs see international non-governmental organizations (INGOs)

Instrument contributing to Stability and Peace (IcSP) 95

Inter-Agency Standing Committee (IASC) 23, 140

Inter-Agency Team on Rapid Transitions from Relief to Development (1996) 21

internally displaced persons (IDPs) 52

International Committee of the Red Cross (ICRC) 20, 45, 114, 130 135; disaster relief 129; evolution within 129-32

international community 4, 52, 56, 69, 101 ; in addressing humanitarian crises 3-4

International Decade for Disaster Reduction (IDDR) 129

International Decade for Natural Disaster Reduction 132

International Deployment Group (IDG) 64

International Emergency Relief Division 10

International Federation of the Red Cross and Red Crescent Societies (IFRG) 4, 12, 129; disaster relief 130

International Financial Institutions (IFI) 21,27

international humanitarian assistance, distribution 11

International Network on Conflict and Fragility (INCAF) 6

international non-governmental organizations (INGOs) 45

International Organization for Migration (IOM) 106

International Red Cross/Red Crescent Conference (IRCC) 130, 131

International Syrian Support Group (ISSG) 103, $12 \ln 2$

IOT see Indian Ocean tsunami (2004)

Iraq: EU regional strategy for 111; refugee crisis in northern 4

Islamic State in Iraq and Levant (ISIL) 104, 120 
Japan: coordination for continuum 191-2; donor engagement 82-3, 89, 93; donor support to Indonesia 167-8; humanitarian assistance 22; Ministry of Foreign Affairs (MOFA) 10, 22, 27, 76, 82; seamless assistance by 21-2; SelfDefense Forces 145; strategies to address continuum 188-9

Japan International Cooperation Agency (JICA) 21, 22, 27, 76, 82, 157n2, 167, 172, 175; aid to Timor-Leste 61-2; infrastructure and economic sectors 62-3; rehabilitating livelihoods 173-4

Java: earthquake 136, 162, 164, 167, 169, 174-7, 179-81; housing in 172-3; Java Reconstruction Fund (JRF) 169, 172, 174

JHDF see Joint Humanitarian and Development Framework (JHDF)

JICA see Japan International Cooperation Agency (JICA)

Joint Assessment Mission (JAM) 84-6

Joint Humanitarian and Development Framework (JHDF) 20, 92

Kawaguchi, Chigumi 101

Khalaf, Rana 115

Koddenbrock, Kai 20

Korset, Svenska Röda 12, 130

Kuala Lumpur, Tsunami Forum in (2007) 131

Kuncoro, A. 174

Land Law Program (LLP) 60

Laurie, A. J. 200

Lehtinen, Terhi 84

Lewis, D. H. 200

Lichtenstein, J. 149

linearity 28, 29; model 29

Linking Relief Rehabilitation and Development (LRRD) 5, 18, 27, 76, 223; by European Union 19-20

LLP see Land Law Program (LLP)

LRRD see Linking Relief Rehabilitation and Development (LRRD)

Machar, Riek 78, 97n4

Macrae, Joanna 12, 19, 79, 97nl

Maduro, Ricardo 143

'Magna Carta' 4

Martina, Santschi 75

Master Plan for National Reconstruction and Transformation (PMRTN) 146, 147,151

Maxwell, Daniel 75

Mayardit, Salva Kiir 78
Mazarr, Michael 118

McAllister, Ian 12, 130

McGoldrick, Claudia 114

Millennium Development Goals (MDGs) 55,153

Ministry of Defense (MOD) 46

Ministry of Foreign Affairs (MOFA), Japan $10,22,27,76,82$

Ministry of Transport Communications and Public Works (MTCPW) 62

Morazan, Pedro 27

multi-donor fund (MDF), Indonesia 168-9

Multi-Donor Trust Funds (MDTFs) 84-6

Multi-hazard Disaster Risk Assessment 24

multi-mandate approach 32

multi-national pooled fund for Southern Sudan (MDTF-SS) 85

Nascimento, Daniela 117

National Coalition for Syrian

Revolutionary and Opposition

Forces 104

National Development Plan (NDP) 55

National Disaster Risk Reduction and Management Council 187

National Priorities Process (NPP) 56

non-governmental organizations (NGOs) $3,4,7,66-7,76,146$

North Sea floods (1953) 129

Nusra Front 104, 105, 121n4

O'Brien, Stephen 105

Ocean Tsunami, India see Indian Ocean tsunami (2004)

OCHA see Office for the Coordination of Humanitarian Affairs (OCHA)

OECD see Organisation for Economic Co-operation and Development (OECD)

OFDA see Office of US Foreign Disaster Assistance (OFDA)

Office for the Coordination of Humanitarian Affairs (OCHA) 4, 27, 78, 120

Office of Presidential Assistant for Rehabilitation and Recovery (OPARR) 185-6, 194

Office of Transition Initiatives (OTI) 21; Timor-Leste 58, 59, 68

Office of US Foreign Disaster Assistance (OFDA) 20, 26, 45, 58

Official Development Assistance (ODA) 47,52 ; budget 3 ; implementation of 22 ; sectoral disbursements by donors 57

Ogata, Sadako 21 
OLS see Operation Lifeline Sudan (OLS)

Olshansky, R. B. 200

'One Humanity: Shared Responsibility' 7-8

Operation Lifeline Sudan (OLS) 79-80, 83, 84

Organisation for Economic Co-operation and Development (OECD) 6, 40, 47, 52

Organisation for Economic Co-operation and Development/Development Assistance Committee (OECD/DAG) Report 77

Oslo Pledging Conference (2005) 85

'Oslo Principles' 129

OTI see Office of Transition Initiatives (OTI)

Overseas Development Institute 24

Paris Declaration on Climate Change 12-13

PBC see Peacebuilding Commission (PBC)

PBSO see Peacebuilding Support Office (PBSO)

peace: and conflict, intervention models between 40, 40; 'continuum' in postconflict transitions to $39-40,40$

peacebuilding 40-3, 42, 52; deficiency of 44; and humanitarian relief in continuum 43-5; model, continuum in linear 84-91

Peacebuilding Commission (PBC), UN 41-3

Peacebuilding Support Office (PBSO) 42 peacekeeping 41, 134, 212; operations 42, 46 peacemaking 41

Peake, Gordon 51

Physicians for Human Rights 105

PMRTN see Master Plan for National Reconstruction and Transformation (PMRTN)

police program, Australia 64-6

Policia Nacional de Timor-Leste (PNTL) 54, 65

Population, Refugees, and Migration (PRM) 81

Post-Conflict Unit, World Bank 5, 6, 21

Post Disaster Needs Assessment (PDNA), UN 134, 179

Poverty Reduction Strategy Paper (PRSP) 148, 155

Presidential Assistant for Rehabilitation and Recovery (PARR) 203n4

'Principles and Good Practice of Humanitarian Donorship' 6

Protracted Relief and Recovery Operations 19
Quadrennial Diplomacy and Development Review (QDDR) 117

Quick Impact Projects (QIPs), UNHCR 18

Red Cross see International Committee of the Red Cross (ICRC)

Red Cross/Red Crescent see International Federation of the Red Cross and Red Crescent Societies (IFRC)

Regional Assistance Mission to the Solomon Islands (RAMSI) 64

rehabilitation programs 129, 150, 166, 171-2, 174; in South Sudan 75, 83, 84, 95-6, 214

Relief Advisory Committee 129

Relief Association of Southern Sudan (RASS) 80, 83

'Relief to Development' 18

'relief to development continuum' model 5

'Report of the Panel on United Nations Peace Operations' (UN, 2000) 40

Resilience approach 5, 23-4, 25, 26, 27, 94, 213; European Union (EU) 31

resilience, defined 102

Resolution 46/182 4, 9

Resosudarmo, B. P. 174

'Restoring Humanity: Global Voices Calling for Action' 7-8

Rotmann, Philipp 46

Sánchez, W. J. 150

Schrikkema, B. 150

SDP see Strategic Development Plan (SDP) seamless assistance approach 18, 27; Japan 21-2, 83, 202

Secretary of State-Security (SoSS) 65

Sector Investment Programs (SIPs) 55

Sector Working Groups (SWGs) 55

Security Council 42; and General Assembly in April 2016 43; UN 104, 107, 223

Security Sector Reform (SSR) 65

Sendai Framework for Action in Disaster Risk Reduction 13

SHARP see Syria Humanitarian Assistance Response Plan (SHARP)

SIPs see Sector Investment Programs (SIPs)

Smillie, Ian 18

South Sudan 12, 48; aid coordination mechanisms 85 ; bilateral ODA by sector for 78; ceasefire agreement 78; comparative analysis 83-4, 89-91, 90, 93-5; crisis and aid in 76-9; donor engagement 80-3, 86-9, 91-3; Humanitarian Implementation Plan (HIP) 
94; North-South conflict 77; operation lifeline Sudan (OLS) 79-80; rehabilitation program 84; third conflict in 2013 77-9; violations of human rights 79 ; violent conflicts and independence 76-7

Sparrow, Annie 113

Sphere Project 6-7

SRRA see Sudanese Relief and

Rehabilitation Association (SRRA)

SSR see Security Sector Reform (SSR)

Stabilization Unit, UK 46

Steets, Julia 18, 22

Steinacker, Lea 46

Stites, Elizabeth 116

Strategic Development Plan (SDP) 56

Study on the Urgent Rehabilitation Plan in East Timor (SURPET) 62

Suárez, G. 150

Sudanese People's Liberation Movement/ Army (SPLM/A) 77, 80, 81, 83, 84

Sudanese Relief and Rehabilitation Association (SRRA) 79-80, 97n6

Sudan Transitional Assistance for Rehabilitation (STAR) program 80-1

Sugiyanto, C. 174

SURPET see Study on the Urgent Rehabilitation Plan in East Timor (SURPET)

Sustainable Development Goals 12 'sustaining peace' 43, 44

SWGs see Sector Working Groups (SWGs)

Syria: anti-regime groups 103-4; assistance operations inside 106; authorities 109; capacity-building programs 116; civil war see civil war, Syria; EU regional strategy for 111; food assistance 113; Free Syrian Army (FSA) 104; Humanitarian Response Plan inside 113; Independent International Commission of Inquiry on 107; Operational Plan 2011-2016 117; refugee crisis 105, 106; response by international community 106-13; Syrian crisis 12, 48, 79, 102, 111; US humanitarian assistance inside 112; 'Whole-of-Syria' approach 108

Syria Humanitarian Assistance Response Plan (SHARP) 102, 106, 107

Syrian Arab Red Crescent (SARC) 107

Syrian National Gouncil (SNG) 103-4

Syria Recovery Trust Fund (SRTF) 110

Tacloban City, housing in 196-201

TEC see Tsunami Evaluation Coalition (TEC)
Tegucigalpa water system project 149

TEP see Transitional Employment Program (TEP)

Timor-Leste 12, 48, 51, 52-4; aid to, from perspective of continuum $56-9,57$, 61-4; conflict prevention 59-60, 67-8; humanitarian crises 53-4; infrastructure and economic sectors 62-3; international support to 55 ; national and international strategies 54-6; NDP 58; ODA disbursements to 53; Office of Transition Initiatives (OTI) in 58, 59, 68; peace and order 66-8; UN missions in 68

transformative agenda 5

Transitional Employment Program (TEP) 59

Tsunami Evaluation Coalition (TEC) 174

Tsunami Forum, in Kuala Lumpur (2007) 131

Tunisia, 'Arab Spring' in 103

Typhoon Yolanda, in Philippines: bilateral funding 195-6; challenges for 'continuum' approaches 191; housing continuum 196-7, 199-201; chronological review of 187-8, 188; Tacloban City 196-7; coordination for continuum 191-3; coordination system in the GOP 193-5; efforts by bilateral cooperation agencies 199; Global Cluster for Early Recovery 197; Government of the Philippines (GOP) 186, 187, 193-5; Humanitarian Country Team 187; multi-lateral cooperating agencies 196; National Economic and Development Authority (NEDA) 187; Strategic Response Plan (SRP) 187-8; strategies to address continuum 188-91

United Nations International Children's Emergency Fund (UNICEF) 19, 79, 82

United Kingdom (UK): Conflict, Stability and Security Fund (CSSF) 118; DFID 111, 111; Global Conflict Prevention Pool (GCCP) 6; Stabilization Unit 46

United Nations (UN): agencies 107, 108, 113; Department of Political Affairs (DPA) 42; Development Programme (UNDP) 16, 19, 24; Disaster Relief Coordinator 4; 'General Assembly Resolution 46/182 (1991) 17, 18, 28, 107; High Commissioner for Refugees (UNHCR) 5, 16, 21; humanitarian operation 48; Human Rights Council 103; institutionalizing humanitarian action in 4; Integrated Mission in 
Timor-Leste (UNMIT) 54; interim authority 52; Mission in Sudan (UNMIS) 85; Office for the Coordination of Humanitarian Affairs (OCHA) 4, 78; Office for Project Services (UNOPS) 62; Peacebuilding Commission (PBC) 41-3; peacekeeping operations 42; postdisaster needs assessments (PDNA) 134; Relief and Works Agency for Palestine Refugees in the Near East (UNRWA) 105; Security Council 39, 104, 107, 223; Security Council Resolution 688 (1991) 4; Supervision Mission in Syria (UNSMIS) 104; SecretaryGeneral's report, core responsibilities 8; Transitional Administration in East Timor (UNTAET) 54 'United Nations Peacekeeping Operations: Principles and Guidelines' 41

United States (US): coordination for continuum 192-3; donor engagement 80-1, 86-8, 92; donor support to Indonesia 166; humanitarian assistance inside Syria 112; relief to development by $20-1$; strategies to address continuum 191-1

United States Agency for International Development (USAID) 10, 20, 21, 23, 24, 26, 109; aid to Timor-Leste 56-9, 57; conflict prevention 59-60; evaluation of LLP 60; USAID-OFDA 76

USAID see United States Agency for International Development (USAID)
Water, Sanitation and Hygiene Program (WASH) 109

WFP see World Food Programme (WFP)

WGA see whole-of-government approach (WGA)

Whittall, Jonathan 118

whole-of-government approach (WGA) 26,46

WHS see World Humanitarian Summit (WHS)

Woodrow, Peter J. 12

Work Plan and Poverty Reduction Strategic Paper (PRSP) 86

World Bank: Joint Assessment Mission (JAM) 55; Post-Conflict Unit and PostConflict Fund 6

World Conference on Disaster Risk Reduction 17

World Development Report (2011) 6

World Disasters Report (1999) 130, 145

World Food Programme (WFP) 19, 61, 79

World Humanitarian Summit (WHS) (2016) 7-9, 12, 16, 17; continuum after $222-5$

Yanguas, P. 152

Yogyakarta: earthquake 164; gross domestic product (GDP) 165; growth rates of population in 166; impacts on development 164; poverty rates in 164

Yoshikawa, Lynn 20, 135

Zelaya, Manuel 143 